\title{
Nutrient Stoichiometry and Plant Life Cycle
}

Relationships between nitrogen : phosphorus ratio and trait expression of grassland species

\section{Shuqiong Wang}

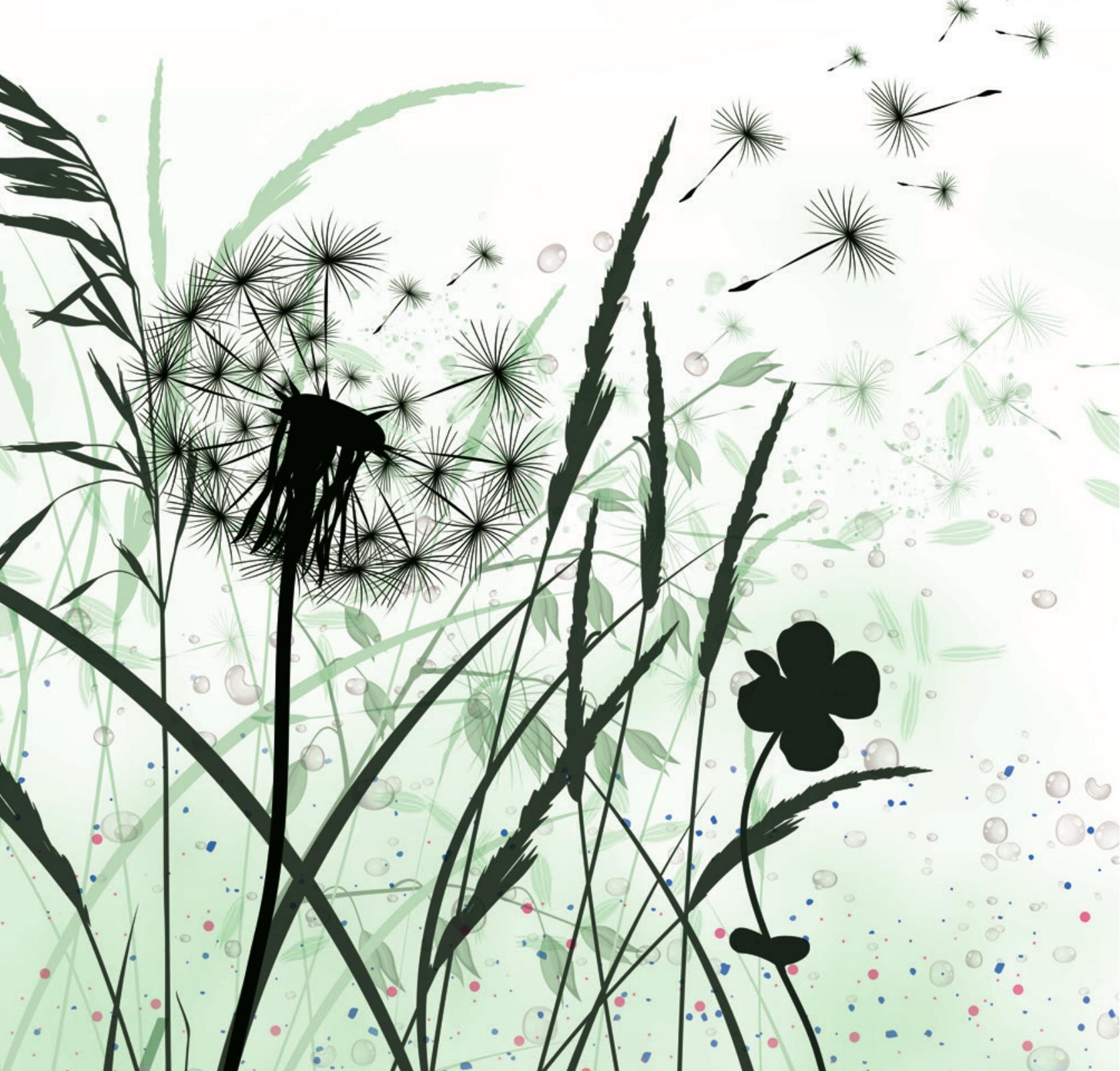




\section{ISBN}

978-94-6421-374-4

\section{Design/lay-out}

Promotie In Zicht (www.promotie-inzicht.nl)

Print

Ipskamp Printing

\section{(c) Shuqiong Wang, 2021}

All rights are reserved. No part of this book may be reproduced, distributed, stored in a retrieval system or transmitted in any form or by any means, without prior written permission of the author. 


\title{
Nutrient Stoichiometry and Plant Life Cycle
}

Relationships between nitrogen : phosphorus ratio and trait expression of grassland species

\section{Nutriënten Stoichiometrie en de Levenscyclus van Planten}

\author{
Relaties tussen de stikstof : fosfor verhouding \\ en eigenschappen van graslandplanten
}

(met een samenvatting in het Nederlands)

\section{Proefschrift}

ter verkrijging van de graad van doctor aan de Universiteit Utrecht op gezag van de rector magnificus, prof.dr. H.R.B.M. Kummeling, ingevolge het besluit van het college voor promoties

in het openbaar te verdedigen op vrijdag 11 juni 2021 des ochtends te 10.15 uur

door

Shuqiong Wang

geboren op 8 Augustus 1992

te Anhui, China 


\section{Promotor}

Prof. dr. M.J. Wassen

\section{Copromotor}

Dr. J. van Dijk

This thesis was partly accomplished with financial support from China Scholarship Council (CSC NO. 201406140142). 


\section{Contents}

$\begin{array}{lll}\text { Chapter } 1 & \text { Introduction to the thesis } & 7\end{array}$

Chapter 2 Influence of parental nitrogen : phosphorus stoichiometry on seed performance of Holcus lanatus L. and Parnassia palustris L. 19

Chapter 3 Source and sink activity of Holcus lanatus L. in response to absolute and relative supply of nitrogen and phosphorus

Chapter 4 Sexual reproduction traits of Holcus lanatus L. and

Parnassia palustris L. in response to absolute and relative supply of nitrogen and phosphorus

Chapter 5 Sexual reproduction trait expression of grassland species along a gradient of nitrogen : phosphorus stoichiometry

Chapter 6 Synthesis

References

Summary 153

Samenvatting

Chinese Summary 169

Acknowledgements 175

Curriculum Vitae 181

Publications 185 

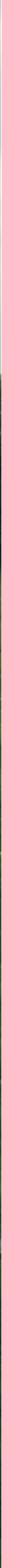


\section{Chapter 1}

Introduction to the thesis 

Since the industrial revolution (1860), human interferences have resulted in dramatic changes of ecosystems (Millennium Ecosystem Assessement 2005). Eutrophication triggered by anthropogenic increases in mineral nutrient availability in natural ecosystems is one of the most important impacts on the Earth's environment (Rockström et al. 2009; Steffen et al. 2015, also see Figure 1.1), driving species extinctions globally (Chapin et al. 2000; Erisman et al. 2008; Barnosky et al. 2011; Lambers et al. 2011).

Nitrogen $(\mathrm{N})$ and phosphorus $(\mathrm{P})$ as primary elements for living organisms that limit productivity across most of the world's aquatic and terrestrial ecosystems (Elser et al. 2007), are major eutrophying elements in the Anthropocene. $\mathrm{N}$ is the major component of proteins, while P is needed for DNA, RNA, and energy transfer. However, excessive anthropogenic $\mathrm{N}$ and $\mathrm{P}$ inputs impact natural environments negatively and seriously and lead to far-reaching ecological as well as evolutionary consequences (Guignard et al. 2017). In aquatic ecosystems human induced point sources of discharges of industrial plants and sewages, as well as "diffuse sources" (non-point source) of excess fertilizer and nutrient leaching from agricultural fields, have resulted in excessive growth of algae and other aquatic plants (Smith 1998), and oxygen depletion leading to fish kills (Carpenter et al. 1998; Smith 1998). Furthermore, the current levels of atmospheric N deposition in many parts of the world has fertilized terrestrial ecosystems to levels that are far beyond natural background levels and have led to substantial species loss (Steven et al. 2004; Clark and Tilman 2008). Simultaneously, the availability of P is also increasing due to human activities, but via different pathways than $\mathrm{N}$ : besides the inflow from agricultural fields, $\mathrm{P}$ availability in ecosystems may also increase atmospheric $\mathrm{P}$ deposition via dust transportation of both natural and human origins (Camarero and Catalan 2012), internal eutrophication triggered by human activities, e.g. increased wetting-drying dynamics (Turner and Haygarth 2001), and sulphate pollution (Lamers et al. 1998).

Grassland ecosystems are widespread globally and have been recognized as being impacted by eutrophication of $\mathrm{N}$ and $\mathrm{P}$ leading to enhanced primary productivity and changes in vegetation structure and species composition (Gough et al. 2000; Harpole and Tilman 2007). The increased above-ground productivity intensifies competition for light and mineral nutrients, allowing taller or fast-growing species to preempt the directionally supplied resource and therefore outcompete other species (Hautier et al. 2009). Competitive exclusion results in dominance of a few, superior species, and thus the loss of biodiversity (Grime 1973a). 
However, the relative contributions of $\mathrm{N}$ and $\mathrm{P}$ in eutrophication are debated. The general viewpoint is that reactive $\mathrm{N}$ has increased relatively more than $\mathrm{P}$ (Figure 1.1). However, the large increase in $\mathrm{P}$ availability is increasingly acknowledged. For aquatic ecosystems, there is ample evidences that the main focus in attempts to reduce eutrophication should be on P (Sundareshwar et al. 2003; Foy 2005; Withers and Haygarth 2007). For European grasslands, the high level of atmospheric $\mathrm{N}$ deposition (mainly caused by intensive agriculture) has been identified as a crucial factor leading to species loss in species-rich grassland ecosystems (Bobbink et al. 1988; Stevens et al. 2004). However, there is increasing evidence for a role of $\mathrm{P}$ enrichment in species extinctions (Olde Venterink et al. 2003; van der Hoek et al. 2004; Wassen et al. 2005; Lannes et al. 2012; Ceulemans et al. 2013). An important reason why there is confusion about the relative

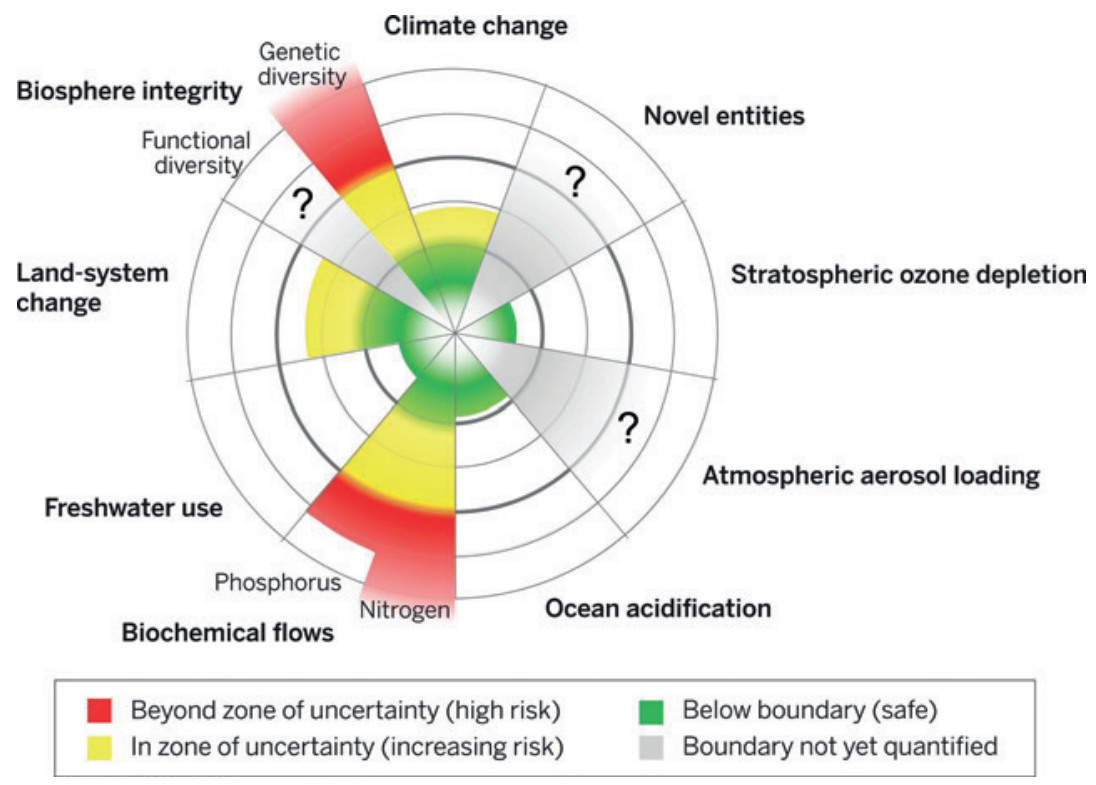

Figure 1.1 Seven of the nine earth systems and associated planetary boundaries (the two bold circles) which, if crossed, could generate unacceptable environmental change for humanity. The inner green shading represents the proposed safe operating space (below the inner bold circle), the yellow wedges represent the zone of uncertainty (increasing risk), and red is the high-risk zone. Two of the nine earth systems (i.e. biosphere integrity, and biochemical flows (mainly about the interference with the nitrogen and phosphorus cycles)) are suggested to have already transgressed to the high-risk zone. Source: Steffen et al. (2015). Reprinted with permission from Copyright Clearance Center: Science (Steffen et al. 2015), copyright 2015. License number: 5006470401517. 
importance of $\mathrm{N}$ and $\mathrm{P}$ enrichment in the process of species extinction is that the type of nutrient limitation was rarely analyzed in previous studies (mostly were implicitly assumed to be N-limited), while a study in European herbaceous ecosystems indicated that, $\mathrm{P}$ limitation or $\mathrm{N}$ and $\mathrm{P}$ co-limitation also frequently occur (Wassen et al. 2005). Moreover, while classical theory suggests that productivity and interspecific competition are affected only by changes in the availability of the nutrient that is limiting primary production (Von Liebig 1842; Tilman 1982; Jungk 2009), fertilization studies have shown that enrichment with a non-limiting nutrient affects growth and diversity as well (Sterner 2008; Vitousek et al. 2010). Combining the phenomena above, it is essential to consider N:P stoichiometry when studying eutrophication, i.e. $\mathrm{N}$ and $\mathrm{P}$ supply ratios in relation to their consumer's requirements in grassland ecosystems (Fujita 2010).

In natural habitats, more than 10 -fold differences in plant N:P ratio are observed among plant communities from different locations (Güsewell and Koerselman 2002). As a result, differences in community composition and richness between communities with low N:P and high N:P (N-limited and P-limited, respectively) were found (Wassen et al. 2005; Roeling et al. 2018). In general, N-limited systems appear to be dominated by competitors with a strong ability to compete for growth-limiting resources, while P-limited systems are characterized by stress tolerators (Fujita et al. 2014). Moreover, the finding of Wassen et al. (2005) that especially endangered plant species persist under P limitation (i.e. high N:P ratio in the environment) rather than under $\mathrm{N}$ limitation (i.e. low $\mathrm{N}: \mathrm{P}$ ratio in the environment) raises questions about the effect of $\mathrm{P}$ on plants' survival.

The hump-backed relationship between plant species richness and productivity is well-established by previous studies (Grime 1973b; Mittelbach et al. 2001). While nutrient availability is a well-known fact influencing vegetative productivity (e.g. Fay et al. 2015), enrichment with a non-limiting nutrient affects growth and diversity as well, which indicates the influence of nutrient stoichiometry on productivity (Sterner 2008; Vitousek et al. 2010). Furthermore, a study by Olde Venterink et al. (2003) showed that the maximum vegetative productivity levels that can be attained may differ among N-, P-, or K-limited sites. Moreover, Liebig's Law of the Minimum states that plant growth is determined not by the total resource available, but by the supply of the scarcest, limiting resource, indicating that organisms need to maintain certain proportions of each element to grow efficiently.

Although plants have various homeostatic mechanisms and adaptive traits to regulate the nutrient balance in their biomass (Lambers et al. 2008), altered nutrient availability in their environment may lead to unbalanced nutrient 
concentrations in biomass, with possible negative impacts on plant growth rate, and therefore species competition (Sterner and Elser 2002). In general, $\mathrm{N}$ and $\mathrm{P}$ concentration in plant biomass varies largely among species (Garnier 1998), while variation in $\mathrm{P}$ is larger than in N concentration (Güsewell and Koerselman 2002). $\mathrm{N}$ and $\mathrm{P}$ concentrations in plant biomass may have similar but also somewhat contrasting effects on plant growth, resulting in different responses of plants to $\mathrm{N}$ limitation and to $\mathrm{P}$ limitation. For example, growth rate and biomass allocation to shoots are more sensitive to $\mathrm{N}$ than to $\mathrm{P}$ limitation, while increases in senescence of leaves and roots are more sensitive to P than to N limitation (Shaver and Melillo 1984; De Groot et al. 2003; El-Kahloun et al. 2003; Güsewell 2005a; b). Such influences of $\mathrm{N}: \mathrm{P}$ stoichiometry on plant growth rate may result in differences in competitive ability among species, and therefore potentially lead to variation in species composition.

Plant functional and performance traits determine plant performance, and therefore plant fitness in communities (Figure 1.2). Fujita et al. (2014) indicate that plant species communities of low $\mathrm{N}: \mathrm{P}$ ratios showed different traits than communities of high N:P ratios. In fact, plants have evolved to have various traits with which they adapted to better cope with nutrient deficiency by enhancing uptake of the limited nutrient elements in the environment (Vance et al. 2003; Lambers et al. 2008). Examples of such traits are N-fixing symbiosis (Bagali 2012), formation of cluster roots (Neumann et al. 2000), mycorrhizal associations (Brundrett 2009) and various kinds of root exudates (e.g. phosphatase enzyme, organic acid, and chitinase enzyme; Dakora and Phillips 2002). Compared with plant inherent traits for $\mathrm{N}$ uptake, traits for $\mathrm{P}$ uptake are more diversified (Vance et al. 2003; Raghothama and Karthikeyan 2005; Lambers et al. 2006), due to the large percentage of immobile $\mathrm{P}$ in the soil (c. 30-65\%; Harrison 1987) in diverse forms (Turner et al. 2003). Plants therefore need to biochemically release P from these immobile $\mathrm{P}$ sources to make it bio-available from various kinds of $\mathrm{P}$ compounds (Vance et al. 2003; Lambers et al. 2006).

Plant functional and performance traits may respond plastically to changing $\mathrm{N}$ and $\mathrm{P}$ availabilities. The plastic responses are defined as flexible reactions of organisms to changing environmental conditions, and are seen as phenotypic variations rather than genetic variations (Fujita 2010). For example, phosphatase, the enzyme which hydrolyzes $\mathrm{P}$ from organically bound $\mathrm{P}$, is stimulated by $\mathrm{N}$ addition and prohibited by $\mathrm{P}$ addition (Johnson et al. 1999; Olander and Vitousek 2000). Reducing sexual reproduction was hypothesized as a way to economize on the use of $\mathrm{P}$ under P limitation. In the analysis of a large empirical field dataset, Fujita et al. (2014) found that species persisting under P-limited conditions invested 
less in sexual reproduction traits than those that persisting under $\mathrm{N}$ limitation/ co-limitation. In this way plants were suggested to economize on P use by limiting investments in the P-rich sexual reproduction organs under P-limited conditions (Fujita et al. 2014). These types of plastic trait responses help plants to maintain a proper balance of nutrients in their biomass, enabling them to survive under fluctuating nutrient conditions. However, the plasticity of functional and performance traits may affect species fitness. For example, the low investment in sexual reproduction under $\mathrm{P}$ limitation probably decreases species occurrence in certain communities, and therefore may limit the dispersal ability of those species. Therefore, Pywell et al. (2003) and McGill et al. (2006) suggested that focusing on functional traits enables us to better understand the general ecological patterns and to provide useful predictions for ecological restoration.

The influence of $\mathrm{N}: \mathrm{P}$ on both vegetative productivity, and on functional and performance traits mentioned above may explain the relationship between N:P stoichiometry and the competitive strength of plant species observed in the field. These observations include more graminoids and/or less forbs in P-limited grasslands or after $\mathrm{N}$ fertilization (Bobbink et al. 1998; Beltman et al. 2007), different effects on species composition of $\mathrm{N}$ - or P-fertilization (Limpens et al. 2003; van der Hoek et al. 2004), and a higher number of threatened species in P-limited grasslands (Olde Venterink et al. 2003; Wassen et al. 2005). However, it is still unclear how the characteristics of species are responsible for the observed patterns of species-specific responses to a particular type of nutrient limitation (Peerez Corona et al. 1996; Güsewell et al. 2003).

Since most terrestrial ecosystems are considered to be N-limited (Vitousek and Howarth 1991; Sala et al. 2000), elevated N-deposition, e.g. nitrogen oxides created during fossil fuel combustion (Ciais et al. 2014), and ammonia produced from intensive animal agriculture (Sutton et al. 2013), may alleviate $\mathrm{N}$ limitation and even may shift ecosystems from N- to P limitation (Elser et al. 2009, 2010). Although studying influences of nutrient condition on the plant community level is of great interest for the management and conservation of grasslands (Verhoeven et al. 1996; Aerts et al. 2003; Olde Venterink et al. 2003), acknowledging the importance of individual performance is central in ecology, as argued by McGill et al. (2006). Considering the essential role of species functional traits shaping community structure via plant growth rate, reproduction, and survival (Figure 1.2) (Violle et al. 2007), research on species functional traits has been intensively tested in a range from low- to high-productive environments (e.g. Campbell and Grime 1992; Fynn et al. 2005). However, to my knowledge, very little attention to date has been paid to explore species functional trait expression along a gradient of $\mathrm{N}: \mathrm{P}$ 
stoichiometry, especially at the individual level. For understanding plant responses to environmental change, it is therefore necessary to test the effects of $\mathrm{N}: \mathrm{P}$ stoichiometry on plant functional traits and their plasticity of plant species. Therefore, this dissertation aims to comprehensively understand the influence of $\mathrm{N}: \mathrm{P}$ stoichiometry on plant growth, and plant functional and performance traits, particularly on plant sexual reproduction traits, at the individual level, to help improve our understanding of how anthropogenic influences on the relative availability of $\mathrm{N}$ and $\mathrm{P}$ affect functioning of grassland plant species.

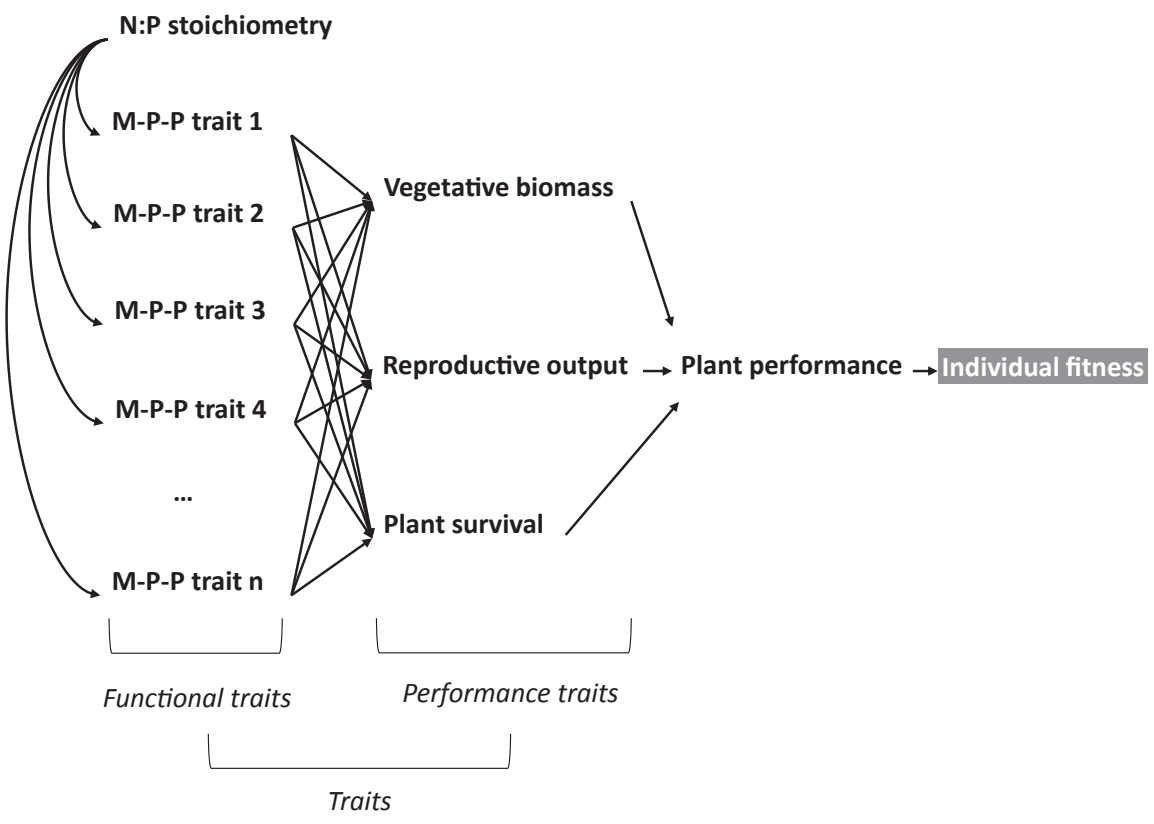

Figure 1.2 N:P stoichiometry was added into Arnold's (1983) framework revisiting a plant ecological perspective. N:P stoichiometry influences Morpho-physio-phenological (M-P-P) traits (from 1 to $n$ ), while the latter modulate one or all three performance traits (vegetative biomass, reproductive output and plant survival) which consequently determine plant performance and individual fitness. For clarity, inter-relations among M-P-P traits, performance traits and feedbacks between performance and M-P-P traits are not represented. 


\section{Aims and outline of this thesis}

As outlined in Figure 1.2, the performance of a species in a particular ecological habitat is assessed by the ability of a sample of individuals to grow, reproduce and survive, which are the three components of plant fitness (Violle et al. 2007). To properly assess the impacts of eutrophication on grassland ecosystems, it is necessary to understand how the stoichiometric balance between $\mathrm{N}$ and $\mathrm{P}$ affects the functioning of plants at the individual plant species level in terms of these three inherent components. Therefore, in this dissertation I examine the effects of absolute and relative availability of $\mathrm{N}$ and $\mathrm{P}$ on seed performance, plant vegetative growth, reproductive investment, and adult-plant survival, to create an understanding of the potential influence of $\mathrm{N}: \mathrm{P}$ stoichiometry along the plant life cycle. Particular attention is paid to the performances of plant sexual reproduction traits, due to the essential influence of sexual reproduction on the ecology and distribution of taxa and their vulnerability to local extinction (Farnsworth and Ogurcak 2008), as well as the fact that the insight into the linkage between the investment in sexual reproduction traits within species along $\mathrm{N}$ :P gradient is largely missing. Moreover, comparisons between common and endangered species under varying N:P stoichiometry were made, given the different preference for nutrient limitation endangered and common grassland species appear to have (Wassen et al. 2005; Fujita et al. 2014).

\section{Specifically, the objectives of the research described in this thesis are:}

- To explore the influence of parental N:P stoichiometry on the seed performance and adult-plant survival for both a common grassland species (Holcus lanatus) and an endangered grassland species (Parnassia palustris), in addition to the effect of overall nutrient availability.

- To clarify the effect of absolute and relative availability of $\mathrm{N}$ and $\mathrm{P}$ on vegetative growth, particularly on photosynthesis and tissue formation of Holcus lanatus.

- To identify the influence of absolute and relative availability of $\mathrm{N}$ and $\mathrm{P}$ on sexual reproduction of both Holcus lanatus and Parnassia palustris.

- To confirm and more deeply explore the effects of N:P stoichiometry on sexual reproduction of multiple grassland species along a gradient of $\mathrm{N}$ :P stoichiometry in the field at both intra- and interspecific level.

- To interpret these results in the context of ecosystem conservation by identifying possible additional effects of eutrophication on grassland ecosystems via its N:P stoichiometric effects. 
A combination of greenhouse experiments, laboratory experiments and a field survey was conducted to address the research objectives mentioned above. In the thesis, Chapter two explores the seed characteristics and germination ability of a common species Holcus lanatus and an endangered species Parnassia palustris collected from parent plants with different N:P stoichiometry backgrounds. Moreover, survival ability of the plants derived from the germinated seedlings under various nutrient treatments was researched in the greenhouse. The follow-up experiment described in Chapter three aimed to examine the differences in vegetative growth of Holcus lanatus along a gradient of N:P stoichiometry. I specifically focus on the effect of absolute and relative availability of $\mathrm{N}$ and $\mathrm{P}$ on one functional trait and one performance trait: photosynthesis as "source activity", and biomass formation as "sink activity", respectively. In addition, I studied whether photosynthesis exerts control on biomass formation under nutrient-limited conditions. Chapter four investigates sexual reproduction in a greenhouse experiment conducted with the same plants as the last two experiments. The aim of this research was to explore how absolute and relative nutrient supply affected sexual reproduction traits of Holcus lanatus and Parnassia palustris. A range of sexual reproduction traits were measured as a proxy of sexual reproduction performance of the plants, e.g. first flowering date, flowering period, number of flower stalks per plant, etc. The resulting knowledge formed a solid basis for a field study described in Chapter five, in which a larger number of grassland species was studied along a gradient of N:P stoichiometry under more complex growth conditions, intended to confirm and more deeply test our conclusions of sexual reproduction performance under various N:P stoichiometry conditions. Finally, Chapter six synthesizes the results of the previous chapters and puts them in a wider perspective. It not only provides the closing statement of this thesis, discussing the achievement of the aims posed at the start but also provides suggestions for future research and implications for ecosystem conservation. 
Introduction to the thesis $\mid \mathbf{1 7}$ 


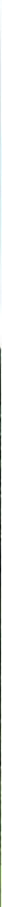

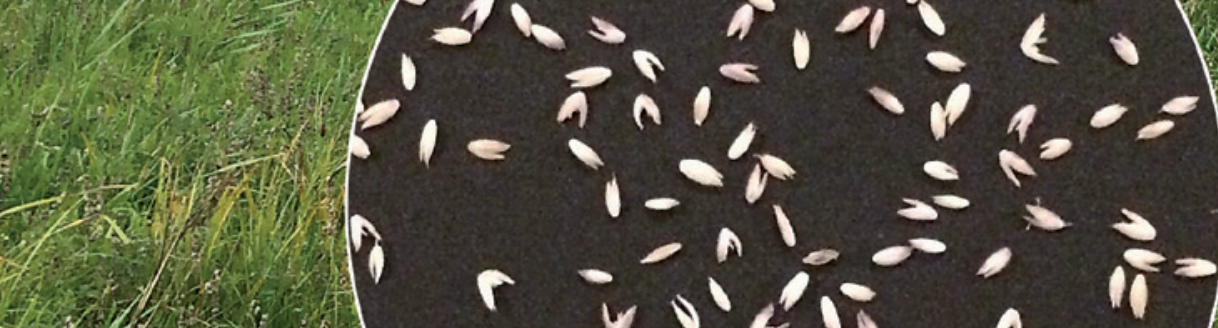

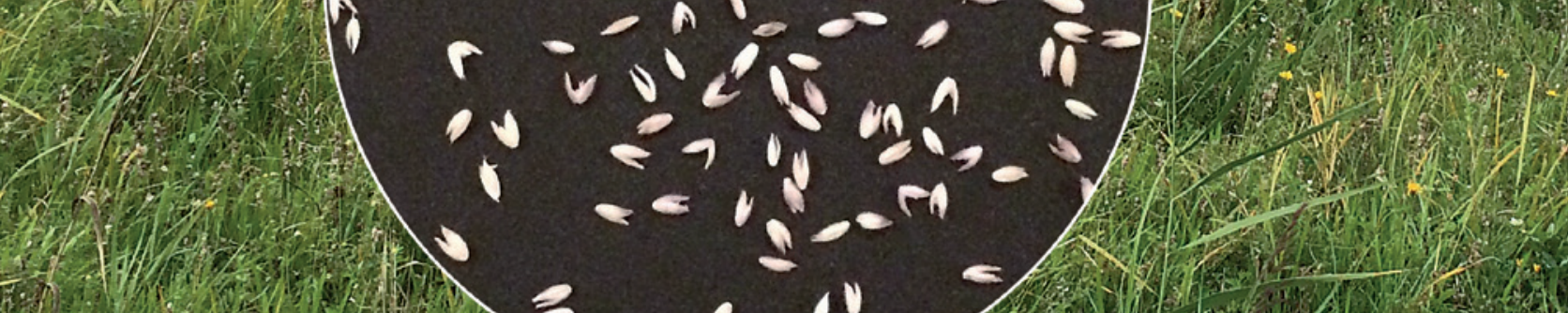

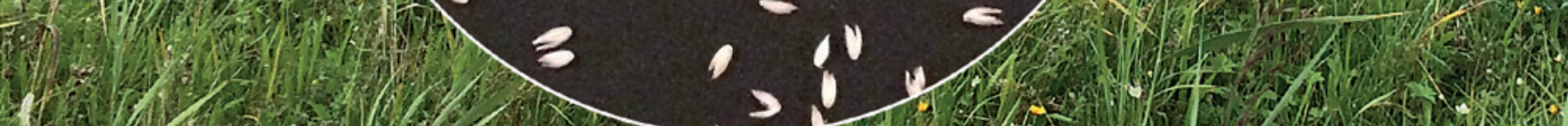

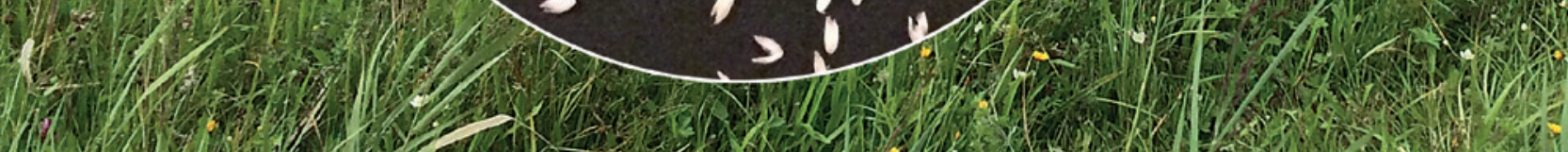
W. 24. (1) (2) 8. 


\section{Chapter 2}

Influence of parental nitrogen : phosphorus stoichiometry on seed performance of Holcus lanatus L. and Parnassia palustris L.

Shuqiong Wang, Jerry van Dijk, Martin J. Wassen

(Currently under Review) 


\begin{abstract}
Nitrogen $(\mathrm{N})$ and phosphorus $(\mathrm{P})$ availability affect plant sexual reproduction performance. To test whether seed, the main product of sexual reproduction, is affected by $\mathrm{N}$ and $\mathrm{P}$ availability in parent plants, we experimentally tested how parental N:P stoichiometry affected seed performance and offspring adult-plant survival of two grassland species.
\end{abstract}

Seeds of a common species (Holcus lanatus) and an endangered species (Parnassia palustris) were collected from parent plants under two different N:P ratio growth conditions. We measured the following traits of the two species from the two parental N:P ratio growth conditions: seed $\mathrm{N}$ concentration and content, seed $\mathrm{P}$ concentration and content, seed length, seed area, seed weight, seed germination success, and offspring survival. No significant inter-site difference was found in seed weight of the collected seeds for either of the two species. However, the stronger P-limited conditions in the sites of the parents affected seed length and area negatively in Holcus lanatus but positively in Parnassia palustris. Stronger P-limited conditions also decreased seed $\mathrm{P}$ concentration and content and increased seed N:P ratio of Holcus lanatus, but no inter-site nutrient difference was found in seeds of Parnassia palustris. Surprisingly, contrary to what could be expected from seed P concentration and content there was no inter-site difference in seed germination success for Holcus lanatus. For Parnassia palustris, stronger P-limited conditions in the parental environment significantly enhanced seed germination success, whereas stronger P-limited conditions in the offspring environment decreased offspring survival, suggesting that P-limitation negatively affects Parnassia palustris rejuvenation.

Our results highlight the different influences of parental N:P ratio and especially of P limitation on seed performance of a common and an endangered species. 


\subsection{Introduction}

Seed are the main product of plant's sexual reproduction, and are rich in mineral nutrients which the adult plant translocates to its seeds to provide nutrition for seedlings in the early stages of establishment before the development of a root system (Lamont and Groom 2013). Among these nutrients, nitrogen (N) and phosphorus (P) are the most essential and have been researched extensively (Henery and Westoby 2001; Lamont and Groom 2013). Studies have shown that nutrient shortages in parent plants lead to increased allocation of plant minerals to seeds (except in the case of iron (Fe)) (Lamont and Groom 2013), although the relative allocation of biomass to the seeds has been shown to be constant (Fenner 1986a). Moreover, the fraction of a plant's total content of a particular element that the plant allocates to its seeds varies widely, depending on the elements. In Fenner's greenhouse experiment (1986), it ranged from $4 \%$ of total potassium (K) to $38 \%$ of total $\mathrm{P}$ in plants on $100 \%$ Hoagland solution, while in the most nutrientdeprived plants it ranged from $2.5 \%$ of total Fe to $52 \%$ of total P. However, both aforementioned cases indicate a high percentage of the plant's P content is invested in sexual reproduction.

Various studies have also pointed to the influence of nutrient supply of parent plants on seed traits and seed performance, such as seed size, dormancy, germination, and dispersal, which are vital components in the plant life cycle (Fenner 1983; Harper 1977; Thompson 1987). Early work on Senecio vulgaris, a short-lived monocarpic plant, showed that seed nutrient concentrations were largely buffered from the differences in parental nutrient status (Fenner 1986b). However, various other studies indicated that mineral nutrient availability of parent plants was positively correlated with seed mass (Willson and Price 1980; Gray and Thomas 1982; Parrish and Bazzaz 1985; Marshall 1986; Wulff 1986a; b; c; Galloway 2001), germination time (Aarssen 1989; Aarssen and Burton 1990), and germination success (Galloway 2001). A contrasting result was obtained by Beadle (1962) and Lamont and Groom (2013) who found that plants on nutrient-poorer soils had larger seeds. This phenomenon was reported not only within species, but also between species on different soil types (Esler et al. 1989; Lee and Fenner 1989).

Nutrient specific effects on seed traits have been widely documented. Greenhouse experiments with pea and watercress indicated that seeds of plants grown under high P supply were some 15\% larger than those of plants grown under low P supply (Austin 1966a). Another study reported that when $\mathrm{N}$ was deficient, seed and fruit production of agricultural crops decreased dramatically (Tonitto et al. 2006). Austin (1966a) showed that seeds from plants deficient in major elements can be 
impaired in germination success and seedling establishments compared to seeds from plants grown in complete nutrient cultures. Nitrate fertilization of parent plants of common lambsquarters (Chenopodium album L.) dramatically increased seed germination success from 3\% to 34\% (Fawcett and Slife 1978). Whereas Stewart et al. (1997) reported that adding $P$ had no effect on seed germination of two cattail species. Several studies highlighted the importance of a balanced $\mathrm{N}$ and P supply to seed germination success by pointing out that seed germination is restricted by P limitation (Hrdličková et al. 2011; Hejcman et al. 2012). Moreover, the positive influence of a high nutrient content of seeds on seedling size is also well established (Lamont and Groom 2013). In Austin's experiment with watercress (Rorippa nasturtium aquaticcum) (Austin 1966b), seeds from plants with high P supply gave larger plants in the first 7 to 9 weeks than otherwise similar seeds from P-deficient plants. Therefore, it seems that the nutrient supply is decisive for seed traits and performance, and thereby plant dispersal, and nutrients stored in the seed before the development of the root system for absorbing nutrients from soil, may impact seedling establishment and may also cause changes in seedling growth. However, the exact impacts are still unclear.

Human activity has led to worldwide changes in plant nutrients in the soil. The most critical of these nutrients are assumed to be the elements $\mathrm{N}$ and $\mathrm{P}$. The resulting changes in $\mathrm{N}$ and $\mathrm{P}$ availability in the environment can change the main type of nutrient limitation, and has been shown to lead to changes in plant species composition in natural vegetation (Steven et al. 2004) and in plant trait composition, including plants' investment in sexual reproduction (Fujita et al. 2014). Several studies have found that N limitation occurs frequently with higher productivity and that N-limited ecosystems harbor competitive fast-growing species whereas P-limited herbaceous ecosystems are mostly characterized by low productivity and slow-growing species (Wassen et al. 2005; Fujita et al. 2014; Roeling et al. 2018). Moreover, under P limitation, higher numbers and percentages of endangered plant species have been found (Wassen et al. 2005), whereas plant species growing under P limitation have been found to invest significantly less in sexual reproduction than species grown under $\mathrm{N}$ limitation, e.g. later flowering starting time, short flowering period, lower seed production (Fujita et al. 2014; Wang et al. 2019). These findings are in line with previous studies that have reported that endangered species have shorter flowering periods (Lahti et al. 1991), smaller seed mass (Murray et al. 2002), and poorer dispersal ability (Farnsworth and Ogurcak 2008). Another study showed that deficiency of P led to a strong reduction in the amount of flowers produced (Brouwer et al. 2001). 
Because of their low investment in sexual reproduction as a strategy to save on $\mathrm{P}$, it seems likely that compared to species persisting under $\mathrm{N}$ limitation, species persisting under P limitation may have lost their capacity to effectively disperse. This would make them more vulnerable to environmental change and extinction (Fujita et al. 2014). However, most studies in this area have been done under controlled conditions in greenhouse experiments, or are based on average traits from databases, but studies that focus on traits and performance of seeds produced in natural vegetation under different nutrient conditions, and that include intraspecific responses are scarce.

We therefore carried out a germination experiment with seeds of both a common species (Holcus lanatus) and an endangered species (Parnassia palustris) collected from plants growing in two field sites differing in N:P ratio in the above-ground vegetation, indicating differences in the relative availability of $\mathrm{N}$ and $\mathrm{P}$ (Wassen et al. 1995). We aimed to test if differences in relative $\mathrm{N}$ and $\mathrm{P}$ availability of parent plants (indicated by differences in above-ground N:P ratio) affects certain seed traits of the two species (seed size, seed weight, seed $\mathrm{N}$ and $\mathrm{P}$ concentrations and contents, seed germination success) and offspring plant survival at the end of the life cycle, under nutrient treatments varying in absolute and relative $\mathrm{N}$ and $\mathrm{P}$ supply. Secondly, we aimed to test if there were interspecific effects between the common and the endangered species. Our hypothesis was that seed traits of both the common and the endangered species respond to their parental N:P ratio. However, we expected that those responses would differ between the common and the endangered species: i.e. that high $\mathrm{N}: \mathrm{P}$ would restrict the seed performance of the common species (i.e. smaller seeds, lighter seeds, lower $\mathrm{N}$ and $\mathrm{P}$ concentrations and contents in the seeds, and lower germination success and offspring survival), but would promote them in the endangered species, due to the fact that endangered species persist under P-limited conditions (Wassen et al. 2005). Moreover, we assumed that with increasing N:P ratio, the plant survival of $H$. lanatus would decrease but the plant survival of $P$. palustris would increase.

\subsection{Materials and methods}

\subsubsection{Study area and site selection}

Seeds were collected from two sites at the Middenduin nature reserve (MD1, $52^{\circ} 16^{\prime} \mathrm{N} 5^{\circ} 9^{\prime} \mathrm{E}$ and MD2, $52^{\circ} 23^{\prime} \mathrm{N} 4^{\circ} 35^{\prime} \mathrm{E}$ ) located in the western Netherlands and owned by the State Forestry Service. The area harbors herb-rich low-productive grassland, with a high species diversity and occurrence of rare species such as Parnassia palustris L., Epipactis palustris L., and Rhinanthus minor L. The climate is 
temperate: mean annual temperature is $11^{\circ} \mathrm{C}$, mean annual minimum temperature is $-9{ }^{\circ} \mathrm{C}$, and mean annual maximum temperature is $33^{\circ} \mathrm{C}$, and the mean annual precipitation is $765 \mathrm{~mm}$ (http://projects.knmi.nl/klimatologie/daggegevens/selectie.cgi).

\subsubsection{Study species and seed collection}

Holcus lanatus L. is a common perennial velvety grass species, often found in nutrient-rich environments throughout Europe. The flowers are wind-pollinated and usually out-crossing. The hermaphroditic inflorescences produce numerous seeds that are shed from June to early autumn (Watt 1978) and remain viable for over five years (www.cabi.org/isc/datasheet/114824).

Parnassia palustris L. is an endangered perennial herb, with a basal cluster of leaves and several straight stems up to $30 \mathrm{~cm}$ high, each carrying one flower at the top. The hermaphroditic flowers are insect-pollinated. Seeds ripen between September and October, and are shed the most in September (Schat 1983). This species declined during the last century, which has resulted in genetic isolation and a threatened status in many European countries (Bossuyt 2007).

Seeds of these species were collected between June and September 2014 from populations at the two selected sites. Seeds were stored in the fridge $\left(4^{\circ} \mathrm{C}\right)$ for 10.7 weeks to break physiological dormancy (vernalization).

\subsubsection{Harvesting and determination of $\mathrm{N}$ concentration, $P$ concentration, and N:P ratio in above-ground biomass}

Above-ground vegetation was harvested in three $20 \mathrm{~cm} \times 20 \mathrm{~cm}$ squares at each site on 20 June 2014, which was the peak of the growing season of that year. Above-ground vegetative material was dried and ground to pass through a 0.5-mm sieve. Total $\mathrm{N}$ concentration of dried plant material was measured with a C/N elemental analyzer (NA1500, Carlo Erba-Thermo Fisher Scientific); total P concentration was measured by TXRF Spectrometer (S2, PICOFOX, Bruker).

We use these plant nutrient concentrations-referred to in this paper as plant $\mathrm{N}$ and plant $\mathrm{P}$-as indicators of plant-available nutrient concentrations (Wassen et al. 1995). Based on above-ground N:P ratios we determined whether the vegetation at the sites of seed collection were N-limited ( $\mathrm{N}: \mathrm{P}<13.5)$, P-limited (N:P $>16)$, or $\mathrm{N}$ and $\mathrm{P}$ co-limited (13.5 $\leq \mathrm{N}: \mathrm{P} \leq 16)$ (Güsewell and Koerselman 2002; Olde Venterink et al. 2003). 


\subsubsection{Analysis of seed $\mathrm{N}$ and $\mathrm{P}$ concentrations and $\mathrm{N}$ and $\mathrm{P}$ contents}

Seeds of H. lanatus and P. palustris from each site were dried and ground into powder with a Retsch MM400 mixer mill. Total $\mathrm{N}$ concentration in seeds was measured using C/N elemental analyzer (NA1500, Carlo Erba-Thermo Fisher Scientific). Total P concentration in seeds was measured using a TXRF Spectrometer (S2, PICOFOX, Bruker).

Seed $\mathrm{N}$ and $\mathrm{P}$ contents of $\mathrm{H}$. lanatus were calculated by multiplying seed $\mathrm{N}$ and $\mathrm{P}$ concentrations of $H$. lanatus respectively by the average weight of 100 seeds of $H$. lanatus; seed $\mathrm{N}$ and $\mathrm{P}$ contents of $\mathrm{P}$. palustris were calculated by multiplying seed $\mathrm{N}$ and $\mathrm{P}$ concentrations of $P$. palustris respectively by the average weight of 200 seeds of P. palustris.

\subsubsection{Seed length, area, and weight}

As indicators for seed size, we measured seed length, cross section area and weight. Random seeds of $H$. lanatus from sites MD1 and MD2 respectively were placed on a flat sheet of white paper next to a ruler. Representative digital images of seeds (457 for seed length of seed from site MD1; 435 for seed area of seed from site MD1; 674 for seed length of seed from site MD2; 666 for seed area of seed from site MD2) were taken using a Nikon D5200 camera (Nikon Corp., Japan) 1 m vertically above the seeds.

Random seeds of $P$. palustris from sites MD1 and MD2 respectively were placed on the plain stand of a Nikon SMZ800N magnification unit (Nikon Cor., Japan). Representative digital images of seeds (569 for seed length of seed from site MD1; 508 for seed area of seed from site MD1; 438 for seed length of seed from site MD2; 375 for seed area of seed from site MD2) were taken using a Nikon Digital Sight DS-Fil camera with photonic F3000 light.

To quantify seed size, the following two attributes were calculated from seed images by ImageJ software:

- Seed length defined as the longest distance between two points on the edge of a seed.

- Seed area defined by the vertical projection area of a seed.

Seed length and area of each species from each site were then calculated by averaging all the measured seeds. 
10 batches of 100 seeds of $H$. lanatus from each of the two sites (MD1 and MD2), and 10 batches of 200 seeds of $P$. palustris also from these sites, were weighed. The weight of 100 seeds of $H$. lanatus from each site and the weight of 200 seeds of $P$. palustris, also from each site, were then calculated by averaging the resulting 10 batch weights.

\subsubsection{Germination experiment}

Healthy and mature seeds of $H$. lanatus and $P$. palustris were selected individually by using a Nikon SMZ800N magnification unit (Nikon Cor., Japan). For H. lanatus we selected 5044 seeds from site MD1, and 5515 from site MD2; for P. palustris we selected 5112 seeds from site MD1, and 6721 from site MD2). These seeds were sown on moist quartz sand in separate germination chambers covered by a piece of glass to retain moisture. Germination chambers were kept in the greenhouse with a relatively high and fluctuating temperature and natural light conditions. After 22 days, when no more new seedlings emerged, the final numbers of seedlings of $H$. lanatus and $P$. palustris from sites MD1 and MD2 were counted. The germination ratio of each species in each site was calculated by dividing the number of seedlings by the number of seeds sown.

\subsubsection{Plant survival at the end of the life cycle, under different nutrient treatments}

A random selection of seedlings was transferred to pots (volume $8 \mathrm{~L}$ for H. lanatus, and $3 \mathrm{~L}$ for $P$. palustris) containing a mixture of quartz sand and natural dune sand collected close to the study areas (for detailed information, see Wang et al. 2019). Four seedlings were planted in each pot and incubated in the greenhouse. Nutrient solutions were supplied following Güsewell (2005a).

A full factorial combination with six nutrient treatments was applied, with three nutrient supply ratios ( $\mathrm{N}: \mathrm{P}=5$ (low relative $\mathrm{N}$ supply), $\mathrm{N}: \mathrm{P}=15$ (co-limitation), and $\mathrm{N}: \mathrm{P}=45$ (low relative $\mathrm{P}$ supply)), and two absolute nutrient supply levels: low and high. The treatments were defined by the total amounts of $\mathrm{N}$ and $\mathrm{P}$ applied per plant throughout the cultivation process (in $\mathrm{mg}$ ), and were calculated as:

$\mathrm{N}=\mathrm{L} \times \sqrt{\mathrm{N}: \mathrm{P}}$, and $\mathrm{P}=\frac{1}{\sqrt{\mathrm{N}: \mathrm{P}}},($ where $\mathrm{L}=\sqrt{\mathrm{N} \times \mathrm{P}})$

in which L is the overall supply level (geometric mean of N and P supply). L was 13.4 $\mathrm{mg}$ for low supply level and $40.3 \mathrm{mg}$ for high supply level, similar to the first-year nutrient treatments of (Güsewell 2005a). 
For each nutrient treatment with seeds of one species from one site, there were 4 pots. The total number of pots was: 2 species $\times 2$ sites $\times 3$ nutrient supply ratios $\times 2$ nutrient supply levels $\times 4$ pot replicates $=96$. Nutrient solutions were applied weekly (for detailed information, see Wang et al. 2019). $\mathrm{N}$ was supplied as $\mathrm{KNO}_{3}$ and $\mathrm{Ca}\left(\mathrm{NO}_{3}\right)_{2}$, $\mathrm{P}$ was provided as $\mathrm{KH}_{2} \mathrm{PO}_{4}$. Both $\mathrm{KNO}_{3}$ and $\mathrm{KH}_{2} \mathrm{PO}_{4}$ supplied part of the $\mathrm{K}$, the remaining $\mathrm{K}$ was added by supplying $\mathrm{KCl}$ (Güsewell 2005a). The other essential macronutrients, such as calcium ( $\mathrm{Ca}$ ), and micronutrients, such as Fe and copper $(\mathrm{Cu})$, were applied in non-limiting concentrations and were supplied in the same amounts to all treatments weekly. Details of the nutrient treatments are given in Appendix 2.1. Chlorine (Cl) was the only element that was not supplied in fixed amounts to all treatments. We have indicated the range of $\mathrm{Cl}$ addition in Appendix 2.1.

In addition to receiving nutrient solutions, plants were watered frequently with demineralized water to prevent drying out.

For both species, the number of dead individuals was recorded at the end of the experiment, after monitoring a full life cycle from seed to seed. Survival of each species from each site was then calculated by dividing the number of surviving plants by the total number of original seedlings.

\subsubsection{Data analysis}

One-tailed t-tests were used to compare $\mathrm{N}$ and $\mathrm{P}$ concentrations in the aboveground biomass of $H$. lanatus and P. palustris, $\mathrm{N}$ and $\mathrm{P}$ concentrations and $\mathrm{N}$ and $\mathrm{P}$ contents of seed material of the two species, seed traits (length, area, weight) and the survival of $P$. palustris between the two sites MD1 and MD2 under various nutrient treatments.

The between-site differences in seed germination success of $H$. lanatus and $P$. palustris were analyzed using a Chi-square test. The difference in plant survival of $P$. palustris per site, and for the two sites together, under different nutrient treatments, was tested in one-way ANOVA with standard post-hoc test of Gabriel's procedure to analyze differences between treatments with the combination of different nutrient supply ratios and levels. Differences were considered to be statistically different at $P \leq 0.05$. All tests were performed with SPSS 24.0 software (SPSS, Chicago, U.S.A.); the figures were also created in SPSS. 


\subsection{Results}

\subsection{1 $\mathrm{N}$ and $\mathrm{P}$ concentrations of above-ground biomass}

$\mathrm{P}$ concentration in the above-ground biomass was significantly higher in site MD1 than in site MD2, but no significant difference was found for N (Table 2.1). The two sites differed significantly in the relative availability of $\mathrm{N}$ and $\mathrm{P}$, as indicated by N:P ratio of the above-ground biomass. The N:P ratio in above-ground plant material was 22.3 in site MD1 but 40.5 in MD2, indicating that in both sites plant growth was limited by P but that site MD2 was more P-limited than site MD1 (Güsewell and Koerselman 2002).

\subsubsection{Seed $N$ and $P$ concentrations and $N$ and $P$ contents}

As with $\mathrm{N}$ concentration in the above-ground biomass, there was no difference in seed $\mathrm{N}$ concentration for either H. lanatus or P. palustris between sites (Table 2.2). The seed P concentration of H. lanatus from the more severely P-limited site (MD2) was significantly higher than that from site MDl, but there was no significant difference in the seed $\mathrm{P}$ concentration of $P$. palustris between sites (Table 2.2). Unlike the N:P ratio of above-ground biomass, and thus contrary to expectations, the seed N:Pratio of H. lanatus from the strongly P-limited site MD2 was significantly lower than that from site MD2 (Table 2.2). No significant inter-site difference was found for the seed N:P ratio of P. palustris.

Table 2.1 Comparisons of $\mathrm{N}$ and $\mathrm{P}$ concentrations ( $\mathrm{mg} \mathrm{g}^{-1}$ dry material) in above-ground biomass from sites MD1 and MD2.

\begin{tabular}{llll}
\hline Site & N conc. & P conc.* & N:P* \\
\hline MD1 & $36.71 \pm 3.69$ & $1.65 \pm 0.06 \mathrm{a}$ & $22.29 \pm 2.14 \mathrm{~b}$ \\
MD2 & $41.81 \pm 5.19$ & $1.03 \pm 0.09 \mathrm{~b}$ & $40.47 \pm 1.67 \mathrm{a}$ \\
\hline
\end{tabular}

Data are means \pm SD. * Different lowercase letters indicate significant difference of the same parameter ( $\mathrm{N}$ conc., $\mathrm{P}$ conc., or $\mathrm{N}: \mathrm{P}$ ) between sites MD1 and MD2. Values without lowercase letter are not significantly different $(P=0.05)$.

The seed $\mathrm{N}$ and $\mathrm{P}$ contents of $H$. lanatus and P. palustris showed the same tendency as seed $\mathrm{N}$ and $\mathrm{P}$ concentrations: no significant inter-site difference was found for seed $\mathrm{N}$ or P content of P. palustris, but the seed P content of $H$. lanatus from site MD2 was significantly higher than that from site MD1 (Table 2.2). 
Table 2.2 Comparisons of seed $\mathrm{N}$ and $\mathrm{P}$ concentrations ( $\mathrm{mg} \mathrm{g}^{-1}$ dry material), seed $\mathrm{N}$ and $\mathrm{P}$ content (mg), and seed $\mathrm{N}: \mathrm{P}$ of H. lanatus and P. palustris between sites MD1 and MD2.

\begin{tabular}{lllllll}
\hline Species & Site & N conc. & P conc. & N content & P content & N:P \\
\hline \multirow{2}{*}{ H. lanatus } & MD1 & $1.375 \pm 0.064$ & $0.053 \pm 0.004 \mathrm{~b}$ & $0.032 \pm 0.002$ & $0.001 \pm 0.0001 \mathrm{~b}$ & $25.754 \pm 0.912 \mathrm{a}$ \\
\cline { 2 - 7 } & MD2 & $1.540 \pm 0.148$ & $0.148 \pm 0.025 \mathrm{a}$ & $0.036 \pm 0.003$ & $0.004 \pm 0.001 \mathrm{a}$ & $10.791 \pm 2.982 \mathrm{~b}$ \\
\multirow{2}{*}{\begin{tabular}{l} 
P. palustris \\
\cline { 2 - 7 }
\end{tabular}} & MD1 & $3.720 \pm 0.085$ & $0.330 \pm 0.001$ & $0.012 \pm 0.0003$ & $0.001 \pm 0.000004$ & $11.273 \pm 0.310$ \\
\hline
\end{tabular}

Seed N and P contents of H. lanatus were measured per 100 seeds; seed N and P contents of P. palustris were measured per 200 seeds.

Data are means $\pm \mathrm{SD}$. Different lowercase letters indicate significant difference of the same parameter (N conc., P conc., N content, $\mathrm{P}$ content, or N:P) between sites MD1 and MD2. Values without lowercase letter are not significantly different $(P=0.05)$.

\subsubsection{Seed length, area, and weight}

Parental N:P ratio influenced seed length and area; the influences differed between H. lanatus and P. palustris. Parental N:P ratio did not influence seed weight in either species (Figure 2.1). Seeds from the more severely P-limited site (site MD2) were shorter and smaller in the case of H. lanatus, but longer and bigger in the case of P. palustris (Figure 2.1).

\subsubsection{Germination success}

Seed germination success differed remarkably between the two species: average germination success was $6.3 \%$ for $H$. lanatus and $59.6 \%$ for P. palustris. When comparing seeds with a different parental N:P ratio (site MD1 versus site MD2), no significant difference was found for the germination success of H. lanatus, whereas seed germination success of $P$. palustris from site MD2 was significantly higher than that from site MDl (Table 2.3).

Table 2.3 Number of seeds, number of seedlings, and germination success of H. lanatus and P. palustris from sites MD1 and MD2.

\begin{tabular}{lllllll}
\hline Species & \multicolumn{2}{l}{ Site MD1 } & \multicolumn{3}{l}{ Site MD2 } \\
\cline { 2 - 7 } & $\begin{array}{l}\text { Number of } \\
\text { seeds }\end{array}$ & $\begin{array}{l}\text { Number of } \\
\text { seedlings }\end{array}$ & $\begin{array}{l}\text { Germination } \\
\text { success \% }\end{array}$ & $\begin{array}{l}\text { Number of } \\
\text { seeds }\end{array}$ & $\begin{array}{l}\text { Number of } \\
\text { seedlings }\end{array}$ & $\begin{array}{l}\text { Germination } \\
\text { success \% }\end{array}$ \\
\hline H. lanatus & 5044 & 325 & $\mathbf{6 . 4 4}$ & 5515 & 329 & $\mathbf{6 . 1 5}$ \\
\hline P. palustris* & 5112 & 2900 & $\mathbf{5 6 . 7 3 b}$ & 6721 & 4193 & $\mathbf{6 2 . 3 9 a}$ \\
\hline
\end{tabular}

Bold values indicated by different characters are significantly different between site MDl and site MD2 $(P=0.05)$. 


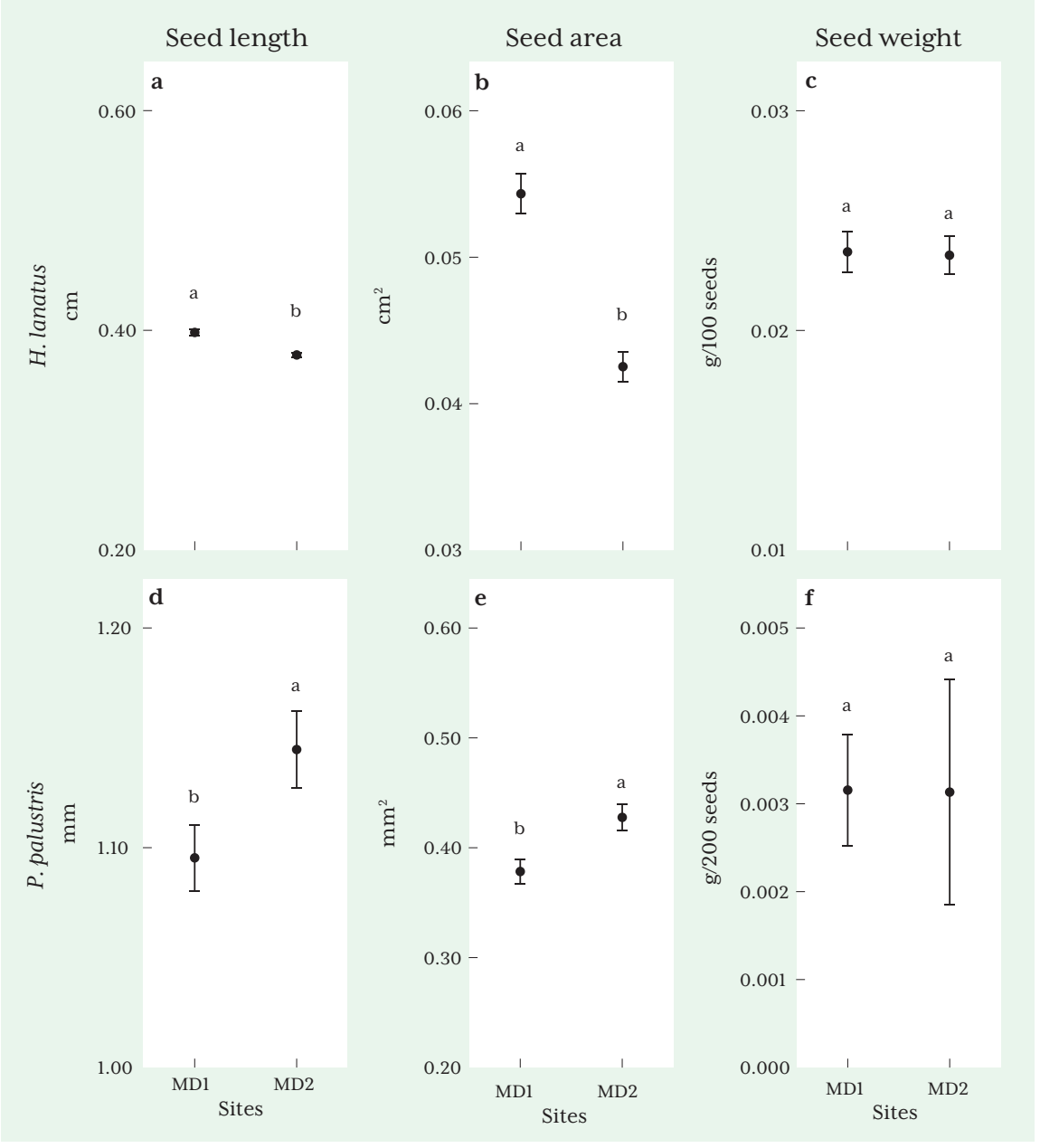

Figure 2.1 Comparisons of seed length, seed area, and seed weight of $H$. lanatus and $P$. palustris from sites MD1 and MD2. Data are means \pm SD. Significant differences between sites are indicated by different lowercase letter(s). Values with the same lower letter(s) are not significantly different $(P=0.05)$.

\subsubsection{Offspring plant survival at the end of the life cycle}

$H$. lanatus grew successfully under all the nutrient treatments, irrespective of the parental N:P ratio. At the end of the experiment, only 4 plants, all in a single pot in treatment $45 \mathrm{H}$ (i.e. $\mathrm{N}: \mathrm{P}$ ratio of 45 , high supply level), had died, resulting in an overall survival of $97.9 \%$ for H. lanatus. 


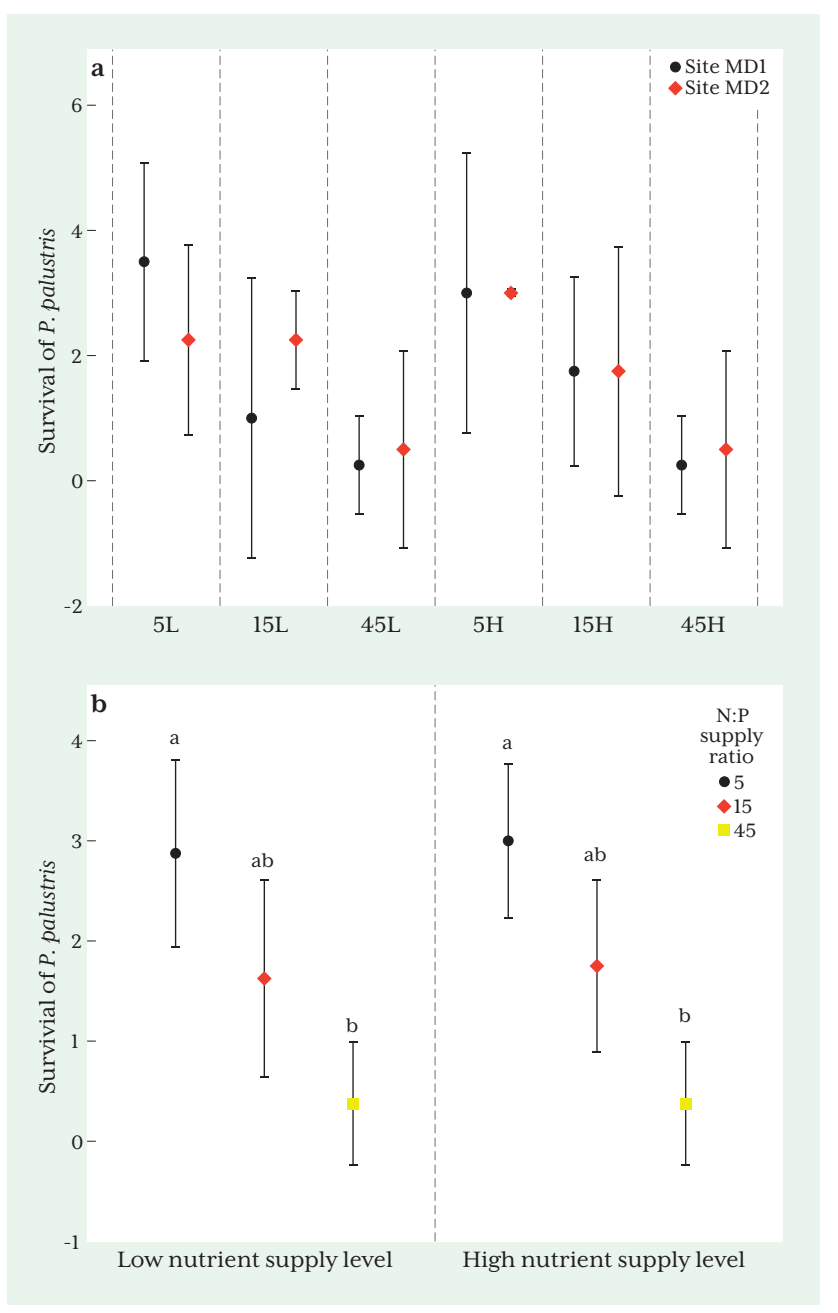

Figure 2.2 Offspring plant survival (\%) of P. palustris from sites MD1 and MD2 under different nutrient treatments (a); offspring plant survival (\%) of $P$. palustris under different nutrient treatments, with sites MD1 and MD2 pooled (b). Values without character indicate no significant difference between sites MD1 and MD2 under the same nutrient treatment $(P=0.05)(a)$; values indicated by the same character are not significantly different $(P=0.05)(b)$.

For P. palustris, again, no effect of parental N:P ratio was detected, i.e. offspring plant survival of $P$. palustris did not differ significantly between site MDl and site MD2 (Figure 2.2a). We therefore pooled the results of sites MD1 and MD2 before further analyzing the survival of $P$. palustris at different N:P ratios and supply levels. 
After pooling, the plant survival of $P$. palustris was found to decrease with increasing $\mathrm{N}: \mathrm{P}$ ratio, irrespective of nutrient supply level (Figure 2.2b): i.e. the survival of P. palustris was the highest (c. 81.3\%) under the treatments with an N:P ratio of 5 (N limitation), and the lowest (c. 6.3\%) under the treatments with an N:P ratio of 45 (P limitation; Figure 2.2b).

\subsection{Discussion}

In this experiment, we tested the effects of nutrient conditions of parent plants on certain seed traits (seed length, seed area, seed weight, seed $\mathrm{N}$ and $\mathrm{P}$ concentrations and contents), seed germination success, and survival of plants grown from these seeds under various nutrient treatments, for a common species (Holcus lanatus) and an endangered species (Parnassia palustris) from two field sites with two different N:P ratio growth conditions. The N:P ratio in the above-ground biomass was 22.3 for site MD1 and 40.5 for site MD2. The latter ratio indicates very strong $\mathrm{P}$ limitation whereas the former is closer to an $\mathrm{N}$ and $\mathrm{P}$ availability that is considered balanced (14.75: cf. Güsewell and Koerselman 2002). The results for Holcus lanatus showed that stronger P-limited conditions for the parent plants decreased $\mathrm{P}$ concentration and content in seeds, and increased N:P ratio. No differences in nutrients in seeds from different parental N:P ratios were found for Parnassia palustris. Stronger P-limited conditions promoted the seed germination ability of Parnassia palustris significantly but not for Holcus lanatus. Additionally, no significant inter-site difference in seed weight was found for either species, while for seeds from parent plants under stronger P-limited conditions, seed length and area were restricted in Holcus lanatus but promoted in Parnassia palustris. Furthermore, no influence of parental N:P ratio on offspring plant survival was found.

\subsubsection{Intraspecific differences between parental N:P ratios of H. lanatus and P. palustris}

Seed traits such as seed length, size, mass, and mineral nutrient concentration have been shown to correlate with seed quality, seed germination, and seedling establishment (Vera 1997; Ellison 2001; Cordazzo 2002; Bu et al. 2007; Wu and Du 2007; Kaya et al. 2008; White and Veneklaas 2012). Our comparisons of traits of seeds of $H$. lanatus and $P$. palustris collected from the two sites with different parental N:P ratios clearly confirmed our hypothesis that parental N:P ratio affects seed trait expression and seed performance.

In detail, seeds of H. lanatus from the more P-limited site (site MD2) were shorter and smaller than those from the site with a more balanced N:P ratio (site MDl) 
(Figure 2.1). This is in line with a previous greenhouse experiment on H. lanatus that showed that seeds produced under $\mathrm{P}$ limitation $(\mathrm{N}: \mathrm{P}=45)$ were significantly smaller and shorter than seeds produced under $\mathrm{N}$ limitation and $\mathrm{N}$ and $\mathrm{P}$ co-limitation ( $\mathrm{N}: \mathrm{P}=5$ and $\mathrm{N}: \mathrm{P}=15$ ) (Wang et al. 2019). The shorter length and smaller seeds of H. lanatus at site MD2 imply that conditions with a low relative P availability in parent plants may reduce the seed quality of common species, possibly because P limitation restricts the vegetative growth of the parent plant (Liao and Yan 1999; Wang et al. 2021). Moreover, this greenhouse experiment on the investment in sexual reproduction of $H$. lanatus under a gradient of N:P ratios indicated that $\mathrm{P}$ limitation dramatically restricted seed number and weight per plant (Wang et al. 2019). In contrast, in P. palustris, P limitation did not reduce seed length and seed area but promoted them: seeds from the more P-limited site (site MD2) were longer and larger in area than those from the more balanced N:P ratio (site MDl) (Figure 2.1). This is in line with the finding by Lamont and Groom (2013) that seeds were larger in poorer soils. However, contrary to their other conclusion that seeds produced on poorer soils are more nutrient-rich, in our study we found no inter-site difference in $\mathrm{N}$ concentration, $\mathrm{P}$ concentration, $\mathrm{N}$ content, or $\mathrm{P}$ content in the seeds of P. palustris (Table 2.2).

The larger seed size might therefore be one of the reasons that seeds of P. palustris from site MD2 had more successful germination than those from site MD1, especially given the positive effect of seed size on seed germination suggested by Schat (1983). However, contrary to expectations, seed germination success of $H$. lanatus did not differ significantly between our two sites, even though, as noted above, there were inter-site differences in seed size and $\mathrm{P}$ concentration in the seeds. The lack of difference in germination success of $H$. lanatus from different parental N:P ratios contrasts with findings from other studies. For instance, Hejcman et al. (2012) showed that when parent plants had been grown under conditions of insufficient $\mathrm{P}$ and $\mathrm{K}$, the seed germination success of Rumex crispus was lower than when parent plants received a balanced supply of N, P, and K. Since $\mathrm{P}$ is an element essential for plant vegetative growth (Wang et al. 2021) as well as for sexual reproduction (Fujita et al. 2014; Wang et al. 2019), the lack of inter-site difference in germination success of seeds of H. lanatus might be explained by the observation that although the seeds from the stronger P-limited site were smaller, they also had a higher P concentration, which may have counterbalanced the negative effects of a smaller seed size.

Where the seedling establishment of $H$. lanatus under the various nutrient treatments was relatively stable, with a high offspring plant survival of $97.9 \%$, the offspring plant survival of $P$. palustris varied greatly under different nutrient 
treatments: the highest survival was at N:P 5 (indicating severe N limitation), and the lowest was at N:P 45 (indicating severe P limitation) (Figure 2.2). In addition, throughout their life cycle, the surviving individuals under N:P 45 also showed poor growth and a stunted appearance compared to the individuals under N:P 5 and 15. According to Tilman's (1982) resource ratio hypothesis, a species whose requirement ratio of multiple resources is closer to the supply ratio of the resources will be likely to persist better than a species with a more divergent ratio. We may therefore deduce that an N:P ratio of 5 is more optimal for P. palustris than a ratio of 15 or 45-which is opposite to our original assumption that the endangered species $P$. palustris would prefer P limitation. This unexpected conclusion might be explained by the fact that although P limitation has proved to be a condition under which endangered species persist, this does not mean that all endangered species predominantly confined to P-limited ecosystems. In fact, $51 \%$ of the endangered species in the dataset of Fujita et al. (2014) occurred under N:P ratios in above-ground biomass that were below 16, indicating $\mathrm{N}$ limitation or $\mathrm{N}$ and $\mathrm{P}$ co-limitation. The apparent preference of the endangered species $P$. palustris for $\mathrm{N}$ limitation during its growth contrasts with our finding that P limitation improved its seed characteristics. Moreover, despite the better performance of seeds of P. palustris from the more P-limited site, i.e. longer and bigger seeds, as well as higher germination success (Figure 2.1, Table 2.3), we noticed that plants of P. palustris growing from seeds from the more P-limited site (site MD2) were more easily infected by fungi. This observation suggests that offspring of endangered plants growing from seeds from parent plants grown under P-limited conditions are more susceptible to fungal infection than those from parent plants grown under more balanced N:P ratio growth conditions, and although at the end of the growing season there was no significant inter-site difference in the offspring plant survival of $P$. palustris (Figure 2.2a), the higher infection rate may affect its competitive ability when grown in competition with other species (Alexander and Holt 1998).

\subsubsection{Interspecific differences between $H$. lanatus and P. palustris}

Seeds of the common species H. lanatus were generally bigger than those of the endangered species $P$. palustris (Figure 2.1). This is consistent with the theory suggested by Mitchley and Grubb (1986) that competitive superiority of largeseeded species allows them to become common, while small-seeded species are fugitive occupants of relatively rare microsites. By comparing the intraspecific differences of the effects of parental N:P ratio on H. lanatus and P. palustris, we found that common and endangered species might respond in opposite ways to parental nutrient limitation. As mentioned in the discussion above, under stronger P limitation, seed quality of $P$. palustris tended to improve (longer, bigger 
seeds, with higher germination success), whereas the seed quality of H. lanatus suffered (shorter and smaller seeds). A possible explanation is that endangered species are more sensitive to $\mathrm{P}$ enrichment, as endangered species occur more frequently under conditions of P limitation (Wassen et al. 2005), where plants invest less in sexual reproduction than they do under conditions of $\mathrm{N}$ limitation or co-limitation (Fujita et al. 2014). As P is proportionally the most important element in plant seeds (Van Andel and Vera 1977; Fenner 1986a), the bigger seed size of $P$. palustris in more P-limited conditions may be a strategy to acquire and store sufficient $\mathrm{P}$ for the next generation.

The somewhat counterintuitive finding that germination success of the larger seeds of H. lanatus was much lower than that of the small seeds of P. palustris (Table 2.3) is in line with the finding of Hanley et al. (2003) that the germination success for fire-following species was greater for the smaller-seeded species than for the larger-seeded species at high temperature. However, to our knowledge, the relationship between seed size and germination success of non-fire-following species have rarely been studied, which probably deserve further research. Interestingly, although germination success was lower for H. lanatus and higher for $P$. palustris, offspring plant survival of these two species was very different: $98 \%$ for $H$. lanatus, but only $42 \%$ for P. palustris. The low germination success but high offspring plant survival of $H$. lanatus in our research is consistent with the result Isselstein et al. (2002) reported for this species. In general, the pattern of plant mortality risk depends largely on specific tolerances, which may strongly differ between species: for instance, P. palustris requires particular environmental conditions (Schat 1983), whereas H. lanatus has a much broader ecological amplitude(Veeranjaneyulu and Ramadas 1982). The relatively low plant survival of $P$. palustris (especially under P limitation) (Figure 2.2, Appendix 2.2) and the fact that its plants are small (Bonnin et al. 2002) indicates that rejuvenation of P. palustris is hampered by $\mathrm{P}$ limitation and probably puts this species at a strong competitive disadvantage vis-à-vis common species like H. lanatus and might be a factor accounting for $P$. palustris being endangered in the wild.

\subsection{Conclusions}

In conclusion, this experiment shows that parental $\mathrm{N}: \mathrm{P}$ ratio, especially $\mathrm{P}$ limitation in the parental environment, influenced seed performance for both of the common species and the endangered species. However, P limitation in the parental environment improved seed quality of the endangered species, while the common species suffered from P limitation. Remarkably, for Parnassia palustris, 
stronger P-limited conditions in the parental environment significantly enhanced seed germination success, whereas stronger P-limited conditions in the offspring environment decreased offspring survival, suggesting that P-limitation negatively affects Parnassia palustris rejuvenation. Based on the findings we highlight the importance of the management to reduce $\mathrm{P}$ availability to conserving endangered species. However, since only two plant species were studied and so little research has been done on the relations between parental $\mathrm{N}$ and $\mathrm{P}$ concentration and seed performance, it is difficult to draw generalizable conclusions. We therefore suggest that future research examines more common and endangered species to better understand the potential impact of eutrophication on the conservation status of plant species by affecting their sexual reproduction success and dispersal capacity.

\section{Acknowledgments}

We acknowledge the China Scholarship Council (CSC) for a doctoral scholarship to Shuqiong Wang (CSC NO. 201406140142). We thank Ineke Roeling for the original seed collection and storing, Ton Markus for improving all the figures, and Joy Burrough for the professional English checking of a near-final draft of the manuscript.

\section{Supplementary materials}

\begin{tabular}{lll}
$\begin{array}{l}\text { Appendix 2.1 Elements other than nitrogen }(\mathrm{N}) \\
\text { to each plant during cultivation. }\end{array}$ \\
\hline $\begin{array}{l}\text { Other elements } \\
\text { for all treatments }\end{array}$ & Resources & $\begin{array}{l}\text { Amount of element supplied } \\
(\mathbf{m g} / \text { plant })\end{array}$ \\
\hline $\mathrm{K}$ & $\mathrm{KNO}_{3} \& \mathrm{KCl}$ & 400 \\
\hline $\mathrm{Ca}$ & $\mathrm{CaCl}_{2} \cdot 2 \mathrm{H}_{2} \mathrm{O}$ & 51.6 \\
\hline $\mathrm{Mg}$ & $\mathrm{MgSO}_{4} \cdot 7 \mathrm{H} 2 \mathrm{O}$ & 11.7 \\
\hline $\mathrm{S}$ & $\mathrm{MgSO}_{4} \cdot 7 \mathrm{H} 2 \mathrm{O}$ & 17.8 \\
\hline $\mathrm{Fe}$ & $\mathrm{Fe}_{\mathrm{EDTA}}$ & 4.1 \\
\hline $\mathrm{Cu}$ & $\mathrm{CuSO}_{4} \cdot 5 \mathrm{H}_{2} \mathrm{O}$ & 0.02 \\
\hline $\mathrm{B}$ & $\mathrm{H}_{3} \mathrm{BO}_{3}$ & 0.39 \\
\hline $\mathrm{Mn}$ & $\mathrm{MnSO}_{4} \cdot \mathrm{H}_{2} \mathrm{O}$ & 0.21 \\
\hline $\mathrm{Mo}$ & $\mathrm{Na}_{2} \mathrm{MoO}_{4} \cdot \mathrm{H} 2 \mathrm{O}$ & 0.04 \\
$\mathrm{Zn}$ & $\mathrm{ZnSO}_{4} \cdot 7 \mathrm{H}_{2} \mathrm{O}$ & 0.10 \\
\hline
\end{tabular}

Cl was the only element not supplied in the same amounts to all treatments; the amount supplied varied between $113.1 \mathrm{mg} /$ plant and $346.5 \mathrm{mg} /$ plant. 


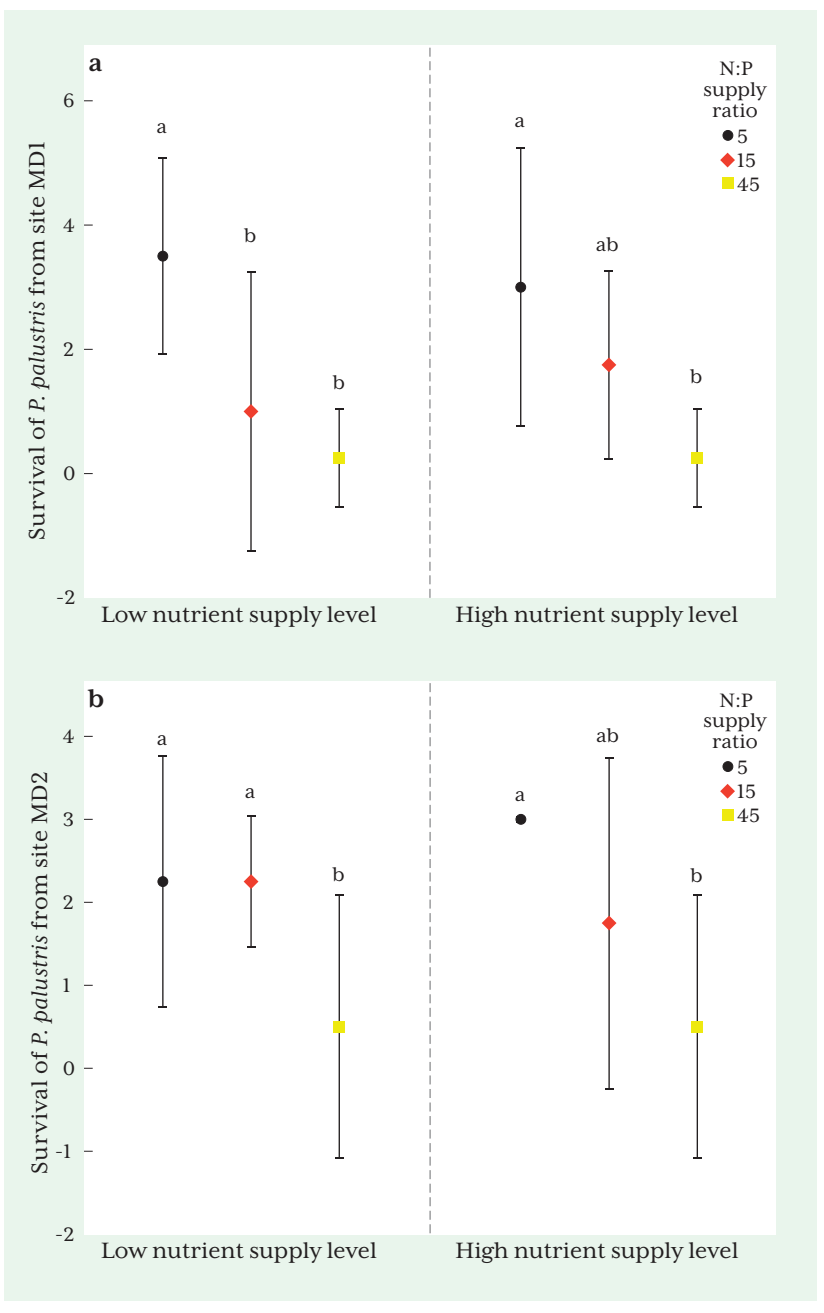

Appendix 2.2 Offspring plant survival (\%) of P. palustris under different nutrient treatments from site MD1 (a) and site MD2 (b). Values followed by the same character are not significantly different $(P=0.05)$. 



\section{Chapter 3}

Source and sink activity of Holcus lanatus L. in response to absolute and relative supply of nitrogen and phosphorus

Shuqiong Wang, Jerry van Dijk, Hugo J. de Boer, Martin J. Wassen

(Published in Functional Plant Biology 48 (2021): 493-502) 


\begin{abstract}
Mineral nutrients influence photosynthesis and tissue formation; a shift from nitrogen (N)-limited to phosphorus (P)-limited growth induced by high $\mathrm{N}$ deposition may change plant growth in grassland in terms of physiology and morphology. This experiment tested how absolute and relative $\mathrm{N}$ and $\mathrm{P}$ supply affect net photosynthesis (source activity) and biomass formation (sink activity), and the relationship between source activity and sink activity of grassland species under various nutrient treatments.

Holcus lanatus L. was grown at three N:P supply ratios $(5,15,45)$ with two absolute supply levels of $\mathrm{N}$ and P. Between N:P 5 at low level and N:P 45 at high level, and N:P 45 at low level and N:P 5 at high level there was a 9-fold difference in the $\mathrm{N}$ and $\mathrm{P}$ supply. Maximum light-saturated net photosynthesis rate $\left(\mathrm{A}_{\max }\right)$, specific leaf area (SLA), leaf area, shoot biomass, and root biomass, were determined during and after the growth process.

$\mathrm{A}_{\text {max }}$ was minimal at N:P 5 and increased only with increasing absolute $\mathrm{N}$ supply. Neither SLA nor leaf area were affected by N:P; increasing absolute P supply significantly increased leaf area. Shoot and root biomass were both minimal at $\mathrm{N}: \mathrm{P} 45$ and increased dramatically with increasing absolute P supply. Plant biomass (sink activity) was not correlated with $\mathrm{A}_{\max }$ (source activity).

Our results highlight that growth of Holcus lanatus L. is predominantly controlled by supply of $\mathrm{P}$ and to a lesser extent by $\mathrm{N}$, whereas source activity (net photosynthesis) exerted no apparent control on growth under these sink-limited growth conditions. Our findings contribute to understanding of plant growth responses under sink-limited conditions.
\end{abstract}




\subsection{Introduction}

Anthropogenic disturbance has been changing nutrient cycles across various ecosystems globally (Vitousek et al. 1997; Sims et al. 1998) leading to serious environmental issues, for example, greater primary productivity (Smith et al. 1999), shifts in species composition and lower diversity (Vermeer and Berendse 1983; Wassen et al. 2005). As nitrogen (N) and phosphorus (P) are the two elements most frequently limiting plant growth in natural vegetation (Wielgolaski et al. 1981; Marion et al. 1989; Shaver and Kummerow 1992), their increased availability due to anthropogenic activities has impacted plant communities in natural and semi-natural ecosystems (Elser et al. 2000; Fujita et al. 2014). Numerous field surveys and fertilization experiments carried out in grasslands have revealed that enrichment by $\mathrm{N}$ and $\mathrm{P}$ could drive changes in plant species diversity (Bobbink et al. 2003, 2010; Steven et al. 2004; Ceulemans et al. 2013; Avolio et al. 2014), due to increased competition for light in response to productivity increases (Hautier et al. 2009) and to other factors such as low investment in sexual reproduction due to $P$ limitation (Fujita et al. 2014; Wang et al. 2019).

The common perception is that $\mathrm{N}$ rather than $\mathrm{P}$ limits primary productivity in most terrestrial ecosystems in the temperate zone (Smith et al. 1999), leading to low $\mathrm{N}: \mathrm{P}$ ratios in above-ground vegetation of N-limited ecosystems (Vitousek and Howarth 1991; Steven et al. 2004; Fujita et al. 2014). However, continued enrichment with $\mathrm{N}$ may induce or reinforce deficiency in $\mathrm{P}$, which may gradually increase the $\mathrm{N}$ :P ratio not only in vegetation but also in litter and organic matter, especially in ecosystems with a low soil P content (Flückiger and Braun 1998). The physiological responses of plants to atmospheric $\mathrm{N}$ deposition have been investigated extensively (Aerts and Bobbink 1999; Güsewell 2005a). However, there is little information on the specific effects of P limitation as opposed to $\mathrm{N}$ limitation on grassland plant growth (Keddy et al. 2001; Güsewell 2005a; Olde Venterink 2011). Moreover, the relative effects of $\mathrm{N}$ and $\mathrm{P}$ on plant growth are complex, since $\mathrm{N}$ and $\mathrm{P}$ are needed in various amounts for different organs and plant processes (Güsewell 2004). Based on a large-scale field survey, Ceulemans et al. (2011) provided insights into the relative contribution of $\mathrm{P}$ enrichment to species loss through increased productivity and showed that the contribution of $\mathrm{P}$ was actually higher than that of $\mathrm{N}$; however, the ecological mechanisms underlying productivity increases in response to increased $\mathrm{N}$ or $\mathrm{P}$ availability are still unclear.

Plant growth is the process of accumulating dry matter. This occurs via two main nutrient pathways: photosynthesis in leaves, in which carbon (C) is assimilated, and the acquisition of mineral elements (e.g. N, P, K, Fe, Cu), mainly via roots. 
The maximum light-saturated photosynthesis rate $\left(\mathrm{A}_{\max }\right)$ has traditionally been assumed to be the factor controlling the rate of plant growth (Gifford 1974; Wardlaw 1990). Foliar $\mathrm{N}$ and $\mathrm{P}$ are the main mineral nutrient elements of critical compounds in the photosynthesis process such as Rubisco (rich in N) and ATP (rich in P), and are generally found to be correlated with $\mathrm{A}_{\max }$ (Herold 1980; Johnson 1984; Reich et al. 1992). Aerts and Chapin (2000) found that in most cases $\mathrm{A}_{\text {max }}$ correlates more closely with foliar $\mathrm{N}$ than with foliar $\mathrm{P}$, with $\mathrm{A}_{\text {max }}$ decreasing significantly when $\mathrm{N}$ deficiency in soil increases. The explanation for this is that $\mathrm{N}$ deficiency decreases chlorophyll content, whereas low P either increases or has no effect on the concentration of chlorophyll in leaf tissue (Terry and Ulrich 1973; Chrysargyris et al. 2016). Nonetheless, increased foliar P stimulates the $\mathrm{A}_{\max }$-foliar $\mathrm{N}$ relation, as indicated by Reich et al. (2009). However, because the function of $\mathrm{P}$ in photosynthesis is much less clear than that of $\mathrm{N}$ and it is difficult to separate $\mathrm{N}$ and $P$ when determining their effect on $A_{\max }$ (Reich et al. 2009), an clear insight into the effect of $\mathrm{N}$ and $\mathrm{P}$ availability on $\mathrm{A}_{\max }$ is still lacking.

Although plant grow upon photosynthesis, Poorter and van der Werf (1998) found no direct link between the capacity for $\mathrm{C}$ uptake per unit leaf area and growth rate or yield. Moreover, Von Liebig (1842) had already shown that crop yield was commonly limited by one or more mineral elements that were in short supply. Following this line of research, Körner (2015) made a distinction between $\mathrm{A}_{\text {max }}$, which he refers to as a source activity, and the formation of tissue, which he refers to as a sink activity. Körner (2015) suggested the latter is a critical controller of plant growth and he stated that net primary production (NPP) of plants is constrained not by the photosynthesis ability in leaves (source activity) but by the tissue growth itself (sink activity). This also implies that in his view it is not the $\mathrm{CO}_{2}$ concentration (directly related to source activity) which is the ultimate limiting resource. Supportive evidence for this view comes from Herold (1980), who concluded that artificial manipulation of sinks for carbohydrates can result in changes in photosynthetic rate, but photosynthesis must be in balance with the acquisition of the other resources and substances needed to form tissues, which are moisture, mineral nutrients, and chemical transmitters such as various hormones. Multiple studies have shown that C uptake by photosynthesis continued long into winter before the peak of tissue formation in spring and stopped long after tissue formation ceased under water shortage (Körner 2003; Muller et al. 2011). This indicates that the function of photosynthesis for plant growth is influenced by other factors and has an impact on multiple plant functional processes. In grasslands, mineral nutrient availabilities have been identified as the main resources competed for by plants, apart from water (Veresoglou and Fitter 1984). The constraints of mineral nutrient availability on plant growth have 
been studied extensively, but little research has considered the influence of mineral nutrients on plant growth via their influence on photosynthesis (Herold 1980).

In this paper we tested rigorously how various physiological and morphological plant vegetative growth traits are influenced by absolute and relative supplies of $\mathrm{N}$ and $\mathrm{P}$ in a factorial greenhouse fertilization experiment with Holcus lanatus, a common fast-growing grass species in European grasslands. The growth traits were divided into two groups: 1) maximum light-saturated net photosynthesis rate $\left(\mathrm{A}_{\text {max }}\right)$, SLA, and leaf area as three parameters indicating "source activity" of $\mathrm{C}$ absorption; and 2) shoot and root biomass as direct growth traits indicating the result of sink activity. In contrast with most experiments - in which absolute levels of one nutrient are varied while keeping the other one constant - we aimed to identify the effect of both absolute and relative $\mathrm{N}$ and $\mathrm{P}$ supply on plant vegetative growth (i.e. nutrient supply level versus N:P supply ratio). Moreover, by comparing different responses of $\mathrm{A}_{\max }$ (as well as SLA and leaf area) and biomass between specific nutrient treatments, we aimed to identify the main drivers of plant

growth sensu Körner (2003; 2015). Two hypotheses were tested: first, that $\mathrm{A}_{\max }$ is primarily determined by absolute and relative $\mathrm{N}$ supply rather than absolute and relative P supply; second, that plant growth is restricted more by low absolute and relative $\mathrm{N}$ supply than by low absolute and relative $\mathrm{P}$ supply. Furthermore, our factorial setup allowed us to test whether the degree of conversion of $\mathrm{C}$ uptake by photosynthesis to plant tissue depends on sufficient nutrient supply or on a balanced N:P supply ratio.

\subsection{Materials and methods}

\subsubsection{Seed collection}

Seeds of H. lanatus were collected on 16-17 August 2014 from the Middenduin nature reserve $\left(52^{\circ} 24^{\prime} \mathrm{N} 4^{\circ} 35^{\prime} \mathrm{E}\right)$ located in the western Netherlands and owned by the State Forestry Service.

\subsubsection{Seedling preparation}

After germination in June 2015, seedlings were transplanted into separate pots (length $\times$ width $\times$ height: $22 \mathrm{~cm} \times 22 \mathrm{~cm} \times 26 \mathrm{~cm}$, volume $11 \mathrm{~L}$ ) (four plants per pot, 48 pots in total). Pots contained a mixture of quartz sand (Carlo Bernasconi, Zürich, CH, 0.1-0.7 $\mathrm{mm}$ ) and dune sand (passed through a $1 \mathrm{~mm}$ sieve) in a ratio of 11:1. The volume of the mixed sand was $8 \mathrm{~L}$. To mimic natural conditions for plant growth, dune sand was collected from the Kennemerland National Park close to 
Middenduin; it has low concentrations of $\mathrm{N}$ and $\mathrm{P}$ but contains a natural microbial community. Total $\mathrm{N}$ and $\mathrm{P}$ concentrations in the water extraction of the pure and dune sand (which we treated as the plant-available $\mathrm{N}$ and $\mathrm{P}$ concentrations (Kachi and Hirose 1983)) were determined using HACH-LANGE colorimetry test cuvettes (LCK 138, LCK 349, Hach-Lange, Germany). We used the measured N and $\mathrm{P}$ concentrations in the sand mixture to fine-tune our nutrient recipe, following Güsewell (2005a).

\subsubsection{Plant cultivation}

The nutrient treatments, which lasted from July 2015 until June 2016, were given in a greenhouse with $400 \mathrm{~W} / \mathrm{m}^{2}$ light from $09.00 \mathrm{~h}$ to $16.00 \mathrm{~h}$. Temperature ranged between $14-30^{\circ} \mathrm{C}$ for most of the time and from October 2015 until March 2016 was manipulated to Dutch winter conditions $\left(-1{ }^{\circ} \mathrm{C}\right.$ to $\left.14^{\circ} \mathrm{C}\right)$. Each pot was placed on a tray, to prevent loss of water and nutrients. The pots were switched around regularly to randomize possible differences in light, temperature, and moisture conditions in the greenhouse. A full factorial combination with six nutrient treatments was applied, with three supply ratios ( $\mathrm{N}: \mathrm{P}=5$ (low relative $\mathrm{N}$ supply), $\mathrm{N}: \mathrm{P}=15$ (co-limitation), and $\mathrm{N}: \mathrm{P}=45$ (low relative $\mathrm{P}$ supply)), and two nutrient supply levels: low and high. The treatments were defined by the total amounts of $\mathrm{N}$ and $\mathrm{P}$ applied per plant, as well as per unit area $\left(\mathrm{cm}^{2}\right)$ and per unit volume $\left(\mathrm{cm}^{3}\right)$ throughout the cultivation process (in $\mathrm{mg}$ ), and were calculated as:

$\mathrm{N}=\mathrm{L} \times \sqrt{\mathrm{N}: \mathrm{P}}$, and $\mathrm{P}=\frac{1}{\sqrt{\mathrm{N}: \mathrm{P}}},($ where $\mathrm{L}=\sqrt{\mathrm{N} \times \mathrm{P}})$

in which L is the overall supply level (geometric mean of N and P supply). L was 13.4 $\mathrm{mg}$ for the low supply level and $40.3 \mathrm{mg}$ for the high supply level, following the method developed by Güsewell (2005a) in the first year of her two-year fertilization experiment (Table 3.1).

The experiment was carried out with seedlings grown in separate square pots; each pot contained four seedlings planted in its corners. Nutrient solutions were applied weekly. The nutrient supply was increased gradually during the growth process (Güsewell 2005a): in weeks 4-6 the weekly supply of nutrients was double the dose in weeks 1-3; in weeks 7-9 it was 1.5 times the dose in weeks 4-6. After week 9, when growth stopped, nutrient doses were kept at those of weeks 4-6, to ensure that plants remained alive and healthy until the day senescence started. Apart from receiving nutrient solutions, plants were watered frequently with demineralized water to prevent drying out; normally this was done once every 1-3 days, but in summer this was necessary daily. 
$\mathrm{N}$ was supplied as $\mathrm{KNO}_{3}$ and $\mathrm{Ca}\left(\mathrm{NO}_{3}\right)_{2}$, $\mathrm{P}$ was provided as $\mathrm{KH}_{2} \mathrm{PO}_{4}$. Both $\mathrm{KNO}_{3}$ and $\mathrm{KH}_{2} \mathrm{PO}_{4}$ supplied part of the potassium $(\mathrm{K})$, the rest of $\mathrm{K}$ was added by supplying $\mathrm{KCl}$ (Güsewell 2005a). All other essential macronutrients such as calcium (Ca) and micronutrients such as iron (Fe) and copper ( $\mathrm{Cu}$ ) were applied in non-limiting concentrations and were supplied in the same amounts to all treatments weekly. Details of the nutrient treatments of $\mathrm{N}$ and $\mathrm{P}$ are given in Table 3.1. Details of the nutrient treatments of the other elements are given in Appendix 3.1. Chlorine (Cl) was the only element that was not supplied in fixed amounts to all treatments. We have indicated the range of $\mathrm{Cl}$ addition in Appendix 3.1.

To prevent nutrient toxicity (Fujita et al. 2010), each pot was leached every six weeks with demineralized water.

\subsubsection{Measured traits}

\subsubsection{1 $A_{\max }$, SLA and leaf area}

After 5 months of growth the rate of maximum light-saturated net photosynthesis gas exchange $\left(\mathrm{A}_{\max }\right)$ was determined from 8 to 19 December 2016 between $09.00 \mathrm{~h}$ and $15.00 \mathrm{~h}$ using an open portable gas exchange chamber (LI 6400 portable, Li Cor Inc., Lincoln, NE, USA) equipped with a light source (6400-02B LED, Li Cor). We used an internal $\mathrm{CO}_{2}$ concentration of $400 \mathrm{ppm}$ and a flow of $350 \mu \mathrm{mol} \mathrm{s} \mathrm{s}^{-1}$. The measurements were carried out in full sunshine on a young, healthy, fully expanded leaf on the longest shoot per plant.

Two leaves were cut off at their nodes per pot. The cut fresh leaves were placed on a flat sheet of white paper and photographed immediately, next to a ruler. Leaf area $\left(\mathrm{cm}^{2}\right)$ was measured from the photos, using Image J software. Leaf dry mass (g) was measured after oven-drying for $48 \mathrm{~h}$ at $70{ }^{\circ} \mathrm{C}$. The data were used to calculate SLA $\left(\mathrm{m}^{2} \mathrm{~kg}^{-1}\right)$, i.e. the ratio of leaf area to leaf dry mass.

\subsubsection{Shoot and root biomass}

Biomass production of $H$. lanatus was measured for both shoot and root biomass. The shoots in each pot were severed at soil level, rinsed with demineralized water, dried for at least $48 \mathrm{~h}$ at $70{ }^{\circ} \mathrm{C}$, and weighed. The roots were carefully washed with demineralized water. Subsequently, roots were dried at $70^{\circ} \mathrm{C}$ for at least $48 \mathrm{~h}$ and weighed. Total biomass and shoot : root biomass ratio were calculated.

\subsubsection{Hypotheses testing and statistical analysis}

The first hypothesis ( $\mathrm{A}_{\max }$ is primarily determined by absolute and relative $\mathrm{N}$ supply rather than absolute and relative P supply) was tested by one-tailed t-test: at low and high nutrient supply level, $\mathrm{A}_{\max }$, SLA and leaf area were compared respectively between treatment N:P 5 and N:P 15, and N:P 45 and N:P 15. In addition, 
the aforementioned traits were also tested (t-test) by means of the following comparisons:

- treatments 5L (1) and 45H (6) (the numbers given here refer to Table 3.1): 45H had the same absolute P supply as 5L but its absolute $\mathrm{N}$ supply was 9 times higher;

- treatments 45L (3) and 5H (4) (the numbers given here refer to Table 3.1): both treatments had the same absolute $\mathrm{N}$ supply but $5 \mathrm{H}$ had a 9 -fold higher absolute P supply than 45L.

In this way, we tested both the effects of low relative $\mathrm{N}$ supply compared to low relative $\mathrm{P}$ supply and the effects of absolute $\mathrm{N}$ and $\mathrm{P}$ supply on $\mathrm{A}_{\text {max }}$, SLA and leaf area.

The second hypothesis (plant growth is restricted more by low absolute and relative $\mathrm{N}$ supply than by low absolute and relative $\mathrm{P}$ supply) was also tested by one-tailed t-test: at low and high nutrient supply level, shoot biomass, root biomass, total biomass, and shoot : root biomass ratio were compared respectively between treatment $\mathrm{N}: \mathrm{P} 5$ and $\mathrm{N}: \mathrm{P}$ 15, and N:P 45 and N:P 15. Again, the aforementioned traits were also tested (t-test) by means of the following comparisons: treatments 5L (1) and 45H (6) (with the same amount of absolute $\mathrm{P}$ supply but a 9 -fold higher absolute $\mathrm{N}$ supply of $45 \mathrm{H}$ than $5 \mathrm{~L}$ ), and between treatments 45L (3) and 5H (4) (with the same amount of absolute N supply but with $5 \mathrm{H}$ having a 9-fold higher absolute $\mathrm{P}$ supply than $45 \mathrm{~L}$ ). These comparisons tested for the effects of raised $\mathrm{N}$ and $\mathrm{P}$ supply separately under the same supply of the other nutrient.

In addition, we used the full factorial setup to test whether the degree of conversion of $\mathrm{C}$ uptake by photosynthesis to plant tissue depends on sufficient nutrient supply or on a co-limited N:P supply ratio. To do so, we compared the differences in $\mathrm{A}_{\text {max }}$ and biomass between the co-limited supply ratio (N:P 15) with specific nutrient treatments N:P 5 (low relative N supply) and N:P 45 (low relative P supply) at both low and high nutrient supply. The relationships between $\mathrm{A}_{\max }$, and shoot biomass, root biomass, and total biomass were analyzed by Pearson correlation.

The effects of N:P supply ratio and supply level and their interactions were analyzed with two-way ANOVA.

All statistical analyses were performed with SPSS 23.0 (SPSS, Chicago, U.S.A.); figures were also created in SPSS. 
Table 3.1 Total amounts of nitrogen (N) and phosphorus (P) supplied per plant, per unit area $\left(\mathrm{cm}^{2}\right)$, and per unit volume $\left(\mathrm{cm}^{3}\right)$ during cultivation.

The six nutrient treatments combined with two nutrient supply levels (low and high) and three N:P supply ratios $(5,15,45)$. N:P supply ratios differ by a factor of 3 between consecutive treatments. N:P supply ratios of 5, 15, and 45 were regarded as a N-limited, co-limited, and P-limited respectively.

\begin{tabular}{lllllllll}
\hline $\begin{array}{l}\text { Nutrient No. } \\
\text { supply } \\
\text { level }\end{array}$ & $\begin{array}{l}\text { N:P } \\
\text { supply supplied } \\
\text { ratio }\end{array}$ & $\begin{array}{l}\mathbf{N} \\
(\mathbf{m g} / \text { plant })\end{array}$ & $\begin{array}{l}\text { supplied } \\
(\mathbf{m g} / \text { plant })\end{array}$ & $\begin{array}{l}\mathbf{N} \\
\text { supplied } \\
\left(\mathbf{m g} / \mathbf{c m}^{2}\right)\end{array}$ & $\begin{array}{l}\mathbf{P} \\
\text { supplied } \\
\left(\mathbf{m g} / \mathbf{c m}^{2}\right)\end{array}$ & $\begin{array}{l}\mathbf{N} \\
\text { supplied } \\
\left(\mathbf{m g} / \mathbf{c m}^{3}\right)\end{array}$ & $\begin{array}{l}\mathbf{P} \\
\text { supplied } \\
\left(\mathbf{m g} / \mathbf{c m}^{3}\right)\end{array}$ \\
\hline \multirow{4}{*}{ Low } & 1 & 5 & 30.0 & $\mathbf{6 . 0}$ & 0.26 & 0.05 & 0.02 & 0.003 \\
& 2 & 15 & 52.0 & 3.5 & 0.46 & 0.03 & 0.03 & 0.002 \\
& 3 & 45 & $\mathbf{9 0 . 0}$ & 2.0 & 0.79 & 0.02 & 0.05 & 0.001 \\
& 4 & 5 & $\mathbf{9 0 . 0}$ & 18.0 & 0.79 & 0.16 & 0.05 & 0.009 \\
High & 5 & 15 & 156.0 & 10.5 & 1.38 & 0.09 & 0.08 & 0.005 \\
& 6 & 45 & 270.0 & $\mathbf{6 . 0}$ & 2.38 & 0.05 & 0.14 & 0.003 \\
\hline
\end{tabular}

* $\mathrm{N}$ and $\mathrm{P}$ supplied per unit area $\left(\mathrm{cm}^{2}\right)$ and per unit volume $\left(\mathrm{cm}^{3}\right)$ sand were calculated from $\mathrm{N}$ and $\mathrm{P}$ supplied per plant, and were not as reliable as $\mathrm{N}$ and $\mathrm{P}$ supplied per plant, given the error in measuring sand volume and density.

\subsection{Results}

\subsubsection{Effect of $\mathrm{N}$ supply on $\mathrm{A}_{\max }$}

$\mathrm{N}: \mathrm{P}$ supply ratio and supply level separately as well as their interaction had significant effects on $A_{\max }$ (Table 3.2). However, neither SLA nor leaf area responded to nutrient treatments (Figure 3.1b, c) apart from a significant increase of leaf area at increased nutrient supply (Table 3.2).

In general, maximum light-saturated net photosynthesis rate $\left(\mathrm{A}_{\max }\right)$ responded to changes in N supply rather than in P supply (Figure 3.1a; Table 3.3). At high nutrient supply and an N:P supply ratio of 5 (low relative $\mathrm{N}$ supply), $\mathrm{A}_{\max }$ was significantly lower than at N:P 15 (co-limited). However, $\mathrm{A}_{\max }$ at N:P 45 (low relative P supply) at high nutrient supply was not significantly different from $\mathrm{A}_{\max }$ at the co-limited supply (N:P 15). Moreover, at low supply no significant difference was found for $\mathrm{A}_{\text {max }}$ among $\mathrm{N}: \mathrm{P}$ supply ratios, although the negative influence of supply ratio 5 (low relative $\mathrm{N}$ supply) compared to supply ratio 15 (co-limited) was near significant $(P=0.060)$ (Figure 3.1a). 
Because $\mathrm{N}$ and $\mathrm{P}$ have different roles in source activity, we also looked at the influence of the absolute supply of $\mathrm{N}$ and of $\mathrm{P}$. The results indicated that absolute $\mathrm{N}$ supply positively influenced $\mathrm{A}_{\text {max }}(P=0.004)$, but no effect was found for absolute P supply $(P=0.920)$ (Table 3.3). $\mathrm{P}$ had a significantly positive effect on leaf area $(P=$ $0.024)$, but no other effect of absolute $\mathrm{N}$ and $\mathrm{P}$ supply was found on leaf traits, apart from the positive effect of $\mathrm{P}$ on leaf area (Table 3.3). In detail, by comparing treatments $5 \mathrm{~L}-45 \mathrm{H}$ and treatments $45 \mathrm{~L}-5 \mathrm{H}$, we found that a 9 -fold increase in absolute $\mathrm{N}$ supply (from $30 \mathrm{mg}$ to $270 \mathrm{mg}$ ) significantly increased $\mathrm{A}_{\max }$ with $52.9 \%$ (increase from 5.76 to $8.80 \mu \mathrm{mol} \mathrm{CO} \mathrm{Cm}^{-2} \mathrm{~s}^{-1}$ ), whereas there was no significant change in $A_{\text {max }}$ in response to a 9-fold increase of absolute P supply (Table 3.3). In addition, absolute $\mathrm{P}$ supply influenced leaf area positively: this was indicated by the differences in leaf area between treatments $45 \mathrm{~L}-5 \mathrm{H}(P=0.024$; Table 3.3) (i.e. enhanced $\mathrm{P}$ supply increased leaf area). Absolute $\mathrm{N}$ supply had no effect on leaf area $(P=0.746)$. Neither absolute $\mathrm{N}$ supply nor absolute $\mathrm{P}$ supply had a significant effect on SLA ( $P=0.904$ and $P=0.058$, respectively; Table 3.3).

\subsubsection{Effect of $\mathrm{N}: \mathrm{P}$ supply ratio on plant growth}

$\mathrm{N}: \mathrm{P}$ supply ratio and supply level separately as well as their interaction had a significant effect on shoot biomass, root biomass, total biomass, and shoot : root biomass ratio (Table 3.2).

Table 3.2 ANOVA results ( $P$ values) for the effects of the nitrogen $(\mathrm{N})$ and phosphorus (P) supply ratio and overall supply level on various plant growth traits of H. lanatus.

\begin{tabular}{|c|c|c|c|c|c|c|c|}
\hline Effect & $\begin{array}{l}\mathrm{A}_{\max } \\
(\mu \mathrm{mol} \\
\left.\mathrm{CO}_{2} / \mathrm{m}^{2} / \mathrm{s}\right)\end{array}$ & $\begin{array}{l}\text { SLA } \\
\left(\mathrm{m}^{2} / \mathrm{kg}\right)\end{array}$ & $\begin{array}{l}\text { Leaf } \\
\text { area } \\
\left(\mathrm{cm}^{2}\right)\end{array}$ & $\begin{array}{l}\text { Shoot } \\
\text { biomass } \\
\text { per plant } \\
\text { (g) }\end{array}$ & $\begin{array}{l}\text { Root } \\
\text { biomass } \\
\text { per plant } \\
\text { (g) }\end{array}$ & $\begin{array}{l}\text { Total } \\
\text { biomass } \\
\text { per plant } \\
\text { (g) }\end{array}$ & $\begin{array}{l}\text { Shoot } \\
\text { : root } \\
\text { biomass } \\
\text { ratio }\end{array}$ \\
\hline $\mathrm{N}: \mathrm{P}$ supply ratio & 0.008 & 0.533 & 0.514 & 0.000 & 0.000 & 0.000 & 0.000 \\
\hline $\begin{array}{l}\text { Overall } \\
\text { supply level }\end{array}$ & 0.000 & 0.255 & 0.011 & 0.000 & 0.000 & 0.000 & 0.000 \\
\hline $\begin{array}{l}\mathrm{N}: \text { P supply ratio } \\
\times \text { Overall } \\
\text { supply level }\end{array}$ & 0.021 & 0.320 & 0.467 & 0.000 & 0.000 & 0.000 & 0.020 \\
\hline
\end{tabular}

Plant biomass was restricted by low relative $\mathrm{P}$ supply rather than $\mathrm{N}$ for both the low and the high nutrient supply (Figure 3.2). At low nutrient supply, shoot and root biomass were both significantly higher at N:P 5 (low relative $\mathrm{N}$ supply) and lower at $\mathrm{N}: \mathrm{P} 45$ (low relative P supply) than they were at the co-limited supply ratio of N:P 15 

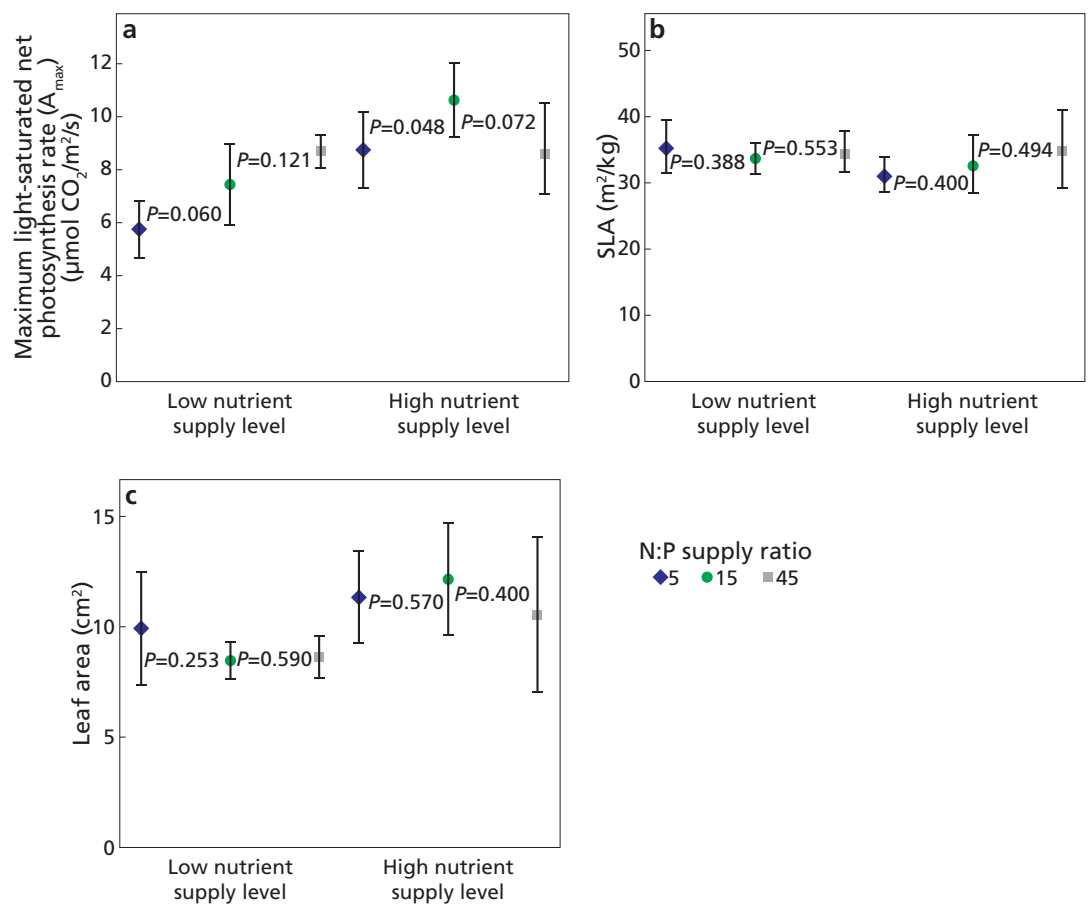

$\mathrm{N}: \mathrm{P}$ supply ratio

Figure 3.1 Maximum light-saturated net photosynthesis rate $\left(\mathrm{A}_{\max }\right)$, SLA, and Leaf area at different nutrient treatments. $P$-values were tested by t-tests between 45L-15L, 15L-5L, $45 \mathrm{H}-15 \mathrm{H}$, and $15 \mathrm{H}-5 \mathrm{H}$ for each trait.

(Figure 3.2a, b). At the high nutrient supply, root biomass showed the same pattern as at low nutrient supply, with the highest biomass at N:P 5 and the lowest at N:P 45 (Figure 3.2b). However, shoot biomass at the high supply was highest at N:P 15, while at N:P 45 the shoot biomass was much lower than at N:P 5 (Figure 3.2a). At both low and high nutrient supply, total biomass was lowest at low relative P supply (N:P 45) (Figure 3.2c). The ratio of shoot : root biomass increased with increasing $\mathrm{N}: \mathrm{P}$ supply ratio (Figure $3.2 \mathrm{~d}$ ).

Because $\mathrm{N}$ and $\mathrm{P}$ have different roles in plant growth, we also examined the influence of the absolute supply of each. Both absolute $\mathrm{N}$ and absolute P supply influenced plant biomass (Table 3.3). However, P supply had a much stronger influence than $\mathrm{N}$ supply. As was the case for $\mathrm{A}_{\max }$, SLA and leaf area, this was clearly apparent from the comparison between treatments $45 \mathrm{~L}-5 \mathrm{H}$ and $5 \mathrm{~L}-45 \mathrm{H}$. A 9-fold increase in absolute P supply (from $2 \mathrm{mg}$ to $18 \mathrm{mg}$ ) led to a $460 \%$ increase 
in shoot biomass (26.51 g compared to $4.73 \mathrm{~g}$ on average), whereas a 9-fold increase in absolute $\mathrm{N}$ supply (from $30 \mathrm{mg}$ to $270 \mathrm{mg}$ ) led to a shoot biomass increase of only 102\% (18.15 g compared to $9.00 \mathrm{~g}$ on average) (Table 3.3). For root biomass, comparisons between treatments $45 \mathrm{~L}-5 \mathrm{H}$ and $5 \mathrm{~L}-45 \mathrm{H}$ showed that a 9 -fold increase in P supply led to a 1062\% higher root biomass (21.91 g compared to $1.89 \mathrm{~g}$ on average) whereas a 9-fold increase of absolute $\mathrm{N}$ supply reduced root biomass from $9.10 \mathrm{~g}$ to $5.55 \mathrm{~g}$ on average (-39\%) (Table 3.3). In terms of total plant biomass, the 9 -fold increase in absolute P supply led to a total biomass of $50.20 \mathrm{~g}$ compared to $6.61 \mathrm{~g}$ on average $(+659 \%)$, whereas a 9 -fold increase in absolute $\mathrm{N}$ supply led to a total biomass of $23.78 \mathrm{~g}$ compared to $18.10 \mathrm{~g}$ on average ( $+31 \%$ ) (Table 3.3). Moreover, shoot : root biomass ratio was lower at high absolute $\mathrm{P}$ supply than at lower $\mathrm{P}$ supply (1.31 versus 2.51 on average $(-48 \%)$ ), whereas under higher absolute $\mathrm{N}$ supply, the ratio was 3.36 compared to 1.02 on average $(+229 \%)$ (Table 3.3$)$.

Table 3.3 T-tests between treatments 45L-5H (the same N supply but different P supplies), and treatments 5L-45H (the same P supply but different N supplies).

\begin{tabular}{lllllllll}
\hline Growth traits & \multicolumn{3}{l}{$\begin{array}{l}\text { 45L-5H } \\
\text { (9-fold increase of P supply) }\end{array}$} & \multicolumn{3}{l}{$\begin{array}{l}\text { 5L-45H } \\
\text { (9-fold increase of N supply) }\end{array}$} \\
\cline { 2 - 8 } & df & $+/-$ & $\%$ increase $\boldsymbol{P}$ & df & $+/$ & \% increase $\boldsymbol{P}$ \\
\hline $\mathrm{A}_{\max }\left(\mathrm{\mu mol} \mathrm{CO}_{2} \mathrm{~m}^{-2} \mathrm{~s}^{-1}\right)$ & 23 & $/$ & $/$ & 0.920 & 19 & + & $53 \%$ & $\mathbf{0 . 0 0 4}$ \\
\hline $\mathrm{SLA}\left(\mathrm{m}^{2} \mathrm{~kg}^{-1}\right)$ & 30 & - & $12 \%$ & 0.058 & 30 & $/$ & $/$ & 0.904 \\
Leaf area $\left(\mathrm{cm}^{2}\right)$ & 30 & + & $29 \%$ & $\mathbf{0 . 0 2 4}$ & 30 & $/$ & $/$ & 0.746 \\
\hline Shoot biomass per plant $(\mathrm{g})$ & 14 & + & $460 \%$ & $\mathbf{0 . 0 0 0}$ & 12 & + & $102 \%$ & $\mathbf{0 . 0 0 0}$ \\
\hline Root biomass per plant $(\mathrm{g})$ & 9 & + & $1062 \%$ & $\mathbf{0 . 0 0 0}$ & 8 & - & $39 \%$ & $\mathbf{0 . 0 2 7}$ \\
\hline Total biomass per plant $(\mathrm{g})$ & 9 & + & $659 \%$ & $\mathbf{0 . 0 0 0}$ & 8 & + & $31 \%$ & $\mathbf{0 . 0 0 7}$ \\
\hline Shoot : root biomass ratio & 9 & - & $48 \%$ & $\mathbf{0 . 0 0 0}$ & 8 & + & $230 \%$ & $\mathbf{0 . 0 0 0}$ \\
\hline
\end{tabular}

+ indicates positive change of the growth traits, - indicates negative change of the growth traits, / indicates no significant change.

\subsubsection{Relationship between $\mathrm{A}_{\text {max }}$ and biomass}

Pearson correlation analyses revealed no significant relationship between $\mathrm{A}_{\max }$, and shoot biomass, root biomass, or total biomass (Figure 3.3). On the other hand, $\mathrm{A}_{\max }$ and biomass (whether shoot and root biomass separately, or total biomass) were higher at high nutrient supply than at low nutrient supply (Figure 3.3). 


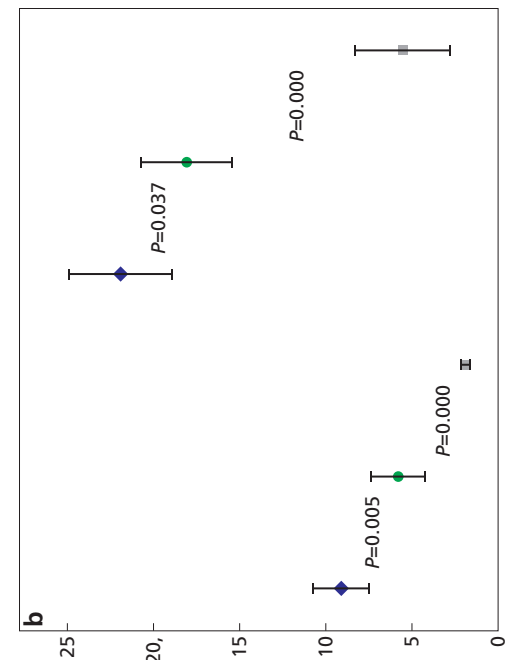

(6) fuejd təd ssemo!̣ zooy

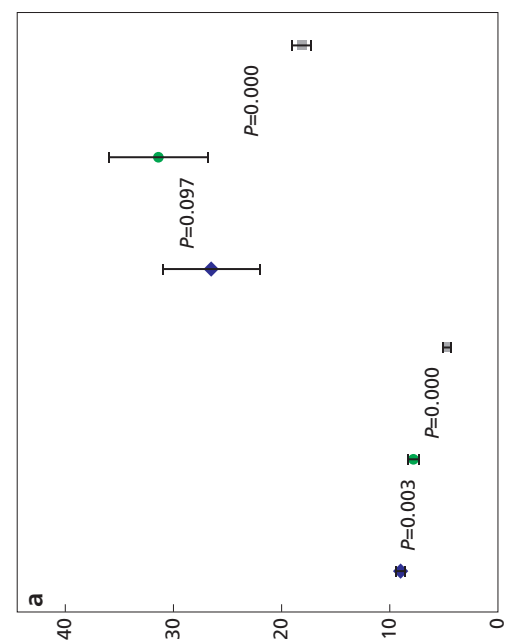

(6) 7uejd ıəd ssemo!̣ toous

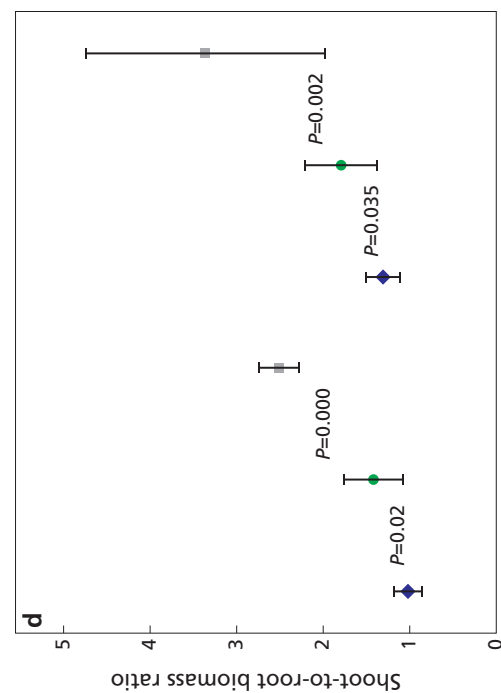

o!ped ssemo!̣ 700ג-07-7004s

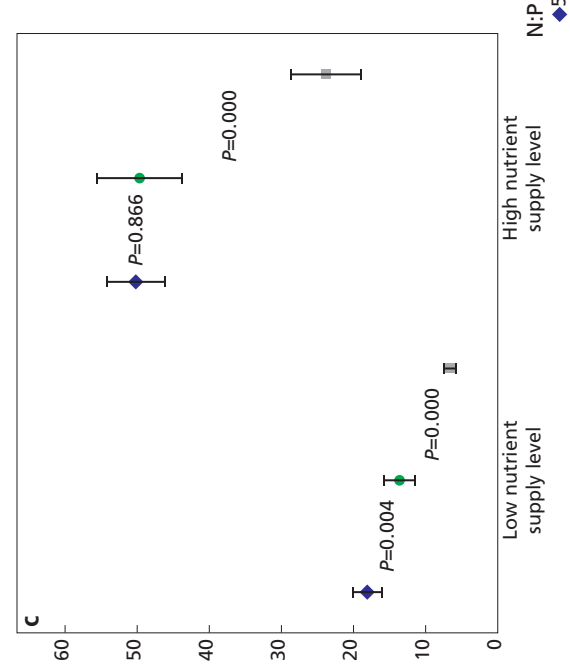

(6) ᄀue $\mid$ dəd ssemo!̣ |eło 

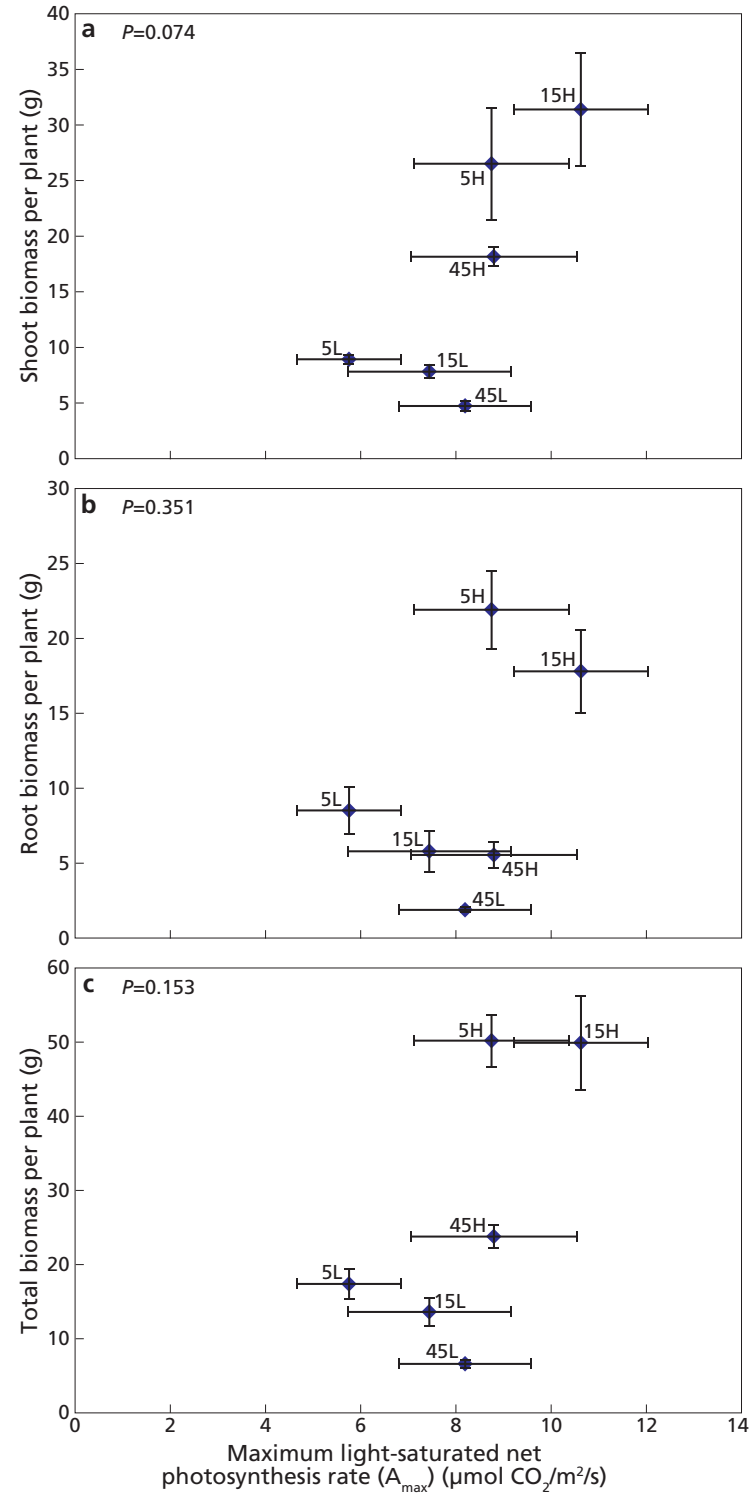

Figure 3.3 Pearson correlation analyses between maximum light-saturated net photosynthesis rate $\left(\mathrm{A}_{\max }\right)$ and three traits: Shoot biomass per plant (a), Root biomass per plant (b), and Total biomass per plant (c) of H. lanatus grown with different nutrient treatments of $\mathrm{N}$ and $\mathrm{P}$ 


\subsection{Discussion}

The results indicate that with the exception of SLA, nutrient treatments significantly influenced the set of traits associated with the source function (net photosynthesis and leaf area) and the sink function (biomass formation) of H. lanatus.

\subsubsection{The impact of $\mathrm{N}$ supply on source activity}

Our data support our first hypothesis that $\mathrm{A}_{\max }$ is primarily determined by absolute and relative $\mathrm{N}$ supply rather than absolute and relative P supply. In detail, low relative $\mathrm{N}$ supply $(\mathrm{N}: \mathrm{P}=5)$ significantly reduced $\mathrm{A}_{\text {max }}$ compared to co-limited nutrient supply $(\mathrm{N}: \mathrm{P}=15)$, especially at high nutrient supply, whereas low relative $\mathrm{P}$ supply $(\mathrm{N}: \mathrm{P}=45)$ had no impact on $\mathrm{A}_{\max }$, independent of the total nutrient supply level. Moreover, the comparisons between treatments with increased $\mathrm{N}$ supply but constant P supply (treatments 5L vs 45H), as well as between increased P supply but constant $\mathrm{N}$ supply (treatments $45 \mathrm{~L}$ vs $5 \mathrm{H}$ ) suggest that this constraint of low relative $\mathrm{N}$ supply on $\mathrm{A}_{\max }$ was mainly attributable to low absolute $\mathrm{N}$ supply rather than to the increase in absolute $\mathrm{P}$ supply. This finding is well supported by previous research that has shown a positive relationship between leaf $\mathrm{N}$ status and photosynthetic biochemical capacity (e.g. Walker et al. 2014). Soil N availability to plants can also strongly influence whether the $\mathrm{A}_{\max }$ of plants responds positively to elevated $\mathrm{CO}_{2}$ (Reich and Hobbie 2013). Although the positive relationship between $\mathrm{A}_{\text {max }}$ and $\mathrm{N}$ supply is well established, the effect of $\mathrm{P}$ supply on $\mathrm{A}_{\max }$ is less clear. In our experiment, neither relative nor absolute $\mathrm{P}$ supply affected $\mathrm{A}_{\text {max }}$, but other studies have reported a clear positive relationship between leaf P content and photosynthetic capacity across species (Güsewell 2005a; Walker et al. 2014). Fay et al. (1996) found a significant linear relation between leaf $\mathrm{P}$ content and $\mathrm{A}_{\max }$ when the leaf P content was between $50-200 \mathrm{mg} \mathrm{kg}^{-1}$ but no relationship when leaf P content increased to 200-800 $\mathrm{mg} \mathrm{kg}^{-1}$. Ghannoum and Conroy (2007) found that low relative $\mathrm{P}$ supply inhibited the $\mathrm{A}_{\max }$ of both $\mathrm{C}_{3}$ and $\mathrm{C}_{4}$ grasses but found no influence of $\mathrm{P}$ on the foliar content of non-structural carbohydrates supplying most energy for plant growth (i.e. starch, simple sugars, and soluble fiber) in these grass types. Apart from grassland species, the effect of $\mathrm{N}$ but not $\mathrm{P}$ on $\mathrm{A}_{\max }$ has also been found in trees, with a clear influence of leaf $\mathrm{N}$ content on $\mathrm{A}_{\max }$ but no correlation between $\mathrm{P}$ and $\mathrm{CO}_{2}$ uptake rate (Tuohy et al. 1991). However, our finding that $\mathrm{P}$ supply did not affect $\mathrm{A}_{\max }$ does not mean that $\mathrm{P}$ is not important in the photosynthesis process. It is generally known that photosynthetic reactions within the chloroplast consume orthophosphate $(\mathrm{Pi})$ and are therefore likely to be inhibited by low Pi and promoted by increased Pi (Ghannoum et al. 2008). The obvious lack of any influence of low relative and absolute P supply on $\mathrm{A}_{\text {max }}$ could 
indicate P is actively reallocated to chloroplast when P supply is low (Herold 1980; Güsewell 2004).

In addition to $\mathrm{A}_{\max }$, SLA and leaf area were analyzed to provide additional information indicating source activity, as these two traits are known to be closely related to $A_{\max }$ (Reich et al. 1992; Reich and Walters 1994; Evans and Poorter 2001; Cornelissen et al. 2003). However, our results revealed no effect of nutrient treatments on SLA and leaf area, apart from a significant increase in leaf area with increased nutrient supply. This lack of effect of nutrient treatments on SLA and leaf area suggests that the investment in leaf morphology might not be a good indicator of the influence of nutrient treatments on source activity in fertilization experiments.

\subsubsection{The impact of absolute and relative $\mathrm{N}$ and $\mathrm{P}$ supply on plant growth}

Our results allow us to refute the second hypothesis that plant growth is restricted more by low absolute and relative $\mathrm{N}$ supply than by low absolute and relative $\mathrm{P}$ supply. In detail, low relative $\mathrm{P}$ supply $(\mathrm{N}: \mathrm{P}=45)$ resulted in the lowest shoot and root biomass per plant, whereas plants grown at low relative $\mathrm{N}$ supply $(\mathrm{N}: \mathrm{P}=5)$ produced the highest biomass, although differences of shoot biomass, as well as total biomass between low relative $\mathrm{N}$ supply $(\mathrm{N}: \mathrm{P}=5)$ and co-limited supply $(\mathrm{N}: \mathrm{P}=$ 15) at high nutrient supply were not significant. The preference of H. lanatus for $\mathrm{N}$ limitation is consistent with the result of the field survey by Fujita et al. (2014), showing that the averaged N:P ratio of the above-ground vascular plants at 191 Eurasian sites with the occurrence of H. lanatus was 9.2 (N limitation). Besides, the remarkable constraint of low relative $\mathrm{P}$ supply on the growth of the grassland species in our experiment agrees with the result of the two-year fertilization experiment on wetland species performed by Güsewell (2005), who showed that $\mathrm{P}$ limitation reduced shoot growth more than $\mathrm{N}$ limitation. Moreover, absolute $\mathrm{P}$ supply proved to have a dramatically bigger impact on plant growth (for both shoots and roots) than absolute N supply. Given that roots absorb most mineral elements for plant growth, and that plants adjust to an imbalance of exogenous resources by allocating new biomass to the organs involved in acquiring the scarcest resources (Marschner 1995), we also analyzed the impact of nutrient treatment on shoot : root biomass ratio in addition to the impact on plant growth. In our experiment, the effects of N:P supply ratios on shoot : root biomass ratio indicated that this ratio was significantly increased by low relative P supply but significantly decreased by low relative $\mathrm{N}$ supply. This increased biomass allocation to roots at low relative $\mathrm{N}$ supply is consistent with findings from previous studies (Andrews et al. 1999; De Groot et al. 2003). However, the effect of low relative P supply on biomass allocation to roots varies between different studies. De Groot et 
al. (2003) did not find any relationship between P supply and root biomass, whereas Hermans et al. (2006) showed that P and N limitation both led to increased root biomass allocation. Several studies showed that internal reallocation of $\mathrm{P}$ probably supports shoot growth at low relative P supply (Usuda 1995; Köhler et al. 2001; Shen et al. 2003), which may be the reason for the lowest root biomass was observed in treatment N:P 45 in our experiment.

\subsubsection{Source-sink relationships}

Although photosynthesis is the critical process providing carbohydrates (source activity) in plants, in our experiment it was not related to plant growth, as shown by the lack of correlation between $\mathrm{A}_{\text {max }}$, and shoot biomass, root biomass, or total biomass. Furthermore, biomass responses to nutrient treatments were different from the responses of $\mathrm{A}_{\max }$ and were sometimes even the opposite: e.g. the treatment of low relative $\mathrm{N}(\mathrm{N}: \mathrm{P}=5)$ led to lower $\mathrm{A}_{\max }$ but higher biomass compared to treatment $\mathrm{N}: \mathrm{P} 15$, while the treatment of low relative $\mathrm{P}(\mathrm{N}: \mathrm{P}=45)$ led to higher $\mathrm{A}_{\text {max }}$ but lower biomass compared to treatment N:P 15 (Figure 3.1a, Figure 3.2a, b, c). These results underline that in our experiment, "sink activity" (biomass formation) was regulated by $\mathrm{N}$ and $\mathrm{P}$ supply rather than by net photosynthesis (source activity). This result is consistent with the statement of Herold (1980) in his review, that a plant's requirements for photosynthesis (source activity) are ultimately linked with the sink activity, by transmitting the appropriate message of this requirement through the envelope of the chloroplast. Therefore, our results, combined with the findings of previous studies (Kuppers et al. 1988; Reich et al. 2018), support the view of Körner (2015) that tissue formation and cell growth are regulated largely independent of photosynthesis.

The observed responses to changes in $\mathrm{P}$ and $\mathrm{N}$ in our experiment indicate that distinct mechanisms influence plant growth, depending on whether or not $\mathrm{P}$ is limiting the sink activity. In detail, under conditions with ample P supply (6-18 $\mathrm{mg}$ ), increases in $\mathrm{N}$ supply enhanced the source activity (Appendix 3.2a) which, in turn should increase the availability of carbohydrates available for growth, as indicated by the increased shoot and root biomass (Appendix 3.2g, i). However, under conditions with low P supply (2-6 mg), increases in N supply can enhance source activity (Appendix 3.2a) without stimulating sink activity (Appendix 3.2g, i). Hence, this result indicates that, under these conditions, $\mathrm{P}$ supply is limiting sink activity independent of source activity. Our data furthermore indicate that influence of P supply on sink activity cannot readily be disentangled from $\mathrm{N}$ supply as shoot and root biomass formation were also influenced by increased $\mathrm{N}$ supply when P supply was constant (Appendix 3.2h, j). 
This critical effect of mineral elements, especially of P supply, on plant growth may extend to community level in natural plant communities. Our results indicate that changes in P supply, which had a large effect on $H$. lanatus shoot and root growth, may significantly influence interspecies competition via increased productivity of fast-growing species in natural plant communities (Wheeler and Shaw 1991; Aerts and Chapin III 2000), and thereby influence species composition and diversity (Wassen et al. 2005; Roeling et al. 2018). Although the influence of P in natural plant communities has been observed in semi-natural grasslands (Wassen et al. 2005; Ceulemans et al. 2011; Roeling et al. 2018), coastal ecosystems (Adam et al. 1989), and forests (Beadle 1962; Huston 1980), we need more information about the specific responses in photosynthesis and growth of other species to better understand and predict community responses to $\mathrm{N}$ and $\mathrm{P}$ enrichment.

\subsection{Conclusions}

In conclusion, this experiment has confirmed the critical effect of P supply on plant growth, and of $\mathrm{N}$ supply on $\mathrm{A}_{\max }$ of Holcus lanatus, while growth and $\mathrm{A}_{\max }$ were found to be independent. These distinct plant responses to differences in $\mathrm{P}$ and $\mathrm{N}$ supply may explain the lack of correlation between plant growth and $\mathrm{A}_{\max }$ : i.e. $\mathrm{N}$ and $\mathrm{P}$ supply rather than carbon assimilation rate were controlling plant growth.

\section{Acknowledgments}

We acknowledge the China Scholarship Council (CSC) for a doctoral scholarship to Shuqiong Wang (CSC NO. 201406140142). We thank Roel Vonk for his helpful suggestions with cultivation. Ton Markus is acknowledged for improving the figures. The English of a near-final draft of the manuscript was checked professionally by Joy Burrough. 


\section{Supplementary materials}

Appendix 3.1 Elements other than nitrogen (N) and phosphorus (P) supplied per plant, per unit area $\left(\mathrm{cm}^{2}\right)$, and per unit volume $\left(\mathrm{cm}^{3}\right)$ during cultivation.

\begin{tabular}{|c|c|c|c|c|}
\hline $\begin{array}{l}\text { Other } \\
\text { elements } \\
\text { for all } \\
\text { treatments }\end{array}$ & Resources & $\begin{array}{l}\text { Amount } \\
\text { of element } \\
\text { supplied } \\
\text { (mg/plant) }\end{array}$ & $\begin{array}{l}\text { Amount } \\
\text { of element } \\
\text { supplied } \\
\left(\mu \mathrm{g} / \mathrm{cm}^{2}\right)\end{array}$ & $\begin{array}{l}\text { Amount } \\
\text { of element } \\
\text { supplied } \\
\left(\mu \mathrm{g} / \mathrm{cm}^{3}\right)\end{array}$ \\
\hline K & $\mathrm{KNO}_{3} \& \mathrm{KCl}$ & 400 & 3532 & 200 \\
\hline $\mathrm{Ca}$ & $\mathrm{CaCl}_{2} \cdot 2 \mathrm{H}_{2} \mathrm{O}$ & 51.6 & 455.6 & 25.8 \\
\hline $\mathrm{Mg}$ & $\mathrm{MgSO} 4.7 \mathrm{H} 2 \mathrm{O}$ & 11.7 & 103.3 & 5.9 \\
\hline S & $\mathrm{MgSO} 4.7 \mathrm{H} 2 \mathrm{O}$ & 17.8 & 157.2 & 8.9 \\
\hline $\mathrm{Fe}$ & Fe-EDTA & 4.1 & 36.2 & 2.1 \\
\hline $\mathrm{Cu}$ & $\mathrm{CuSO}_{4} \cdot 5 \mathrm{H}_{2} \mathrm{O}$ & 0.02 & 0.18 & 0.01 \\
\hline B & $\mathrm{H}_{3} \mathrm{BO}_{3}$ & 0.39 & 3.4 & 0.20 \\
\hline $\mathrm{Mn}$ & $\mathrm{MnSO} 4 . \mathrm{H}_{2} \mathrm{O}$ & 0.21 & 1.9 & 0.11 \\
\hline Mo & $\mathrm{Na} 2 \mathrm{MoO} 4 . \mathrm{H} 2 \mathrm{O}$ & 0.04 & 0.35 & 0.02 \\
\hline $\mathrm{Zn}$ & $\mathrm{ZnSO} 4.7 \mathrm{H}_{2} \mathrm{O}$ & 0.10 & 0.88 & 0.05 \\
\hline
\end{tabular}

$\mathrm{Cl}$ was the only element not supplied in the same amounts to all treatments; the amount supplied varied between $113.1 \mathrm{mg} /$ plant and $346.5 \mathrm{mg} / \mathrm{plant}$.

*Amount of element supplied per unit area $\left(\mathrm{cm}^{2}\right)$ and per unit volume $\left(\mathrm{cm}^{3}\right)$ sand were calculated from amount of element supplied per plant, and were not as reliable as amount of element supplied per plant, given the error in measuring sand volume and density. 

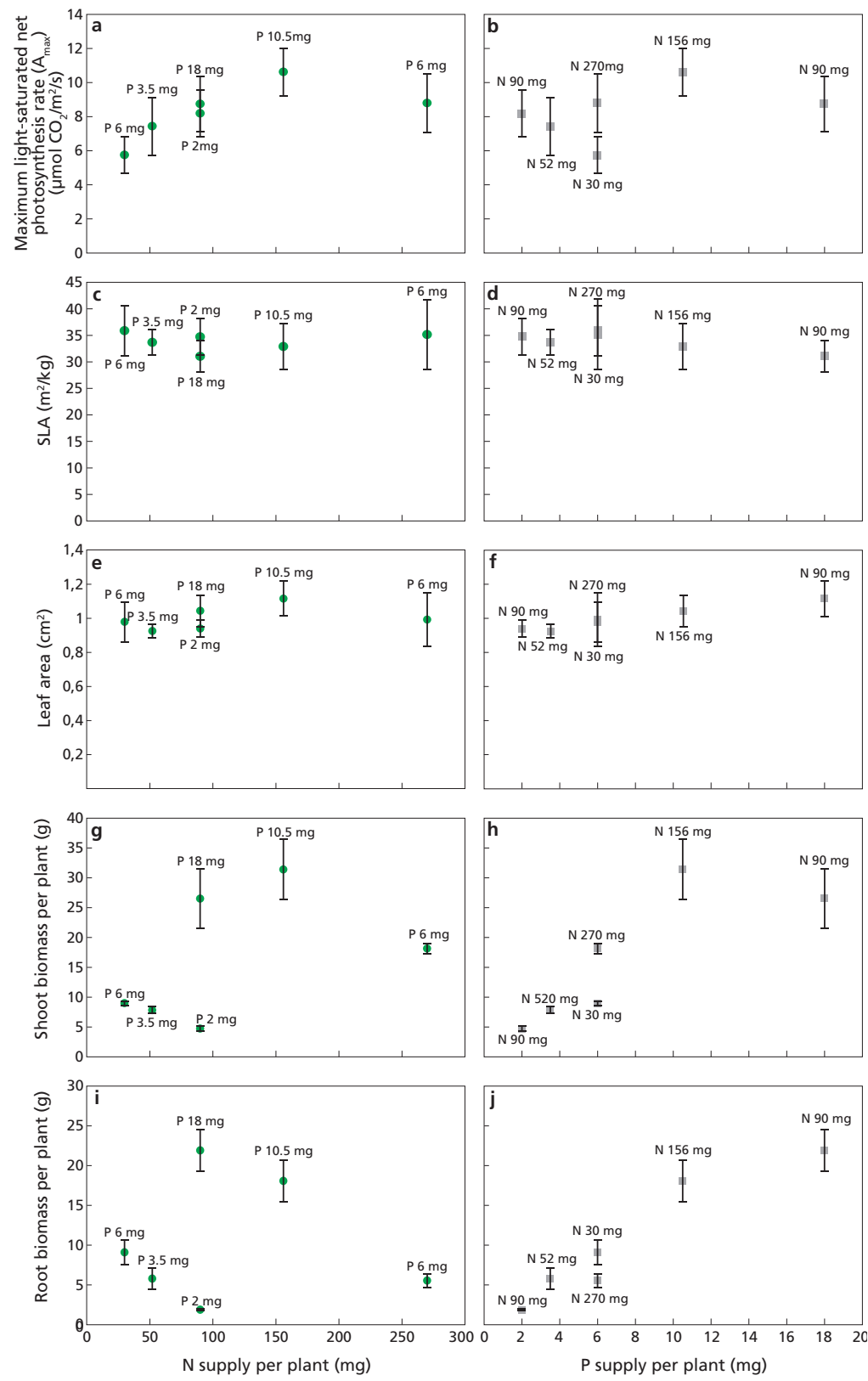

Appendix 3.2 Maximum light-saturated net photosynthesis rate $\left(\mathrm{A}_{\max }\right)(\mathrm{a}, \mathrm{b})$, Specific leaf area (SLA) (c, d), Leaf area $\left(\mathrm{cm}^{2}\right)$ (e, f), Shoot biomass per plant (g) (g, h), and Root biomass per plant (g) (i, j), of H. lanatus, in relation to absolute $\mathrm{N}$ supply and absolute $\mathrm{P}$ supply. 


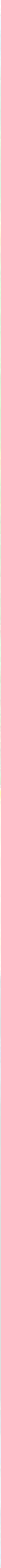




\section{Chapter 4}

Sexual reproduction traits of Holcus lanatus L. and Parnassia palustris L. in response to absolute and relative supply of nitrogen and phosphorus

Shuqiong Wang, Jerry van Dijk, Martin J. Wassen

(Published in Environmental and Experimental Botany 168, December (2019): 103813) 


\begin{abstract}
Plant investment in sexual reproduction is affected by absolute and relative nitrogen $(\mathrm{N})$ and phosphorus (P) supply. Reduced investment in reproductive traits has been suggested as an important adaptation to strong P limitation. We experimentally tested how absolute and relative nutrient supply affected sexual reproduction traits of two grassland species.

Seedlings of a common grass (Holcus lanatus) and an endangered forb (Parnassia palustris) were grown from seed from a dune area with low relative P-availability. Plants were grown in a full factorial experiment with three N:P supply ratios $(5,15$, 45 ) and two absolute supply levels of $\mathrm{N}$ and $\mathrm{P}$. After one year, a range of traits was measured as a proxy for investment in sexual reproduction. We found that $\mathrm{N}: \mathrm{P}$ supply ratio did not affect sexual reproduction at low nutrient supply; at high nutrient supply, investment in sexual reproduction was significantly less at higher $\mathrm{N}$ :P supply ratios. For Holcus lanatus, N:P supply ratio 45 restricted the increase in sexual reproduction upon increasing nutrient supply. Parnassia palustris survival and flowering were low, especially at N:P supply ratio 15 (no results were available for $P$. palustris at $\mathrm{N}$ :P supply ratio 45 due to the high mortality).

Our results highlight that at low nutrient supply N:P ratio rarely affected investment in sexual reproduction traits but at high supply low relative P supply restricted plants' sexual reproduction investment.
\end{abstract}




\subsection{Introduction}

Plant species diversity in natural ecosystems is influenced by nutrient supply as well as by nutrient stoichiometry, i.e. the ratio of available nutrients in relation to their consumers' requirements (Tilman 1980; Cardinale et al. 2009), with nitrogen (N) and phosphorus $(\mathrm{P})$ as the two main nutrients that frequently limit vegetation productivity (Elser et al. 2007; Fort et al. 2015). In general, fast-growing plants dominate in nutrient-rich environments, whereas slow-growing species may persist in nutrient-poor conditions, where fast-growing species cannot dominant (Grime and Hunt 1975; Lambers and Poorter 1992) leading to differences in species composition between N-limited and P-limited sites (Verhoeven and Schmitz 1991; Tomassen et al. 2003; Wassen et al. 2005; Roeling et al. 2018). N-limited grassland ecosystems frequently have higher productivity and harbor species such as Phragmites australis and Holcus lanatus (Wassen et al. 2005; Fujita et al. 2014; Roeling et al. 2018). In contrast, P-limited herbaceous ecosystems are mostly characterized by low productivity and slow-growing species such as Succisa pratensis and Parnassia palustris (Roeling et al. 2018). Many of these species are endangered (Wassen et al. 2005) or have narrow geographical ranges (Brown 1984; Lahti et al. 1991).

P-limited systems are characterized by species that have evolved functional traits to acquire the scarce P resources, e.g. cluster roots, symbiosis with arbuscular mycorrhizae, and high phosphatase activity, which enables them to assimilate enough P for growth in a low P environment (Güsewell 2005a, b; Lambers et al. 2008; Ceulemans et al. 2011). Another adaptation of these species to a low $\mathrm{P}$ environment is that their nutrient use efficiency is high (Aerts 1999), enabling them to survive in extremely infertile habitats. Since the highest percentage of all acquired P is required for sexual reproduction (van Andel and Vera 1977; Fenner 1986a), lower investment in sexual reproduction appears to be an effective way of saving on P. Recently it has been shown that species adapted to P-limited environments, especially if endangered, have a shorter flowering period, smaller seed mass and lower seed number than other species (Fujita et al. 2014), indicating that these species do indeed invest less in sexual reproduction. These findings are in line with previous findings that endangered species have shorter flowering periods (Lahti et al. 1991), smaller seed mass (Murray et al. 2002), and poorer dispersal ability (Farnsworth and Ogurcak 2008). Other studies have shown that deficiency of P leads to a strong reduction in the number of flowers produced (Brouwer et al. 2001). Together, these results indicate that reproduction traits and dispersal capacity are influenced not only by absolute supply levels but also by nutrient stoichiometry. The effect of nutrient stoichiometry on reproduction and dispersal has, however, received little attention to date. 
Given that human activities have altered elemental global cycles considerably (Falkowski et al. 2008; Seitzinger et al. 2005; Rockström et al. 2009), the absolute availability of $\mathrm{N}$ and $\mathrm{P}$, as well as their relative availability are changing in natural environments (Peñuelas et al. 2013; Bobbink and Willems 1991; Hölzel and Otte 2003). How these changes will affect plants' investment in sexual reproduction, and hence dispersal capacity, remains unknown. In one of the few studies that systematically analyzed the relation between reproduction traits and nutrient stoichiometry, Fujita et al. (2014) suggested that the low investment in sexual reproduction traits of endangered species adapted to $\mathrm{P}$ limitation might have contributed to their current endangered status. Their analysis, however, was based on average trait values (Fujita et al. 2014), whereas trait plasticity is very common and has been identified as a key characteristic for adaptation to environmental change (Callaway et al. 2003; Berg and Ellers 2010).

We therefore experimentally tested plant species' investment in sexual reproduction in a fertilization experiment in which we varied $\mathrm{N}$ and $\mathrm{P}$ supply levels and ratios for two species: one common (Holcus lanatus) and the other endangered (Parnassia palustris). We measured six sexual reproduction traits on plant individuals or populations. First, we included first flowering date (FFD) because it has been shown that nutrient fertilization in nutrient-poor conditions may lead to earlier flowering (Putterill et al. 2004); second, flowering period in individuals (FPI) and in the population (FPP) were included because it has been shown that length of flowering period was related to investment in sexual reproduction (Fujita et al. 2014); third, number of panicle or flower stalks per plant (NPS or NFS) was included because this type of trait was used as a good index of sexual reproduction in other studies (e.g. Burton 1943); fourth, seed stalks and flower stalks: height (SSH or FSH) and length (SSL or FSL) were included because we assume that the greater the height at which the seeds or pollen are released, the greater the chance that the seeds or pollen will be dispersed over longer distances (Soons et al. 2004); fifth, seed panicle length and weight (SPL and SPW) were included because longer and heavier seed panicles may be indicative of more and heavier seeds; and lastly, total seed weight and number of seeds produced per pot (TSW and TNS). Our aim was to test the relative importance of N:P supply ratios compared to total nutrient supply levels for the investment of plants in sexual reproduction traits for these two species. 


\subsection{Materials and Methods}

\subsubsection{Field area description}

Seeds of H. lanatus and P. palustris were collected in October 2014 from the State Forestry Service Middenduin nature reserve $\left(52^{\circ} 24^{\prime} \mathrm{N} 4^{\circ} 35^{\prime} \mathrm{E}\right)$ in the west of the Netherlands. The area harbors herb-rich low-productive grassland, with occurrence of species such as P. palustris L., Epipactis palustris L., and Rhinanthus minor L. The climate is temperate, with annual temperatures between the lowest average of $-2{ }^{\circ} \mathrm{C}$ and the highest average of $20^{\circ} \mathrm{C}$; mean annual precipitation is $939 \mathrm{~mm} / \mathrm{yr}$. Seeds of each species were collected from two sites. We measured the N:P ratio of the above-ground plant community in three samples at each of these sites, which were averaged. N:P ratios were $22.3 \pm 2.1$ and $40.5 \pm 1.7$ respectively. Total $N$ concentration of plant material was measured with a Carlo Erba-NA 1500 NCS analyzer; total P concentration of plant material was measured with a Bruker S2 PICOFOX TXRF spectrometer. These values indicate P-limited conditions (cf. Olde Venterink et al. 2003; Güsewell 2005b; Wassen et al. 2005). The method of determining the type of nutrient limitation of the site by the N:P ratio in above-ground plant material has the advantage of measuring integratively over the seasons instead of only one snapshot over time provided by water/soil N and P concentration (Fujita et al. 2014). However, the distinction between site MD1 and site MD2 was not made in the end of the experiment due to non-significant differences after statistical analysis. Hence, we feel safe to assume that the donor sites from which we obtained our seeds have a low relative P-availability (compared to $\mathrm{N}$ ).

\subsubsection{Species studied and seed collection}

Holcus lanatus L. is a common velvety perennial grass species, often found in nutrient-rich environments throughout Europe. The hermaphroditic inflorescence flowers between May and September, with numerous seeds shedding from June to early autumn (Watt 1978). Seeds shed easily, and are mainly dispersed by wind (Beddows 1961a). Flowers of H. lanatus were reported to be cross pollinated by wind (Beddows 1961a), and have been shown to be "highly self-sterile" (Beddows 1961b).

Parnassia palustris L. is a perennial herb, with a basal cluster of leaves and several straight stems up to $30 \mathrm{~cm}$ high, each culminating in a hermaphroditic flower. Usually the stigma matures later than the stamen. The species flowers from June until October and seeds ripen between September and October. The tiny dust-like seeds are dispersed by water and wind. This species is insect- and cross- pollinated. Seed set is enhanced if pollinated by plants from different genotype fragments (Bossuyt 2007). In the $20^{\text {th }}$ century this species became less frequent, which has resulted in genetic isolation and an endangered status in many European countries (Bossuyt 2007). 
Seed collection was from June until September 2014. Seeds were stored at $4{ }^{\circ} \mathrm{C}$ for 10.7 weeks to break physiological dormancy (vernalization).

\subsubsection{Nutrient treatments and sexual reproduction traits research}

\subsubsection{Seedling preparation}

After germination in June 2015, seedlings were transplanted into separate pots per species (four per pot, 48 pots in total). Pots contained a mixture of quartz sand (Carlo Bernasconi, Zürich, CH, 0.1-0.7 mm) and dune sand at a ratio of 11:1. To create relatively natural conditions for plant growth, dune sand was collected from the Kennemerland National Park close to Middenduin; it has low concentrations of $\mathrm{N}$ and $\mathrm{P}$ but contains a natural microbial community. Total $\mathrm{N}$ and $\mathrm{P}$ concentration in the water extraction of the pure and dune sand (which we treated as the plantavailable $\mathrm{N}$ and P concentration (Kachi and Hirose 1983)) were determined using HACH-LANGE colorimetry test cuvettes (LCK 138, LCK 349, Hach-Lange, Germany). Based on the measured $\mathrm{N}$ and $\mathrm{P}$ concentration in the sand mixture we could fine-tune our nutrient recipe, following Güsewell (2005a).

\subsubsection{Plant cultivation}

The nutrient treatments, which lasted from July 2015 until June 2016, were given in a greenhouse with $400 \mathrm{~W} / \mathrm{m}^{2}$ light from 9 am to $4 \mathrm{pm}$. From October 2015 until March 2016, temperature was manipulated to Dutch winter conditions $\left(-1{ }^{\circ} \mathrm{C}\right.$ to $14^{\circ} \mathrm{C}$ ), to stimulate vernalization (Wiebe et al. 1992); for the rest of the experimental period, temperature ranged between $14-30{ }^{\circ} \mathrm{C}$. Each pot was placed on a tray, to prevent loss of water and nutrients. The pots were switched around regularly to randomize possible differences in light, temperature, and moisture conditions in the greenhouse.

A full factorial combination with six nutrient treatments was applied, with three supply ratios ( $\mathrm{N}: \mathrm{P}=5$ (low relative $\mathrm{N}$ supply), $\mathrm{N}: \mathrm{P}=15$ (co-limitation), and $\mathrm{N}: \mathrm{P}=45$ (low relative P supply)), and two absolute nutrient supply levels: low and high. The treatments have been defined by the total amounts of $\mathrm{N}$ and $\mathrm{P}$ applied per plant throughout the cultivation process (in $\mathrm{mg}$ ), and were calculated as:

$\mathrm{N}=\mathrm{L} \times \sqrt{\mathrm{N}: \mathrm{P}}$, and $\mathrm{P}=\frac{1}{\sqrt{\mathrm{N}: \mathrm{P}}},($ where $\mathrm{L}=\sqrt{\mathrm{N} \times \mathrm{P}})$

in which $\mathrm{L}$ is the overall supply level (geometric mean of $\mathrm{N}$ and $\mathrm{P}$ supply). L was $13.4 \mathrm{mg}$ for low supply level and $40.3 \mathrm{mg}$ for high supply level, following the method developed by Güsewell (2005a) in the first year of her two years' fertilization experiment. 
The experiment was carried out with seedlings grown in separate pots for each species; each pot contained four seedlings planted in its corners. The total number of pots was 2 species $\times 3$ nutrient supply ratios $\times 2$ nutrient supply levels $\times 8$ pot replicates $=96$. Nutrient solutions were applied weekly. The nutrient supply was increased gradually during the growth process (Güsewell 2005a): in weeks 4-6 the weekly supply of nutrients was double the dose in weeks 1-3; in weeks 7-9 it was 1.5 times the dose in weeks 4-6. After week 9 when growth stopped, nutrient doses were kept at those of weeks 4-6, to ensure that plants remained alive and healthy until the day when senescence started. Apart from receiving nutrient solutions, plants were watered frequently with demineralized water to prevent drying out; normally this was done once every 1-3 days, but in summer this was necessary daily.

$\mathrm{N}$ was supplied as $\mathrm{KNO}_{3}$ and $\mathrm{Ca}\left(\mathrm{NO}_{3}\right)_{2}$, $\mathrm{P}$ was provided as $\mathrm{KH}_{2} \mathrm{PO}_{4}$. Both $\mathrm{KNO}_{3}$ and $\mathrm{KH}_{2} \mathrm{PO}_{4}$ supplied part of the potassium $(\mathrm{K})$, the rest of $\mathrm{K}$ was added by $\mathrm{KCl}$ (Güsewell 2005a). The other essential macro-nutrients for example calcium (Ca) and micronutrients such as iron $(\mathrm{Fe})$ and copper $(\mathrm{Cu})$ were applied in non-limiting concentrations and were supplied in the same amounts to all treatments weekly. Details of the nutrient treatments are given in Appendix 4.1. Chlorine (Cl) was the only element that was not supplied in fixed amounts to all treatments. We have indicated the range of $\mathrm{Cl}$ addition to Appendix 4.1.

To prevent nutrient toxicity (Fujita et al. 2010), each pot was leached every six weeks with demineralized water.

When pollination of $H$. lanatus started in May (13-5-2016), two fans were installed at the corners of the platform to create sufficient air movement for pollination. The position of the fans was changed regularly. P. palustris has bigger and fewer flowers, so pollination was done manually, using a small brush.

\subsubsection{Data collection and analysis}

\subsubsection{First flowering date (FFD) and length of the flowering period (FPI or FPP)}

First flowering date (FFD): The day on which the first flower appeared in a pot was taken to be the first flowering date for all four individuals within that pot. The FFD of the first pot was assigned the value 0 .

Flowering period in individuals (FPI) and in the population (FPP): Since we did not find a clear definition of flowering period in the literature, we recorded the length of the flowering period at both individual level (FPI) and population level (FPP). The first approach (FPI) consisted of marking a random individual flower or panicle (how many depended on the total number of flowers or panicles in one 
pot and ranged between 1 and 8), and tracking the selected individuals to be able to define the start and end of the flowering period. The second method (FPP) consisted of calculating the difference between starting time as defined above (FFD) and the moment the last flower in that pot disappeared.

\subsubsection{Number of panicle or flower stalks per plant (NPS or NFS)}

Both H. lanatus and P. palustris carry one panicle or flower per stalk. Per pot we cumulatively counted the panicle stalks (number of panicle stalks: NPS) or flower stalks (number of flower stalks: NFS) as soon as they appeared. Later, the mean NPS or NFS per plant was calculated by dividing the number of panicle (or flower) stalks in one pot by the number of plants in that pot.

\subsubsection{Seed stalks and flower stalks: height (SSH or FSH) and length (SSL or FSL)}

The height of the stalks bearing seed and the flower stalks were measured as a proxy for the dispersibility of seed of H. lanatus and of pollen of P. palustris (most plants of the latter did not set seeds in the experiment). We measured the stalk height (SSH or FSH) relative to the soil surface and also measured the stalk length (SSL or FSL) by straightening the stalks manually so they were vertical and then measuring the distance between the soil surface to the top of the seeds panicle or flower (Heady and Anne 2015). The first method is indicative of seed or pollen release height, while the second one (which is a more standardized measurement) is indicative of a plants' investment in the structure of stalks.

\subsubsection{Seed panicle length and weight (SPL and SPW)}

SPL (the straight length of panicles) was measured from the bottom to the top of each seed panicle. Panicles were weighed with all the seeds on them (SPW).

\subsubsection{Total seed weight and number of seeds produced per pot (TSW and TNS)}

Collection of seeds of H. lanatus lasted from May to July 2016. All the seed panicles were collected individually immediately upon ripening. The collected seeds were dried in an oven at $30{ }^{\circ} \mathrm{C}$ for four hours and stored in a sealed box with silica. Average weight of an individual seed from each pot was determined by weighing 1000 random seeds in each pot and then dividing by 1000. To obtain total seed weight in each pot (TSW), all seeds from one pot were weighed. Total number of seeds in each pot (TNS) was calculated by dividing TSW by the average weight of an individual seed in each pot.

\subsubsection{Data analysis}

T-tests were used for comparing two data groups (treatments $5 \mathrm{H}$ and $15 \mathrm{H}$ ) with normal distributions (NFS, FSL and FSH of P. palustris). We used ANOVA to test for 
the main effects of and the interactions between nutrient supply ratio and nutrient supply level on sexual reproduction traits. Since we identified many significant interaction effects between nutrient supply level and $\mathrm{N}: \mathrm{P}$ supply ratios (see Appendix 4.2), we further explored the difference among all treatment combinations of nutrient supply ratios and nutrient supply levels, using pairwise comparisons with a correction for making multiple comparisons. For traits with small differences $(\leq 40 \%)$ in sample size between treatments (FFD, NPS, SSL, SSH, SPW, TSW, and TNS of H. lanatus), Gabriel's procedure was used for post-hoc testing. When the differences in sample size between treatments were large (> $40 \%$ ) (FPP and FPI of H. lanatus), Hochberg's GT2 was used for post-hoc testing. Both of these tests have good control of Type I errors in multiple comparisons (Field 2013). In instances of heteroscedasticity or non-normality, data was log- or square root-transformed. In cases where homogeneity of variances was significantly different, Games-Howell procedure was applied, which was the case for SPL of H. lanatus. This test performs well when homogeneity of variances cannot be assumed, but is more liberal in controlling Type I errors than the other tests used (Field 2013). Linear regression was used to test the combined effects of SSL and either SPL or SPW on SSH. All tests were performed with SPSS 23.0 (SPSS, Chicago, U.S.A.); figures were also created in SPSS.

\subsection{Results}

\subsubsection{Holcus lanatus}

In general, plants of $H$. lanatus grew healthily with $97 \%$ survival.

\subsubsection{First flowering date (FFD) and length of the flowering period (FPP and FPI)}

Flowering of H. lanatus started in the beginning of April; the first treatment to flower was $15 \mathrm{H}$ (i.e. N:P supply ratio of 15, high supply level): see Figure 4.1a. Nutrient supply level (low supply level (L) versus high supply level (H)) rather than nutrient supply ratio $(5,15,45)$ was decisive for FFD: plants growing under treatment $15 \mathrm{H}$ flowered earlier than those under treatments 5L and 15L (Figure 4.1a).

The effects of nutrient supply level on FPP were similar to those found for FFD, but only for the N:P 15 treatment, i.e. plants growing under treatment $15 \mathrm{H}$ had a significantly longer flowering period than plants growing under treatment $15 \mathrm{~L}$ (Figure 4.1b).

However, the effect of nutrient supply ratio rather than nutrient supply level was decisive for FPI: plants growing under treatments $5 \mathrm{H}$ and $15 \mathrm{H}$ had significantly 
longer FPI than those under treatment $45 \mathrm{H}$, as well as those under treatments $5 \mathrm{~L}$, 15L and 45L (Figure 4.1c).

\subsubsection{Number of panicle stalks (NPS), seed stalk length (SSL) and height (SSH), as well as seed panicle length (SPL) and weight (SPW)}

NPS was significantly higher at the high nutrient supply treatments with the highest numbers at N:P 15 (Figure 4.2a). SSL was significantly higher for plants growing under treatment $5 \mathrm{H}$ than those under treatment $45 \mathrm{H}$, as well as those under treatments 15L and 45L (Figure 4.2b). However, SSH did not vary significantly between different treatments (Figure 4.2c).
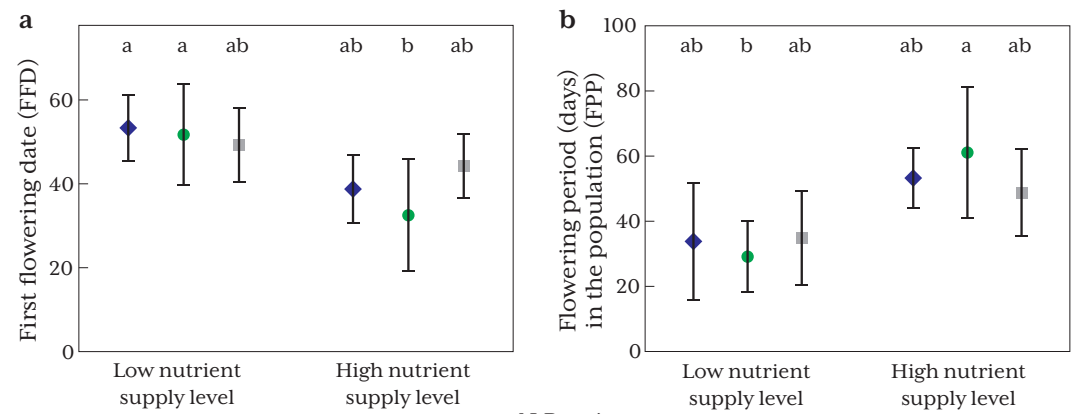

N:P ratio

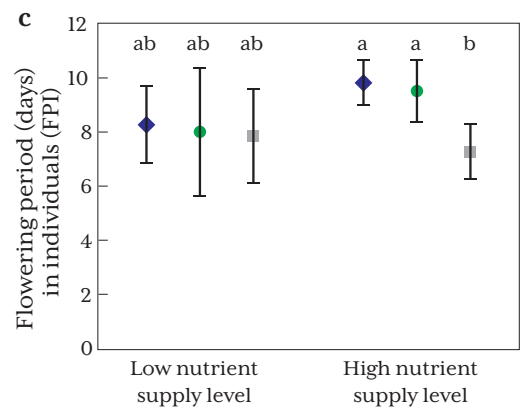

Figure 4.1 First flowering date (FFD) and length of the flowering period (FPP and FPI) plotted against the supply ratios and levels of $\mathrm{N}$ and $\mathrm{P}$ of $\mathrm{H}$. lanatus. (a) First flowering date (FFD) in days relative to the date the first flower appeared in each pot; the first date in the experiment on which flowering occurred was taken as 0. (b) Flowering period (days) in the population (FPP) was calculated by subtracting the FFD in a certain pot from the time the last flower in that pot finished flowering. (c) Flowering period (days) in individuals (FPI) was tracked on random individual flowers in each pot by recording the starting time and finishing time of flowering of each individual flower. Data are means \pm SD. Significant differences between treatment combinations are indicated by different letter codes. Values with the same character are not significantly different $(P=0.05)$. 

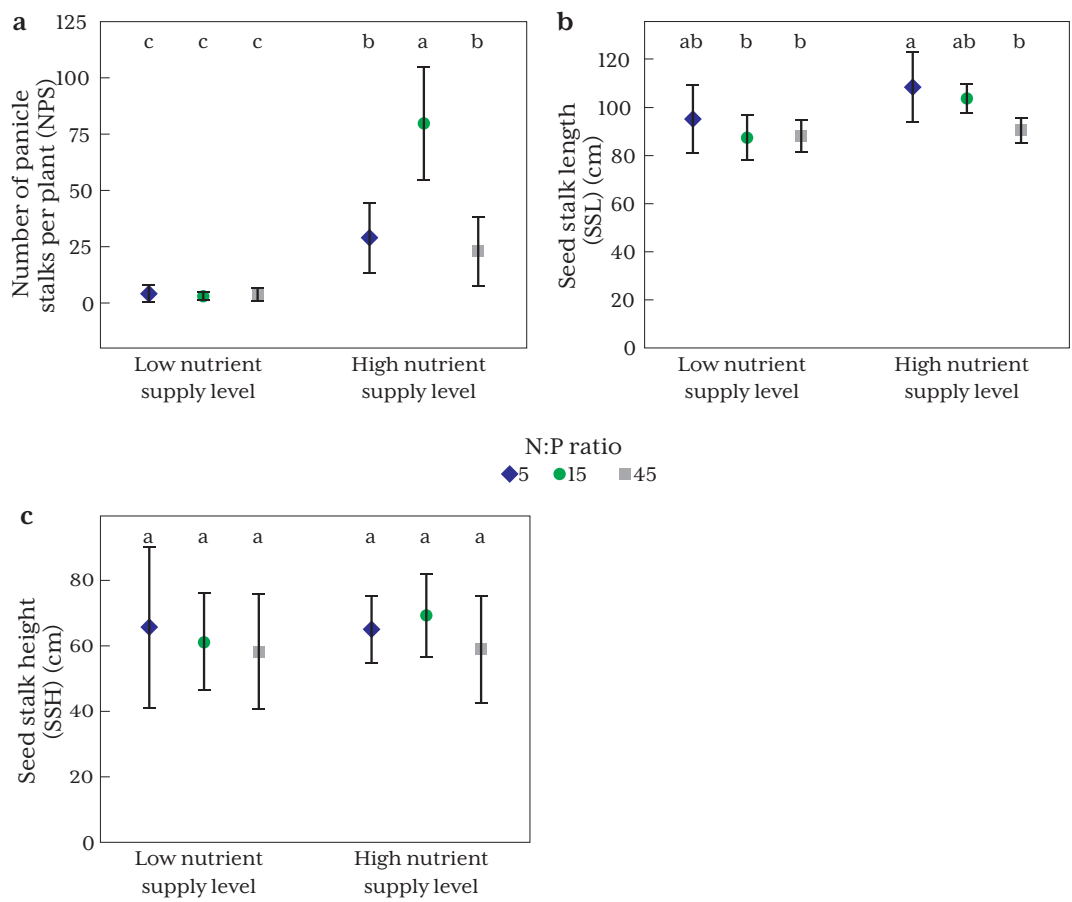

Figure 4.2 Number of panicle stalks (NPS) (a), seed stalk length (SSL) (b), and seed stalk height (SSH) (c) of H. lanatus. Data are means \pm SD. Values indicated by the same character are not significantly different $(P=0.05)$.

SPL showed a similar tendency as SSL (Figure 4.2b), i.e. plants growing under treatment $5 \mathrm{H}$ produced longer seed panicles than those under treatment $45 \mathrm{H}$, as well as those under treatments $15 \mathrm{~L}$ and $45 \mathrm{~L}$ (Figure 4.3a). Plants produced significantly heavier panicles under treatment $5 \mathrm{H}$ than in treatments $45 \mathrm{H}, 5 \mathrm{~L}$, 15L, and 45L (SPW; Figure 4.3b).

\subsubsection{Seeds: total weight and number produced per pot (TSW and TNS)}

At the end of the experiment, the number of seeds collected was 207,861 and their total dry weight was $65.4 \mathrm{~g}$. The average numbers of seeds per pot per treatment were: 1138.84 (5L), 306.27 (15L), 696.61 (45L), $8353.92(5 \mathrm{H}), 13927.00(15 \mathrm{H})$ and 2113.11 $(45 \mathrm{H})$; the average weights of seeds per pot per treatment were: $0.26 \mathrm{~g}(5 \mathrm{~L}), 0.10 \mathrm{~g}$ (15L), $0.18 \mathrm{~g}(45 \mathrm{~L}), 2.43 \mathrm{~g}(5 \mathrm{H}), 4.69 \mathrm{~g}(15 \mathrm{H})$ and $0.67 \mathrm{~g}(45 \mathrm{H})$. In general, nutrient supply had a critical influence on both TSW and TNS in each pot for both N:P 5 and 15 , but not for N:P 45. At high nutrient supply level, seed number and weight in 

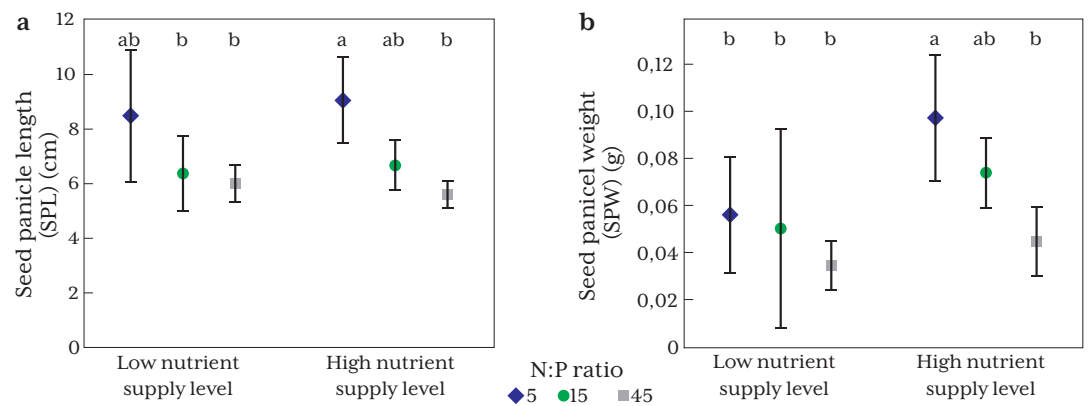

Figure 4.3 Seed panicle length (SPL) (a) and seed panicle weight (SPW) (b) of H. lanatus. Data are means \pm SD. Values indicated by the same character are not significantly different $(P=0.05)$.
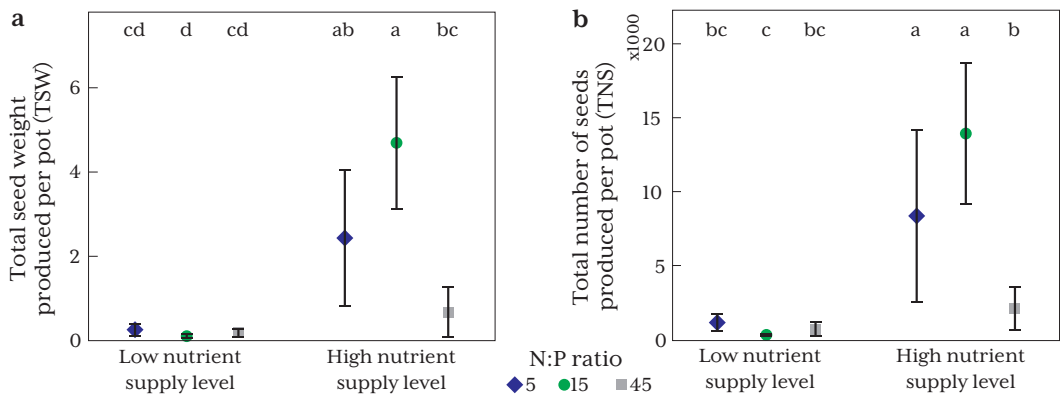

Figure 4.4 Total seeds weight (TSW) (a) and number of seeds (TNS) (b) produced per pot of $H$. lanatus. Data are means \pm SD. Values indicated by the same character are not significantly different $(P=0.05)$.

treatment $15 \mathrm{H}$ were slightly higher than in treatment $5 \mathrm{H}$ and about seven times higher than in treatment $45 \mathrm{H}$. The difference between treatments $5 \mathrm{H}$ and $45 \mathrm{H}$ for TNS was significantly different. Nutrient supply ratio had no effect at low nutrient supply level (Figure 4.4).

\subsubsection{Parnassia palustris}

Although germination success of $P$. palustris was high, only $42 \%$ of the seedlings of $P$. palustris survived in the experiment. 


\subsubsection{First flowering date (FFD)}

The earliest first flowering date was in the beginning of June, while the latest first flowering date was in the beginning of August. However, differences between treatments in FFD of $P$. palustris could not be statistically tested because of the low survival of flowering individuals in the experiment.

\subsubsection{Number of flower stalks per plant (NFS), flower stalk length (FSL) and height (FSH)}

The comparisons of these three sexual reproduction traits of $P$. palustris were restricted between treatment $5 \mathrm{H}$ and treatment $15 \mathrm{H}$, due to the high mortality and low bearing flowers and seeds rate of the other treatments. In detail, the number of flower stalks per plant of $P$. palustris (NFS) was significantly higher on plants under treatment $5 \mathrm{H}$ than treatment $15 \mathrm{H}$ (Table 4.1). However, there was no significant difference of flower stalks length (FSL) or flower stalks height (FSH) growing on plants under treatment $5 \mathrm{H}$ and treatment $15 \mathrm{H}$ (Table 4.1).

Table 4.1 P. palustris flower stalks: number per plant (NFS), length (FSL) and height (FSH).

\begin{tabular}{llll}
\hline & NFS & FSL & FSH \\
\hline $5 \mathrm{~L}$ & $0.07 \pm 0.13$ & $/$ & $/$ \\
\hline $15 \mathrm{~L}$ & $0.13 \pm 0.33$ & 39.5 & 39.5 \\
$45 \mathrm{~L}$ & 0 & $/$ & $/$ \\
\hline $5 \mathrm{H}$ & $2.33 \pm 1.55^{\mathrm{A}}$ & $29.01 \pm 6.23^{\mathrm{A}}$ & $24.16 \pm 11.05^{\mathrm{A}}$ \\
\hline $15 \mathrm{H}$ & $0.75 \pm 0.79^{\mathrm{B}}$ & $22.54 \pm 12.30^{\mathrm{A}}$ & $19.25 \pm 5.86^{\mathrm{A}}$ \\
\hline $45 \mathrm{H}$ & 0 & $/$ & $/$ \\
\hline
\end{tabular}

Values of each trait indicated by different characters are significantly different $(P=0.05)$. Values without \pm SD indicate that only one value was collected from plants under that treatment. / indicates no data available under the treatment.

\subsubsection{Seed production}

At the end of the experiment, seeds of $P$. palustris could only be collected from plants growing under treatment $5 \mathrm{H}$, since in the other treatments plants did not flower or produced ovaries that died before seeds developed. As it was not possible to compare seed production among different treatments, we do not report the number and weight of $P$. palustris seeds. 


\subsection{Discussion}

In this experiment, we measured the response of traits that can be regarded as a set of proxies for the investment in sexual reproduction and dispersal capacity to fertilization treatments varying in $\mathrm{N}: \mathrm{P}$ supply ratios $(5,15$, and 45 , respectively indicating low relative $\mathrm{N}$ supply, co-limited $\mathrm{N}$ and $\mathrm{P}$ supply and low relative $\mathrm{P}$ supply) and nutrient supply levels (low and high). We did so for a common species (Holcus lanatus) and an endangered species (Parnassia palustris) that were grown from seeds collected from two sites where relative P-availability was low.

\subsubsection{Nutrient supply level-dependent effects of N:P supply ratio on investment in sexual reproduction}

The results of this study showed that N:P supply ratio affected plant investment in sexual reproduction differently at low and high nutrient supply levels: N:P supply ratio affected reproduction traits at the high nutrient supply level markedly, but rarely had an effect at the low supply level. Since the results for P. palustris were very limited due to high mortality and extremely low flowering, we restrict this analysis to H. lanatus.

At the high nutrient supply level, H. lanatus invested less in sexual reproduction at the high N:P supply ratios indicative of low relative P supply: the flowering period of individual flowers was shorter (Figure 4.1c), and there were fewer and shorter flower stalks (Figure 4.2a, b), lighter and shorter seed panicles (Figure 4.3b), as well as lower seed production (Figure 4.4). The differences between N:P 5 (low relative $\mathrm{N}$ supply) and N:P 15 (co-limitation) were always small, except for the number of panicle stalks, with N:P 5 restricting NPS significantly compared to N:P 15. The larger number of stalks in N:P co-limitation than in low relative $\mathrm{N}$ supply in our experiment is in line with results obtained for Meadow Bromegrass, which showed a significant increase of panicle stalk density upon $\mathrm{N}$ fertilization (Loeppky and Coulman 2001). Surprisingly, H. lanatus showed considerably higher seed stalk lengths at N:P 5 than at N:P 45, as well as N:P 5 and N:P 45 at low supply level, while no significant differences for seed stalk height were found between any of the treatments. This could be explained by the fact that the stalks bent under the heavier weight of the seed panicles (SPW). This was confirmed by a linear regression, that showed that seed stalk height was not only positively influenced by seed stalk length (SSL), but also negatively by the weight and length of the seed panicles (SPW and SPL; Appendix 4.3). In a word, the lack of $\mathrm{N}$ in treatment $5 \mathrm{H}$ for $H$. lanatus led to fewer panicles per plant but heavier individual seed panicles. 
We did not observe an effect of N:P supply ratio on sexual reproduction traits at low nutrient supply level. A possible explanation for greater investment in sexual reproduction at high nutrient supply could be the dependency of sexual reproduction on plant size, i.e. an economic strategy for plants only to invest in sexual reproduction when they have surpassed a threshold plant size (Bloom 1985; Schmid et al. 1995). As sexual reproduction organs contain high nutrient concentrations, investing nutrients in sexual reproduction under nutrient-limited conditions may create a high risk for the plant's establishment. The optimal nutrient allocation for plants under nutrient-limited conditions therefore seems to be to first build a stronger vegetative body to increase survival and allow for greater future reproduction (Koslowski 1992). Our conclusion challenges a contention made by Fujita et al. (2014) that investment in sexual reproduction of vegetation is mainly related to N:P supply ratio and is independent of nutrient supply level. However, the contrasting result might be explained by the origin of the data. The dataset of Fujita et al. (2014) contained field observations instead of experimental results; if plants are already growing at a particular site, it can be assumed that the nutrient supply level is sufficient to support adequate vegetative growth for investments in sexual reproduction to take place. Furthermore, Fujita et al. worked with average trait values per species and any difference they observed in trait values between sites is therefore the result of species turnover, not of changes in trait expression within species like those we observed in our experiment. Our finding that the effects of N:P supply ratio on investment in sexual reproduction are dependent on nutrient supply level strongly suggests that total nutrient supply should be taken into account when studying the impact of N:P supply ratio on plant sexual reproduction. However, no effect of N:P supply ratio was found on either the first flowering date or the flowering period in the population.

\subsubsection{Low relative $P$ supply restricts the effect of increasing nutrient supply level on plant investment in sexual reproduction}

The results of our experiment also allow for analysis of how trait expressions may change depending on nutrient stoichiometry when overall nutrient supply rises. Same as the discussion above, we restricted this analysis to H. lanatus due to the limited results of $P$. palustris.

At N:P 15, increasing the nutrient level significantly advanced the first flowering date (Figure 4.1a) and prolonged the flowering period in the population (Figure 4.1b), with more seed stalks (Figure 4.2a) and higher seed production (Figure 4a, b). Similarly, in their research on plant vegetative growth, Olde Venterink and Güsewell (2010) showed that at N:P 15 Alopecurus pratensis and Agrostis capillaris responded most strongly to an increased nutrient supply by producing more biomass. The vegetative growth of $H$. lanatus in our research showed a comparable response on increased nutrient supply (result not shown). 
In contrast to these findings at co-limited N:P supply (N:P 15), we observed no influence of increasing nutrient level under low relative P supply (N:P 45) on any of the sexual reproduction traits except for one (number of panicle stalks per plant (Figure 4.2a)). Similarly, increasing nutrient supply levels under low relative N supply (N:P 5) also had no effect on sexual reproduction traits except for all the four traits directly related to seed output (i.e. number of panicle stalks per plant (Figure 4.2a), seed panicle weight (Figure 4.3b), total seed weight and number of seeds produced per pot (Figure $4 \mathrm{a}, \mathrm{b})$ ). This restrictive effect of deviation from co-limited N:P supply (N:P 5 and N:P 45 compared to N:P 15) may be explained by the phenomenon that adding $\mathrm{N}$ (or P) accelerates the uptake of $\mathrm{P}$ (or $\mathrm{N}$ ), whereas $\mathrm{N}$ (or P) deprivation restricts the uptake of $\mathrm{P}$ (or N) (Gillespie and Pope 1989; Chaudhary et al. 2008). These relations between $\mathrm{N}$ and $\mathrm{P}$ can be brought about by a variety of mechanisms. Under natural conditions, the main mechanisms would be the control of $\mathrm{P}$ on $\mathrm{N}$ microbial fixation and the effect of $\mathrm{N}$ on $\mathrm{P}$ mineralization (Eisele et al. 1989; Gressel and McColl 1997). In our fertilization experiment a possible mechanism could be the shortage of N- or P-related substances needed for growth, such as enzymes (e.g. $\mathrm{PO}_{4}{ }^{3-}$ symporter (Maathuis 2007), ATP synthase (Oster and Wang 2000)), nucleic acid, ATP, etc. However, considering the critical role of seed output in sexual reproduction, low relative $\mathrm{P}$ supply might be the critical restriction to the positive response to greater nutrient supply on sexual reproduction rather than low relative $\mathrm{N}$ supply.

\subsubsection{Species-specific responses}

Nearly all (98\%) the plants of H. lanatus grew successfully and produced seed in most treatments, whereas less than half (42\%) of the plants of $P$. palustris survived, of which only $10 \%$ produced flowers and only two (in the same pot) produced seeds. The pattern of plant survival of $P$. palustris was surprisingly similar to the pattern of sexual reproduction investment of H. lanatus: at low nutrient supply level the mortality of $P$. palustris was extremely high and the sexual reproduction investment of $H$. lanatus was markedly worse than at high nutrient supply level. Apparently, both species were seriously hampered by low nutrient supply. High nutrient supply level resulted in better establishment for both species, while at the same time significant differences emerged between N:P supply ratios in investment in sexual reproduction: both the survival of $P$. palustris and the investment of $H$. lanatus in sexual reproduction were good at low N:P supply ratio, whereas at high $\mathrm{N}$ :P supply ratio almost all plants of $P$. palustris died and H. lanatus invested less in sexual reproduction. However, the effect of $\mathrm{pH}$ on the survival of the plants, especially on $P$. palustris was not considered in our research. 


\subsection{Conclusions}

In summary, our experiment shows that sufficient nutrient supply was the condition for N:P supply ratio to appreciably influence sexual reproduction - i.e. $\mathrm{N}:$ P supply ratio had no effect on investment in sexual reproduction at low nutrient supply level but a significant effect at high nutrient supply level. A high N:P supply ratio (indicating a low relative $\mathrm{P}$ supply) led to significantly lower investment in sexual reproduction. On the other hand, low relative P supply critically limited plant investment in sexual reproduction when nutrient supply level was raised. Based on these findings we highlight the strongly negative influence of low relative $\mathrm{P}$ supply on investment in sexual reproduction, very clearly for the common species and also likely for the endangered species we investigated. However, since we only investigated one common species and one endangered species, we recommend more in-depth empirical studies be carried out on a wider range of species.

\section{Acknowledgments}

We acknowledge the China Scholarship Council (CSC) for a doctoral scholarship to Shuqiong Wang (CSC NO. 201406140142). We appreciate the valuable suggestions of Ineke Roeling on the research setup and comments on the draft manuscript. We thank Roel Vonk, Gerard van Buiten, Fred Siesling, Bas Valstar, and colleagues from the greenhouse for their helpful suggestions with cultivation. Thom Claessen (Geolab) is acknowledged for advices about preparing nutrient solutions, Ton Markus for improving the Figures and Elizabeth Haber for her help with botanical terms. The English of a near-final draft of the manuscript was checked professionally by Joy Burrough. 


\section{Supplementary materials}

\begin{tabular}{|c|c|c|c|}
\hline Nutrient supply level & $\mathrm{N}: \mathrm{P}$ supply ratio & $\begin{array}{l}\text { Supplied N } \\
(\mathrm{mg} / \text { plant })\end{array}$ & $\begin{array}{l}\text { Supplied P } \\
(\mathrm{mg} / \text { plant })\end{array}$ \\
\hline \multirow{3}{*}{ Low } & 5 & 30.0 & 6.0 \\
\hline & 15 & 52.0 & 3.5 \\
\hline & 45 & 90.0 & 2.0 \\
\hline \multirow{3}{*}{ High } & 5 & 90.0 & 18.0 \\
\hline & 15 & 156.0 & 10.5 \\
\hline & 45 & 270.0 & 6.0 \\
\hline $\begin{array}{l}\text { Other elements } \\
\text { for all treatments }\end{array}$ & Resources & \multicolumn{2}{|c|}{$\begin{array}{l}\text { Supplied amount of element } \\
\text { (mg/plant) }\end{array}$} \\
\hline K & $\mathrm{KNO}_{3} \& \mathrm{KCl}$ & \multicolumn{2}{|l|}{400} \\
\hline $\mathrm{Ca}$ & $\mathrm{CaCl}_{2} \cdot 2 \mathrm{H}_{2} \mathrm{O}$ & \multicolumn{2}{|l|}{51.6} \\
\hline $\mathrm{Mg}$ & $\mathrm{MgSO}_{4} \cdot 7 \mathrm{H}_{2} \mathrm{O}$ & \multicolumn{2}{|l|}{11.7} \\
\hline S & $\mathrm{MgSO}_{4} \cdot 7 \mathrm{H}_{2} \mathrm{O}$ & \multicolumn{2}{|l|}{17.8} \\
\hline $\mathrm{Fe}$ & Fe-EDTA & \multicolumn{2}{|l|}{4.1} \\
\hline $\mathrm{Cu}$ & $\mathrm{CuSO}_{4} \cdot 5 \mathrm{H}_{2} \mathrm{O}$ & \multicolumn{2}{|l|}{0.02} \\
\hline B & $\mathrm{H}_{3} \mathrm{BO}_{3}$ & \multicolumn{2}{|l|}{0.39} \\
\hline $\mathrm{Mn}$ & $\mathrm{MnSO}_{4} \cdot \mathrm{H}_{2} \mathrm{O}$ & \multicolumn{2}{|l|}{0.21} \\
\hline Mo & $\mathrm{Na}_{2} \mathrm{MoO}_{4} \cdot \mathrm{H}_{2} \mathrm{O}$ & \multicolumn{2}{|l|}{0.04} \\
\hline Zn & $\mathrm{ZnSO}_{4} \cdot 7 \mathrm{H}_{2} \mathrm{O}$ & \multicolumn{2}{|l|}{0.10} \\
\hline
\end{tabular}

Cl was the only element that was not supplied in fixed amounts to all treatments; the amount supplied varied between $113.1 \mathrm{mg} /$ plant and $346.5 \mathrm{mg} /$ plant. 


\begin{tabular}{|c|c|c|c|}
\hline Sexual reproduction trait & Factor & $\mathbf{F}$ & $P$ \\
\hline \multirow{3}{*}{ First flowering date (FFD) } & Ratio & 0.7 & 0.506 \\
\hline & Level & 13.3 & 0.001 \\
\hline & Ratio $\times$ level & 1.4 & 0.269 \\
\hline \multirow{3}{*}{ Flowering period in the population (FPP) } & Ratio & 0.1 & 0.877 \\
\hline & Level & 15.6 & 0.000 \\
\hline & Ratio $\times$ level & 1.1 & 0.359 \\
\hline \multirow{3}{*}{ Flowering period in individuals (FPI) } & Ratio & 4.6 & 0.019 \\
\hline & Level & 3.5 & 0.071 \\
\hline & Ratio $\times$ level & 2.6 & 0.090 \\
\hline \multirow{3}{*}{ Seed stalk length (SSL) } & Ratio & 4.4 & 0.020 \\
\hline & Level & 9.5 & 0.004 \\
\hline & Ratio $\times$ level & 1.4 & 0.251 \\
\hline \multirow{3}{*}{ Seed stalk height (SSH) } & Ratio & 0.7 & 0.509 \\
\hline & Level & 0.3 & 0.604 \\
\hline & Ratio $\times$ level & 0.3 & 0.768 \\
\hline \multirow{3}{*}{ Seed panicle length (SPL) } & Ratio & 14.5 & 0.000 \\
\hline & Level & 0.1 & 0.725 \\
\hline & Ratio $\times$ level & 0.4 & 0.669 \\
\hline \multirow{3}{*}{ Seed panicle weight (SPW) } & Ratio & 7.8 & 0.002 \\
\hline & Level & 10.2 & 0.003 \\
\hline & Ratio $\times$ level & 10.2 & 0.003 \\
\hline \multirow{3}{*}{ No. of panicle stalks (NPS) } & Ratio & 8.0 & 0.001 \\
\hline & Level & 99.1 & 0.000 \\
\hline & Ratio $\times$ level & 7.7 & 0.002 \\
\hline \multirow{3}{*}{ Total no. of seeds produced per pot (TNS) } & Ratio & 5.2 & 0.011 \\
\hline & Level & 94.1 & 0.000 \\
\hline & Ratio $\times$ level & 10.4 & 0.000 \\
\hline \multirow{3}{*}{ Total seeds weight produced per pot (TSW) } & Ratio & 3.8 & 0.032 \\
\hline & Level & 79.3 & 0.000 \\
\hline & Ratio $\times$ level & 7.4 & 0.002 \\
\hline
\end{tabular}


Table 2 Two-way ANOVA of nutrient supply ratio and nutrient supply level on No. of flower stalk (NFS) of P. palustris.

\begin{tabular}{llll}
\hline Sexual reproduction trait & Factor & F & $\boldsymbol{P}$ \\
\hline \multirow{2}{*}{ No. of flower stalks (NFS) } & Ratio & 2.9 & 0.107 \\
& Level & 13.8 & $\mathbf{0 . 0 0 0}$ \\
\cline { 2 - 4 } & Ratio $\times$ level & 3.5 & 0.126 \\
\hline
\end{tabular}

Appendix 4.3 Linear regression analyses for the effect on seed stalk height (SSH) of seed stalk length (SSL) and seed panicle length (SPL) or seed panicle weight (SPW) respectively of H lanatus. ß means standardized coefficient.

\begin{tabular}{|c|c|c|c|c|c|c|}
\hline Combination & Variable & SSH & & & & \\
\hline & & d.f. & $\mathbf{F}$ & $\mathbf{R}^{2}$ & $P$ & $\beta$ \\
\hline \multirow{2}{*}{$\mathrm{SSL} \times \mathrm{SPW}$} & SSL & \multirow{2}{*}{2} & \multirow{2}{*}{22.133} & \multirow{2}{*}{0.087} & 0.000 & 0.328 \\
\hline & SPW & & & & 0.008 & -0.132 \\
\hline \multirow{2}{*}{$\mathrm{SSL} \times \mathrm{SPL}$} & SSL & \multirow{2}{*}{2} & \multirow{2}{*}{47.787} & \multirow{2}{*}{0.17} & 0.000 & 0.503 \\
\hline & SPL & & & & 0.000 & -0.390 \\
\hline
\end{tabular}


$\mathrm{N}: P$ stoichiometry and plant sexual reproduction in the greenhouse $\mid \mathbf{8 1}$ 


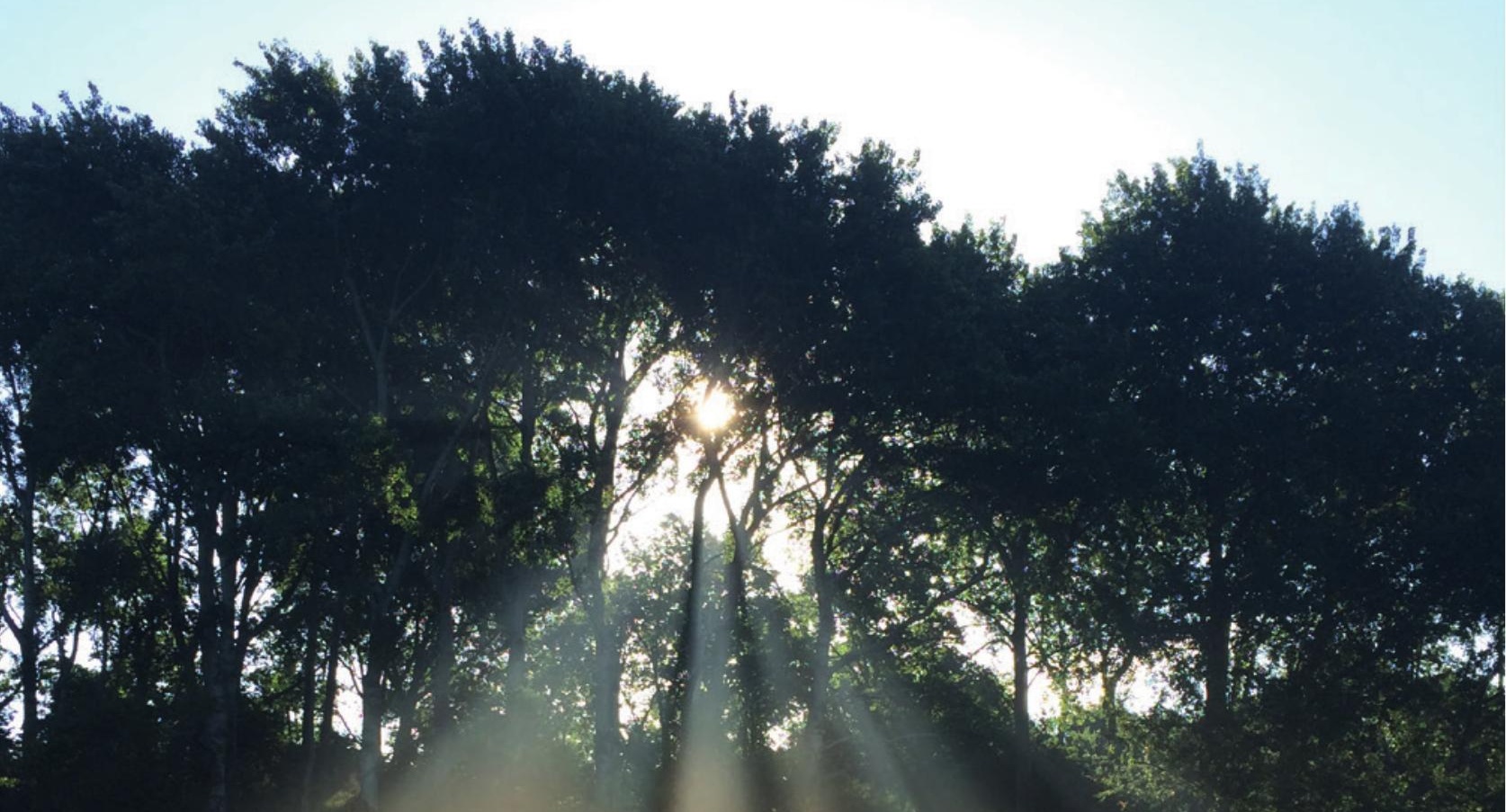

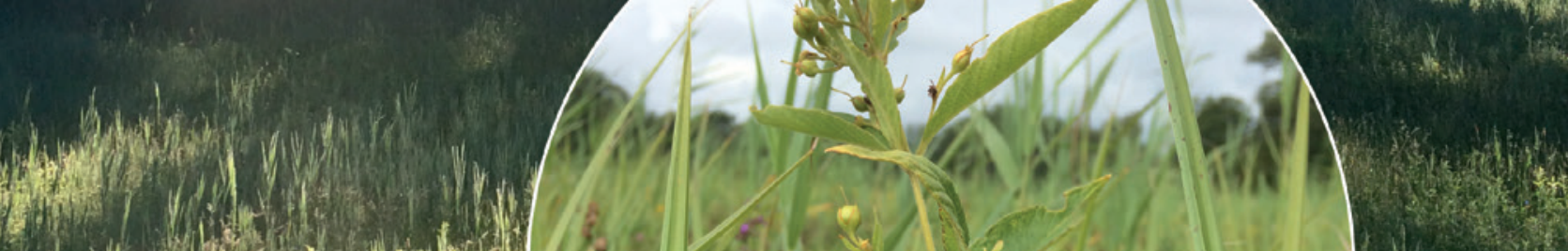

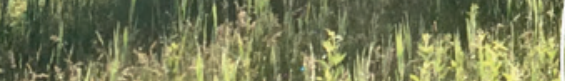
14.

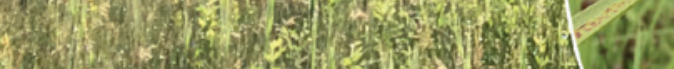

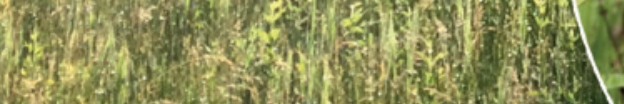

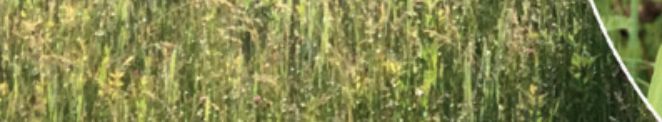

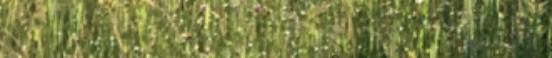
(1)

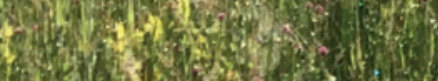

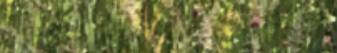
(4)

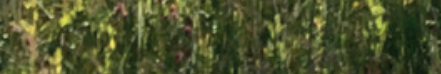
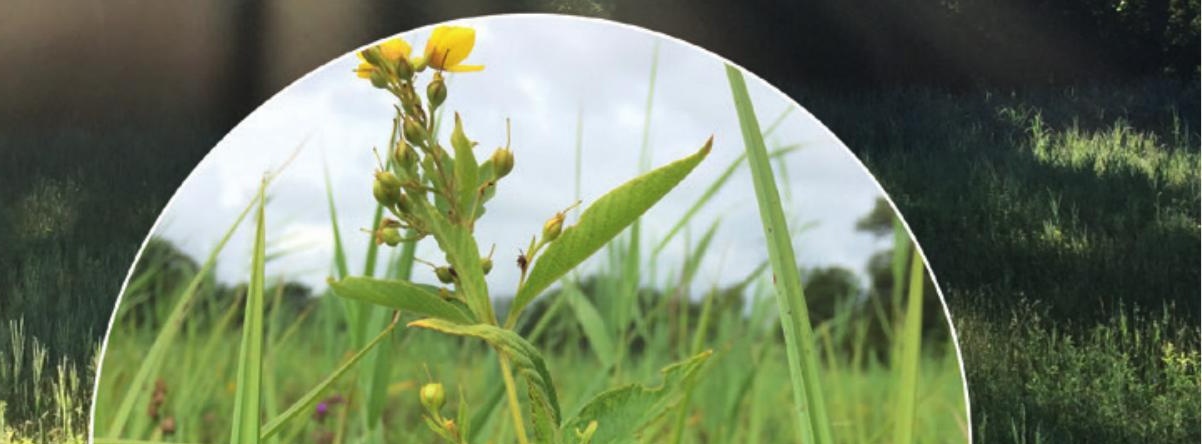


\section{Chapter 5}

Sexual reproduction trait expression of grassland species along a gradient of nitrogen : phosphorus stoichiometry

Shuqiong Wang, Jerry van Dijk, Martin J. Wassen

(Currently under Review) 


\begin{abstract}
Plant investment in sexual reproduction is affected by nitrogen $(\mathrm{N})$ : phosphorus (P) stoichiometry. It has been suggested that an important adaptation to strong $\mathrm{P}$ limitation is reduced investment in sexual reproduction. In a field survey we investigated the influence of $\mathrm{N}: \mathrm{P}$ on sexual reproduction performance within and between grassland species.

Eleven grassland species were selected in ten plots covering all three types of nutrient limitation ( $\mathrm{N}$ limitation, $\mathrm{N}$ and $\mathrm{P}$ co-limitation, and $\mathrm{P}$ limitation) distributed over three sites in the Netherlands. Nutrients in soil and above-ground biomass were determined, plus two environmental variables (soil $\mathrm{pH}$ and soil moisture). A range of sexual reproduction traits were measured as a proxy for investment in sexual reproduction. At the intraspecific level we found the following patterns: compared with N-limited plots, in P-limited/co-limited plots, flowering period in individuals was shorter in Lythrum salicaria, flowering time was later in Plantago lanceolata, Lotus uliginosus, and Anthoxanthum odoratum, and Anthoxanthum odoratum had fewer inflorescences. At interspecific level, species occurring in P-limited/co-limited plots had a significantly earlier flowering time and a longer seed stalk and seed panicle, than those in N-limited plots. However, flowering period was shorter and number of flowers (inflorescences) per individual was less under P limitation/co-limitation than those under N limitation. Moreover, soil $\mathrm{pH}$ and soil moisture were found to significantly influence sexual reproduction performance of the selected grassland species: under acid conditions, flowering time was earlier, seed stalk and panicle was longer, but flowering period was shorter, which is similar to the condition with higher N:P; under higher soil moisture conditions, flowering time was earlier, while flowering period was shorter and number of flowers (inflorescences) per individual was less.

Our results show that $\mathrm{P}$ limitation/co-limitation restrict the sexual reproduction of grassland species, which may hamper their dispersal capacity. We recommend that future studies further analyze the relationship between soil $\mathrm{pH}$ and $\mathrm{N}: \mathrm{P}$ stoichiometry and the influence of soil $\mathrm{pH}$, as well as soil moisture on sexual reproduction performance of grassland species in addition to analyzing N:P stoichiometry.
\end{abstract}




\subsection{Introduction}

Human interference in the global cycles of $\mathrm{N}$ and $\mathrm{P}$ is exposing many terrestrial, freshwater, and marine ecosystems to a degree of nutrient enrichment that threatens their functioning (Pimm 1991; Rockström et al. 2009). N enrichment impacts ecosystems via dry and wet deposition and inflow of mineral $\mathrm{N}$ via surface water and groundwater (Vitousek and Howarth 1991; Dentener et al. 2006). The global P cycle, however, may even be more disruptive than that of $\mathrm{N}$, due to increased mining of P-containing rocks for fertilizer production (Falkowski et al. 2000). Classical theory suggests that productivity and interspecific competition are affected only by changes in the availability of the nutrient that is limiting primary production (Von Liebig 1842; Tilman 1982). However, more recently, this theory has been challenged: both $\mathrm{N}$ and $\mathrm{P}$ have been shown to limit (or co-limit) many ecosystems worldwide (Elser et al. 2007) and fertilization studies have shown that enrichment with a non-limiting nutrient affects growth and diversity too (Sterner 2008; Vitousek et al. 2010). Therefore, in eutrophication studies it is necessary to consider both $\mathrm{N}$ and $\mathrm{P}$ availabilities in conjunction.

Compared to other ecosystems, Europe grasslands have a rich flora and may develop a high species diversity (Pärtel et al. 1996; Schaminée et al. 1996). Many of these grasslands are naturally N-limited and their native flora has evolved mechanisms to cope with low $\mathrm{N}$ availability (Chapin 1980). It is therefore not surprising that the prevailing paradigm is that $\mathrm{N}$ enrichment diminishes or removes $\mathrm{N}$ limitation and enables fast-growing grasses with high $\mathrm{N}$ requirements to outcompete slow-growing forb species, which leads to loss of diversity (Bobbink et al. 2010; Stevens et al. 2010). However, the type of nutrient limitation has rarely been analyzed and empirical data from a wide array of European grasslands have revealed that $\mathrm{N}$ limitation, $\mathrm{P}$ limitation or $\mathrm{N}$ and $\mathrm{P}$ co-limitation occur frequently, whereas $\mathrm{K}$ limitation is very rare (Wassen et al. 2005). Moreover, European grasslands are prone to simultaneous enrichment of both $\mathrm{N}$ and $\mathrm{P}$, and there are regional variations in the geographic extent and magnitude of this enrichment. In line with these observations, Roeling et al. (2018) showed that the species composition and diversity of European grasslands depend not only on $\mathrm{N}$ and $\mathrm{P}$ availability in isolation, but also on their stoichiometric ratios. Wassen et al. (in press) found that, in line with stoichiometric niche theory, these stoichiometric ratios influence species pools at the continental level and especially affect the distribution of threatened species. 
These effects of stoichiometric ratios have been attributed to adaptations of plant species to environments of low nutrient availability or to specific types of nutrient limitation, and to trade-offs with growth and competitive ability (Grime 2001; Fujita et al. 2014; Roeling et al. 2018). Several plant traits have been identified that enhance nutrient acquisition, improve nutrient retention and/or nutrient use efficiency, and together contribute to a conservative nutrient strategy (Aerts and Chapin III 2000; Grime 2001; Lambers et al. 2008). These traits have been used to explain the ability of species to cope with low $\mathrm{N}$ availability (symbiotic $\mathrm{N}_{2}$ fixation, chitinase production: Leake and Read 1990; Aerts and Chapin III 2000) or low P availability (organic acid and phosphatase production: Lambers et al. 2008; Fujita et al. 2014; Wang and Lambers 2020), but irrespective of the type of nutrient limitation, most traits (high root: shoot ratio, formation of cluster roots, resorption from senescing tissues) may be beneficial (Aerts and Chapin III 2000; Lambers et al. 2008). A competition experiment for two grasses along an N:P stoichiometric gradient could only partly explain the competitive advantages of plant traits (Olde Venterink and Güsewell 2010). Under changing environmental conditions, a species' plasticity in its traits becomes a key determinant for its future performance (Callaway et al. 2003; Berg and Ellers 2010), which leads us to suggest that phenotypic plasticity for acquiring and using nutrients is beneficial in a world in which nutrient availabilities are in flux. For one particular trait (phosphatase production), Fujita et al. (2010a) showed that N:P stoichiometry is the most important determinant for such plastic responses. Moreover, Fujita et al. (2014) showed that plants adapted to P-limited environments invest less in sexual reproduction. Specifically, by comparison with common species, species of P-limited environments have lower seed number and seed investment, start flowering later, have a shorter flowering period, and have a longer lifespan (perennials rather than annuals). The combination of these traits suggests that species adapted to P-limited environments are adapting by investing less in above-ground production and in sexual reproduction. Furthermore, Wang et al. (2019) showed species can also respond to changes in absolute and relative $\mathrm{P}$ availability by exhibiting intraspecific plastic responses in investments in sexual reproduction. Such adaptations may enable species to survive in low P environments, provided that (1) other more competitive species are unable to grow under these circumstances and (2) eutrophication by P does not occur. In the present study we focused on sexual reproduction traits and investigated whether they vary not only between species but also within species along an N:P gradient in the field.

We hypothesized that along this gradient: 1) Species' responses in terms of investment in sexual reproduction are plastic, i.e. under P-limited conditions they invest less in sexual reproduction than they do under $\mathrm{N}$-limited conditions 
(intraspecific differences); 2) Characteristic species of P-limited environments invest less in sexual reproduction than do common species or species characteristic of N-limited conditions (interspecific differences). To test these hypotheses we analyzed the expression of five types of sexual reproduction traits of 11 selected grassland species along a gradient of relative $\mathrm{N}$ and $\mathrm{P}$ availability in natural herbaceous plant communities. We selected unfertilized grassland sites in nature reserves that taken together we expected to encompass an N:P gradient (De Mars and Garritsen 1997; Wassen 2017; Roeling et al. unpublished data). First flowering date (FFD), peak of flowering (PF) and last flowering date (LFD) were included because it has been shown that nutrient fertilization in nutrient-poor conditions may advance flowering (Putterill et al. 2004). The duration of the flowering period in individuals (FPI) and in the population (FPP) were included because it has been shown that duration of flowering is related to investment in sexual reproduction (Fujita et al. 2014). Stalk height with seed panicle (SHP) and stalk length with seed panicle (SLP) were included because we assumed that the greater the height at which the seeds are released, the greater the chance that the seeds will be dispersed over longer distances (Soons et al. 2004). Seed panicle length (SPL) was included because longer seed panicles might indicate more seed production. Percentage of flowered individual (PFI) was included to indicate the floral promotive effect along nutrient conditions (Krekule and Kohli 1981). Lastly, number of flowers or inflorescences per individual (NF(I)I) was included because in other studies (e.g. Burton 1943), traits like this appeared to be a good indicator of sexual reproduction.

\subsection{Materials and Methods}

\subsubsection{Study area and plot selection}

The study was carried out in moist non-fertilized grasslands in three nature reserves located in two regions c. $42 \mathrm{~km}$ apart: the Middenduin (MD) nature reserve in the west of the Netherlands, near Haarlem $\left(52^{\circ} 23^{\prime} \mathrm{N} 4^{\circ} 35^{\prime} \mathrm{E}\right.$ ), and Laegieskamp (LK) and Koeiemeent (KM) nature reserves, which are $40 \mathrm{~km}$ further east, near Naarden-Bussum (52 ${ }^{\circ} 16^{\prime} \mathrm{N} 5^{\circ} 8^{\prime} \mathrm{E}$ ) (Figure 5.1). Syntaxonomically the studied grasslands belong to Molinio-Arrhenatheretea / Parvocaricetea (Westhoff and Den Held 1969). The three sites were chosen because, taken together, they encompass a gradient from $\mathrm{N}$ to $\mathrm{P}$ limitation in which nutrient availability overall is relatively low. The two regions are subjected to similar $\mathrm{N}$ input from atmospheric deposition (1500-2000 mol/ha) (https://www.atlasnatuurlijkkapitaal.nl/grootschaligestikstofdepositie-nederland) and are not fertilized. All three nature reserves are mown annually in summer by a nature management organization, and the hay is 
removed. The two regions differ slightly in their major soil type: peaty sand (De Mars and Garritsen 1997) prevails in Naarden-Bussum, and sand (van Raalte 2014) in Middenduin. The altitude of both regions is between 0 and $1 \mathrm{~m}$ above mean sea level. Their mean annual precipitation is $887 \mathrm{~mm}$ and their mean annual temperature is $11.2^{\circ} \mathrm{C}$ (https://www.clo.nl/indicatoren/nl0004-meteorologischegegevens-in--nederland?ond=20883).

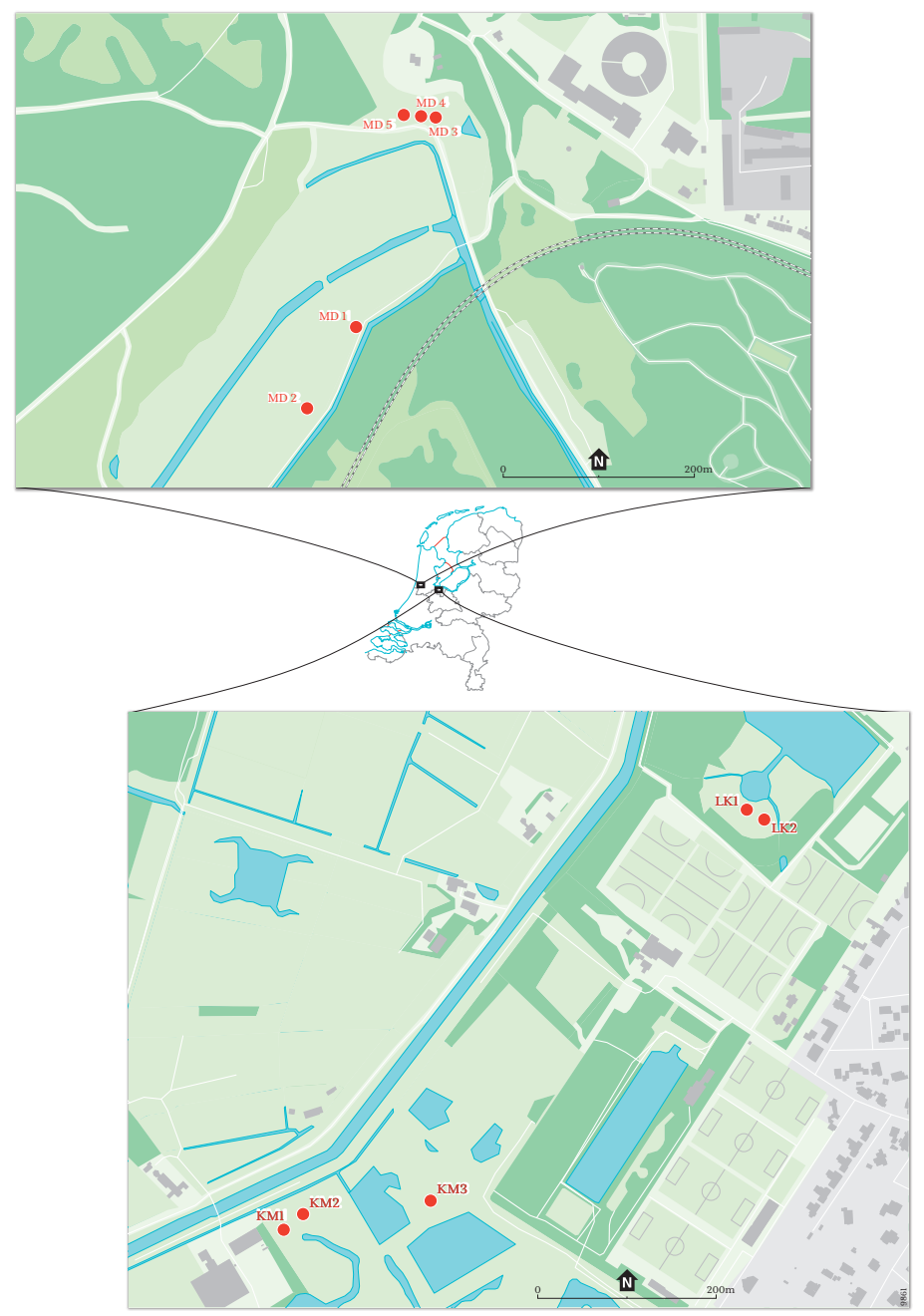

Figure 5.1 Locations of the 10 plots. Red dots are the two plots in Laegieskamp (LK) and the three plots in Koeiemeent (KM) and the five plots located in Middenduin (MD). The figure was made with the GIS package ArcGIS 9.2 (ESRI, Redlands, GA, U.S.A.). 
We selected a total of $102 \times 2 \mathrm{~m}^{2}$ plots: two in LK, three in KM, and five in MD. The location of each plot was recorded using GPS. Plots were chosen in homogeneous vegetation.

\subsubsection{Field surveys and chemical analyses}

\subsubsection{Species composition, vegetative productivity, and soil sampling}

Vegetation relevées were made on 19 and 20 June 2017, at the peak of the growing season. All herbaceous species were identified on the basis of Meijden (2005), and the cover was estimated with the Braun-Blanquet (1964) scale (Appendix 5.5).

To obtain a proxy for site productivity, above-ground standing biomass was harvested on 19 and 20 June 2017, which were the peaks of the growing seasons of the year (Roeling et al. 2018). The total above-ground biomass of each plot was estimated by clipping the above-ground vegetation in four $20 \mathrm{~cm} \times 20 \mathrm{~cm}$ squares, one at each of the four corners of each plot. Occasional shrubs and litter were excluded from biomass sampling. Samples were dried immediately at $75^{\circ} \mathrm{C}$ for 48 $\mathrm{h}$ in the lab and weighed. Our estimate of productivity is an underestimate of annual net above-ground productivity since we did not include bryophyte production (cf. Pałczynski and Stepa 1991; Wassen et al. 1995).

In May 2017, 4 soil samples (upper $10 \mathrm{~cm}$ ) were collected in the four corners of each plot, using a $2 \mathrm{~cm}$ diameter auger. The soil samples were collected in plastic bags and stored at $4{ }^{\circ} \mathrm{C}$ for a maximum of $48 \mathrm{~h}$ before analysis.

\subsubsection{Chemical analysis}

5.2.2.2.1 Determination of $N$ concentration, $P$ concentration, K concentration, N:P ratio, $\mathrm{N}: \mathrm{K}$ ratio, and K:P ratio in plant material

Vegetation material was ground to pass through a $0.5-\mathrm{mm}$ sieve. Total $\mathrm{N}$ concentration of dried plant material was measured with a $\mathrm{C} / \mathrm{N}$ elemental analyzer (NA1500, Carlo Erba-Thermo Fisher Scientific); total P concentration was measured by trace element analyzer (S2, PICOFOX, Bruker). Total K concentration was determined spectrophotometrically with a Sherwood Model 420 Flame Photometer.

We use these plant nutrient concentrations-referred to in this paper as plant $\mathrm{N}$, plant $\mathrm{P}$, and plant $\mathrm{K}$-as indicators of plant-available nutrient concentrations (Fujita et al. 2014). The plant N:P, N:K, and K:P ratios together express a gradient with varying degrees of $\mathrm{N}, \mathrm{P}$, and $\mathrm{K}$ deficiency for plant growth and can be used to assess whether the production of biomass in a community is $\mathrm{N}$-limited $(\mathrm{N}: \mathrm{P}<13.5)$, P-limited (N:P > 16), or co-limited $(13.5 \leq \mathrm{N}: \mathrm{P} \leq 16)$ (Güsewell and Koerselman 2002). For $\mathrm{K}$ limitation and $\mathrm{K}$ and $\mathrm{N}$ co-limitation, we referred to the standard of Olde Venterink et al. (2003), i.e. $\mathrm{N}: \mathrm{K}>2.1$ and $\mathrm{K}: \mathrm{P}<3.4$. 


\subsection{Determination of plant-available $N, P$, and N:P ratio in soil material}

To estimate plant-available $\mathrm{N}, c .4 \mathrm{~g}$ of moist soil per sample was placed into a $50 \mathrm{ml}$ centrifuge tube (polypropylene) and extracted with $40 \mathrm{ml} 2.0 \mathrm{M} \mathrm{KCl}$ by shaking the suspension immediately for $30 \mathrm{mins}$ at $160 \mathrm{rpm}$ (Barrett et al. 2002). Next, samples were centrifuged at $4000 \mathrm{rpm}$ for $4 \mathrm{~min}$ and then filtered through a 0.45 um nylon filter (National $25 \mathrm{ml}$ Nonsterile Centrifugal Filters, Thermo Scientific). The filtrate was stored at $-20{ }^{\circ} \mathrm{C}$ until further analysis. $\mathrm{NH}_{4}-\mathrm{N}$ and $\mathrm{NO}_{3}-\mathrm{N}$ concentrations in the extract were measured on a colorimetrical auto-analyzer (AA3, Bran \& Luebbe). N concentration in the soil was calculated as mg N/g dry wt. soil, using the specific moist soil weight of each sample and soil moisture concentration.

To estimate plant-available $\mathrm{P}$, c. $0.4 \mathrm{~g}$ of moist soil per sample was placed into a 50 $\mathrm{ml}$ centrifuge tube (polypropylene) and extracted with $40 \mathrm{ml}$ ammonium lactate-acetic acid by shaking the suspension for $4 \mathrm{~h}$ at $100 \mathrm{rpm}$ (Houba et al. 1979). Samples were then centrifuged at $4000 \mathrm{rpm}$ for $4 \mathrm{~min}$ and filtered through a 0.45 um nylon filter (National $25 \mathrm{ml}$ Nonsterile Centrifugal Filters, Thermo Scientific). The filtrate was stored at $4{ }^{\circ} \mathrm{C}$ until further analysis. P concentration in the extract was determined with ICP-OES (Spectro Acros, Spetro). P concentration in the soil was calculated as mg P/g dry wt. soil, using the specific moist soil weight of each sample and soil moisture concentration.

\subsection{Determination of other environmental variables}

The investigation was completed by determining soil $\mathrm{pH}$ and soil moisture content, which are known to be relevant for grassland species richness and community composition (Silvertown 1980; Cornwell and Grubb 2003; Duprè et al. 2010).

- Soil moisture: c. $5 \mathrm{~g}$ of moist soil was oven dried at $70^{\circ} \mathrm{C}$ for $48 \mathrm{~h}$ to determine gravimetric water content.

- Soil pH: soil and water were mixed in a ratio 1 : 2.5 (c. $4 \mathrm{~g}$ air-dry soil and $10 \mathrm{~g}$ water) and then shaken for $2 \mathrm{~h}$. Soil $\mathrm{pH}$ was measured in suspensions (Houba et al. 1979).

\subsubsection{Field surveys of sexual reproduction traits}

\subsubsection{Selected species and their flowering status}

We monitored the flowering phenology and a set of traits representative for the investment in sexual reproduction of a preselected set of 11 species with relatively high occurrence in the 10 plots. The species list and information about their flowering status are presented in Table 5.2. 


\subsubsection{Investigation of sexual reproduction performance}

The sexual reproduction performance of the selected species was monitored almost weekly from the middle of April to the end of August 2017. After the growing season, the frequency of investigation was gradually reduced from once/ week to once/two weeks, and to once/month, ending at the end of November 2017. The variables and traits recorded in each plot are discussed below.

\subsection{Budding, flowering, and faded individuals}

We define a budding individual as an individual of a species with only buds at the time of recording, a flowering individual was an individual of a species with open flowers or inflorescences at the time of recording, and a faded individual was an individual of a species with only faded flowers or inflorescences at the time of recording. These three variables of each selected species occurring in each plot were counted as accurately as possible at every field visit, from the first flowering data (FFD) to the last flowering date (LFD) of that species (for definitions of FFD and LFD, see below). Using these three variables of each species, we generated an overview of the flowering phenology of that species over the whole growing season.

\subsection{First flowering date (FFD)}

We define the day on which the first flower or inflorescence of a certain species occurred in a certain plot as the first flowering date of that species in that plot. Since the interval between consecutive visits was $c$. 1 week, if a species did not have flowering individuals in one visit but did the next time, the first flowering date (FFD) of that species in that plot was taken to be the median date of those two visits' dates. The date of the earliest flowering individual of all monitored species in all plots combined (which was that of Anthoxanthum odoratum in plot KM3) was assigned the value 0 . For statistical analysis, we then converted the other FFDs, which were originally in Julian dates, into numbers (i.e. days after day 0).

\subsection{Last flowering date (LFD)}

We define the day on which the last flower or inflorescence faded in a certain plot as the last flowering date of that species in that plot. If necessary, as explained above, we used the median date of two consecutive visits. The LFD was converted into a day number relative to the earliest FFD, as mentioned above.

\subsection{Peak of flowering (PF)}

We define the day on which the maximum number of flowers or inflorescences of a certain species occurred in a certain plot as the peak of flowering of that species in that plot. To obtain this value, the number of flowers or inflorescences of each 
species occurring in each plot were counted as accurately as possible at every field visit from FFD until LFD.

\subsection{Flowering period in individuals (FPI) and in the population (FPP)}

In most studies, flowering duration is measured monthly or in seasons (Lahti et al. 1991; Fujita et al. 2014). However, in our previous greenhouse experiment (Wang et al. 2019), we observed that flowering duration measured in days provides much better data at the intraspecific level under various nutrient treatments. Given the lack of a commonly agreed or specific definition of flowering period, we used two indices to assess flowering period in days.

1) Flowering period in individuals (FPI): this method consisted of marking random flowers or inflorescences of a species per plot (how many flowers or inflorescences depended on the total number of flowers or inflorescences of that species in the plot and ranged between 1 and 8). A waterproof marker denoting the FFD of a certain flower or inflorescence was tied to the stalk of the flower or inflorescence on its first flowering day and the day on which that flower or inflorescence started to fade was recorded. The duration between these two dates was the FPI of that flower or inflorescence. The average of all the monitored flowers or inflorescences of a certain species in a certain plot was considered as the flowering period in individuals (FPI) of that species in that plot. However, the result of this trait measure was probably not accurate, since the flowering period of individual flower or inflorescence was short (mostly a few days) and there was an interval of c. one week between two consecutive visits.

2) Flowering period in the population (FPP): this method consisted of calculating the time in days between the first flowering date (FFD) and the last flowering date (LFD) of a certain species in a certain plot.

\subsection{Stalk height with seed panicle (SHP) and stalk length with seed panicle (SLP)}

We measured the stalk height with seed panicle relative to the soil surface (SHP). Next, after straightening the stalks manually so they were vertical we measured the distance between the soil surface to the top of the seed panicle (Heady 1957). The first method is indicative of seed release height, while the second one (which is a more standardized measurement) is indicative of a plant's investment in the structure of seed stalks.

\subsection{Seed panicle length (SPL)}

Seed panicle length was measured from the bottom to the top of each seed panicle. 


\subsection{Percentage of flowered individuals (PFI)}

We counted the number of budding individuals, flowering individuals, faded individuals, and vegetative individuals without sexual reproduction of each species in each plot in each time visiting. Percentage of flowered individuals (PFI) was calculated by dividing the largest number of the total of budding individuals, flowering individuals, and faded individuals, by the largest number of the total of budding individuals, flowering individuals, faded individuals, and vegetative individuals.

\subsection{Number of flowers or inflorescences per individual (NF(I)I)}

The total number of flowers or inflorescences $(\mathrm{NF}(\mathrm{I}))$ of a certain species was acquired by counting the number of all flowers or inflorescences of that species in a certain plot accurately during each visit. If a species had started to set seed, the seed panicles were counted as well. The largest number recorded was taken to be the $\mathrm{NF}(\mathrm{I})$ of that species in that plot. Number of flowers or inflorescences per individual (NF(I)I) was calculated by dividing NF(I) by the total number of flowered individuals, i.e. the total of budding individuals, flowering individuals, and faded individuals of each species in each plot.

\subsubsection{Data analysis}

One-tailed t-tests were used for comparing two data groups (group l of P limitation/ co-limitation and group 2 of N limitation) with normal distributions. The variables investigated were plant variables (plant $\mathrm{N}$, plant $\mathrm{P}$, plant $\mathrm{N}: \mathrm{P}$, and plant biomass), and soil variables (soil N, soil P, soil N:P, soil pH, and soil moisture); and intraspecific and interspecific differences in trait expression between group 1 and group 2 . We used one-way ANOVA for comparing three data groups (groupl of site LK, group 2 of site $\mathrm{KM}$, and group 3 of site $\mathrm{MD}$ ), which included plant variables (plant N, plant P, plant N:P, and plant biomass), and soil variables (soil N, soil P, soil N:P, soil pH, and soil moisture). Games-Howell procedure was applied for post-hoc testing since homogeneities of variances were significantly different. Simple linear regression analyses were used to determine the relationships between soil nutrient concentrations (i.e. soil $\mathrm{N}$, soil $\mathrm{P}$, and soil $\mathrm{N}: \mathrm{P}$ ), and plant nutrient concentrations (i.e. plant N, plant $\mathrm{P}$, and plant N:P) and plant biomass. Simple linear regression analyses were also used to identify relationships between plant $\mathrm{N}: \mathrm{P}$, soil $\mathrm{N}: \mathrm{P}$, soil $\mathrm{pH}$, soil moisture, and first weighted then averaged traits, i.e. FFD, PF, LFD, FPP, FPI, SLP, SPL, PFI, and NF(I)I of all species in each plot. All the analyses mentioned above were performed in SPSS 23.0 (SPSS, Chicago, U.S.A.); the corresponding figures were also created in SPSS. A detrended correspondence analysis (DCA) was carried out using CANOCO 5, to explore the relationship between environmental variables and species composition; the corresponding figure was also created in CANOCO. 


\subsection{Results}

\subsubsection{Nutrient conditions of the grasslands}

The DCA (Figure 5.2) gave a general view of the relationship between the species composition of the selected plots and the selected environmental variables (in addition to nutrients, we measured two other important environmental variables: soil pH and soil moisture) (Figure 5.2). Gradients of soil N:P ratio, plant N:P ratio, as well as soil pH are along the horizontal (first) axis, with plots with higher soil $\mathrm{N}: \mathrm{P}$ ratio and plant $\mathrm{N}: \mathrm{P}$ ratio, and lower soil $\mathrm{pH}$ located at the left side of the graph, while plots with lower soil N:P and plant N:P, and higher soil $\mathrm{pH}$ are located the right side of the graph. The vertical (second) axis was mainly determined by plant biomass and plant $\mathrm{N}$ concentration. This implies that plots located in the top half of the figure are characterized by higher above-ground biomass, but lower plant $\mathrm{N}$ concentration.

In detail, the selected plots covered all three types of nutrient limitation (Figure 5.3). N:P ratios in above-ground biomass indicate that the Laegieskamp plots (LK 1 and LK 2) are limited by $\mathrm{P}$ and $\mathrm{KM} 1$ and $\mathrm{KM} 2$ are co-limited by $\mathrm{N}$ and $\mathrm{P}$. The other six plots are limited by N (KM3, MD1-5) (Figure 5.3). Examining the plot results after the plots had been divided into two nutrient limitation classes (P limitation/ co-limitation ( $\mathrm{N}: \mathrm{P} \geq 13.5$; i.e. LK1, LK2, KM1, KM2) and $\mathrm{N}$ limitation ( $\mathrm{N}: \mathrm{P}<13.5$; i.e. KM3, MD1, MD2, MD3, MD4, MD5)) revealed that the plots with P limitation/ co-limitation had significantly higher mean plant $\mathrm{N}$ :P than plots with $\mathrm{N}$ limitation (Table 5.1). No K limitation or K and N co-limitation was found in the selected plots (data not shown).

$\mathrm{N}$ concentrations in above-ground biomass were similar for all plots, with largest variation occurring in the Middenduin area. Although $\mathrm{N}$ concentrations in above-ground biomass were significantly higher in Laegieskamp and Middenduin than in Koeiemeent, the differences were small (in LK and MD, $+11.00 \%$ and $7.29 \%$ higher than KM; Appendix 5.1). On the other hand, P concentration in aboveground biomass of Laegieskamp was significantly lower than that in Koeiemeent and Middenduin, and the differences were large (in LK, 53.69\% lower than in $\mathrm{KM}$ and 59.76\% lower than in MD; Appendix 5.1). The minor difference in $\mathrm{N}$ concentration but big differences of $\mathrm{P}$ concentration in above-ground biomass between sites indicate that the high N:P ratio in Laegieskamp is mainly attributable to low $\mathrm{P}$ availability. In Koeiemeent, the above-ground biomass is significantly lower than in the other areas (Appendix 5.1) and the P-limited plots have lower biomass than N-limited plots (Table 5.1). 


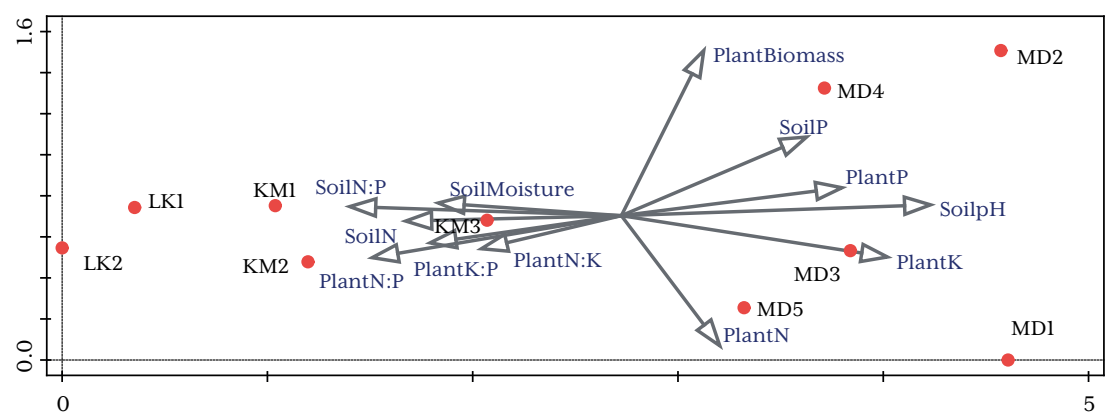

Figure 5.2 Detrended correspondence analysis (DCA) biplot, showing the relationship between environmental variables (gray arrows) and species composition of the plots (red dots). Arrow length reflects the magnitude of the correlation between environmental variable and plots distribution. The value of the variable increases along the arrow.

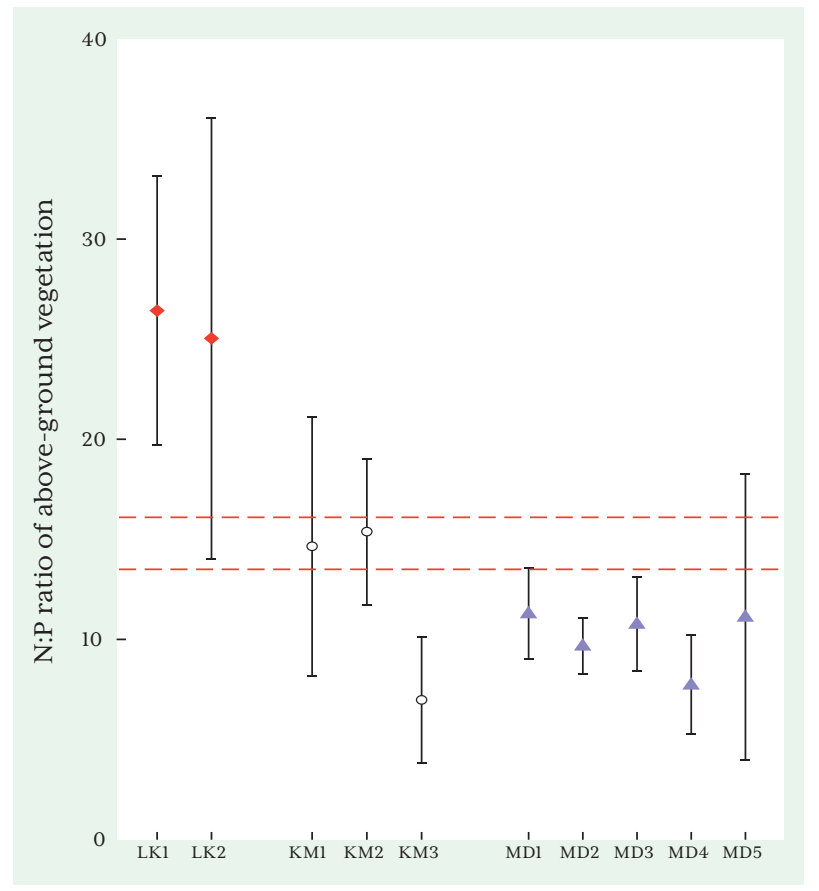

Figure 5.3 N:P ratio in above-ground living phanerogam biomass per plot. Plot codes refer to the areas: $\mathrm{LK}=$ Laegieskamp, $\mathrm{KM}=$ Koeiemeent, $\mathrm{MD}=$ Middenduin. Critical thresholds for P and N limitation cf. Olde Venterink et al. (2003) are indicated with red horizontal lines. P limitation relative to $\mathrm{N}$ when $\mathrm{N}: \mathrm{P}>16, \mathrm{~N}$ and $\mathrm{P}$ co-limitation when $13.5 \leq \mathrm{N}: \mathrm{P} \leq 16, \mathrm{~N}$ limitation relative to $\mathrm{P}$ when $\mathrm{N}: \mathrm{P}<13.5$. 
Plant-available P concentration in soil was a good predictor of plant nutrients and plant biomass (Appendix 5.2e-h). In detail, soil $\mathrm{P}$ was found to be significantly correlated with plant $\mathrm{N}\left(\mathrm{R}^{2}=0.187\right)$, plant $\mathrm{P}\left(\mathrm{R}^{2}=0.248\right)$, and plant biomass $\left(\mathrm{R}^{2}=\right.$ $0.618)$, but the correlation between soil $\mathrm{P}$ and plant $\mathrm{N}: \mathrm{P}$ was weak $\left(\mathrm{R}^{2}=0.088\right)$. On the other hand, there was a much weaker relationship between soil $\mathrm{N}$ and plant $\mathrm{N}$ and between soil $\mathrm{N}$ and plant biomass (Appendix 5.2a, d). We found a significantly negative relationship between soil $\mathrm{N}$ and plant $\mathrm{P}$ and a significantly positive relationship between soil $\mathrm{N}$ and plant $\mathrm{N}: \mathrm{P}$ (Appendix 5.2b, c).

The three areas differ significantly in soil pH, with Laegieskamp and Koeiemeent having acidic environments and Middenduin having alkaline conditions (Appendix 5.1). P-limited plots had a significantly lower $\mathrm{pH}$ than $\mathrm{N}$-limited plots (Table 5.1). Soil moisture was higher in Laegieskamp than in Koeiemeent and Middenduin throughout the season and was higher in P-limited plots than in N-limited plots (Table 5.1, Appendix 5.1, Appendix 5.3).

\subsubsection{Species composition of the grasslands}

Species composition differed considerably between the areas (Appendix 5.5). Laegieskamp is a fen meadow dominated by Cirsium dissectum, Carex panicea, Molinea caerulea, Juncus acutiflorus, Danthonia decumbens, and Anthoxanthum odoratum. Four species occur both in the Koeiemeent plots and the Laegieskamp plots: Juncus acutiflorus, Agrostis stolonifera, Anthoxanthum odoratum, and Ranunculus flammula. In terms of species composition, KM1 and KM2 are more similar to Laegieskamp than is KM3. The latter lacks Carex panicea and has Trifolium repens, Hypochaeris radicata, Betula pubescens, Ranunculus acris, and Cerastium fontanum which are absent in LK, KM1, and KM2. Although Koeiemeent has typical grassland species, it also has some fen species, such as Carex echinata, Pedicularis palustris, and Drosera rotundifolia. The Middenduin plots have only few species in common with Laegieskamp and Koeiemeent plots, such as Agrostis stolonifera, Lythrum salicaria, and Holcus lanatus. The Middenduin plots most closely resemble KM3. Five species are present in all Middenduin plots but absent in Laegieskamp and Koeiemeent: Parnassia palustris, Trifolium pratense, Euphrasia stricta, Phragmites australis, and Festuca rubra. None of the species were present in all plots and only a very few species were present in all three areas. These are Lysimachia vulgaris, Agrostis stolonifera, Lotus uliginosus, and Plantago lanceolata. In terms of the selected species, Succisa pratensis, Juncus acutiflorus, Ranunculus flammula, Anthoxanthum odoratum, and Carex panicea mainly occurred under P limitation/co-limitation, while Parnassia palustris, Lysimachia vulgaris, Plantago lanceolata, and Holcus lanatus were mainly found under $\mathrm{N}$ limitation. Lythrum salicaria and Lotus uliginosus as mentioned above, occurred both under P limitation/co-limitation and N limitation (Table 5.2, Appendix 5.5). 
Table 5.1 Differences in N- and P-concentrations ( $\mathrm{mg} / \mathrm{g}$ ), and N:P ratios in above-ground living phanerogam biomass, above-ground living phanerogam biomass $\left(\mathrm{g} / \mathrm{m}^{2}\right)$, soil $\mathrm{N}$ and $\mathrm{P}$ concentration $(\mathrm{mg} / \mathrm{g})$, soil $\mathrm{N}: \mathrm{P}$ ratio, soil $\mathrm{pH}$, and soil moisture (mg/g) between P-limited/co-limited plots ( $\mathrm{N}: \mathrm{P} \geq 13.5$; i.e. LK1, LK2, KM1, KM2) and N-limited plots (N:P < 13.5; i.e. KM3, MD1, MD2, MD3, MD4, MD5).

\begin{tabular}{lll}
\hline & P-limited/co-limited plots & N-limited plots \\
\hline Plant N & $12.94 \pm 1.00$ & $13.15 \pm 1.72$ \\
\hline Plant P* & $0.70 \pm 0.16$ & $1.44 \pm 0.29$ \\
\hline Plant N:P* & $20.38 \pm 5.45$ & $9.60 \pm 1.69$ \\
\hline Plant Biomass* & $235.94 \pm 91.03$ & $306.69 \pm 97.10$ \\
\hline Soil N* & $0.06 \pm 0.06$ & $0.02 \pm 0.01$ \\
\hline Soil P* & $0.02 \pm 0.01$ & $0.05 \pm 0.04$ \\
\hline Soil N:P* & $3.16 \pm 1.48$ & $0.70 \pm 0.94$ \\
\hline Soil pH* & $4.53 \pm 0.19$ & $7.46 \pm 1.12$ \\
\hline Soil moisture* & $43.01 \pm 14.89$ & $29.59 \pm 3.28$ \\
\hline
\end{tabular}

Significant differences are indicated by * (one-tailed t-test $P<0.01$ ).

\subsubsection{Intraspecific and interspecific sexual reproduction performance of the selected grassland species along the gradient in $\mathrm{N}: \mathrm{P}$ ratio}

Because of the absence of overlap in species composition between plots, only a limited number of the 11 species that were monitored (Table 5.3) could be statistically compared for intraspecific differences in trait expression between P-limited/co-limited plots and N-limited plots (Hypothesis 1). In plots with $\mathrm{P}$ limitation/co-limitation, individuals of Lythrum salicaria had a significantly shorter flowering period in individuals (Table 5.3), Plantago lanceolata started to flower later, and flowering of Lotus uliginosus and Anthoxanthum odoratum peaked later (Table 5.3). In these plots, Anthoxanthum odoratum had fewer inflorescences per individual and Plantago lanceolata had longer seed stalks and the height of the seeds above the soil surface was greater (Table 5.3).

To test our second hypothesis, we analyzed interspecific differences in trait expression between species from $\mathrm{P}$ limitation/co-limitation and species from $\mathrm{N}$ limitation. In species from sites with P limitation/co-limitation, the first flowering date, peak of flowering, and last flowering date were all significantly earlier than in the species from N-limited plots (Table 5.4). 
Table 5.2 Number of flowered plant individuals of the selected species in the 10 plots in the three sites.

\begin{tabular}{|c|c|c|c|c|c|c|c|c|c|c|}
\hline & \multicolumn{2}{|c|}{ Site LK } & \multicolumn{3}{|c|}{ Site KM } & \multicolumn{5}{|c|}{ Site MD } \\
\hline & LK1 & LK2 & KMl & KM2 & KM3 & MD1 & MD2 & MD3 & MD4 & MD5 \\
\hline Anthoxanthum odoratum & $\sqrt{ }$ & $\sqrt{ }$ & $\sqrt{ }$ & $\sqrt{ }$ & $\sqrt{ }$ & & & & & \\
\hline Holcus lanatus & & & $\sqrt{ }$ & & $\sqrt{ }$ & & & $\sqrt{ }$ & $\sqrt{ }$ & $\sqrt{ }$ \\
\hline Lysimachia vulgaris & $\checkmark$ & & $\checkmark$ & & & $\sqrt{ }$ & $\sqrt{ }$ & & $\sqrt{ }$ & \\
\hline Plantago lanceolata & $\sqrt{ }$ & & & & $\sqrt{ }$ & $\sqrt{ }$ & $\sqrt{ }$ & $\sqrt{ }$ & $\checkmark$ & $\sqrt{ }$ \\
\hline Lythrum salicaria & $\sqrt{ }$ & & & & & & $\checkmark$ & $\sqrt{ }$ & $\sqrt{ }$ & $\checkmark$ \\
\hline Parnassia palustris & & & & & & $\sqrt{ }$ & $\sqrt{ }$ & $\sqrt{ }$ & $\sqrt{ }$ & $\sqrt{ }$ \\
\hline Succisa pratensis & & $\sqrt{ }$ & $\sqrt{ }$ & & & & & & & \\
\hline Ranunculusflammula & $\sqrt{ }$ & $\sqrt{ }$ & $\sqrt{ }$ & $\sqrt{ }$ & $\sqrt{ }$ & & & & & \\
\hline Lotus uliginosus & $\checkmark$ & $\checkmark$ & $\sqrt{ }$ & $\checkmark$ & $\sqrt{ }$ & $\sqrt{ }$ & $\sqrt{ }$ & $\sqrt{ }$ & & $\checkmark$ \\
\hline Juncus acutiflorus & $\sqrt{ }$ & $\sqrt{ }$ & $\sqrt{ }$ & $\sqrt{ }$ & $\sqrt{ }$ & & & & & \\
\hline Carexpanicea & $\sqrt{ }$ & $\sqrt{ }$ & $\sqrt{ }$ & $\sqrt{ }$ & & & & & & \\
\hline
\end{tabular}

" $\sqrt{ }$ " means the number of flowered plant individuals is relative high $(>5)$, while " $/$ " indicates a relatively low number of flowered plant individuals $(\leq 5)$.

Intraspecific and interspecific differences in trait expression along the N:P, soil $\mathrm{pH}$ and soil moisture gradients were further explored by plotting the traits against the N:P in plant material, N:P in soil, soil pH and soil moisture. We included soil $\mathrm{pH}$ and soil moisture since these environmental factors were found to differ significantly between the plots with P limitation/co-limitation and the N-limited plots (Table 5.1).

Strong correlations were found between environmental factors (especially soil $\mathrm{N}: \mathrm{P}$ and soil $\mathrm{pH}$ ) and first weighted then averaged sexual reproduction traits of all the species in each plot (Appendix 5.4). In detail, flowering phenology, i.e. first flowering data (FFD), peak of flowering (PF), last flowering date (LFD), flowering period in the population (FPP), and flowering period in individuals (FPI) were all significantly negatively correlated with increasing plant and soil N:P (Appendix 5.4a, b, e, f, i, j, m, n, q, r), as well as with increasing soil moisture (Appendix 5.4d, $\mathrm{h}, \mathrm{l}, \mathrm{p}, \mathrm{t}$ ), indicating an earlier flowering time, but shorter flowering period under $\mathrm{P}$ limitation and high moisture condition. However, the traits mentioned above were all positively correlated with increasing soil pH (Appendix 5.4c, g, k, o, s). Moreover, seed stalk length with seed panicle (SLP), seed panicle length (SPL), and percentage of flowered individual (PFI) were all positively correlated with 


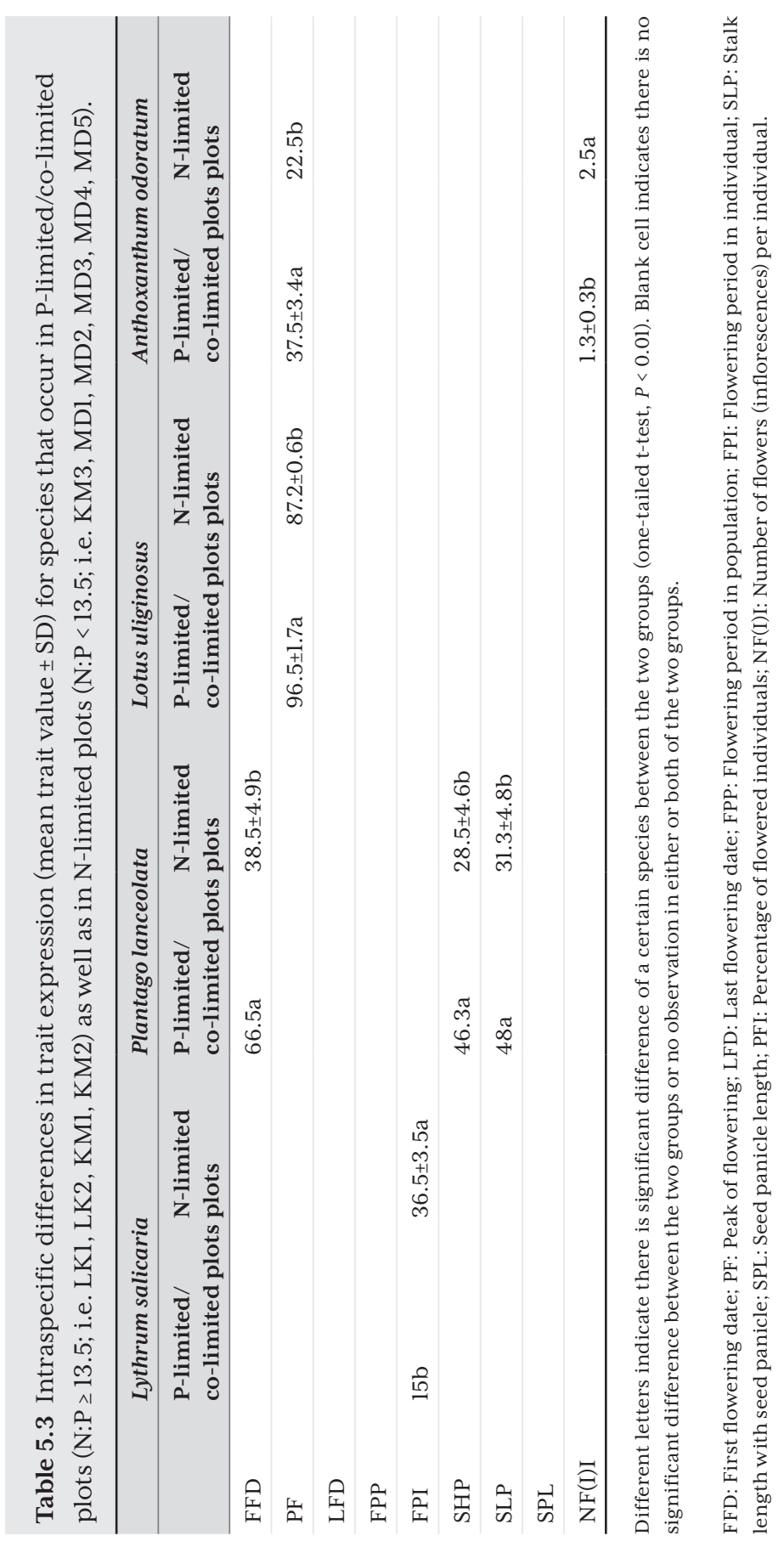


Table 5.4 Interspecific differences in trait expression (mean trait value \pm SD) between characteristic species of P-limited/co-limited condition (i.e. Succisa pratensis, Juncus acutiflorus, Ranunculus flammula, Anthoxanthum odoratum and Carex panicea), and characteristic species of N-limited condition (i.e. Parnassia palustris, Lysimachia vulgaris, Plantago lanceolata and Holcus lanatus).

\begin{tabular}{lll}
\hline & Species of P-limited/co-limited plots & Species of N-limited plots \\
\hline FFD $^{*}$ & $44.0 \pm 29.7$ & $74.1 \pm 35.1$ \\
PF* $^{*}$ & $45.2 \pm 32.5$ & $91.8 \pm 35.3$ \\
\hline LFD $^{*}$ & $87.5 \pm 33.2$ & $121.0 \pm 38.9$ \\
\hline FPP & $43.5 \pm 21.9$ & $47.0 \pm 31.8$ \\
\hline FPI & $14.1 \pm 3.6$ & $14.1 \pm 6.6$ \\
\hline SLP & $34.2 \pm 9.8$ & $33.3 \pm 10.4$ \\
SPL & $2.6 \pm 0.6$ & $1.9 \pm 1.6$ \\
PFI & $54.8 \pm 35.7$ & $36.9 \pm 29.4$ \\
NF(I)I & $2.2 \pm 1.0$ & $1.9 \pm 1.0$ \\
\hline
\end{tabular}

* indicates there is significant difference of a certain sexual reproduction traits between the species of the two groups (one-tailed t-test, $P<0.01$ ).

FFD: First flowering date; PF: Peak of flowering; LFD: Last flowering date; FPP: Flowering period in population; FPI: Flowering period in individual; SLP: Stalk length with seed panicle; SPL: Seed panicle length; PFI: Percentage of flowered individuals; NF(I)I: Number of flowers (inflorescences) per individual.

increasing soil N:P (Appendix 5.4v, z, ad), and negatively correlated with soil pH (Appendix 5.4w, aa, ae), while no effect of plant N:P and soil moisture was found on those three traits. Furthermore, negative effects of plant N:P and soil moisture were found on number of flowers (inflorescences) per individual (NF(I)I) (Appendix 5.4ag, aj). Note that the trends mentioned above are based on the species pooled without accounting for differences in species occurrence between the plots (see Table 5.2). When the trait expression of individual species was inspected more closely in species (Appendix 5.4) several observations can be made. Notably, many species do not show large phenological trait plasticity of flowering time (FFD, PF, LFD) and seed panicle length (SPL) along the N:P gradient (in both plant and soil). However, it seems like Plantago lanceolata, Anthoxanthum odoratum, Lythrum salicaria, and Lotus uliginosus all flower later in P-limited/ co-limited conditions (Appendix 5.4a, b, e). Lotus uliginosus and Plantago lanceolata are examples of species with significantly earlier last flowering date (LFD), while Ranunculus flammula is a species with significantly later LFD under P limitation/ 
co-limitation (Appendix 5.4i, j). The late LFD of Ranunculus flammula leads to a very long flowering period in the population (FPP) of this species under P limitation/ co-limitation (Appendix $5.4 \mathrm{~m}, \mathrm{n}$ ). Both flowering period in the population (FPP) and in individuals (FPI) differ largely within and between species (Appendix $5.4 \mathrm{~m}, \mathrm{n}, \mathrm{q}, \mathrm{r}$ ). Different from other species, FPP of Ranunculus flammula is longer under P limitation/co-limitation (Appendix 5.4m, n), as mentioned above, while FPI of Anthoxanthum odoratum is longer under P limitation/co-limitation (Appendix $5.4 \mathrm{q}, \mathrm{r}$ ). Likewise, the percentage of flowered individuals (PFI) and the plasticity in number of flowers (inflorescences) per individual (NF(I)I) differ largely within and between species and show very different responses along the N:P gradient (positive as well as negative), leading to non-significant or poorly correlated average trends (Appendix 5.4ac, ad, ah). Stalk length including the seed panicle (SLP) is a trait that species generally appear to share with comparable tendencies along increasing soil N:P, with the exception of Lythrum salicaria and Ranunculus flammula, which showed low phenological trait plasticity (Appendix 5.4v). Furthermore, it becomes again evident from inspecting these figures that for soil $\mathrm{pH}$ and moisture our data consist of two 'clumps': alkalic (Middenduin) versus rather acidic (Laegieskamp and Koeiemeent) and wet (Laegieskamp) versus moist (Koeiemeent and Middenduin) and that most species, even those present in $\geq 3$ plots occur in one of these 'clumps' and are not found along the entire gradient. Therefore, the weighted averaged trends were mostly determined by interspecific differences, except for the influences of species occurring in both 'clumps' with significant intraspecific variation along soil pH or moisture, e.g. Plantago lanceolata (Appendix 5.4c, g, k, o, s, w, d, p, aj), Lythrum salicaria (Appendix 5.4c, k, o, s, aa, ae, $\mathrm{d}, \mathrm{p}, \mathrm{t}$ ), and Holcus lanatus (Appendix 5.4c, g, k, o, w, aa). In general, we conclude from Appendix 5.4 that inter- as well as intraspecific variation in trait expression is large and that species behave very different in their trait expression along the nutrient and environmental gradients we measured.

\subsection{Discussion}

In the field, we tracked and measured a list of plant traits that can be regarded as a set of proxies for the investment in sexual reproduction and dispersal capacity in ten plots that covered all three types of nutrient limitation ( $\mathrm{N}$ limitation, $\mathrm{N}$ and $\mathrm{P}$ co-limitation, and P limitation) and were distributed over three grassland sites in the Netherlands. We did this to test whether there were significant intraspecific and interspecific variations in the expression of sexual reproduction traits of grassland species along an N:P gradient. 


\subsubsection{Nutrient conditions in the plant and in the soil of the investigated grassland plots}

In this field survey, in which we used a method of measuring nutrient concentrations in above-ground biomass to indicate the general nutrient conditions for plant growth that has been applied in various studies (e.g. Verhoeven et al. 1996; Olde Venterink et al. 2003; Fujita et al. 2014; Roeling et al. 2018), we did indeed find a gradient of $\mathrm{N}: \mathrm{P}$ stoichiometry, from $\mathrm{N}$ limitation (Middenduin) to $\mathrm{N}$ and $\mathrm{P}$ co-limitation (Koeiemeent), and P limitation (Laegieskamp). However, because there were fewer P-limited plots than N-limited plots, and because of the proximity and similar plant growth conditions of Koeiemeent ( $\mathrm{N}$ and $\mathrm{P}$ co-limitation) and Laegieskamp (P limitation), we mainly focused on comparing differences between $\mathrm{N}$ limitation and $\mathrm{P}$ limitation/co-limitation. In addition, soil nutrients were measured in order to provide extra information to further indicate nutrient conditions, revealing that the trends in soil N:P and N:P in above-ground biomass were quite similar (see Appendix 5.2i). Moreover, measurements of soil nutrients supported the exploration of relationships between nutrient conditions and sexual reproduction traits, e.g. seed stalk and seed panicle length, and percentage of flowered individual were all more correlated with soil N:P rather than plant $\mathrm{N}$ :P in this survey (Appendix 5.4v, z, ad). Surprisingly, soil P was found to correlate significantly with plant $\mathrm{N}\left(\mathrm{R}^{2}\right.$ soil P-plant $\left.\mathrm{N}=0.187\right)$, plant $\mathrm{P}\left(\mathrm{R}^{2}\right.$ soil P-plant $\left.\mathrm{P}=0.248\right)$, as well as with above-ground vegetative biomass $\left(\mathrm{R}^{2}\right.$ soil P-plant biomass $\left.=0.618\right)$, whereas soil $\mathrm{N}$ seldom had influence (Appendix 5.2). This partly agrees with the results reported by Bollens et al. (2001), who found a positive correlation between the $\mathrm{P}$ concentration in plant biomass and extractable $\mathrm{P}$ in soil. However, unlike them, we did not find a positive correlation between $\mathrm{N}$ in biomass and extractable soil $\mathrm{N}$. The dominant influence of soil $\mathrm{P}$ rather than soil $\mathrm{N}$ on plant nutrient concentrations and growth is in line with the results of a greenhouse experiment we carried out, in which we found a strong correlation between P fertilization and plant tissue formation, but a much weaker correlation between $\mathrm{N}$ fertilization and tissue formation (Wang et al. 2021). The mechanism underlying this phenomenon might be the P-rich rRNA, as rapid protein synthesis by ribosomes is required to support fast growth of wild plant species (Elser et al. 2000).

\subsubsection{Species composition of the investigated grassland plots}

In general, species richness was the lowest in the P-limited area Laegieskamp (14 species) while the highest species numbers were found in the N-limited area Middenduin (26 \pm 4 species) (Appendix 5.5). The reason may be either that the $\mathrm{P}$ limitation in Lagjeskamp restricts species richness (cf. Wassen et al. 2005; Ceulemans et al. 2011; Olde Venterink 2011; Roeling et al. 2018), or that acidic soil has a negative influence (cf. Stevens et al. 2010; Roeling et al. 2018). However, 
because the Laegieskamp area had both low $\mathrm{P}$ and low $\mathrm{pH}$, it is not possible to disentangle their individual effects on species richness. Roem and Berendse (2000) demonstrated that in grassland and heathland communities in the Netherlands, the variable most strongly correlated with plant species diversity is acidity, and speculated that increased N:P imposed an additional negative effect. Given the global issue of chronic $\mathrm{N}$ deposition, and the acidifying effect of $\mathrm{N}$ deposition on soil acidity of poorly buffered soils (Stevens et al. 2010), the synergistic effect of $\mathrm{N}$ deposition and acidity on species richness may deserve more attention in nature conservation (Duprè et al. 2010; Stevens et al. 2010).

The species occurrence patterns enabled us to roughly classify the species into two groups: species having their optimum in conditions of P limitation/co-limitation, and species with an optimum in N-limited conditions (Appendix 5.5). Species have specific trait-based strategies to cope with nutrient limitation (Aerts and Chapin 2000; Grime 2001; Lambers et al. 2008; Fujita et al. 2010; Fujita et al. 2014). For example, low N:P environments favor fast-growing species with long roots, or species that fix N (e.g. Trifolium repens (Kumar and Goh 2000) and the present study), whereas high N:P environments favor slow-growing species with specialized P uptake traits such as cluster roots, arbuscular mycorrhizae, or high phosphatase activity (e.g. Cirsium dissectum (John 1999) and the present study). Moreover, consistent with the finding of Wassen et al. (2005) that endangered species persist under P limitation, Succisa pratensis-one of the two endangered species in our survey-occurred only in the P-limited sites (LK2) and in a co-limited plot with the closest N:P to that of Laegieskamp (KM1). However, unexpectedly and contrary to this contention of Wassen et al. (2005), the other endangered species, Parnassia palustris, persisted in the N-limited sites-a finding that is in agreement with our greenhouse experiment in which we found P. palustris grew best at an N:P ratio of 5, rather than at N:P ratios of 15 or 45 (Wang et al. 2019). Given that most terrestrial ecosystems of the temperate zone are considered to be N-limited (Vitousek and Howarth 1991; Sala et al. 2000), it seems possible that $\mathrm{N}$ deposition promotes dominant species (Chapin et al. 1986; Bobbink et al. 2010; Stevens et al. 2010), thereby increasing the threat to species vulnerable to extinction that occur in $\mathrm{N}$-limited environments. The natural cycles of $\mathrm{N}$ and $\mathrm{P}$ are considered to be the global biogeochemical cycles that are most disturbed by anthropogenic activities (Steffen et al. 2015). In line with earlier research (Olde Venterink et al. 2003; Wassen et al. 2005; Lannes et al. 2012; Roeling et al. 2018), our observations that $\mathrm{N}$ - and P-limited herbaceous ecosystems have distinct species compositions and both harbor threatened species underline the need for environmental policy and conservation management to target the reduction of both $\mathrm{N}$ and $\mathrm{P}$ to prevent plant species being lost as a result of eutrophication. 


\subsubsection{Species invest less in sexual reproduction traits under P limitation/co-limitation than they do under $\mathrm{N}$ limitation (intra- specific differences)}

Unfortunately, in the present survey, none of the species was present in all plots and very few were present in all three areas, which made it difficult to study the sexual reproduction performance of the selected grassland species intraspecifically along the full N:P gradient from N limitation to $\mathrm{P}$ limitation/ co-limitation. Nevertheless, our results generally support our first hypothesis that under P limitation/co-limitation, species invest less in sexual reproduction than they do under $\mathrm{N}$ limitation.

Seven out of the 11 species occurred in sufficient plots to enable an analysis of intraspecific variation (intraspecific differences) of sexual reproduction trait expression between $\mathrm{N}$ limitation and P limitation/co-limitation, but significant differences were found for only four species: Lythrum salicaria, Plantago lanceolata, Lotus uliginosus, and Anthoxanthum odoratum. In general, compared with species occurring under $\mathrm{N}$ limitation, individuals occurring under $\mathrm{P}$ limitation/ co-limitation showed lower investments in sexual reproduction (i.e. shorter flowering period in individuals (Lythrum salicaria), later flowering starting time (Plantago lanceolata), later peak of flowering (Lotus uliginosus and Anthoxanthum odoratum), and a lower number of inflorescences per individual (Anthoxanthum odoratum) (Table 5.3). These species responses are in line with the finding of a greenhouse experiment with Holcus lanatus, a grass species that showed lower expression of several sexual reproduction traits at low P supply (Wang et al. 2019). Surprisingly, however, in the present field survey, Holcus lanatus showed no intraspecific differences in sexual reproduction performance. The possible reason might be the absence of this species in the most strongly P-limited area in our study (Laegieskamp). Other research has also shown that deficiency of P leads to a strong reduction in the number of flowers produced in a range of wetland species (Brouwer et al. 2001). The low investment in sexual reproduction under conditions of high N:P in our study further supports the idea that plant species can apply a strategy of economizing their P expenditure in response to P deficiency by investing less in sexual reproduction (Fujita et al. 2014; Wang et al. 2019), since classical allocation studies (Van Andel and Vera 1977; Fenner 1986a) have shown that sexual reproduction generally requires a higher percentage of $\mathrm{P}$ than of $\mathrm{N}$ and other elements plant acquired. 
However, unexpectedly and contrary to our hypothesis, Plantago lanceolata in the plots with P limitation/co-limitation had higher and longer seed stalks (SHP and SLP) than it had in N-limited plots (Table 5.3), whereas in our greenhouse experiment we found that $\mathrm{P}$ limitation restricted the development of the seed stalk length and height of Holcus lanatus (Wang et al. 2019). To our knowledge, although seed release height is the most important plant-controlled dispersal parameter for grassland plants (Soons et al. 2004), studies of the influence of nutrient limitation on seed stalk length and height are lacking, possibly because such measurements are labor-intensive.

Moreover, in our study, under different nutrient conditions, the responses in sexual reproduction traits differed between species. With regard to flowering time, for instance, Lotus uliginosus and Anthoxanthum odoratum responded to $\mathrm{P}$ limitation/co-limitation in terms of peak of flowering time (the date with the most flowers or inflorescences), whereas the only significant flowering time response in Plantago lanceolata was a significantly postponed first flowering date (the date on which the first inflorescence occurred in that community) (Table 5.3). The differences in species responses in our field study coupled with the lack of systematic experimental studies on the relationship between trait expression and nutrient supply and limitation in a wide range of species make it hard to draw general conclusions about the intraspecific plasticity of sexual reproduction traits along nutrient gradients in the field.

\subsubsection{Interspecific differences of sexual reproduction traits of the selected grassland species along an N:P gradient}

The results of our field survey also allow for the analysis of how trait expressions may change along an N:P gradient at interspecific level.

With regard to flowering phenology, in characteristic species of environments with P limitation/co-limitation, the first flowering dates (FFD), peaks of flowering $(\mathrm{PF})$, and the last flowering dates (LFD) were all earlier than those of characteristic species of N-limited environments (Table 5.4; Appendix 5.4a, b, e, f, i, j). This is in contrast with previous research that reported that species persisting in high N:P had later flowering starting time (Fujita et al. 2014). Moreover, seed stalk length (SLP) and seed panicle length (SPL) were longer in P limitation/co-limitation (Appendix 5.4v, z), which were opposite to the result of Wang et al. (2019) that Holcus lanatus had shorter seed stalks and seed panicle under P limitation. A possible reason for the earlier flowering time and longer stalk length and seed panicle length we found under conditions of P limitation/co-limitation might be the influence of soil $\mathrm{pH}$, which is known to have a significant effect on plant 
growth as well as on nutrient availability to plants (Evans and Conway 1980; Bernal and McGrath 1994). In our survey, N- and P-limited sites also differed significantly in soil $\mathrm{pH}$, with low $\mathrm{pH}$ coinciding with significantly higher soil $\mathrm{N}$ concentrations and significantly lower P concentrations (Table 5.1, Appendix 5.1). Furthermore, soil pH was significantly correlated with sexual reproduction performance of the grassland species: in acidic soils, flowering time was earlier, and seed stalks and panicles were longer (Appendix 5.4). This opposite but possibly stronger influence of soil $\mathrm{pH}$ on investment in sexual reproduction than that of plant and soil $\mathrm{N}: \mathrm{P}$ may have confounded the effect of high $\mathrm{N}: \mathrm{P}$ on the investment in sexual reproduction reported by Fujita et al. (2014) and Wang et al. (2019), even though-as noted above-at the intraspecific level, high N:P levels restricted flowering time significantly.

One the other hand, flowering period in the population (FPP) and in individuals (FPI), as well as number of flowers (inflorescences) per individual (NF(I)I) were restricted by P limitation/co-limitation (Appendix 5.4m, n, q, r, ag). The restriction of P limitation/co-limitation on flowering period is consistent with the conclusion of Fujita et al. (2014) that species persisting in P-limited communities had shorter flowering period than those of $\mathrm{N}$ limitation/co-limitation, as well as with the result of a study on Holcus lanatus, intraspecifically indicating that flowering period was shorter at both the population level and the individual level under $\mathrm{P}$ limitation (Wang et al. 2019).

In addition, soil moisture was found to have a considerable effect on the sexual reproduction performance of the selected grassland species. We found that in Laegieskamp and in plots with P limitation/co-limitation, the soil moisture content was significantly higher (Table 5.1, Appendix 5.1). Higher soil moisture was related with earlier flowering time (Appendix 5.4d, h, l), but shorter flowering period (Appendix 5.4p, t), and a lower number of flowers (inflorescences) per individual (Appendix 5.4aj). The shorter flowering period and lower number of flowers (inflorescences) per individual of species under higher soil moisture may indicate the restriction of higher soil moisture on the investment in sexual reproduction of grassland species, given that soil moisture has been shown to influence various plant physiological activities via temperature in the root zone (Hood 2001; Miralles et al. 2012). 


\subsection{Conclusions}

In line with our first hypothesis, there was significant intraspecific variation in sexual reproduction traits along the N:P gradient we studied, with expression of reproduction traits being generally lower under $\mathrm{P}$ limitation. However, which specific trait showed plastic responses along the gradient differed per plant species, making it difficult to interpret these results as providing unequivocal support for the notion that plants adopt a general strategy of reducing their investment in sexual reproduction, thereby economizing on their use of $\mathrm{P}$ to be able to persist under P-limited conditions.

In line with our second hypothesis, there was significant interspecific variation in sexual reproduction traits along the N:P gradient. P limitation/co-limitation led to shorter flowering period and lower number of flowers (inflorescences) per individual. However, earlier flowering time, and longer seed stalk and seed panicle length were also found under $\mathrm{P}$ limitation/co-limitation. The reason of the promotion of $\mathrm{P}$ limitation/co-limitation on earlier flowering time and longer seed stalk and seed panicle length could probably be the confounding effect of soil $\mathrm{pH}$. Moreover, it must be noted that the interpretation of trait expression patterns between plots may have been hampered by the limited number (only 11) of species included in the comparison. We deliberately restricted the number of species studied because it is extremely arduous to monitor these traits in a large number of individuals in a field situation.

We recommend more in-depth field surveys be carried out in future on a wider range of species and longer nutrient gradients. Such studies are currently rare because of the practical challenges associated with large-scale field monitoring of phenological traits. Complementing field studies with controlled fertilization experiments may alleviate those challenges and could shed more light on the potential confounding effects of other environmental variables covarying with nutrient availability in the field.

\section{Acknowledgments}

We acknowledge the China Scholarship Council (CSC) for a doctoral scholarship to Shuqiong Wang (CSC NO. 201406140142). We express appreciation for Dineke van der Meent for her professional guidance with soil nutrient measurement, Natuurmonumenten, and State Forestry Service for permission to enter the study areas and for protecting the study plots from annual mowing, Ineke Roeling for her helpful tips with field survey preparation, Sanne Poppeliers for her help at the beginning of the field survey, and Mojtaba Zaresefat for helping to make the GIS 
108 | Chapter 5

map. We are also grateful for Ton Markus for improving all the figures, and Joy Burrough for the professional English checking of a near-final draft of the manuscript. 


\section{Supplementary materials}

Appendix 5.1 Differences in N- and P-concentrations (mg/g), and N:P ratios in above-ground living phanerogam biomass, above-ground living phanerogam biomass $\left(\mathrm{g} / \mathrm{m}^{2}\right)$, soil $\mathrm{N}$ and $\mathrm{P}$ concentration $(\mathrm{mg} / \mathrm{g})$, soil $\mathrm{N}: \mathrm{P}$ ratio, soil $\mathrm{pH}$, and soil moisture $(\mathrm{mg} / \mathrm{g})($ mean $\pm \mathrm{SD})$ among site $\mathrm{LK}, \mathrm{KM}$, and MD.

\begin{tabular}{llll}
\hline & LK & KM & MD \\
\hline Plant N & $13.701 \pm 0.557 \mathrm{a}$ & $12.343 \pm 0.636 \mathrm{~b}$ & $13.243 \pm 1.868 \mathrm{a}$ \\
Plant P & $0.546 \pm 0.039 \mathrm{~b}$ & $1.179 \pm 0.477 \mathrm{a}$ & $1.357 \pm 0.244 \mathrm{a}$ \\
\hline Plant N:P & $25.733 \pm 0.709 \mathrm{a}$ & $12.339 \pm 3.862 \mathrm{~b}$ & $10.119 \pm 1.331 \mathrm{c}$ \\
\hline Plant Biomass & $320.969 \pm 3.550 \mathrm{a}$ & $190.563 \pm 66.553 \mathrm{~b}$ & $314.050 \pm 104.969 \mathrm{a}$ \\
\hline Soil N & $0.115 \pm 0.033 \mathrm{a}$ & $0.016 \pm 0.009 \mathrm{~b}$ & $0.017 \pm 0.011 \mathrm{~b}$ \\
Soil P & $0.032 \pm 0.003 \mathrm{~b}$ & $0.006 \pm 0.003 \mathrm{c}$ & $0.061 \pm 0.037 \mathrm{a}$ \\
Soil N:P & $3.785 \pm 1.449 \mathrm{a}$ & $2.602 \pm 1.021 \mathrm{~b}$ & $0.275 \pm 0.153 \mathrm{c}$ \\
\hline Soil pH & $4.368 \pm 0.108 \mathrm{c}$ & $4.803 \pm 0.174 \mathrm{~b}$ & $7.945 \pm 0.255 \mathrm{a}$ \\
\hline Soil moisture & $57.663 \pm 1.944 \mathrm{a}$ & $29.668 \pm 1.902 \mathrm{~b}$ & $29.049 \pm 3.338 \mathrm{~b}$ \\
\hline
\end{tabular}

Significant differences between sites are indicated by different letter codes. Values with the same character are not significantly different $(P=0.05)$. 
110 | Chapter 5

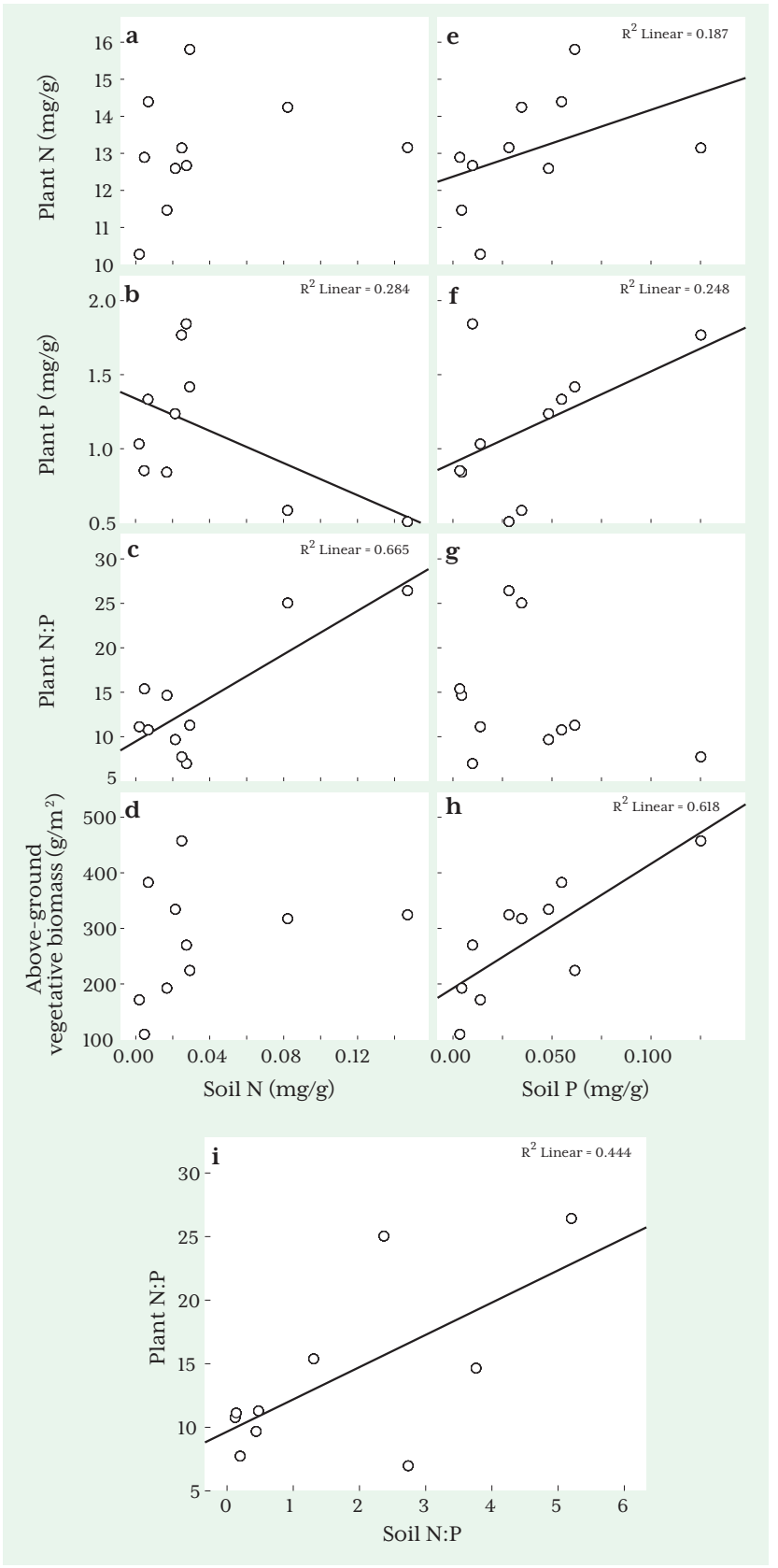

Appendix 5.2 Correlations between soil nutrients (soil N, soil P, soil N:P), and plant nutrients (plant N, plant P, plant $\mathrm{N}: \mathrm{P}$ ) and plant biomass. 


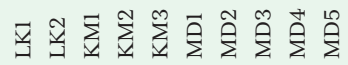
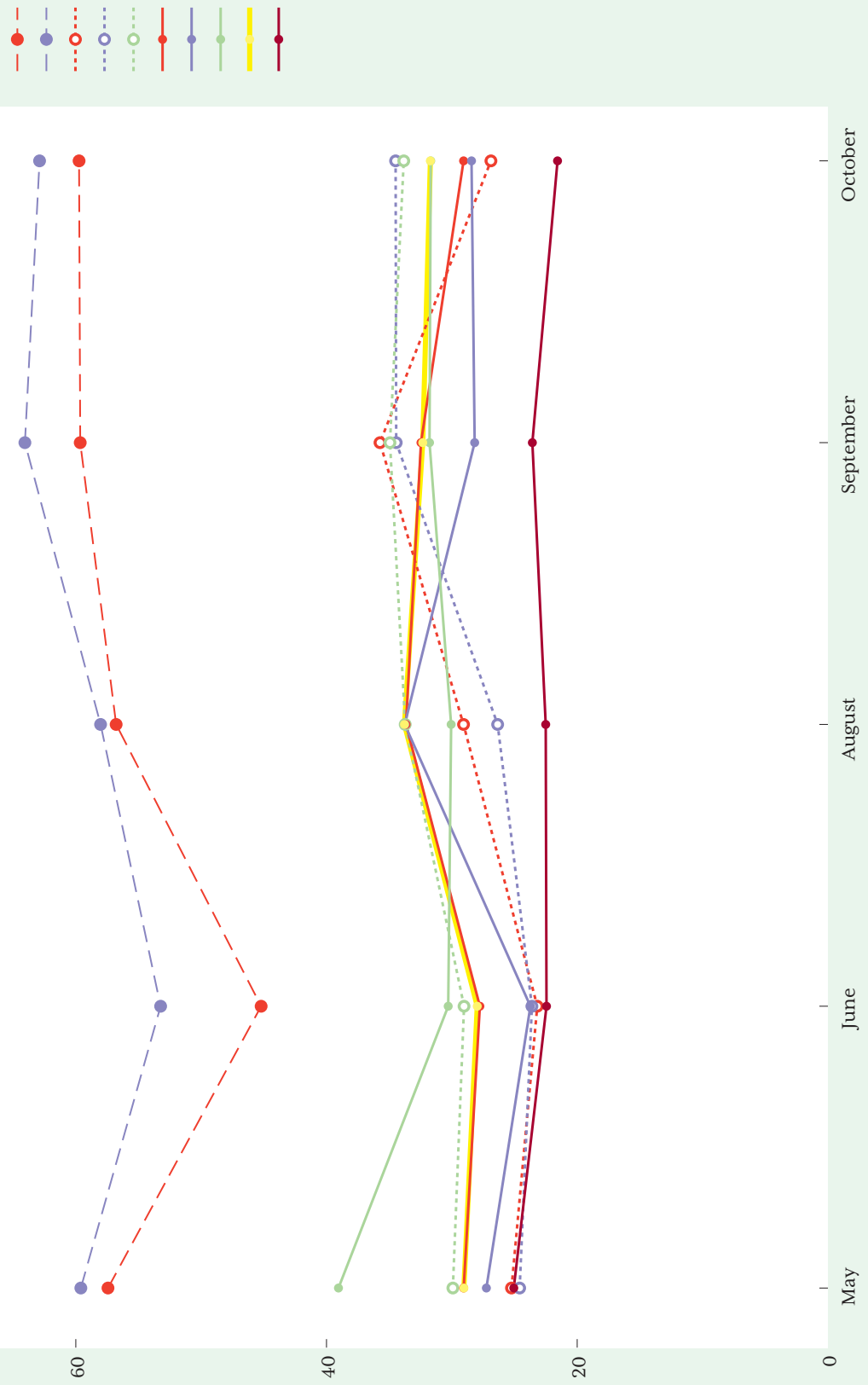
112 Chapter 5

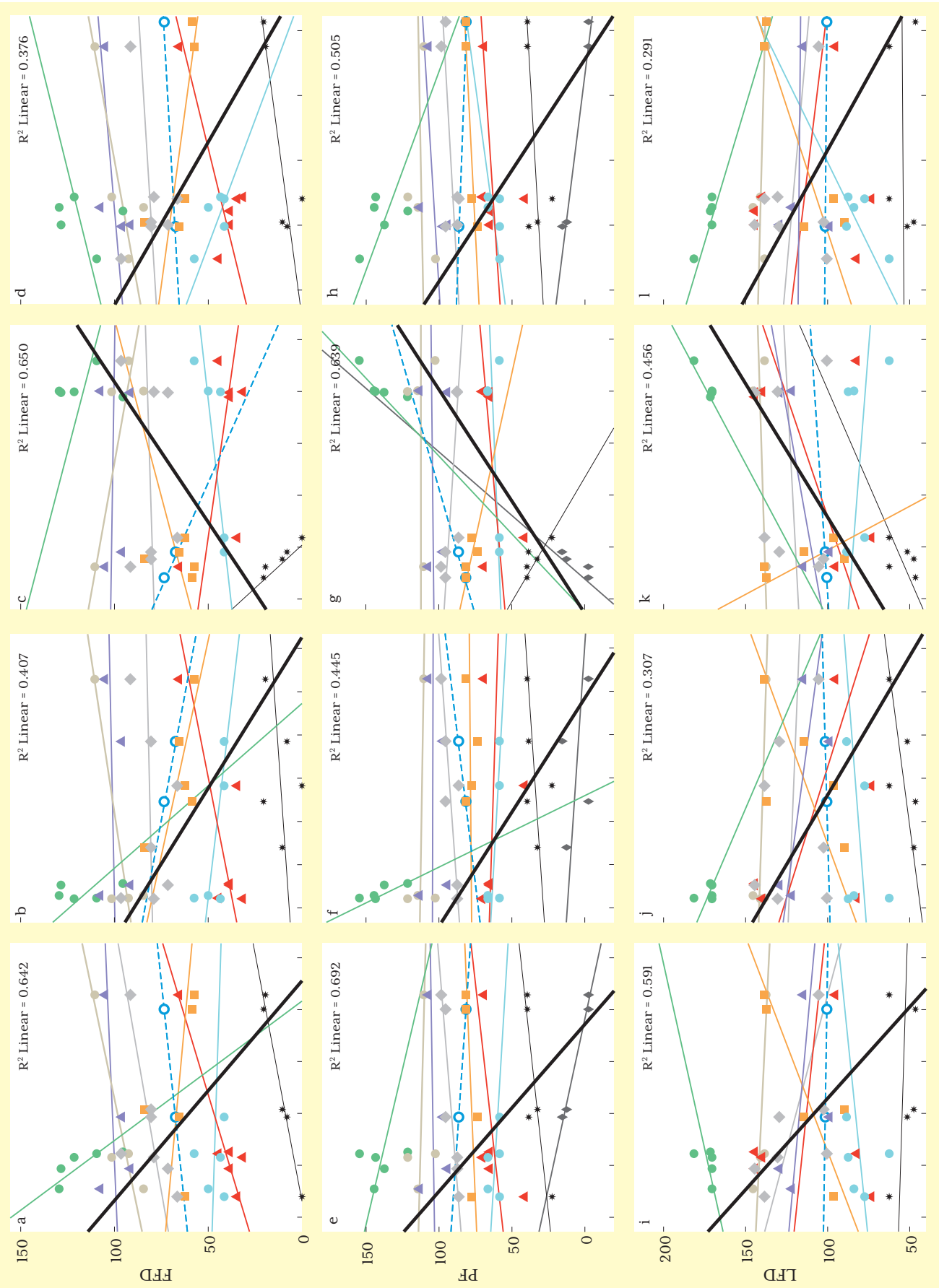



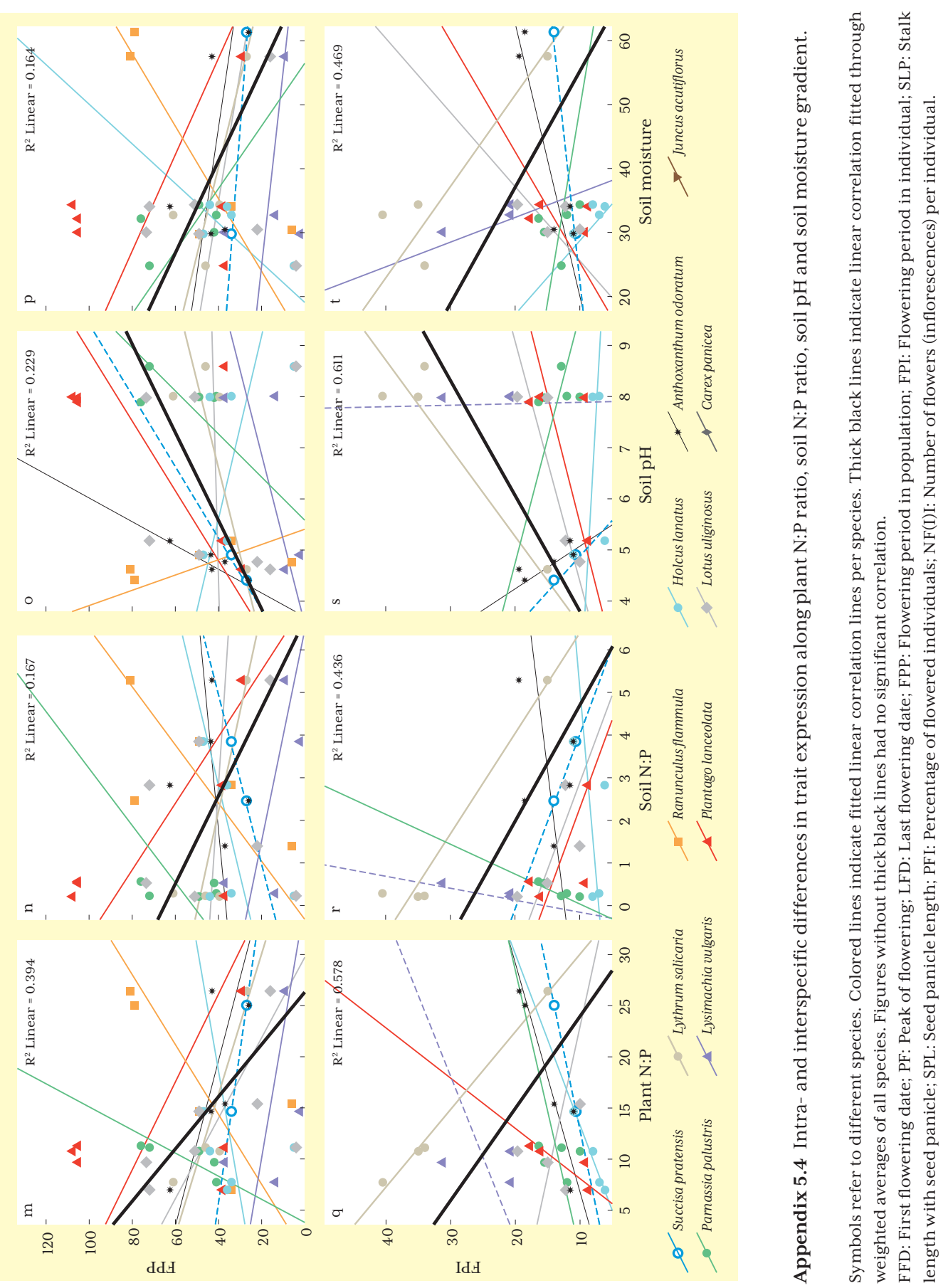
114 Chapter 5

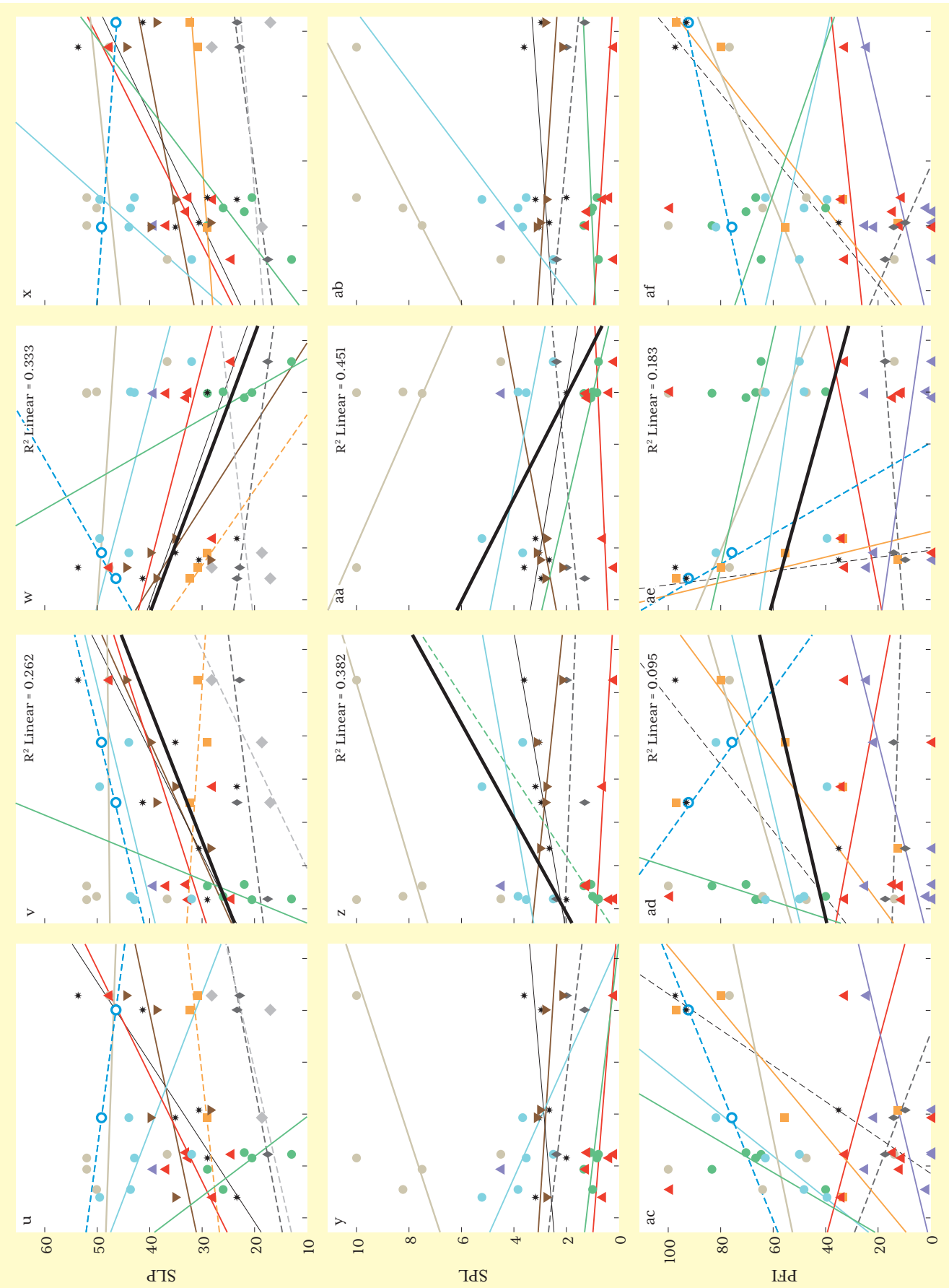




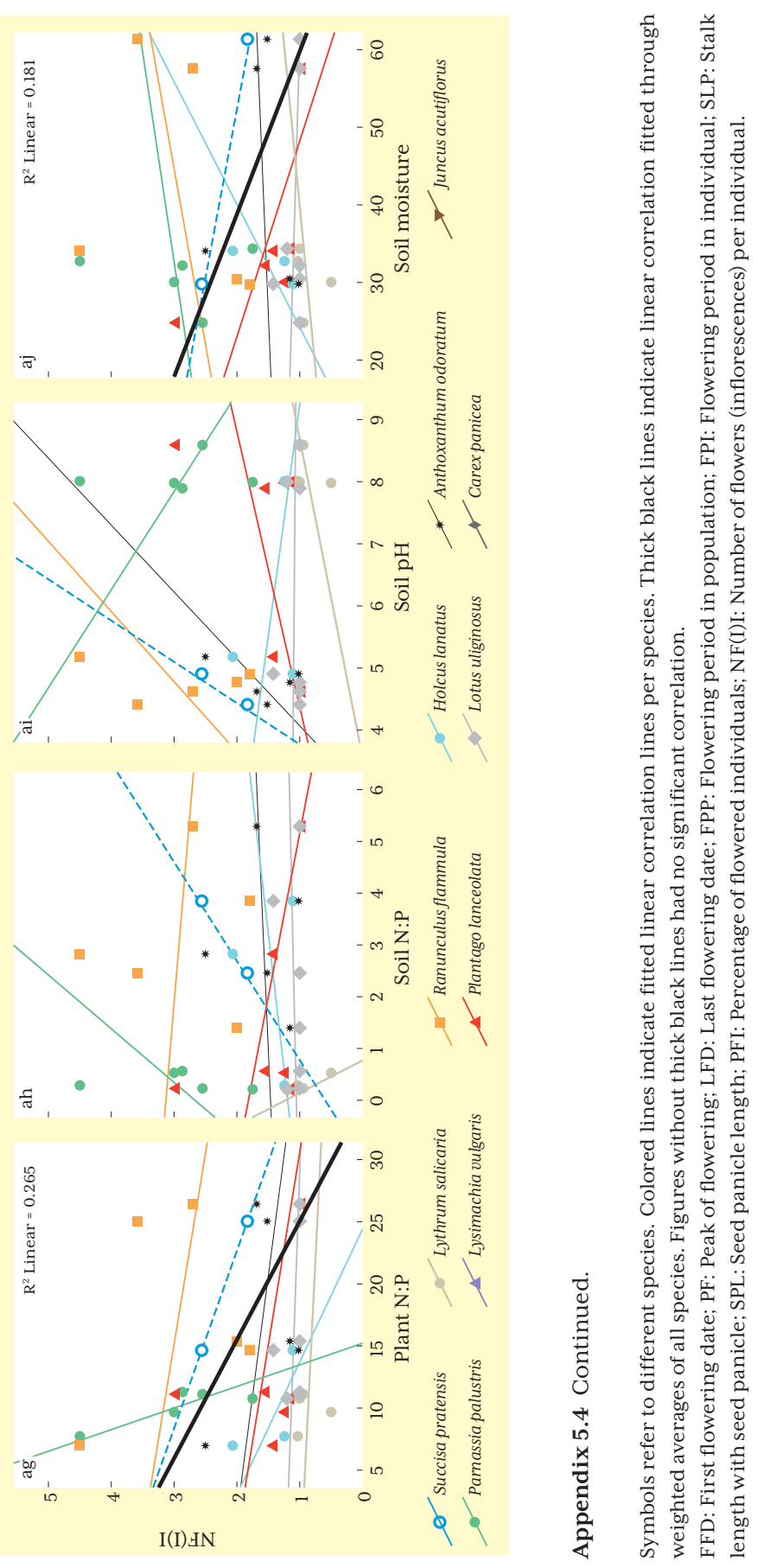


116 | Chapter 5

Appendix 5.5 Species composition of the 10 plots. Numbers given in the table are coverages (\%) of each species in a $2 \times 2 \mathrm{~m}$ plot.

\begin{tabular}{|c|c|c|c|c|c|c|c|c|c|c|}
\hline & LK1 & LK2 & KM1 & KM2 & KM3 & MD1 & MD2 & MD3 & MD4 & MD5 \\
\hline Cirsium dissectum & 27 & 22 & & & & & & & & \\
\hline Carexpanicea & 17 & 32 & 5 & 5 & & & & & & \\
\hline Molinia caerulea & 17 & 17 & & & & & & & & \\
\hline Juncus acutiflorus & 6 & 1.5 & 20 & 2 & 22 & & & & & \\
\hline Lysimachia vulgaris & 1 & & 0.75 & 0.75 & & 0.25 & 2 & & 9 & 0.25 \\
\hline Danthonia decumbens & 2 & 1 & & & & & & & & \\
\hline Agrostis stolonifera & 1 & 1 & 4 & 2 & 5 & & & 2 & 2 & 0.75 \\
\hline Anthoxanthum odoratum & 1 & 1 & 2 & 2 & 12 & & & & & \\
\hline Ranunculus flammula & 2 & 1 & 0.5 & 0.5 & 0.5 & & & & & \\
\hline Iris pseudacorus & 0.5 & 0.5 & & & & & & & & \\
\hline Lythrum salicaria & 1 & & & & & & 0.05 & 1 & 2 & 1.5 \\
\hline Agrostis canina & 2 & & 2 & 0.5 & & & & & & \\
\hline Betula pendula & & 1 & 0.05 & 0.5 & & & & & & \\
\hline Potentilla erecta & & 0.5 & & 0.5 & & & & & & \\
\hline Lotus uliginosus & 1 & 0.5 & 1 & 0.25 & 22 & 9 & 27 & 9 & & 1 \\
\hline Quercussp. & & 0.5 & & & & & & & & \\
\hline Succisa pratensis & & 2 & 6 & & & & & & & \\
\hline Crepis padulosa & & & 5 & 10 & & 1 & 1 & & & \\
\hline Hydrocotyle vulgaris & & & 3 & & & & & & & \\
\hline Carexechinata & & & 2 & 2 & & & & & & \\
\hline Pedicularis palustris & & & 2 & 3 & 2 & & & & & 3 \\
\hline Salix aurita & & & 2 & 1 & 1 & & & & & \\
\hline Drosera rotundifolia & & & 1 & 1 & 0.25 & & & & & \\
\hline Holcus lanatus & & & 0.5 & & 5 & & & 0.25 & 1 & 0.25 \\
\hline Cirsium palustre & & & 0.5 & & & & & & & \\
\hline Juncus conglomeratus & & & 0.05 & & & & & & & \\
\hline Salix repens & & & & 2 & & & & 2 & & 10 \\
\hline Hydrocotyle vulgare & & & & 0.5 & & & & & & \\
\hline Eriophorum angustifolium & & & & 0.5 & & & & & & \\
\hline Epilobium hirsutum & & & & 0.5 & & & & & & \\
\hline Trifolium repens & & & & & 4 & 7 & 1 & 3 & 16 & 0.5 \\
\hline Hypochaeris radicata & & & & & 2 & & & & & \\
\hline Plantago lanceolata & 0.25 & & 0.25 & & 2 & 9 & 9 & 9 & 0.1 & 0.25 \\
\hline
\end{tabular}


Appendix 5.5 Continued.

\begin{tabular}{|c|c|c|c|c|c|c|c|c|c|c|}
\hline & LK1 & LK2 & KMl & KM2 & KM3 & MD1 & MD2 & MD3 & MD4 & MD5 \\
\hline Betula pubescens & & & & & 1 & & & & & 0.25 \\
\hline Ranunculus acris & & & & & 0.75 & 7 & 1 & 3 & & \\
\hline Cerastium fontanum & & & & & 0.01 & & & & 0.05 & \\
\hline Rhinanthus angustifolius & & & & & & 19 & 11 & 0.5 & & 0.5 \\
\hline Carex disticha & & & & & & 13 & 8 & & & \\
\hline Trifolium dubium & & & & & & 10 & & & & \\
\hline Ranunculus repens & & & & & & 3 & 17 & 0.05 & & \\
\hline Parnassia palustris & & & & & & 2 & 0.05 & 0.05 & 0.05 & 1.5 \\
\hline Carexacuta & & & & & & 2 & 13 & & & \\
\hline Ajuga reptans & & & & & & 2 & & 0.25 & & 0.1 \\
\hline Trifolium pratense & & & & & & 1 & 1 & 4 & 11 & 0.5 \\
\hline Cardamine pratensis & & & & & & 1 & & & & \\
\hline Linum catharticum & & & & & & 1 & & & & \\
\hline Euphrasia stricta & & & & & & 1 & 1 & 0.25 & 0.05 & 0.5 \\
\hline Vicia cracca & & & & & & 1 & 4 & & & \\
\hline Juncus subnodulosus & & & & & & 1 & & 15 & 3 & 1 \\
\hline Phragmites australis & & & & & & 1 & 0.5 & 1 & 6 & 0.1 \\
\hline Prunellavulgaris & & & & & & 0.5 & & & & \\
\hline Rumexacetosa & & & & & & 0.5 & 0.5 & & & \\
\hline Hypericum tetrapterum & & & & & & 0.5 & 0.5 & 0.75 & & 1 \\
\hline Taraxacum officinale & & & & & & 0.5 & & & & \\
\hline Festuca rubra & & & & & & 0.5 & 0.5 & 5 & 6 & 0.25 \\
\hline Mentha aquatica & & & & & & 0.5 & & 0.05 & & 0.25 \\
\hline Carexhirta & & & & & & 0.1 & & & & \\
\hline Festuca pratensis & & & & & & 0.1 & & & & \\
\hline Leontodon saxatilis & & & & & & 0.1 & & & & 0.05 \\
\hline Lysimachia thyrsiflora & & & & & & & 1 & & & \\
\hline Linum cartharticum & & & & & & & 1 & & & \\
\hline Equisetum arvense & & & & & & & 1 & & & 0.01 \\
\hline Cardamine pratense & & & & & & & 1 & & & \\
\hline Salix cinerea & & & & & & & 0.5 & 2 & 1.5 & 0.5 \\
\hline Angelica sylvestris & & & & & & & 0.5 & & & \\
\hline 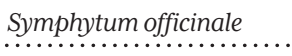 & & & & & & & $\begin{array}{l}0.5 \\
\ldots \ldots\end{array}$ & & & \\
\hline
\end{tabular}


118 Chapter 5

Appendix 5.5 Continued.

\begin{tabular}{|c|c|c|c|c|c|c|c|c|c|c|}
\hline & LK1 & LK2 & KMl & KM2 & KM3 & MD1 & MD2 & MD3 & MD4 & MD5 \\
\hline Poa pratensis & & & & & & & 0.5 & & & \\
\hline Epipactis palustris & & & & & & & 0.25 & & & \\
\hline Epilobium tetragonum & & & & & & & 0.25 & & & \\
\hline Poatrivialis & & & & & & & 0.1 & 0.5 & 0.5 & 0.25 \\
\hline $\begin{array}{l}\text { Dactylorhiza majalis subsp. } \\
\text { praetermissa }\end{array}$ & & & & & & & & 0.5 & & 0.05 \\
\hline Neottia cordata & & & & & & & & 0.5 & & \\
\hline Lotus pedicularis & & & & & & & & 0.25 & & \\
\hline Luzula campestris & & & & & & & & 0.25 & & \\
\hline Heracleum sphondylium & & & & & & & & 0.1 & & \\
\hline Holcus mollis & & & & & & & & & 5 & \\
\hline Carexflacca & & & & & & & & & 1 & 0.25 \\
\hline Rhinanthus angustifolius & & & & & & & & & 0.1 & \\
\hline Arrhenathia elatius & & & & & & & & & 0.05 & \\
\hline Alchemilla mollis & & & & & & & & & & 0.75 \\
\hline Species richness & 14 & 14 & 20 & 19 & 15 & 29 & 30 & 26 & 19 & 27 \\
\hline
\end{tabular}

The bold species were studied in the present research. 

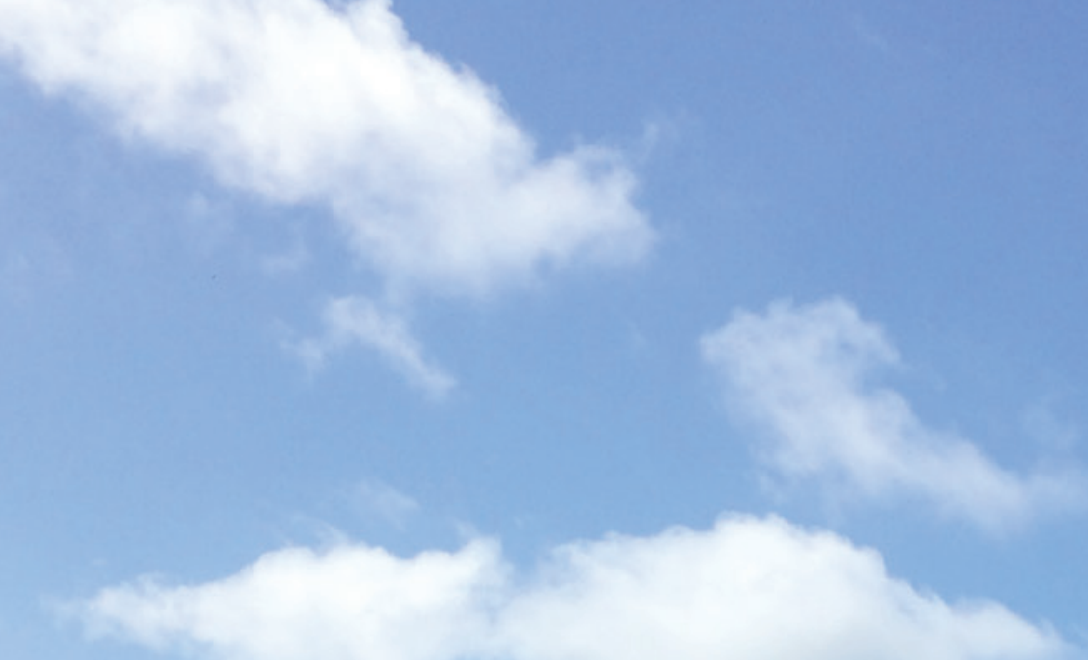

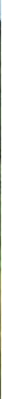

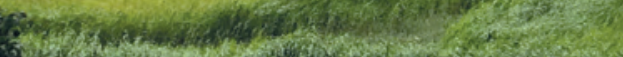

B. 1. H.

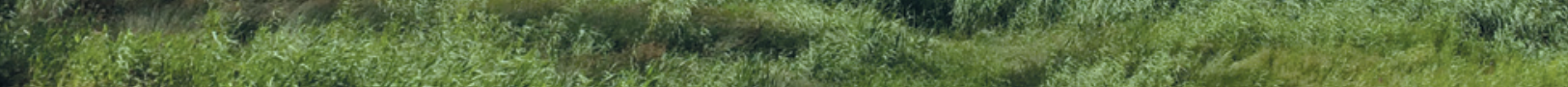

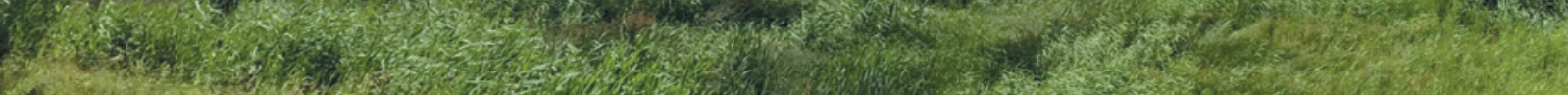
6. 20 -

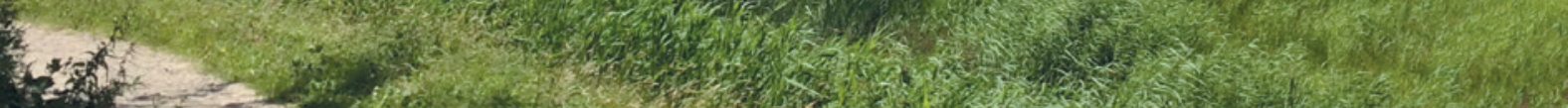

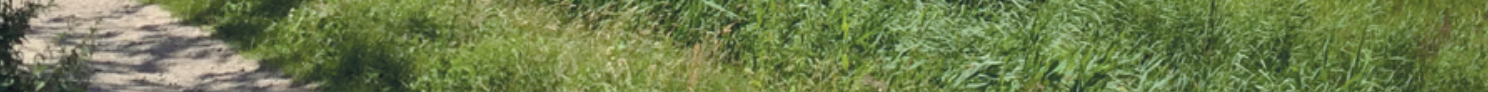

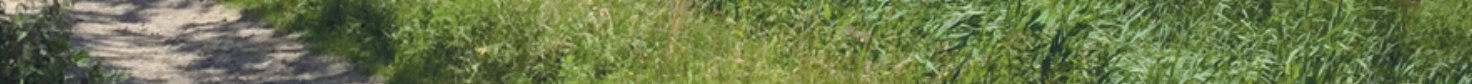

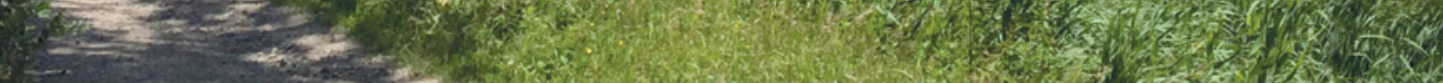

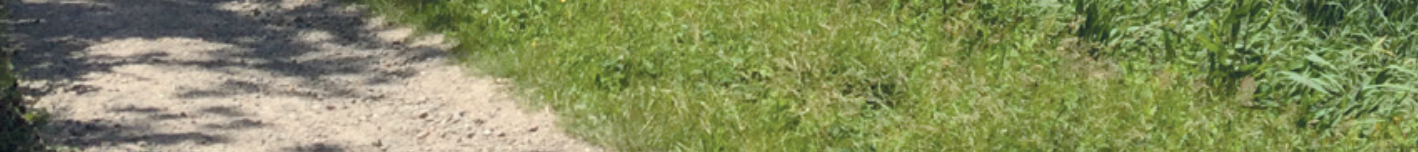

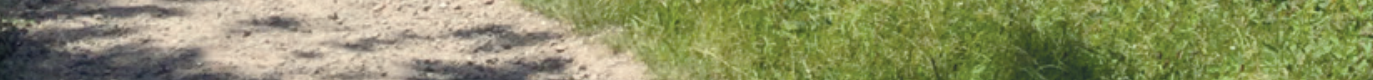

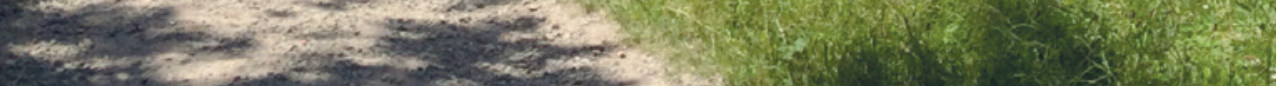

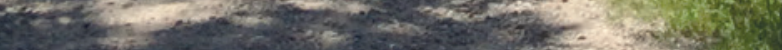

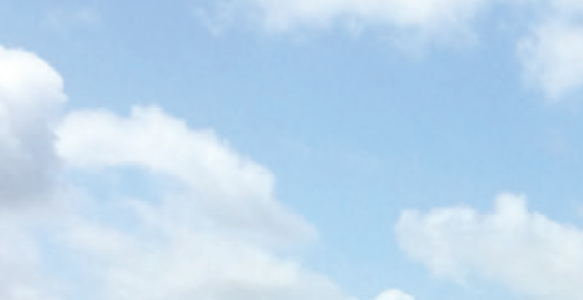

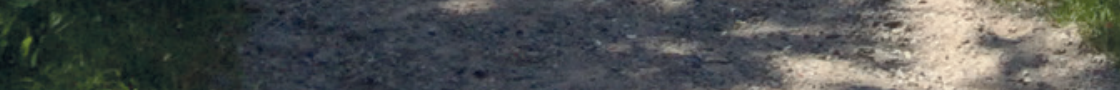

4.

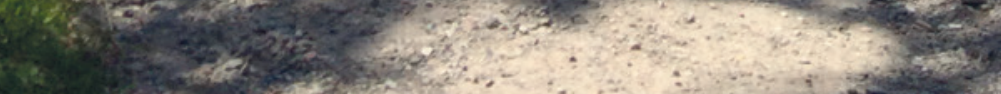


Chapter 6

Synthesis 



\subsection{Introduction}

Nitrogen $(\mathrm{N})$ and phosphorus $(\mathrm{P})$ are the two main mineral nutrients for plants, and need to be supplied in balance for optimal plant growth and community diversity (Sterner and Elser 2002; Güsewell 2004). However, since anthropogenic eutrophication has been threatening ecosystems worldwide (Vitousek et al. 1997; Rockström et al. 2009), N and P supply to natural vegetation have changed considerably, leading to severe biodiversity loss, especiallyvia decreased individual fitness of threatened species in the communities, as a result of for example lower plant stature (Bobbink et al. 1998) and poorer dispersal capacity (Fujita et al. 2014) of threatened species. To conserve ecosystems, it is therefore necessary to study the impacts of imbalanced $\mathrm{N}$ and $\mathrm{P}$ availability on species individual performance along their life cycle (vegetative growth, reproduction and survival). In this dissertation I have tried to narrow the gap in our understanding of the influence of absolute and relative availability of $\mathrm{N}$ and $\mathrm{P}$ on grassland plant germination success, vegetative growth, sexual reproduction performance, and final survival under eutrophication, using a combination of greenhouse experiments as well as a field study (see Figure 6.1).

My dissertation started with exploring the influence of N:P stoichiometry in parent plants on the offspring's seed characteristics, seed germination success, and plant survival in the end of the life cycle under different nutrient treatments (Chapter 2). Offspring plants with healthy performance were used to study the effect of absolute and relative supply of $\mathrm{N}$ and $\mathrm{P}$ on photosynthesis ability (source activity) and tissue formation (sink activity) of a grass species (Chapter 3), as well as the effect of absolute and relative supply of $\mathrm{N}$ and $\mathrm{P}$ on sexual reproduction traits of two grassland species (a grass and a forb) (Chapter 4). These greenhouse experiments shed light on the fundamental mechanisms of how $\mathrm{N}$ and $\mathrm{P}$ supply affect the life cycle of plant species. Since research on sexual reproduction investment of grassland species along N:P gradients in the field are lacking, I performed a field survey to complement the greenhouse experiments (Chapter 5).

In this final chapter I integrate the results of the studies above in order to gain a comprehensive understanding of plant eco-physiological responses to N:P stoichiometry. I synthesize the results of my dissertation to answer the following questions:

- How does parental N:P stoichiometry influence offspring seed characteristic and germination success (chapter 2, chapter 4)?

- What is the influence of relative and absolute $\mathrm{N}$ and $\mathrm{P}$ supply on plant photosynthesis activity (source activity), and is it source activity, or the availability of $\mathrm{N}$ and $\mathrm{P}$ that directly influences plant growth (sink activity) (chapter 3)? 
- What is the influence of relative and absolute $\mathrm{N}$ and $\mathrm{P}$ supply on inter- and intraspecific sexual reproduction performance in grassland communities (chapter 4, chapter 5)?

I conclude with a discussion of the impact of $\mathrm{N}: \mathrm{P}$ stoichiometry on plant survival and species diversity with an emphasis on threatened species, based on the results above. Finally, based on the preceding discussion, I provide implications for ecosystem conservation and perspectives for future research.

a

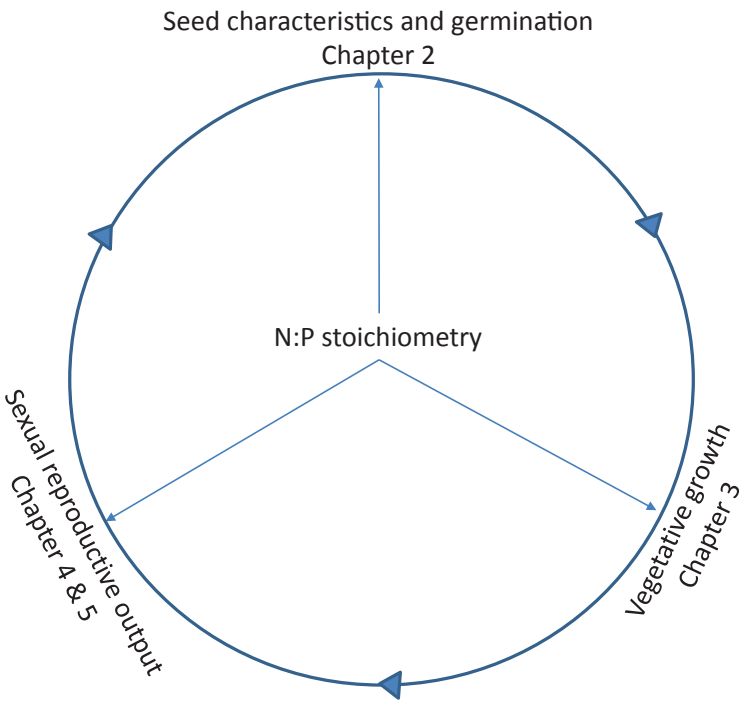

Figure 6.1 N:P stoichiometry and plant life cycle (a). Influence of N:P stoichiometry on specific plant functional and performance traits summarizing the main results of this thesis (b).

The arrows indicate assumed causal relationship, the bold lines represent positive correlations, the dashed bold lines represent negative correlations, the dashed lines represent no correlations. Identical colors of functional or performance traits indicate the same types, which are directly related to the three performance traits (vegetative biomass, reproductive output, and survival) in the same colors.

SL: seed length; SA: seed area; SM: seed mass; SNConc.: seed N concentration; SPConc.: seed P concentration; SNC: seed N content; SPC: seed P content; GS: germination success; Survival: plant survival; Photo.: net photosynthesis capacity; SLA: specific leaf area; LA: leaf area; AGB: above-ground biomass; BGB: below-ground biomass; AGB/BGB: above-ground biomass/below-ground biomass; FFD: first flowering date; PF: peak of flowering; LFD: last flowering date; FPP: flowering period in the population; FPI: flowering period in individuals; SLP: seed stalk length with panicle; SHP: seed stalk height with panicle; NF(I)I: number of flowers (inflorescences) per individual; SPL: seed panicle length; SPW: seed panicle weight; TNS: total number of seeds produced per pot; TSW: total seed weight produced per pot; PFI: percentage of flowered individual. 


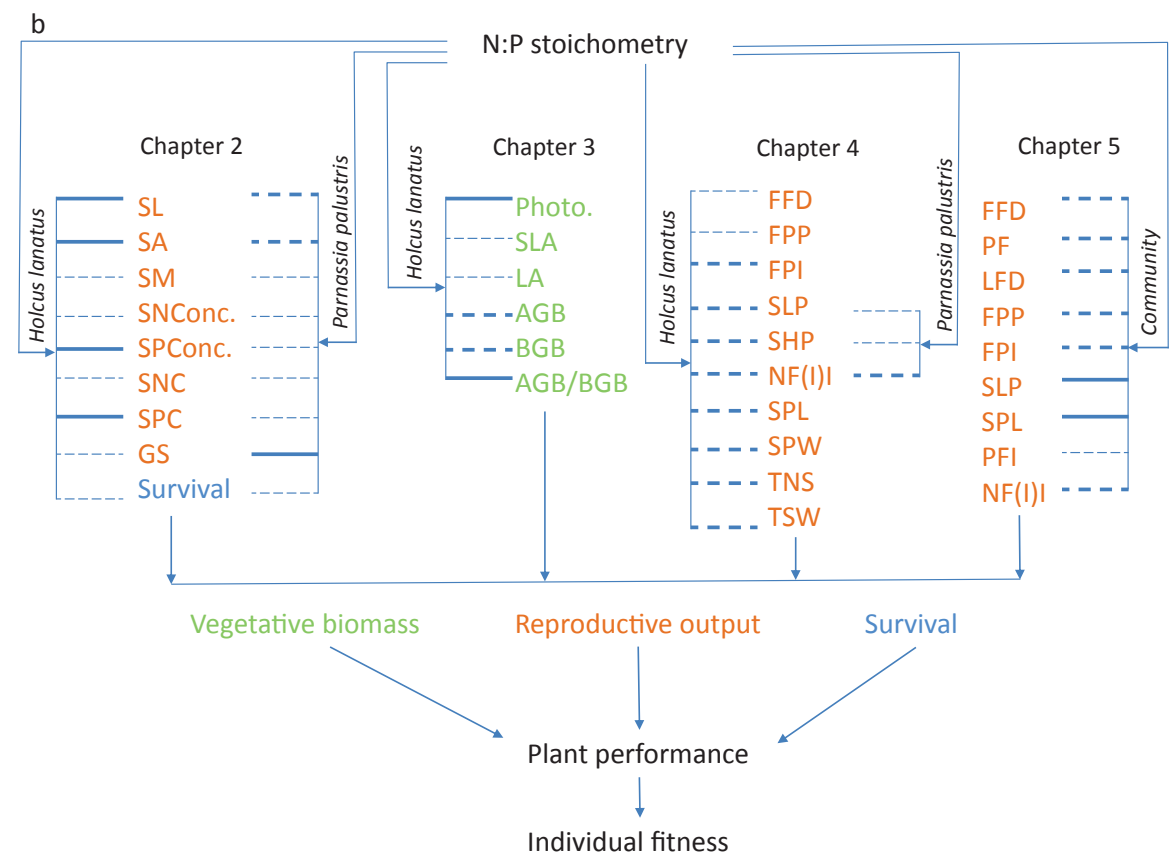

Figure 6.1 Continued.

\subsection{Phase one: parental N:P stoichiometry and seed characteristics}

Seeds are produced by plants sexual reproduction, and represent the end of one plant life cycle, and the beginning of the next. On an evolutionary scale, sexual reproduction via seeds provides dramatic advantages for plant's survival because it can help a species to survive in periods of poor growth conditions, such as drought and harsh nutrient competition (Tüzel et al. 2001; Otto 2009), contributes to collecting beneficial mutations allowing adaptation to environmental changes (Peck 1994), and diverse genes by combining those from both sides of the parents (Peck 1994; Vellend and Geber 2005). N (the main component of protein) and $\mathrm{P}$ (the main component of nucleic acid) are the two major mineral elements in seeds that vary remarkably among species (Henery and Westoby 2001). However, it has been argued that parental nutrient status in terms of both absolute and relative availability of $\mathrm{N}$ and $\mathrm{P}$, affects seed characteristics. To investigate the effect of parental N:P stoichiometry on seed characteristics, seeds of a common species Holcus lanatus and an endangered species Parnassia palustris from parent plants 
growing in two different N:P stoichiometry backgrounds were collected and studied (chapter 2).

The results showed that parental N:P stoichiometry affects seed traits: high parental N:P significantly decreased seed length and area (indicating a decrease in seed size) of the common species, while it increased seed size of the endangered species. Nevertheless, no influence of N:P ratio was found on germination success of the common species, while high parental N:P promoted germination success of seed of the endangered species (chapter 2). The restriction of high parental N:P on seed characteristics of the common species Holcus lanatus is consistent with our greenhouse experiment on the same species described in chapter 4, in which seeds produced under P limitation were significantly smaller. Additionally, investment in sexual reproduction, i.e. flowering phenology, flowering period, as well as seed production were all found to be reduced by P limitation (chapter 4, chapter 5) which is consistent with earlier studies (Lahti et al. 1991; Murray et al. 2002; Farnsworth and Ogurcak 2008; Fujita et al. 2014). These effects of P limitation on seed characteristics might result from the high $\mathrm{P}$ requirement in seeds compared to other organs because P-rich RNA constitutes a high proportion of reproductive organs (Kerkhoff et al. 2006). Plants under P limitation therefore reduce their investment in reproductive organs as a strategy to deal with low $\mathrm{P}$ availability (Lambers et al. 2011; Fujita et al. 2014). Despite the smaller seed size under more strong P limitation, the germination success of the common species was not affected, which is in contrast with other studies that found that smaller seed size was associated with lower gemination rates and lower germination percentages (Vera 1997; Cordazzo 2002). The reason might be that despite a reduction in seed size the $\mathrm{P}$ concentration in the seed of the common species was still high even in the strongly P-limited condition (chapter 2), illustrating the importance of P for seed quality (White and Veneklaas 2012).

The influence of parental N:P on seed characteristics of the endangered species deviated from the results found for the common species. While high parental N:P decreased seed size of seeds of the common species, it increased seed size of seeds of the endangered species, which led to a significantly higher germination success of seeds of the endangered species from the strongly P-limited site (chapter 2). The positive effect of stronger $\mathrm{P}$ limitation on seed size and germination rate of the seeds of Parnassia palustris is in line with the suggested sensitivity of endangered species to P enrichment (Wassen et al. 2005). However, remarkably we also found that the survival of the offspring of Parnassia palustris was lower under stronger P-limited conditions, suggesting that P limitation negatively affects Parnassia palustris rejuvenation. Hence, our results not unambiguously confirm the suggestion of 
Wassen et al. (2005) that endangered species thrive well in P-limited environments, at least from a reproduction perspective.

\subsection{Phase two: N:P stoichiometry and plant vegetative growth}

Photosynthesis is the process of assimilating carbon for plant biomass formation (source activity), and has generally assumed to be main factor controlling the rate of plant growth (sink activity) since the early days of recognizing $\mathrm{CO}_{2}$ as the substrate for photosynthesis (Körner 2015). Our study showed that $\mathrm{N}$ availability controlled source activity significantly, while P availability did not affect source activity (chapter 3). This result is supported by previous research showing a positive relationship between leaf $\mathrm{N}$ status and photosynthesis capacity (Walker et al. 2014), as well as the positive effect of soil $\mathrm{N}$ on the positive response of photosynthesis to elevated $\mathrm{CO}_{2}$ (Reich and Hobbie 2013). It was therefore expected that $\mathrm{N}$, as a major component of Rubisco, was the most critical element for plant growth as well through its influence on source activity. However, our results do not support the assumption that source activity controls sink activity, and showed that the availability of mineral elements, specifically P, determined sink activity (chapter 3, Figure 6.2), which supports the suggestion was also concluded by Körner (2015) that mineral nutrition might be a more important determinant of plant growth than carbon assimilation. In our study, the restriction of low $\mathrm{P}$ availability relative to $\mathrm{N}$ on both above-ground and below-ground biomass formation was stronger than that of low $\mathrm{N}$ availability relative to $\mathrm{P}$, with a dominant influence of absolute P availability (chapter 3). Our results are in line with Güsewell (2005) found that P limitation reduced shoot growth more significant than $\mathrm{N}$ limitation in a two-year fertilization experiment with wetland plant species. Similarly, a model study on the relative growth rates of the leaves of 131 vascular plants found that the power of leaf P scales $4 / 3$ of that of leaf $\mathrm{N}$ on annual leaf growth (Niklas et al. 2005). Furthermore, in crops such as lavender, P was the element mainly affecting the plant growth rather than $\mathrm{N}$ (Chrysargyris et al. 2016). This unexpected finding that $\mathrm{P}$ rather than $\mathrm{N}$ controlled plant biomass formation dominantly, points to the possibility that the formation of P rich rRNA, which controls protein formation might be more critical in determining plant growth than the provision of $\mathrm{N}$ for formation of the proteins themselves.

These observations advance our understanding of the influence of absolute and relative $\mathrm{N}$ and $\mathrm{P}$ on plant vegetative growth, which may extend to community level if it affects interspecific competition. The question of how absolute and relative availability of $\mathrm{N}$ and $\mathrm{P}$ affect the next life phase, i.e. sexual reproduction, will be discussed in the following paragraph. 


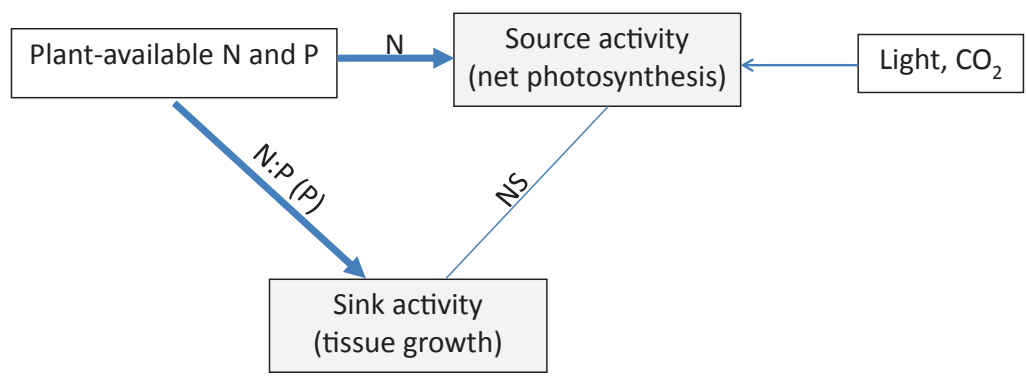

Figure 6.2 Relationships among plant-available $\mathrm{N}$ and $\mathrm{P}$ in soil, source activity (net photosynthesis), and sink activity (tissue formation). Arrow with $\mathrm{N}$ indicates significant effect of N availability. Arrow with N:P(P) indicates significant effect of N:P, with P influences dominantly. NS indicates no significant correlation.

\subsection{Phase three: N:P stoichiometry and plant sexual reproduction performance: summary of the greenhouse experiment and the field survey}

Community effects of N:P stoichiometry do not only rise from its impact on the performance of individuals after establishment, but also from its impact on plants capacity to reproduce and disperse. Both the greenhouse experiment and the field survey in this thesis allow for a comparison of plant sexual reproduction performance along an N:P gradient (chapter 4, chapter 5). In general, high N:P restricted the investment in sexual reproduction for the common (Holcus lanatus) and the endangered species (Parnassia palustris) in a greenhouse experiment (chapter 4), as well as for a larger set of selected species in the field (chapter 5).

Two possible explanations go along with the lower investment in sexual reproduction under P limitation within species. First, given the fact that greater reproduction is usually associated with stronger vegetative growth (Koslowski 1992), and a low productivity is often associated with low P supply (McJannet et al. 1995; Olde Venterink et al. 2003), low P supply may therefore restrict plant's investment in sexual reproduction. In light of the results presented in this thesis, however, this is not the most plausible explanation. Although P limitation indeed restricted plant vegetative growth at low supply levels (chapter 3), no influence on sexual reproduction performance was observed (chapter 4). A second explanation might be that it is a strategy of species to save $\mathrm{P}$ by restricting the use of $\mathrm{P}$ for the 
formation of P-rich reproductive structures and seeds (Fujita et al. 2014). This would leave them less affected by P scarcity. Such a reproduction strategy with lower seed production, however, may have the disadvantage of a trade-off resulting in poor dispersal ability on a regional scale.

My results generally indicate that $\mathrm{P}$ limitation restricts investment in sexual reproduction in many grassland species (chapter 5), which is in line with the result of Fujita et al. (2014). Only the results for the onset of flowering deviate from those of Fujita et al. (2014) who found a later start of flowering time under P limitation in contrast to our field study that showed that flowering time was earlier in P-limited sites (chapter 5). Two factors are important to be considered when exploring the possible reason of earlier flowering time under P limitation in our survey: soil moisture and soil pH. Generally, high soil moisture is combined with lower root-zone soil temperature (Hood 2001; Miralles et al. 2012), which could delay the flowering time rather than advance that in the generally wetter P-limited conditions of our field survey (Jagadish et al. 2016). Thus, I suggest that the phenomenon of earlier flowering time under P limitation might be caused by the acid soil conditions that also coincided with P limitation in our study sites, considering the strong influence of soil $\mathrm{pH}$ on plant growth and species diversity (Robson 1989; Roem and Berendse 2000), and the significant positive correlation between soil $\mathrm{pH}$ and flowering phenology in the field survey presented in chapter 5. However, to my knowledge, studies on the relationship between soil $\mathrm{pH}$ and flowering phenology are largely lacking. Therefore, I suggest to pay more attention in future studies to the effect of stressors such as severely acidic conditions on flowering phenology, especially since poorly buffered soils experience acidification from atmospheric deposition and flowering phenology and rejuvenation of plants may be hampered by this. Fujita et al. (2014) considered a later start of flowering as an indication of lower investment in sexual reproduction of species with the argument that an earlier flowering time should be beneficial for plant sexual reproduction performance by providing more chances for successful fertilization. We suggest that the total length of the flowering period might be a better indicator for the influence of $\mathrm{N}: \mathrm{P}$ stoichiometry on plant sexual reproduction performance rather than flowering time when considering flowering phenology in future studies. 


\subsection{N:P stoichiometry and plant survival}

No difference of plant survival along an experimental N:P gradient was found for the common species Holcus lanatus when grown in monoculture (chapter 3). However, considering the restrictions of $\mathrm{P}$ limitation on the vegetative growth and the sexual reproduction performance of this species (chapter 3, chapter 4), P limitation could possibly negatively influence the survival of the common species under the stress of natural competition. In contrast with the common species, plant survival of the selected endangered species (Parnassia palustris) varied notably at the end of its life cycle along the experimental N:P gradient in the greenhouse, with P limitation restricting it most (chapter 2). Besides, as mentioned above, vegetative growth and sexual reproduction performance of the endangered species were both restricted under P limitation (chapter 3, chapter 4). The unexpected outcome that the endangered species did not do better under $\mathrm{P}$ limitation could possibly be explained by the following two reasons:

1. It is not that endangered species are preferring $\mathrm{P}$ limitation, but that $\mathrm{P}$ limitation restricts endangered species less than common species. According to Fujita (2010), no particular species have evolved to be adapted to P-limited conditions in terms of their nutrient use efficiency. Thus, it is probably misleading to say that endangered species prefer P limitation, but more properly would be to say that under P limitation endangered species have a competitive advantage and are thus not outcompeted by other more common species. With regard to our experiments, a possibility could be that Parnassia palustris favors $\mathrm{N}$ limitation inherently, but can only survive in P-limited conditions in absence of competitors that are able to grow in N-limited conditions but not in P-limited conditions.

2. In spite of the fact that P limitation was proved to be favored by endangered species (Wassen et al. 2005), not all endangered species can exclusively survive under Plimitation. In fact, according to the dataset of Fujita 2014, 51\% of endangered species occurred under N:P ratios in above-ground biomass below 16, indicating $\mathrm{N}$ or N and P co-limitation. Moreover, in our field survey (chapter 5), the selected endangered species Parnassia palustris was only found in N-limited conditions. The latter implies that the second explanation is more probable than the first: $\mathrm{N}$ limitation or $\mathrm{N}$ and $\mathrm{P}$ co-limitation is preferred by the selected endangered species over P limitation. 


\subsection{Implications for ecosystem conservation}

Outcompeting of endangered species by common species can lead to decreased species diversity in natural conditions (Elser et al. 2000). Thus, understanding the responses of both common and endangered species to changing N:P stoichiometry triggered by $\mathrm{N}$ and $\mathrm{P}$ fertilizations is vital for conservation management. Apart from the different influences of $\mathrm{N}: \mathrm{P}$ on plant survival between the common species and the endangered species as mentioned in the previous paragraphs, the results of this thesis highlight the restriction of $\mathrm{P}$ limitation on plant vegetative growth above- and below-ground (chapter 3). This negative influence of $\mathrm{P}$ limitation on plant growth at the individual level may extend to community level, as suggested by Ceulemans et al. (2013) that the possible detrimental effects of $\mathrm{P}$ enrichment in terrestrial ecosystems may have been underestimated, in spite of the prevailing paradigm of N driven decreased biodiversity (e.g. Steven et al. 2004; Clark and Tilman 2008; Duprè et al. 2010). Moreover, in accordance with previous studies (Lahti et al. 1991; Murray et al. 2002; Farnsworth and Ogurcak 2008; Fujita et al. 2014), we found P limitation restricted sexual reproduction performance of grassland species at both intraspecific and interspecific level. The hampered dispersal ability, e.g. low seed production, and poorer seed dispersal, may thereby restrict these species from dispersing and settling in suitable sites across the landscape, and eventually influence community structure (Fenner and Thompson 2005). Continental scale analyses of plant species distribution already indicate reduced species pools for P-limited grasslands and a high incidence of threatened species (Wang et al. 2020). Considering the uneven distribution of common and endangered species in N limitation and P limitation (Wassen et al. 2005; Roeling et al. 2018; Wang et al. 2020), I suggest to further study functional and performance traits of common and endangered grassland species along a gradient of N:P stoichiometry in the field, in order to comprehensively understand species responses to the changing $\mathrm{N}$ and $\mathrm{P}$ availability in nature.

This thesis presents fundamental research on the influence of N:P stoichiometry on the various phases of the plant life cycle and leads to the general conclusion, as discussed in the sections above, that $\mathrm{P}$ limitation restricted the individual performance of plant species. Given the globally large increase in N deposition, relative to the increase in $\mathrm{P}$ (Steffen et al. 2015), an important question for nature conservation and restoration is how individual fitness of common and endangered species change, under the potential change in the N:P balance in N-limited and P-limited conditions, respectively? 
As mentioned above, both $\mathrm{N}$-limited and P-limited grasslands contain common and endangered species. Under $\mathrm{N}$ limitation, the greater $\mathrm{N}$ fertilization compared to $\mathrm{P}$ fertilization may shift $\mathrm{N}$ limitation to less severe $\mathrm{N}$ limitation in the short term, and even may switch to P limitation in the long term (Verhoeven et al. 1996), which is probably beneficial for fast-growing species at least in the short term because they will better be able to outcompete slow-growing species (Grime 1979), which are as a consequence becoming more threatened or even endangered (left hand panel of Figure 6.3). Therefore, decreasing $\mathrm{N}$ deposition is strongly recommended for conversation of species diversity under this circumstance (Steven et al. 2004). Moreover, resource management, e.g. mowing and harvesting fodder or sod cutting, both leading to removal of both $\mathrm{N}$ and $\mathrm{P}$ from plant biomass is also suggested (Koerselman et al. 1990).

Common and threatened species under P limitation could both possibly be under stress and vulnerable, given the continuous $\mathrm{N}$ deposition world-wide (Steven et al. 2004, right hand panel of Figure 6.3). Since threatened species have a high presence in P-limited sites (Wassen et al. 2005), conservation of species diversity in this type of environment should be of special concern. The current trend of high $\mathrm{N}$-deposition compared to $\mathrm{P}$ input may increase the occurrence of P-limited conditions in natural ecosystems, and therefore might work out positive for endangered species by weakening their competitors, as long as the N:P is lower than the threshold value for the endangered species to establish (left hand panel of Figure 6.3). However, considering the risk of decreased plant species diversity, by losing the original common species, and the part of the endangered species that could not benefit from the increasing P-limited conditions, leads to the conclusion that controlling $\mathrm{N}$ eutrophication under this circumstance is still essential. Furthermore, it has been shown that low productive wetlands with low $\mathrm{P}$ availability are disappearing (Wassen et al. 1996). Therefore, I recommend natural resource managers to implement measures that facilitate P limitation in terrestrial ecosystems, and invest in multiple management tools to preserve and restore P-limited ecosystems. For example, mowing and sod cutting, which could not only result in a balanced $\mathrm{N}$ in-output but a continuous $\mathrm{P}$ output, which might enhance P-limited conditions in the long run, but also have been proved to be supportive of P-limited plant communities, by enhancing seed germination success and seedling establishment (Rasran et al. 2007; Williams et al. 2007). Protecting groundwater from $\mathrm{P}$ pollution and manipulating water levels in an attempt to dissolve absorbed phosphate from the soil complex and flush it away, could also be a practical measure for preserving P-limited ecosystems (Wang et al. 2020). However, the latter measure of flushing $P$ away by manipulating water levels has to be operated cautiously, due to the risk of triggering a tremendous $\mathrm{P}$ eutrophication in the ecosystems. 


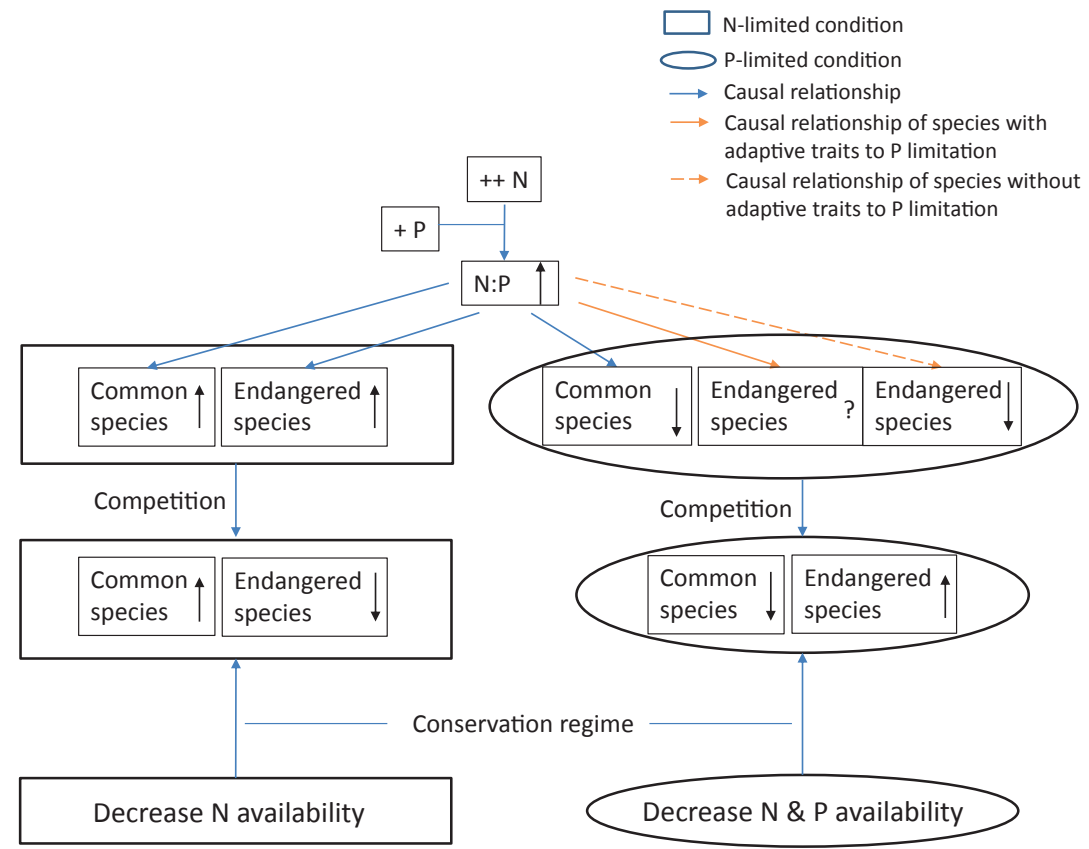

Figure 6.3 Hypothesized effects of increased $\mathrm{N}$ input on plant performance and individual fitness of common and endangered species under $\mathrm{N}$ limitation (left hand side) and under $\mathrm{P}$ limitation (right hand side). Under $\mathrm{N}$ limitation, increased $\mathrm{N}$ input increases plant performance of both common and endangered species. However, common species under $\mathrm{N}$ limitation, which are usually more fast-growing and competitive than the endangered species under $\mathrm{N}$ limitation, will have a better individual fitness and ultimately outcompetes the endangered species, leading to decreased species diversity (Grime 1979). The conservation regime suggested in this type of environment is to decrease $\mathrm{N}$ availability (mainly by reducing the input in general). Under P limitation, the situation is more complex. Increased $\mathrm{N}$ input (relatively larger than increased $\mathrm{P}$ input), leads to a shift to more severe P-limited conditions and is expected to decrease plant performance of both common species and those endangered species that do not have adaptive traits to P limitation (Steven et al. 2004). For endangered species with adaptive traits to $\mathrm{P}$ limitation, increased $\mathrm{N}$ input is expected to either have no influence, or to decrease their performance (Fujita 2010). The result of competition between common and endangered species under $\mathrm{P}$ limitation is that the endangered species with adaptive traits are expected to have a competition advantage and possibly outcompete the common species, however, at the expense of individuals of common species and endangered species without adaptive traits. Therefore, a management of increasing $\mathrm{N}$ to promote $\mathrm{P}$ limitation and thus protect endangered species is not advisable. Considering the high percentage of endangered species under P limitation (Wassen et al. 2005), I therefore suggest a conservation regime of reducing both $\mathrm{N}$ and $\mathrm{P}$ availability (reducing input and for $\mathrm{P}$ also rendering it unavailable via specific local measures; see text). 
Moreover, considering the asymmetric impacts of conservation management measures on $\mathrm{N}$ and $\mathrm{P}$ cycles, for instance, mowing regime on grasslands shifts $\mathrm{N}$ limitation to P limitation over a long time period (Verhoeven et al. 1996), it is essential to not only decrease nutrient availability, but also consider the importance of tracking the kind of nutrient limitation (Olde Venterink 2000), and the associated effects on functional and performance traits of common and endangered grassland species (this thesis), to well predict plant performance and individual fitness of grassland species confronting the global $\mathrm{N}$ and $\mathrm{P}$ changes.

\subsection{Perspectives}

Grassland as one of the largest biomes on earth, has high plant species diversity (Gibson 2009). However, due to anthropogenic activities, a large number of grassland plant species are threatened, especially in semi-natural grasslands (Aune et al. 2018). Conservation of the species diversity in grassland ecosystems is therefore essential.

Threatened species in many grasslands were proved to persist better under $\mathrm{P}$ limitation (Wassen et al. 2005), where plants were shown to invest less in sexual reproduction (Fujita et al. 2014). In this thesis I showed that P limitation not only restricts sexual reproduction performance, but also impacts on other phases in the life cycle of selected grassland species at individual level, e.g. germination success, vegetative growth, and the final survival.

However, it also seems from my results that we are only beginning to understand how the relative availability of $\mathrm{N}$ and $\mathrm{P}$ influences species performance, survival and persistence in real communities under field conditions. Clearly, a combination of controlled experiments in the greenhouse and under field conditions need to be combined with larger scale field surveys, as well as lab work. Below, I present three specific suggestions for further research:

1. Endangered species conservation: based on the investigation in this thesis, $\mathrm{P}$ limitation may damage the seed performance of common species, while improve the seed performance of endangered species (chapter 2), although juvenile survival of the endangered species was lower in P-limited conditions. This finding could possibly be applied to conserve endangered species, by improving their dispersal to other area where they might under less severe $\mathrm{P}$ limitation be able to compete with common species. However, to my knowledge, no similar research exists until now, making it hard to draw a 
general conclusion. Therefore, it will be valuable to invest more into research comparing the influences of different N:P stoichiometries on seed characteristics, as well as the subsequent germination success and seedling establishment between common and endangered species.

2. Species competition and community composition predictions: previous studies shew that plant species assembly between $\mathrm{N}$ limitation and $\mathrm{P}$ limitation is different (Elser et al. 2007; Cardinale et al. 2009), while endangered species persist under $\mathrm{P}$ limitation (Wassen et al. 2005). In the research in this thesis, $\mathrm{P}$ limitation was found to restrict both vegetative growth (chapter 3 ) and sexual reproduction (chapter 4,5) of grassland species. Considering the global nutrient eutrophication, and the higher $\mathrm{N}$ enrichment relative to $\mathrm{P}$, the current status of nutrient limitation in ecosystems may shift in the future, which would probably be followed by a change in plant community composition. It is therefore essential to understand the responses of common and endangered species to various $\mathrm{N}: \mathrm{P}$ stoichiometry, especially in field conditions, to be able to predict the influence of human-induced changes in nutrient limitation on plant species diversity.

3. Molecular studies: according to the research in this thesis, relative availability of $\mathrm{N}$ and $\mathrm{P}$ significantly influences the main stages of a plant's life cycle. Since N and $\mathrm{P}$ are the major components of proteins and nucleic acids, linking molecular mechanisms such as $\mathrm{N}$ and $\mathrm{P}$ metabolisms during the plant life cycle, to plant physiological processes and ecological patterns will help us to better understand the mechanisms underlying the effect of parental N:P stoichiometry on seed qualities of common and endangered species (chapter 2), the significant effects of $\mathrm{N}$ and $\mathrm{P}$, especially $\mathrm{P}$ on plant vegetative growth (chapter 3), as well as the remarkable restriction of P limitation on plant sexual reproduction performance (chapter 4,5 ). Such studies will also enable us to explore the influence of $\mathrm{N}: \mathrm{P}$ stoichiometry on vegetation community composition and species diversity at the molecular level. 

References 

Aarssen LW (1989) Competitive ability and species coexistence: a 'plant's-eye' view. Oikos 56, 386-401.

Aarssen LW, Burton SM (1990) Maternal effects at four levels in Senecio vulgaris (Asteraceae) grown on a soil nutrient gradient. American Journal of Botany 77, 1231-1240.

Adam P, Stricker P, Anderson DJ (1989) Species-richness and soil phosphorus in plant communities in coastal New South Wales. Australian Journal of Ecology 14, 189-198.

Aerts R (1999) Interspecific competition in natural plant communities: mechanisms, trade-offs and plant-soil feedbacks. Journal of Experimental Botany 50, 29-37.

Aerts R, Bobbink R (1999) The impact of atmospheric nitrogen deposition on vegetation processes in terrestrial, non-forest ecosystems. 'Impact Nitrogen Depos. Nat. Semi-natural Ecosyst.' pp. 85-122. (Kluwer Academic Publishers: Dordrecht)

Aerts R, de Caluwe H, Beltman B (2003) Is the relation between nutrient supply and biodiversity co-determined by type of nutrient limitation? Oikos 101, 489-498.

Aerts R, Chapin III FS (2000) The mineral nutrition of wild plants revisited: a re-evaluatin of processes and patterns. Advances in Ecological Research 30, 1-67.

Alexander HM, Holt RD (1998) The interaction between plant competition and disease. Perspectives in Plant Ecology, Evolution and Systematics 1, 206-220.

Van Andel J, Vera F (1977) Reproductive allocation in Senecio sylvaticus and Chamaenerion angustifolium in relation to mineral nutrition. Journal of Ecology 65, 747-758.

Andrews M, Sprent JI, Raven JA, Eady PE (1999) Relationships between shoot to root ratio, growth and leaf soluble protein concentration of Pisum sativum, Phaseolus vulgaris and Triticum aestivum under different nutrient deficiencies. Plant, Cell and Environment 22, 949-958.

Arnold SJ (1983) Morphology, performance and fitness. American Zoologist 23, 347-361.

Aune S, Bryn A, Hovstad KA (2018) Loss of semi-natural grassland in a boreal landscape: impacts of agricultural intensification and abandonment. Journal of Land Use Science 13, 375-390.

Austin RB (1966a) The influene of the phosphorus and nitrogen nutrition of pea plants on the growth of their progeny. Plant and soil 3, 359-368.

Austin RB (1966b) The growth of watercress (Rorippa nasturtium aquaticum (L) Hayek) from seed as affected by the phosphorus nutrition of the parent plant. Plant and Soil 1, 113-120.

Avolio ML, Koerner SE, La Pierre KJ, Wilcox KR, Wilson GWT, Smith MD, Collins SL (2014) Changes in plant community composition, not diversity, during a decade of nitrogen and phosphorus additions drive above-ground productivity in a tallgrass prairie. Journal of Ecology 102, 1649-1660.

Bagali SS (2012) Review: nitrogen fixing microorganisms. International Journal of Microbiological Research 3, 46-52.

Barnosky AD, Matzke N, Tomiya S, Wogan GOU, Swartz B, Quental TB, Marshall G, McGuire JL, Lindsey EL, Maguire KC, Mersey B, Ferrer EA (2011) Has the Earth's sixth mass extinction already arrived? Nature 471, 51-57.

Barrett JE, Virginia RA, Wall DH (2002) Trends in resin and KCl-extractable soil nitrogen across landscape gradients in Taylor Valley, Antarctica. Ecosystems 5, 289-299.

Beadle NCW (1962) Soil phosphate and the delimitation on plant communities in eastern Australia II. Ecology 43, 281-288.

Beddows AR (1961a) Biological flora of the British Isles: No. 2148. Holcus lanatus L. The Journal of Ecology 49, 421-430.

Beddows AR (1961b) Flowering behaviour, compatibility and major gene differences in Holcus lanatus L. New Phytologist 60, 312-324.

Beltman B, Willems JH, Güsewell S (2007) Flood events overrule fertiliser effects on biomass production and species richness in riverine grasslands. Journal of Vegetation Science 18, 625-634.

Berg MP, Ellers J (2010) Trait plasticity in species interactions: a driving force of community dynamics. Evolutionary Ecology 24, 617-629.

Bernal MP, McGrath SP (1994) Effects of pH and heavy metal concentrations in solution culture on the proton release, growth and elemental composition of Alyssum murale and Raphanus sativus L. Plant and Soil 166, 83-92. 
Bloom AJ (1985) Resource limitation in plants - an economic analogy. Annual Review of Ecology and Systematics 16, 363-392.

Bobbink R, Ashmore MR, Braun S, Flückiger W, Van den Wyngaert IJJ (2003) Empirical nitrogen critical loads for natural and semi-natural ecosystems: 2002 update. 'Empir. Crit. Loads Nitrogen'. pp. 43-170. (Swiss Agency for Environment, Forest and Landscape SAEFL: Berne)

Bobbink R, Bik L, Willems JH (1988) Effects of nitrogen fertilization on vegetation structure and dominance of Brachypodium pinnatum (L.) Beauv. in chalk grassland. Acta Botanica Neerlandica 37, 231-242.

Bobbink R, Hicks K, Galloway J, Spranger T, Alkemade R, Ashmore M, Bustamante M, Cinderby S, Davidson E, Dentener F, Emmett B, Erisman JW, Fenn M, Gilliam F, Nordin A, Pardo L, De Vries W (2010) Global assessment of nitrogen deposition effects on terrestrial plant diversity: a synthesis. Ecological Applications 20, 30-59.

Bobbink R, Hornung M, Roelofs JGM (1998) The effects of air-borne nitrogen pollutants on species diversity in natural and semi-natural European vegetation. Journal of Ecology 86, 717-738.

Bobbink R, Willems JH (1991) Impact of different cutting regimes on the performance of Brachypodium pinnatum in Dutch chalk grassland. Biological Conservation 56, 1-21.

Bollens U, Güsewell S, Klötzli F (2001) Vegetation changes in two Swiss fens affected by eutrophication and desiccation. 111, 139-155.

Bonnin I, Colas B, Bacles C, Holl AC, Hendoux F, Destiné B, Viard F (2002) Population structure of an endangered species living in contrasted habitats: Parnassia palustris (Saxifragaceae). Molecular Ecology 11, 979-990.

Bossuyt B (2007) Genetic rescue in an isolated metapopulation of a naturally fragmented plant species, Parnassia palustris. Conservation Biology 21, 832-841.

Braun-Blanquet J (1964) 'Pflanzensoziologie. Grundzüge der Vegetationskunde.' (Springer: Wien)

Brouwer E, Hans B, Roelofs JGM (2001) Nutrient requirements of ephemeral plant species from wet, mesotrophic soils. Journal of Vegetation Science 12, 319-326.

Brown JH (1984) On the relationship between abundance and distribution of species. The American Naturalist 124, 255-279.

Brundrett MC (2009) Mycorrhizal associations and other means of nutrition of vascular plants: understanding the global diversity of host plants by resolving conflicting information and developing reliable means of diagnosis. Plant and Soil 320, 37-77.

Bu H, Chen X, Xu X, Liu K, Jia P, Du G (2007) Seed mass and germination in an alpine meadow on the eastern Tsinghai-Tibet plateau. Plant Ecology 191, 127-149.

Burton GW (1943) Factors influencing seed setting in several southern grasses. Journal of the American Society of Agronomy 35, 465-474.

Callaway RM, Pennings SC, Richards CL (2003) Phenotypic plasticity and interactions among plants. Ecology 84, 1115-1128.

Camarero L, Catalan J (2012) Atmospheric phosphorus deposition may cause lakes to revert from phosphorus limitation back to nitrogen limitation. Nature Communications 3, 6-10.

Campbell BD, Grime JP (1992) An experimental test of plant strategy theory. Ecology 73, 15-29.

Cardinale BJ, Hillebrand H, Harpole WS, Gross K, Ptacnik R (2009) Separating the influence of resource 'availability' from resource 'imbalance' on productivity-diversity relationships. Ecology Letters 12, 475-487.

Carpenter SR, Caraco NF, Correll DL, Howarth RW, Sharpley AN, Smith VH (1998) Nonpoint pollution of surface waters with phosphorus and nitrogen. Ecological Applications 8, 559-568.

Ceulemans T, Merckx R, Hens M, Honnay O (2011) A trait-based analysis of the role of phosphorus vs. nitrogen enrichment in plant species loss across North-west European grasslands. Journal of Applied Ecology 48, 1155-1163.

Ceulemans T, Merckx R, Hens M, Honnay O (2013) Plant species loss from European semi-natural grasslands following nutrient enrichment - is it nitrogen or is it phosphorus? Global Ecology and Biogeography 22, 73-82. 
Chapin FS (1980) The mineral nutrition of wild plants. Annual Review of Ecology and Systematics 11, 233-260. Chapin FS, Vitousek PM, Van Cleve K (1986) The nature of nutrient limitation in plant communities. American Naturalist 127, 48-58.

Chapin FSI, Zavaleta ES, EvinerVT, Naylor RL, Vitousek PM, Reynolds HL, Hooper DU, Lavorel S, Sala OE, Hobbie SE, Mack MC, Díaz S (2000) Consequences of changing biodiversity. Nature 405, 234-242.

Chaudhary MI, Adu-Gyamfi JJ, Saneoka H, Nguyen NT, Suwa R, Kanai S, El-Shemy HA, Lightfoot DA, Fujita K (2008) The effect of phosphorus deficiency on nutrient uptake, nitrogen fixation and photosynthetic rate in mashbean, mungbean and soybean. Acta Physiologiae Plantarum 30, 537-544.

Chrysargyris A, Panayiotou C, Tzortzakis N (2016) Nitrogen and phosphorus levels affected plant growth, essential oil composition and antioxidant status of lavender plant (Lavandula angustifolia Mill.). Industrial Crops \& Products 83, 577-586.

Ciais P, Sabine C, Bala G, Bopp L, Brovkin V, Canadell J (2014) Carbon and other biogeochemical cycles. 'Clim. Chang. 2013 Phys. Sci. Basis'. pp. 465-570. (Cambridge University Press: Cambridge)

Clark GM, Tilman D (2008) Loss of plant species after chronic low-level nitrogen deposition to prairie grasslands. Nature 451, 712-715.

Cordazzo CV (2002) Effect of seed mass on germination and growth in three dominant species in southern Brazilian coastal dunes. Brazilian Journal of Biology 62, 427-435.

Cornelissen JHC, Lavorel S, Garnier E, Díaz S, Buchmann N, Gurvich DE, Reich PB, ter Steege H, Morgan HD, van der Heijden MGA, Pausas JG, Poorter H (2003) A handbook of protocols for standardised and easy measurement of plant functional traits worldwide. Australian Journal of Botany 51, 335-380.

Cornwell WK, Grubb PJ (2003) Regional and local patterns in plant species richness with respect to resource availability. Oikos $100,417-428$.

Dakora FD, Phillips DA (2002) Root exudates as mediators of mineral acquisition in low-nutrient environments. Plant and Soil 245, 35-47.

Dentener F, Stevenson D, Ellingsen K, Van Noije T, Schultz M, Amann M, Atherton C, Bell N, Bergmann D, Bey I, Bouwman L, Butler T, Cofala J, Collins B, Drevet J, Doherty R, Eickhout B, Eskes H, Fiore A, Gauss M, Hauglustaine D, Horowitz L, Isaksen ISA, Josse B, Lawrence M, Krol M, Lamarque JF, Montanaro V, Müller JF, Peuch VH, Pitari G, Pyle J, Rast S, Rodriguez J, Sanderson M, Savage NH, Shindell D, Strahan S, Szopa S, Sudo K, Van Dingenen R, Wild O, Zeng G (2006) The global atmospheric environment for the next generation. Environmental Science and Technology 40, 3586-3594.

Duprè C, Stevens CJ, Ranke T, Bleeker A, Peppler-Lisbach C, Gowing DJG, Dise NB, Dorland E, Bobbink R, Diekmann M (2010) Changes in species richness and composition in European acidic grasslands over the past 70 years: the contribution of cumulative atmospheric nitrogen deposition. Global Change Biology 16, 344-357.

Eisele KA, Schimel DS, Kapustka LA, Parton WJ (1989) Effects of available P and N : P ratios on non-symbiotic dinitrogen fixation in tallgras prairie soils. Oecologia 79, 471-474.

El-Kahloun M, Boeye D, van Haesebroeck V, Verhagen B (2003) Differential recovery of above- and below-ground rich fen vegetation following fertilization. Journal of Vegetation Science 14, 451-458.

Ellison AM (2001) Interspecific and intraspecific variation in seed size and germination requirements of Sarracenia (sarraceniaceae). American Journal of Botany 88, 429-437.

Elser JJ, Andersen T, Baron JS, Bergström A, Jansson M, Kyle M, Nydick KR, Steger L, Hessen DO (2009) Shifts in lake N:P stoichiometry and nutrient limitation driven by atmospheric nitrogen deposition. Science 326, 835-837.

Elser JJ, Bracken MES, Gleland EE, Gruner DS, Harpole WS, Hillebrand H, Ngai JT, Seabloom EW, Shurin JB, Smith JE (2007) Global analysis of nitrogen and phosphorus limitation of primary producers in freshwater, marine and terrestrial ecosystems. Ecology Letters 10, 1135-1142.

Elser JJ, Fagan WF, Kerkhoff AJ, Swenson NG, Enquist BJ (2010) Biological stoichiometry of plant production: metabolism, scaling and ecological response to global change. New Phytologist 186, 593-608.

Elser JJ, Sterner RW, Gorokhova E, Fagan WF, Markow TA, Cotner JB, Harrison JF, Hobbie SE, Odell GM, Weider LW (2000) Biological stoichiometry from genes to ecosystems. Ecology Letters 3, 540-550. 
Erisman JW, Sutton MA, Galloway J, Klimont Z, Winiwarter W (2008) How a century of ammonia synthesis changed the world. Nature Geoscience 1, 636-639.

Esler KJ, Cowling RM, Witkowski ETF, Mustart PJ (1989) Reproductive traits and accumulation of nitrogen and phosphorus during the development of fruits of Protea compacta R. Br. (Calcifuge) and Protea obtusifolia Buek. ex Meisn. (Calcicole). New Phytologist 112, 109-115.

Evans LS, Conway CA (1980) Effects of acidic solutions on sexual reproduction of Pteridium aquilinum. American Journal of Botany 67, 866-875.

Evans JR, Poorter H (2001) Photosynthetic acclimation of plants to growth irradiance: the relative importance of specific leaf area and nitrogen partitioning in maximizing carbon gain. Plant, Cell and Environment 24, 755-767.

Falkowski PG, Fenchel T, Delong EF (2008) The microbial engines that drive earth's biogeochemical cycles. Science 320, 1034-1039.

Falkowski P, Scholes RJ, Boyle E, Canadell J, Canfield D, Elser J, Gruber N, Hibbard K, Hogberg P, Linder S, Mackenzie FT, Moore B, Pedersen T, Rosental Y, Seitzinger S, Smetacek V, Steffen W (2000) The global carbon cycle: a test of our knowledge of earth as a system. Science 290, 291-296.

Farnsworth EJ, Ogurcak DE (2008) Functional groups of rare plants differ in levels of imperilment. American Journal of Botany 95, 943-953.

Fawcett RS, Slife FW (1978) Effects of field applications of nitrate on weed seed germination and dormancy. Weed Science 26, 594-596.

Fay P, Mitchell DT, Osborne BA (1996) Photosynthesis and nutrient-use efficiency of barley in response to low arbuscular mycorrhizal colonization and addition of phosphorus. New Phytologist 132, 425-433.

Fay PA, Prober SM, Harpole WS, Knops JMH, Bakker JD, Borer ET, Lind EM, MacDougall AS, Seabloom EW, Wragg PD, Adler PB, Blumenthal DM, Buckley YM, Chu C, Cleland EE, Collins SL, Davies KF, Du G, Feng X, Firn J, Gruner DS, Hagenah N, Hautier Y, Heckman RW, Jin VL, Kirkman KP, Klein J, Ladwig LM, Li Q, McCulley RL, Melbourne BA, Mitchell CE, Moore JL, Morgan JW, Risch AC, Schuetz M, Stevens CJ, Wedin DA, Yang LH (2015) Grassland productivity is limited by multiple nutrients. Nature Plants 1, 1-5.

Fenner M (1983) 'Seed Ecology.' (Chapman and Hall: London)

Fenner M (1986a) The allocation of minerals to seeds in Senecio vulgaris plants subjected to nutrient shortage. Journal of Ecology 74, 385-392.

Fenner M (1986b) A bioassay to determine the limiting minerals for seeds from nutrient-deprived Senecio vulgaris plant. Journal of Ecology 74, 497-505.

Fenner M, Thompson K (2005) 'The Ecology of Seeds.' (Cambridge University Press: New York)

Field A (2013) 'Discovering Statistics Using IBM SPSS Statistics.' (SAGE Publications Ltd: London)

Flückiger W, Braun S (1998) Nitrogen deposition in Swiss forests and its possible relevance for leaf nutrient status, parasite attacks and soil acidification. Environmental Pollution 102, 69-76.

Fort F, Cruz P, Catrice O, Delbrut A, Luzarreta M, Stroia C, Jouany C (2015) Root functional trait syndromes and plasticity drive the ability of grassland Fabaceae to tolerate water and phosphorus shortage. Environmental and Experimental Botany 110, 62-72.

Foy RH (2005) The return of the phosphorus paradigm: agricultural phosphorus and eutrophication. 'Phosphorus Agric. Environ.' pp. 911-939. (American Society of Agronomy Monograph No. 46: Madison)

Fujita Y (2010) Balance Matters-N:P Stoichiometry and Plant Diversity in Grassland Ecosystems. Utrecht University.

Fujita Y, Robroek BJM, de Ruiter PC, Heil GW, Wassen MJ (2010) Increased N affects P uptake of eight grassland species: the role of root surface phosphatase activity. Oikos 119, 1665-1673.

Fujita Y, de Ruiter PG, Wassen MJ, Heil GW (2010) Time-dependent, species-specific effects of N:P stoichiometry on grassland plant growth. Plant and Soil 334, 99-112.

Fujita Y, Olde Venterink H, van Bodegom PM, Douma JC, Heil GW, Hölzel N, Jabłońska E, Kotowski W, Okruszko T, Pawlikowski P, de Ruiter PC, Wassen MJ (2014) Low investment in sexual reproduction threatens plants adapted to phosphorus limitation. Nature 505, 82-86.

Fynn RWS, Morris CD, Kirkman KP (2005) Plant strategies and trait trade-offs influence trends in competitive ability along gradients of soil fertility and disturbance. Journal of Ecology 93, 384-394. 
Galloway LF (2001) The effect of maternal and paternal environments on seed characters in the herbaceous plant Campanula americana (Campanulaceae). American Journal of Botany 88, 832-840.

Ghannoum O, Conroy JP (2007) Phosphorus deficiency inhibits growth in parallel with photosynthesis in a C3 (Panicum laxum) but not two C4 (P. coloratum and Cenchrus ciliaris) grasses. Functional Plant Biology 34, 72-81.

Ghannoum O, Paul MJ, Ward JL, Beale MH, Corol DI, Conroy JP (2008) The sensitivity of photosynthesis to phosphorus deficiency differs between C3and C4 tropical grasses. Functional Plant Biology 35, 213-221.

Gibson DJ (2009) 'Grasses and Grassland Ecology.' (Oxford University Press: New York)

Gifford RM (1974) A comparison of potential photosynthesis, productivity and yield of plant species with differing photosynthetic metabolism. Australian Journal of Plant Physiology 1, 107-117.

Gillespie AR, Pope PE (1989) Alfalfa $\mathrm{N}_{2}$-fixation enhances the phosphorus uptake of walnut in interplantings. Plant and Soil 113, 291-293.

Gough L, Osenberg CW, Gross KL, Collins SL, Fertilization SL (2000) Fertilization effects on species density and primary productivity in herbaceous plant communities. Oikos 3, 428-439.

Gray D, Thomas TH (1982) Seed germination and seedling emergence as influenced by the position of development of the seed on, and chemical applications to, the parent plant. 'Physiol. Biochem. Seed Dev. Dormancy Germination'. pp. 111-136. (Elsevier: Amsterdam)

Gressel N, McColl JG (1997) Phosphorus mineralisation and organic matter decomposition: a critical review. 'Driven by Nature, Plant Litter Qual. Decompos.' pp. 297-309. (CAB International: Wallingford)

Grime JP (1973a) Competitive exclusion in herbaceous vegetation. Nature 242, 344-347.

Grime JP (1973b) Control of species density in herbaceous vegetation. Journal of Environmental Management 1, 151-167.

Grime JP (1979) 'Plant Strategies and Vegetation Processes.' (Wiley: Chichester)

Grime JP (2001) 'Plant Strategies, Vegetation Processes, and Ecosystem Properties.' (Wiley: Chichester)

Grime JP, Hunt R (1975) Relative growth-rate: its range and adaptive significance in a local flora. Journal of Ecology 63, 393-422.

De Groot CC, Marcelis LFM, van Den Boogaard R, Kaiser WM, Lambers H (2003) Interaction of nitrogen and phosphorus nutrition in determining growth. Plant and Soil 248, 257-268.

Guignard MS, Leitch AR, Acquisti C, Eizaguirre C, Elser JJ, Hessen DO, Jeyasingh PD, Neiman M, Richardson AE, Soltis PS, Soltis DE, Stevens CJ, Trimmer M, Weider LJ, Woodward G, Leitch IJ (2017) Impacts of nitrogen and phosphorus: from genomes to natural ecosystems and agriculture. Frontiers in Ecology and Evolution 5, 70.

Güsewell S (2004) N : P ratios in terrestrial plants: variation and functional significance. New Phytologist 164, 243-266.

Güsewell S (2005a) High nitrogen : phosphorus ratios reduce nutrient retention and second-year growth of wetland sedges. New Phytologist 166, 537-550.

Güsewell S (2005b) Responses of wetland graminoids to the relative supply of nitrogen and phosphorus. Plant Ecology 176, 35-55.

Güsewell S, Bollens U, Ryser P, Kloetzli F (2003) Contrasting effects of nitrogen, phosphorus and water regime on first- and second-year growth of 16 wetland plant species. Functional Ecology 17, 754-765.

Güsewell S, Koerselman W (2002) Variation in nitrogen and phosphorus concentrations of wetland plants. Perspectives in Plant Ecology, Evolution and Systematics 5, 37-61.

Hanley ME, UnnaJE, Darvill B (2003) Seed size and germination response: a relationship for fire-following plant species exposed to thermal shock. Oecologia 134, 18-22.

Harper JL (1977) 'Population Biology of Plants.' (Academic Press: London)

Harpole WS, Tilman D (2007) Grassland species loss resulting from reduced niche dimension. Nature 446, 791-793.

Harrison AF (1987) 'Soil Organic Phosphorus: a review of world literature.' (C. A. B. International: Wallingford)

Hautier Y, Niklaus PA, Hector A (2009) Competition for light causes plant biodiversity loss after eutrophication. Science 324, 636-638. 
Heady HF (1957) The measurement and value of plant height in the study of herbaceous vegetation. Ecology 38, 313-320.

Hejcman M, Kristalova V, Cervena K, Hrdlickova J, Pavlu V (2012) Effect of nitrogen, phosphorus and potassium availability on mother plant size, seed production and germination ability of Rumex crispus. Weed Research 52, 260-268.

Henery ML, Westoby M (2001) Seed mass and seed nutrient content as predictors of seed output variation between species. Oikos 92, 479-490.

Hermans C, Hammond JP, White PJ, Verbruggen N (2006) How do plants respond to nutrient shortage by biomass allocation? Trends in Plant Science 11, 610-617.

Herold A (1980) Regulation of photosynthesis by sink activity-the missing link. New Phytologist 86, 131-144.

van der Hoek D, van Mierlo AJEM, van Groenendael JM (2004) Nutrient limitation and nutrient-driven shifts in plant species composition in a species-rich fen meadow. Journal of Vegetation Science 15, 389-396.

Hölzel N, Otte A (2003) Restoration of a species-rich flood meadow by topsoil removal and diaspore transfer with plant material. Applied Vegetation Science 6, 131-140.

Hood RC (2001) The effect of soil temperature and moisture on organic matter decomposition and plant growth. Isotopes in Environmental and Health Studies 37, 25-41.

Houba VJG, van Schouwenburg JC, Walinga I, Novozamsky I (1979) 'Soil Analysis II. Methods of Analysis for Soils.' (Agricultural University: Wageningen)

Hrdličková J, Hejcman M, Křištálová V, Pavlů V (2011) Production, size, and germination of broad-leaved dock seeds collected from mother plants grown under different nitrogen, phosphorus, and potassium supplies. Weed Biology and Management 11, 190-201.

Huston M (1980) Soil nutrients and tree species richness in costa rican forests. Journal of Biogeography 7, 147-157.

Isselstein J, Tallowin JRB, Smith REN (2002) Factors affecting seed germination and seedling establishment of fen-meadow species. Restoration Ecology 10, 173-184.

Jagadish SVK, Bahuguna RN, Djanaguiraman M, Gamuyao R, Prasad PVV, Craufurd PQ (2016) Implications of high temperature and elevated $\mathrm{CO}_{2}$ on flowering time in plants. Frontiers in Plant Science 7, 1-11.

John R (1999) The Autecology of the Meadow Thistle (Cirsium dessectum L. Hill) on Devon Rhos Pastures with Particular Reference to the Effect of Major Environmental Variables on the Population Dynamics. University of Plymouth.

Johnson CR (1984) Phosphorus nutrition on mycorrhizal colonization, photosynthesis, growth and nutrient composition of Citrus aurantium. Plant and Soil 42, 35-42.

Johnson AD, Leake JR, Lee JA (1999) The effects of quantity and duration of simulated pollutant nitrogen deposition on root-surface phosphatase activities in calcareous and acid grasslands: a bioassay approach. New Phytologist 141, 433-442.

Jungk A (2009) Carl sprengel-The founder of agricultural chemistry: a re-appraisal commemorating the 150th anniversary of his death. Journal of Plant Nutrition and Soil Science 172, 633-636.

Kachi N, Hirose T (1983) Limiting nutrients for plant growth in coastal sand dune soils. Journal of Ecology 71, 937-944.

Kaya M, Kaya G, Kaya MD, Atak M, Saglam S, Khawar KM, Ciftci CY (2008) Interaction between seed size and $\mathrm{NaCl}$ on germination and early seedling growth of some Turkish cultivars of chickpea (Cicer arietinum L.). Journal of Zhejiang University-SCIENCE B 9, 371-377.

Keddy P, Fraser LH, Keogh TA (2001) Responses of 21 wetland species to shortages of light, nitrogen and phosphorus. Bulletin of the Geobotanical Institute ETH 67, 13-25.

Kerkhoff AJ, Fagan WF, Elser JJ, Enquist BJ (2006) Phylogenetic and growth form variation in the scaling of nitrogen and phosphorus in the seed plants. The American Naturalist 168, E103-E122.

Koerselman W, Bakker SA, Blom M (1990) Nitrogen, phosphorus and potassium budgets for two small fens surrounded by heavily fertilized pastures. The Journal of Ecology 78, 428.

Köhler B, Ryser P, Güsewell S, Gigon A (2001) Nutrient availability and limitation in traditionally mown and in abandoned limestone grasslands: a bioassay experiment. Plant and Soil 230, 323-332. 
Körner C (2003) Carbon limitation in trees. Journal of Ecology 91, 4-17.

Körner C (2015) Paradigm shift in plant growth control. Current Opinion in Plant Biology 25, 107-114.

Koslowski J (1992) Optimal allocation of resources to growth and reproduction: implications for age and size at maturity. Trends in Ecology and Evolution 7, 15-19.

Krekule J, Kohli RK (1981) The condition of the apical meristem of seedlings responsive to a promotive effect of abscisic acid on flowering in the short-day plant, Chenopodium rubrum. Zeitschrift für Pflanzenphysiologie 103, 45-51.

Kumar K, Goh KM (2000) Biological nitrogen fixation, accumulation of soil nitrogen and nitrogen balance for white clover (Trifolium repens L.) and field pea (Pisum sativum L.) grown for seed. Field Crops Research 68, 49-59.

Kuppers M, Koch G, Mooney H (1988) Compensating effects to growth of changes in dry matter allocation in response to variation in photosynthetic characteristics induced by photoperiod, light and nitrogen. Functional Plant Biology 15, 287-298.

Lahti T, Kemppainen E, Kurtto A, Uotila P (1991) Distribution and biological characteristics of threatened vascular plants in Finland. Biological Conservation 55, 299-314

Lambers H, Brundrett MC, Raven JA, Hopper SD (2011) Plant mineral nutrition in ancient landscapes: high plant species diversity on infertile soils is linked to functional diversity for nutritional strategies. Plant and Soil 348, 7-27.

Lambers H, Chapin III FS, Pons TL (2008) 'Plant Physiological Ecology.' (Springer: New York)

Lambers H, Poorter H (1992) Inherent variation in growth rate between higher plants: a search for physiological causes and ecological consequences. Advances in Ecological Research 23, 187-261.

Lambers H, Raven JA, Shaver GR, Smith SE (2008) Plant nutrient-acquisition strategies change with soil age. Trends in Ecology and Evolution 23, 95-103.

Lambers H, Shane MW, Cramer MD, Pearse SJ, Veneklaas EJ (2006) Root structure and functioning for efficient acquisition of phosphorus: matching morphological and physiological traits. Annals of Botany 98, 693-713.

Lamers LPM, Tomassen HBM, Roelofs JGM (1998) Sulfate-induced eutrophication and phytotoxicity in freshwater wetlands. Environmental Science and Technology 32, 199-205.

Lamont BB, Groom PK (2013) Seeds as a source of carbon, nitrogen, and phosphorus for seedling establishment in temperate regions: a synthesis. American Journal of Plant Sciences 4, 30-40.

Lannes LS, Bustamante MMC, Edwards PJ, Olde Venterink H (2012) Alien and endangered plants in the Brazilian Cerrado exhibit contrasting relationships with vegetation biomass and $\mathrm{N}$ : P stoichiometry. New Phytologist 196, 816-823.

Leake JR, Read DJ (1990) Chitin as a nitrogen source for mycorrhizal fungi. Mycological Research 94, 993-995.

Lee WG, Fenner M (1989) Mineral nutrient allocation in seeds and shoots of twelve Chionochloa species in relation to soil fertility. Journal of Ecology 77, 704-716.

Liao H, Yan X (1999) Seed size is closely related to phosphorus use efficiency and photosynthetic phosphorus use efficiency in common bean. Journal of Plant Nutrition 22, 877-888.

Von Liebig J (1842) 'Die organische Chemie in ihrer Anwendung auf Agricultur und Physiologie.' (Friedrich Vieweg und Sohn: Braunschweig)

Limpens J, Tomassen HBM, Berendse F (2003) Expansion of Sphagnum fallax in bogs: striking the balance between $\mathrm{N}$ and $\mathrm{P}$ availability. Journal of Bryology 25, 1-8.

Loeppky HA, Coulman BE (2001) Residue removal and nitrogen fertilization affects tiller development and flowering in meadow bromegrass. Agronomy Journal 93, 891-895.

Maathuis FJ (2007) Transport across plant membranes. 'Plant Solute Transp.' pp. 75-96. (Blackwell Publishing: Oxford)

Marion GM, Hastings SJ, Oberbauer SF, Oechel WC (1989) Soil-plant element relationships in a tundra ecosystem. Holarctic Ecology 12, 296-303.

De Mars H, Garritsen AC (1997) Interrelationship between water quality and groundwater flow dynamics in a small wetland system along a sandy hill ridge. Hydrological Processes 11, 335-351.

Marschner H (1995) 'Mineral Nutrition of Higher Plants.' (Academic Press: London) 
Marshall DL (1986) Effect of seed size on seedling success in three species of Sesbania (Fabaceae). American Journal of Botany 73, 457-464.

McGill BJ, Enquist BJ, Weiher E, Westoby M (2006) Rebuilding community ecology from functional traits. Trends in Ecology and Evolution 21, 178-185.

McJannet CL, Keddy PA, Pick FR (1995) Nitrogen and phosphorus tissue concentrations in 41 wetland plants: a comparison across habitats and functional groups. Functional Ecology 9, 231-238.

van der Meijden R (2005) 'Heukels' Flora van Nederland.' (Wolters-Noordhoff: Groningen)

Millennium Ecosystem Assessement (2005) 'Ecosystems and Human Well-being: Synthesis.' (Island Press)

Miralles DG, van den Berg MJ, Teuling AJ, de Jeu RAM (2012) Soil moisture-temperature coupling: a multiscale observational analysis. Geophysical Research Letters 39, 2-7.

Mitchley J, Grubb PJ (1986) Control of relative abundance of perennials in chalk grassland in southern England: I. Constancy of rank order and results of pot- and field-experiments on the role of interference. The Journal of Ecology 74, 1139-1166.

Mittelbach GG, Steiner GF, Scheiner SM, Gross KL, Reynolds HL, Waide RB, Willig MR, Dodson SI, Gough L (2001) What is the observed relationship between species richness and productivity? Ecology 82, 2381-2396.

Muller B, Pantin F, Génard M, Turc O, Freixes S, Piques M, Gibon Y (2011) Water deficits uncouple growth from photosynthesis, increase $\mathrm{C}$ content, and modify the relationships between $\mathrm{C}$ and growth in sink organs. Journal of experimental Botany 62, 1715-1729.

Murray BR, Thrall PH, Gill AM, Nicotra AB (2002) How plant life-history and ecological traits relate to species rarity and commonness at varying spatial scales. Austral Ecology 27, 291-310.

Neumann G, Massonneau A, Langlade N, Dinkelaker B, Hengeler C, Roemheld V, Martinoia E (2000) Physiological aspects of cluster root function and development in phosphorus-deficient White Lupin (Lupinus albus L.). Annals of Botany 85, 909-919.

Niklas KJ, Owens T, Reich PB, Cobb ED (2005) Nitrogen/phosphorus leaf stoichiometry and the scaling of plant growth. Ecology Letters 8, 636-642.

Olander LP, Vitousek PM (2000) Regulation of soil phosphatase and chitinase activity by N and P availability. Biogeochemistry 49, 175-190.

Olde Venterink H (2000) Nitrogen, Phosphorus and Potassium Flows Controlling Plant Productivity and Species Richness. Utrecht University.

Olde Venterink H (2011) Does phosphorus limitation promote species-rich plant communities? Plant and Soil 345, 1-9.

Olde Venterink H, Wassen MJ, Verkroost AWM, De Ruiter PC (2003) Species richness-productivity patterns differ between N-, P-, and K-limited wetlands. Ecology 84, 2191-2199.

Oster G, Wang H (2000) Reverse engineering a protein: the mechanochemistry of ATP synthase. Biochimica et Biophysica Acta - Bioenergetics 1458, 482-510.

Otto SP (2009) The evolutionary enigma of sex. American Naturalist 174, S1-S14.

Pałczynski A, Stepa T (1991) Biomass production in main plant associations of the Biebrza valley with respect to soil conditions. Polish Ecological Studies 17, 53-62.

Parrish JAD, Bazzaz FA (1985) Nutrient content of Abutilon theophrasti seeds and the competitive ability of the resulting plants. Oecologia 65, 247-251.

Pärtel M, Zobel M, Zobel K, van der Maarel E (1996) The species pool and its relation to species richness: evidence from Estonian plant communities. Oikos 75, 111-117.

Peck JR (1994) A ruby in the rubbish: beneficial mutations, deleterious mutations and the evolution of sex. Genetics 137, 597-606.

Peerez Corona MEP, van der Klundert I, Verhoeven JTA (1996) Availability of organic and inorganic phosphorus compounds as phosphorus sources for Carex species. New Phytologist 133, 225-231.

Peñuelas J, Poulter B, Sardans J, Ciais P, van der Velde M, Bopp L, Boucher O, Godderis Y, Hinsinger P, Llusia J, Nardin E, Vicca S, Obersteiner M, Janssens IA (2013) Human-induced nitrogen-phosphorus imbalances alter natural and managed ecosystems across the globe. Nature Communications 4, 1-10.

Pimm SL (1991) 'The Balance of Nature? Ecological Issues in the Conservation of Species and Communities.' (The University of Chicago Press: Chicago) 
Poorter H, van der Werf A (1998) Is inherent variation in RGR determined by LAR at low light and by NAR at high light? 'Inherent Var. Plant Growth'. pp. 309-336. (Backhuys Publishers: Leiden)

Putterill J, Laurie R, Macknight R (2004) It's time to flower: the genetic control of flowering time. BioEssays 26, 363-373.

Pywell RF, Bullock JM, Roy DB, Warman L, Walker KJ, Rothery P (2003) Plant traits as predictors of performance in ecological restoration. Journal of Applied Ecology 40, 65-77.

van Raalte G (2014) Vegetatieontwikkeling na Omvorming van Bollenvelden naar Natte Duinvalleien. (Wageningen)

Raghothama KG, Karthikeyan AS (2005) Phosphate acquisition. Plant and Soil 274, 37-49.

Rasran L, Vogt K, Jensen K (2007) Effects of litter removal and mowing on germination and establishment of two fen-grassland species along a productivity gradient. Folia Geobotanica 42, 271-288.

Reich PB, Hobbie SE (2013) Decade-long soil nitrogen constraint on the $\mathrm{CO}_{2}$ fertilization of plant biomass. Nature Climate Change 3, 278-282.

Reich PB, Hobbie SE, Lee TD, Pastore MA (2018) Unexpected reversal of C3 versus C4 grass response to elevated $\mathrm{CO}_{2}$ during a 20 -year field experiment. Science 360, 317-320.

Reich PB, Oleksyn J, Wright IJ (2009) Leaf phosphorus influences the photosynthesis-nitrogen relation: a cross-biome analysis of 314 species. Oecologia 160, 207-212

Reich PB, Walters MB (1994) Photosynthesis-nitrogen relations in Amazonian tree species. Oecologia 97, 73-81.

Reich PB, Walters MB, Ellsworth DS (1992) Leaf life-span in relation to leaf, plant, and stand characteristics among diverse ecosystems. Ecological Monographs 62, 365-392.

Robson AD (1989) 'Soil Acidity and Plant Growth.' (Academic Press INC.: California)

Rockström J, Steffen W, Noone K, Persson Å, Chapin FS, Lambin EF, Lenton TM, Scheffer M, Folke C, Schellnhuber HJ, Nykvist B, de Wit CA, Hughes T, van der Leeuw S, Rodhe H, Sörlin S, Snyder PK, Costanza R, Svedin U, Falkenmark M, Karlberg L, Corell RW, Fabry VJ, Hansen J, Walker B, Liverman D, Richardson K, Crutzen P, Foley JA (2009) A safe operating space for humanity. Nature 461, 472-475.

Roeling IS, Ozinga WA, van Dijk J, Eppinga MB, Wassen MJ (2018) Plant species occurrence patterns in Eurasian grasslands reflect adaptation to nutrient ratios. Oecologia 186, 1055-1067.

Roem WJ, Berendse F (2000) Soil acidity and nutrient supply ratio as possible factors determining changes in plant species diversity in grassland and heathland communities. Biological Conservation 92, 151-161.

Sala OE, Chapin III FS, Armesto JJ, Berlow E, Dirzo R, Huber-sanwald E, Huenneke LF, Robert B, Kinzig A, Leemans R, Lodge DM, Mooney HA, Oesterheld M, Poff NL, Sykes MT, Walker BH, Walker M, Wall DH, Sala OE, Chapin FS, Armesto JJ, Berlow E, Bloomfield J, Dirzo R, Huber-sanwald E, Huenneke LF, Jackson RB, Kinzig A, Leemans R, Lodge DM, Mooney HA, Oesterheld M, Poff NL, Sykes MT, Walker BH, Walker M, Wall DH (2000) Global biodiversity scenarios for the year 2100. Science 287, 1770-1774

Schaminée JHJ, Stortelder AHF, Weeda EJ (1996) 'De Vegetatie van Nederland. Deel 3: Plantengemeenschappen van Graslanden, Zomen en Droge Heiden.' (Opulus: Uppsala)

Schat H (1983) Germination of some dune ecology slack pioneers. Acta Botanica Neerlandica 32, 203-212.

Schmid B, Bazzaz FA, Weine J (1995) Size dependency of sexual reproduction and of clonal growth in two perennial plants. Canadian Journal of Botany 73, 1831-1837.

Seitzinger SP, Harrison JA, Dumont E, Beusen AHW, Bouwman AF (2005) Sources and delivery of carbon, nitrogen, and phosphorus to the coastal zone: an overview of Global Nutrient Export from Watersheds (NEWS) models and their application. Global Biogeochemical Cycles 19, 1-11.

Shaver G, Kummerow J (1992) Phenology, resource allocation, and growth of arctic vascular plants. 'Arct. Ecosyst. a Chang. Clim.' pp. 193-211. (Academic Press: California)

Shaver GR, Melillo JM (1984) Nutrient budgets of marsh plants: efficiency concepts and relation to availability. Ecology 65, 1491-1510.

Shen J, Rengel Z, Tang C, Zhang F (2003) Role of phosphorus nutrition in development of cluster roots and release of carboxylates in soil-grown Lupinus albus. Plant and Soil 248, 199-206.

Silvertown J (1980) The dynamics of a grassland ecosystem: botanical equilibrium in the park grass experiment. Journal of Applied Ecology 17, 491-504. 
Sims JT, Simard RR, Joern BC (1998) Phosphorus loss in agricultural drainage: historical perspective and current research. Journal of Environment Quality 27, 277-293.

Smith VH (1998) Cultural eutrophication of inland, estuarine, and coastal waters. 'Limitations, Front. Ecosyst. Ecol.' pp. 7-49. (Springer-Verlag: New York)

Smith VH, Tilman GD, Nekola JC (1999) Eutrophication: impacts of excess nutrient inputs on freshwater, marine, and terrestrial ecosystems. Environmental Pollution 100, 179-196.

Soons MB, Heil GW, Nathan R, Katul GG (2004) Determinants of long-distance seed dispersal by wind in grasslands. Ecology 85, 3056-3068.

Steffen W, Richardson K, Rockström J, Cornell SE, Fetzer I, Bennett EM, Biggs R, Carpenter SR, de Vries W, de Wit CA, Folke C, Gerten D, Heinke J, Mace GM, Persson LM, Ramanathan V, Reyers B, Sörlin S (2015) Planetary boundaries: guiding human development on a changing planet. Science 347, 736.

Sterner RW (2008) Review paper on the phosphorus limitation paradigm for lakes. International Review of Hydrobiology 93, 433-445.

Sterner R, Elser J (2002) 'Ecological Stoichiometry: The Biology of Elements from Molecules to the Biosphere.' (Princeton University Press: Princeton)

Stevens CJ, Dise NB, Mountford JO, Gowing DJ (2004) Impact of nitrogen deposition on the species richness of grasslands. Science 303, 1876-1879.

Stevens CJ, Dupr C, Dorland E, Gaudnik C, Gowing DJG, Bleeker A, Diekmann M, Alard D, Bobbink R, Fowler D, Corcket E, Mountford JO, Vandvik V, Aarrestad PA, Muller S, Dise NB (2010) Nitrogen deposition threatens species richness of grasslands across Europe. Environmental Pollution 158, 2940-2945.

Stewart H, Miao SL, Colbert M, Carraher Jr. CE (1997) Seed germination of two cattail (Typha) species as a function of everglades nutrient levels. Wetlands 17, 116-122.

Sundareshwar P, Morris J, Koepfler E, Fornwalt B (2003) Phosphorus limitation of coastal ecosystem processes. Science 299, 563-565.

Sutton MA, Reis S, Riddick SN, Dragosits U, Nemitz E, Theobald MR, Tang YS, Braban GF, Vieno M, Dore AJ, Mitchell RF, Wanless S, Daunt F, Fowler D, Blackall TD, Milford C, Flechard CR, Loubet B, Massad R, Cellier P, Personne E, Coheur PF, Clarisse L, van Damme M, Ngadi Y, Clerbaux C, Skjøth CA, Geels C, Hertel O, Kruit RJW, Pinder RW, Misselbrook TH, Bleeker A, Dentener F, de Vries W (2013) Towards a climate-dependent paradigm of ammonia emission and deposition. Philosophical Transactions of the Royal Society B: Biological Sciences 368, 20130166.

Terry N, Ulrich A (1973) Effects of phosphorus deficiency on the photosynthesis and respiration of leaves of sugar beet. Plant Physiology 51, 43-47.

Thompson K (1987) Seeds and seed banks. New Phytologist 106, 23-34.

Tilman D (1980) Resources: a graphical-mechanistic approach to competition and predation. The American Naturalist 116, 362-393.

Tilman D (1982) 'Resource Competition and Community Structure.' (Princeton University Press: Princeton)

Tomassen HBM, Smolders AJP, Lamers LPM, Roelofs JGM (2003) Stimulated growth of Betula pubescens and Molinia caerulea on ombrotrophic bogs: role of high levels of atmospheric nitrogen deposition. Journal of Ecology 91, 357-370.

Tonitto G, David MB, Drinkwater LE (2006) Replacing bare fallows with cover crops in fertilizer-intensive cropping systems: a meta-analysis of crop yield and $\mathrm{N}$ dynamics. Agriculture, Ecosystems and Environment 112, 58-72.

Tuohy JM, Prior JAB, Stewart GR (1991) Photosynthesis in relation to leaf nitrogen and phosphorus content in Zimbabwean trees. Oecologia 88, 378-382.

Turner BL, Chudek JA, Whitton BA, Baxter R (2003) Phosphorus composition of upland soils polluted by long-term atmospheric nitrogen deposition. Biogeochemistry 65, 259-274.

Turner BL, Haygarth PM (2001) Phosphorus solubilization in rewetted soils. Nature 411, 258.

Tüzel E, Sevim V, Erzan A (2001) Strategies for the evolution of sex. Physical Review E 64, 1-13.

Usuda H (1995) Phosphate deficiency in maize. V. Mobilization of nitrogen and phosphorus within shoots of young plants and its relationship to senescence. Plant and Cell Physiology 36, 1041-1049. 
Vance CP, Uhde-Stone C, Allan DL (2003) Phosphorus acquisition and use: critical adaptations by plants for securing a nonrenewable resource. New Phytologist 157, 423-447.

Veeranjaneyulu K, Ramadas V (1982) Heavy metal tolerance in normal populations of some weed species. Indian Journal of Plant Physiology 26, 148-154.

Vellend M, Geber MA (2005) Connections between species diversity and genetic diversity. Ecology Letters 8, 767-781.

Olde Venterink H, Güsewell S (2010) Competitive interactions between two meadow grasses under nitrogen and phosphorus limitation. Functional Ecology 24, 877-886.

Vera ML (1997) Effects of altitude and seed size on germination and seedling survival of heathland plants in north spain. Plant Ecology 133, 101-106.

Veresoglou ADS, Fitter AH (1984) Spatial and temporal patterns of growth and nutrient uptake of five co-existing grasses. Journal of Ecology 72, 259-272.

Verhoeven JTA, Koerselman W, Meuleman AFM (1996) Nitrogen- or phosphorus-limited growth in herbaceous, wet vegetation: relations with atmospheric inputs and management regimes. Trends in Ecology and Evolution 11, 494-497.

Verhoeven JTA, Schmitz MB (1991) Control of plant growth by nitrogen and phosphorus in mesotrophic fens. Biogeochemistry 12, 135-148.

Vermeer JG, Berendse F (1983) The relationship between nutrient availability, shoot biomass and species richness in grassland and wetland communities. Vegetatio 53, 121-126.

Violle C, Navas M-L, Vile D, Kazakou E, Fortunel C, Hummel I, Garnier E (2007) Let the concept of trait be functional! Oikos 116, 882-892.

Vitousek PM, Aber JD, Howarth RH, Likens GE, Matson PA, Schindler DW, Schlesinger WH, Tilman DG (1997) Human alteration of the global nitrogen cycle: source and consequences. Ecological Applications 7, 737-750

Vitousek PM, Howarth RW (1991) Nitrogen limitation on land and in the sea: how can it occur? Biogeochemistry 13, 87-115.

Vitousek PM, Porder S, Houlton BZ, Chadwick OA (2010) Terrestrial phosphorus limitation: mechanisms, implications, and nitrogen-phosphorus interactions. Ecological Applications 20, 5-15.

Walker AP, Beckerman AP, Gu L, Kattge J, Cernusak LA, Domingues TF, Scales JC, Wohlfahrt G, Wullschleger SD, Woodward FI (2014) The relationship of leaf photosynthetic traits $-\mathrm{V}_{\mathrm{cmax}}$ and $\mathrm{J}_{\max }$ - to leaf nitrogen, leaf phosphorus, and specific leaf area: a meta-analysis and modeling study. Ecology and Evolution 4, 3218-3235.

Wang S, van Dijk J, de Boer HJ, Wassen MJ (2021) Source and sink activity of Holcus lanatus in response to absolute and relative supply of nitrogen and phosphorus. Functional Plant Biology. doi:10.1071/FP20118 Source.

Wang S, van Dijk J, Wassen MJ (2019) Sexual reproduction traits of Holcus lanatus L. and Parnassia palustris L. in response to absolute and relative supply of nitrogen and phosphorus. Environmental and Experimental Botany 103813

Wang C, Fang F, Yuan Z, Zhang R, Zhang W, Guo J (2020) Spatial variations of soil phosphorus forms and the risks of phosphorus release in the water-level fluctuation zone in a tributary of the Three Gorges Reservoir. Science of the Total Environment 699, 134124.

Wang Y, Lambers H (2020) Root-released organic anions in response to low phosphorus availability: recent progress, challenges and future perspectives. Plant and Soil 447, 135-156.

Wardlaw IF (1990) The control of carbon partitioning in plants. New Phytologist 116, 341-381.

Wassen MJ (2017) De verhouding tussen fosfaat en stikstof doet er toe. 'Samen Werken aan Biodiversiteit - Result. uit het “Onderzoekprogramma Biodiversiteit Werkt” Prakt.' pp. 45-48. (NWO: Den Haag)

Wassen MJ, van Diggelen R, Wolejko L, Verhoeven TA (1996) A comparison of fens in natural and artificial landscapes. Vegetatio 126, 5-26.

Wassen MJ, Olde Venterink H, Lapshina ED, Tanneberger F (2005) Endangered plants persist under phosphorus limitation. Nature 437, 547-550.

Wassen MJ, Olde Venterink HGM, de Swart EOAM (1995) Nutrient concentrations in mires vegetation as a measure of nutrient limitation in mire ecosystems. Journal of Vegetation Science 6, 5-16. 
Watt TA (1978) The biology of Holcus lanatus L. (Yorkshire fog) and its significance in grassland. Herbage Abstracts 48, 195-204.

Westhoff V, Den Held AJ (1969) 'Plantengemeenschappen in Nederland.' (Thieme: Zutphen)

Wheeler BD, Shaw SC (1991) Above-ground crop mass and species richness of the principal types of herbaceous rich-fen vegetation of lowland England and Wales. Journal of Ecology 79, 285-301.

White PJ, Veneklaas EJ (2012) Nature and nurture: the importance of seed phosphorus content. Plant and Soil 357, 1-8.

Wiebe HJ, Habegger R, Liebig HP (1992) Quantification of vernalization and devernalization effects for kohlrabi (Brassica oleracea convar. acephala var. gongylodes L.). Scientia Horticulturae 50, 11-20.

Wielgolaski FE, Bliss LC, Svoboda J, Doyle G (1981) Primary production of tundra. 'Tundra Ecosyst. A Comp. Anal.' pp. 187-225. (Cambridge University Press: Cambridge.)

Williams DW, Jackson LL, Smith DD (2007) Effects of frequent mowing on survival and persistence of forbs seeded into a species-poor grassland. Restoration Ecology 15, 24-33.

Willson MF, Price PW (1980) Resource limitation of fruit and seed production in some Asclepias species. Canadian Journal of Botany 58, 2229-2233.

Withers PJA, Haygarth PM (2007) Agriculture, phosphorus and eutrophication: a European perspective. Soil Use and Management 23, 1-4.

Wu G, Du G (2007) Germination is related to seed mass in grasses (Poaceae) of the eastern Qinghai-Tibetan Plateau, China. Nordic Journal of Botany 25, 361-365.

Wulff RD (1986a) Seed size variation in Desmodium paniculatum. II. Effects on seedling growth and physiological performance. Journal of Ecology 74, 99-114.

Wulff RD (1986b) Seed size variation in Desmodium paniculatum. I. Factors affecting seed size. Journal of Ecology 74, 87-97.

Wulff RD (1986c) Seed mass variation in Desmodium paniculatum: effects on reproductive yield and competitive ability. Journal of Ecology 74, 115-121. 
References | 151 

Summary 

Anthropogenic activities interfere with the nitrogen $(\mathrm{N})$ and phosphorus $(\mathrm{P})$ biogeochemical cycles globally, and cause various environmental issues. In Europe, it is widely recognized that increased $\mathrm{N}$ deposition leads to decreased grassland plant species diversity. Moreover, the threat of increasing P availability on endangered species has been reported in recent research.

One of the well-known influences of eutrophication on grassland ecosystems is via enhanced primary productivity of plant communities, which intensifies the competition for light, and thus benefits taller or fast-growing species to preempt the directional supplied resource and therefore outcompete slow- and lowgrowing species, leading to loss of species diversity ultimately.

However, the relative contribution of $\mathrm{N}$ and $\mathrm{P}$ in eutrophication is controversial. Although many studies point to $\mathrm{N}$ as the key element in the eutrophication process, others found that the main focus should be on $\mathrm{P}$ when dealing with eutrophication. Furthermore, while common species favor N-limited environments, field observations indicate that threatened or endangered species frequently persist in P-limited environments. This stresses the importance of preventing P eutrophication and diminishing $\mathrm{P}$ availability. Considering the fact that $\mathrm{N}$ deposition may shift the type of nutrient limitation in grassland ecosystems from $\mathrm{N}$ limitation to limitation by other resources such as $\mathrm{P}$, it is essential to study plant growth responses to N:P stoichiometry.

This thesis aims at unraveling the influences of N:P stoichiometry, i.e. the ratio of available $\mathrm{N}$ and $\mathrm{P}$ in relation to their consumer's requirements, on the functional and performance traits of the main life stages of grassland species at individual level, i.e. germination, vegetative growth, sexual reproduction performance, and survival. Several greenhouse experiments and a field survey were carried out to specifically explore the following questions: How does parental N:P stoichiometry influence seed germination success and offspring survival, besides the effect of overall nutrient availability? What is the effect of absolute and relative availability of $\mathrm{N}$ and $\mathrm{P}$ on vegetative growth, particularly on photosynthesis and tissue formation? What is the influence of absolute and relative availability of $\mathrm{N}$ and $\mathrm{P}$ on sexual reproduction performance at intraspecific level, as well as at interspecific level? The questions mentioned above will help us understand more in detail how nutrient fertilization affects functioning of grassland species along their life cycle via the effects of N:P stoichiometry, which will possibly provide new information for ecosystem conservation. 
First, the influence of parental N:P stoichiometry on seed characteristics and offspring survival were studied (chapter 2). For this, seeds of one common species (Holcus lanatus) and one endangered species (Parnassia palustris) were collected from parent plants growing in two different N:P stoichiometric environments in the field. I examined differences in seed characteristics, as well as offspring survival at the end of their life cycle under nutrient treatments with three N:P supply ratios under two overall nutrient supply levels. The results showed that seed characteristics of the common species were restricted, while seed characteristics of the endangered species were promoted in individuals from high N:P stoichiometric environments, i.e. strongly P-limited conditions compared to less strong limitation. Surprisingly, seed germination was opposite to what could be expected on the basis of $\mathrm{P}$ concentration and content of the seeds: there was no difference for Holcus lanatus between offspring from the two parental sites, whereas stronger P-limited conditions in the parental environment promoted seed germination success of offspring of Parnassia palustris significantly. However, no influence of parental $\mathrm{N}: \mathrm{P}$ ratio on offspring survival was found in this experiment, but offspring survival of endangered species was generally lower than that of the common species. These results, although not completely coherent, confirm the suggestion of previous research that the endangered species is able to cope with low $\mathrm{P}$ availability by producing larger seeds that maintain high $\mathrm{N}$ and $\mathrm{P}$ concentrations and have a large germination success.

The influence of absolute and relative supply of $\mathrm{N}$ and $\mathrm{P}$ on maximum lightsaturated net photosynthesis $\left(\mathrm{A}_{\max }\right)$ (source activity) and tissue formation (sink activity) were tested in the following chapter (chapter 3). Here seedlings of common species Holcus lanatus germinated from the previous experiment were grown using readily available forms of $\mathrm{N}$ and $\mathrm{P}$, with three $\mathrm{N}$ :P supply ratios under two overall nutrient supply levels. Positive relationships were found between absolute and relative $\mathrm{N}$ availability and $\mathrm{A}_{\max }$, while the availability of mineral elements, specifically P, showed strong correlations with plant biomass. However, no correlation between source activity $\left(\mathrm{A}_{\max }\right)$ and sink activity (biomass) was found. These results indicate that mineral nutrient supply rather than source activity is the factor that controls sink activity of grassland species.

Moreover, in chapter 4 and 5, the next main life stage, i.e. sexual reproduction performance of grassland species along gradients of N:P stoichiometry were explored at both intra- and interspecific level, by combining a greenhouse experiment and a field survey. 
In chapter 4, sexual reproduction performance of the same plants as those of the experiment in chapter 2, i.e. the common species (Holcus lanatus) and the endangered species (Parnassia palustris) were studied under various nutrient treatments, with three N:P supply ratios under two overall nutrient supply levels. We found that N:P supply ratio did not affect sexual reproduction at low nutrient supply level. At high nutrient supply, investment in sexual reproduction was significantly less at higher N:P supply ratios. Moreover, at high N:P supply ratio, higher nutrient supply level did not increase sexual reproduction performance for Holcus lanatus. Furthermore, the endangered species, Parnassia palustris generally had low survival and flowering, especially at high N:P supply ratio. These results highlight the strong negative influence of low relative P supply on plant investment in sexual reproduction, very clearly for the common species and also likely for the endangered species we investigated.

Furthermore, sexual reproduction performance of grassland species along a gradient of N:P stoichiometry in the field was tested at the intra- and interspecific level in chapter 5. A range of sexual reproduction traits of eleven selected species were measured as a proxy for investment in sexual reproduction. Our results show that compared to $\mathrm{N}$ limitation, $\mathrm{P}$ limitation, and $\mathrm{N}$ and $\mathrm{P}$ co-limitation generally restricted sexual reproduction performance of the selected grassland species, at both intraspecific and interspecific level. This restriction of P limitation/ co-limitation may possibly hamper dispersal capacity of grassland species. Furthermore, soil $\mathrm{pH}$ and soil moisture were found to significantly influence sexual reproduction performance of the selected grassland species. We therefore recommend that future studies further analyze the relationship between soil $\mathrm{pH}$ and N:P stoichiometry and the influence of soil $\mathrm{pH}$, as well as soil moisture on sexual reproduction performance of grassland species in addition to analyzing $\mathrm{N}: \mathrm{P}$ stoichiometry.

This thesis provides several implications for ecosystem conservation. Since eutrophication and conservation management for grassland ecosystems often have asymmetric effects on the bioavailability of $\mathrm{N}$ and $\mathrm{P}$, and since my thesis has shown that plants show different responses in the main phases of their life cycle between N-limited and P-limited grasslands, I recommend the following. 1) N:P stoichiometric effects on plants should be explicitly considered when developing conservation strategies for grasslands; 2) It is essential to preserve and restore P-limited grasslands. However, since N-limited grasslands are also species rich in many cases and also contain a large proportion of endangered species and since $\mathrm{N}$ eutrophication ultimately may lead to a switch to P limitation it is of utmost importance that $\mathrm{N}$ and $\mathrm{P}$ are considered together. Moreover, due to the fact that $\mathrm{N}$ 
fertilization is expected to be larger in the near future than P fertilization, strongly $\mathrm{N}$-limited grasslands, often species rich and harboring threatened species, may shift from strong $\mathrm{N}$ limitation to moderate $\mathrm{N}$ limitation, with the possibility of benefitting fast-growing species and threatening slow-growing species.

The results in this thesis that show the significant influence of N:P stoichiometry, especially the restriction of $\mathrm{P}$ limitation on different main life phrases of grassland species, underline the importance of considering relative $\mathrm{N}$ and $\mathrm{P}$ availability apart from absolute $\mathrm{N}$ and $\mathrm{P}$ availability, for preservation of biodiverse grasslands. 

Samenvatting 

Antropogene activiteiten beïnvloeden de biogeochemische cycli van stikstof (N) en fosfor (P) wereldwijd en veroorzaken verschillende milieuproblemen. In Europa wordt algemeen aangenomen dat een verhoogde $\mathrm{N}$-depositie heeft geleid tot een verminderde plantendiversiteit van graslanden. Bovendien wijst recent onderzoek op het belang van instandhouding van graslanden waarin de P-beschikbaarheid laag is met het doel een specifiek set aan bedreigde soorten te behoeden voor uitsterven.

Een bekende invloed van eutrofiëring op graslandecosystemen is een verhoogde primaire productiviteit, waarbij de concurrentie om licht en voedingsstoffen toeneemt, wat vooral grotere of snel groeiende soorten ten goede komt en kleinere en langzaam groeiende soorten niet. Uiteindelijk leidt dit tot verlies van biodiversiteit.

De relatieve bijdrage van $\mathrm{N}$ en $\mathrm{P}$ aan eutrofiëring is echter omstreden. Hoewel in de meeste onderzoeken $\mathrm{N}$ als het belangrijkste element in het eutrofiëringsproces wordt aangewezen, is er toenemende evidentie dat P eutrofiëring eveneens een bedreiging vormt. Veldonderzoeken geven aan dat algemene soorten relatief vaker voorkomen op N-gelimiteerde locaties, terwijl veel bedreigde soorten zich vooral handhaven in P-beperkte milieus. Deze studies benadrukken het belang van het voorkómen van P-eutrofiëring in dit soort ecosystemen. Het is daarom essentieel om de vestiging, groei, reproductie en overleving van planten in relatie tot de relatieve beschikbaarheid van $\mathrm{N}$ en $\mathrm{P}$, de zogenaamde $\mathrm{N}$ :P stoichiometrie, te onderzoeken.

Dit proefschrift heeft tot doel het effect van N:P stoichiometrie te begrijpen op planteigenschappen in verschillende levensfasen van graslandsoorten op individueel niveau, zoals kieming, overleving van kiemplanten, groei, bloei en zaadvorming. Daartoe zijn verschillende experimenten in de kas en het veld uitgevoerd, waarmee specifiek de volgende vragen zijn gepoogd te beantwoorden: Hoe beïnvloedt de absolute beschikbaarheid van $\mathrm{N}$ en $\mathrm{P}$ en de N:P verhouding het succes van zaadontkieming en overleving van de nakomelingen? Wat is het effect van de absolute en relatieve beschikbaarheid van $\mathrm{N}$ en $\mathrm{P}$ op fotosynthese en groei? Wat is de invloed van de absolute en relatieve beschikbaarheid van $\mathrm{N}$ en $\mathrm{P}$ op de reproductie op intra-specifiek en inter-specifiek niveau? Met het beantwoorden van deze vragen hoop ik het begrip te vergroten van de invloed van nutriënten stoichiometrie op de levenscyclus en het functioneren van graslandsoorten en bij te dragen aan kennis tot behoud van kruidenrijke graslanden. 
Eerst is de invloed van de N:P stoichiometrie in ouderplanten op zaadkenmerken en overleving van de nakomelingen onderzocht (hoofdstuk 2). Hiervoor zijn zaden van één veel voorkomende soort (Holcus lanatus) en één bedreigde soort (Parnassia palustris) verzameld uit wilde planten groeiend in een natuurreservaat waar twee verschillende N:P stoichiometrie milieus heersen. Vervolgens zijn de verschillen geanalyseerd in kenmerken van de zaden en de overleving van de nakomelingen aan het einde van hun levenscyclus waarbij ze werden opgekweekt onder nutriëntenbehandelingen met drie N:P verhoudingen en twee absolute nutriëntenniveaus. De resultaten lieten zien dat de zaadkenmerken van de gewone soort negatief beïnvloed werden als ze afkomstig waren van de hoge ouderlijke N:P stoichiometrie plek, waar sterke P-limitatie heerste. Daarentegen werden de zaadkenmerken van de bedreigde soort positief beïnvloed door sterke P-limitatie. Verrassend genoeg was de kieming van zaden tegengesteld aan wat kon worden verwacht op basis van de P-concentratie in de zaden: geen verschil voor de algemene soort (Holcus lanatus) tussen nakomelingen van de twee ouderlijke locaties, terwijl sterkere P-gelimiteerde omstandigheden in de ouderomgeving de kieming van Parnassia palustris aanzienlijk verhoogde. In dit experiment werd echter geen invloed van de ouderlijke N:P ratio op de overleving van de nakomelingen gevonden, maar de overleving van de nakomelingen van bedreigde soorten was over het algemeen wel lager dan die van de gewone soort, en ook lager in $\mathrm{P}$ gelimiteerde omstandigheden dan in $\mathrm{N}$ gelimiteerde omstandigheden. Deze resultaten, hoewel niet volledig coherent, bevestigen de suggestie van meerdere eerdere onderzoeken dat de bedreigde soort in staat is om te gaan met een lage beschikbaarheid van $\mathrm{P}$ door grotere zaden te produceren die hoge $\mathrm{N}$ - en P-concentraties behouden en een behoorlijk kiemingsucces hebben.

Vervolgens is in het volgende hoofdstuk (hoofdstuk 3) de invloed onderzocht van de absolute en relatieve beschikbaarheid van $\mathrm{N}$ en $\mathrm{P}$ op de maximale lichtverzadigde netto fotosynthese $\left(\mathrm{A}_{\max }\right)$ (source-activiteit) en groei (sink-activiteit). Zaailingen van $H$. lanatus uit het vorige experiment zijn ontkiemd en opgekweekt onder drie N:P verhoudingen en twee absolute nutriëntenniveaus. Er werden positieve verbanden gevonden tussen de absolute en relatieve beschikbaarheid van $\mathrm{N}$ en $\mathrm{A}_{\text {max }}$, terwijl de absolute beschikbaarheid van met name $\mathrm{P}$ een goede correlatie vertoonde met de groei (de vorming van biomassa). Er werd echter geen verband gevonden tussen bronactiviteit $\left(\mathrm{A}_{\max }\right)$ en biomassa. Deze resultaten geven aan dat de beschikbaarheid van nutriënten duidelijker gerelateerd is aan groei dan het fotosynthese-proces zelf.

In hoofdstuk 4 en 5 werd de volgende belangrijke levensfase, de reproductiefase, onderzocht. Dit werd gedaan in een kasexperiment en langs gradiënten van N:P 
stoichiometrie in het veld en de analyse werd gedaan op zowel intra- als interspecifiek niveau.

In hoofdstuk 4 zijn aan dezelfde planten als die van het experiment in hoofdstuk 2 , de algemene soort (H. lanatus) en de bedreigde soort (P. palustris), reproductie-eigenschappen onderzocht onder verschillende behandelingen, wederom met twee absolute niveaus en drie N:P verhoudingen. We ontdekten dat de N:P ratio de reproductie niet beïnvloedde bij een laag absoluut voedingsniveau. Bij een hoge dosis aan voedingsstoffen waren de investeringen in reproductie significant minder bij hogere N:P verhoudingen, dus bij een lagere relatieve P-beschikbaarheid. Bovendien leidde een hogere absolute dosis aan voedingsstoffen bij een hoge $\mathrm{N}$ :P ratio niet tot een verbetering van de reproductie voor $H$. lanatus. P. palustris, de bedreigde soort in het experiment, vertoonde in het algemeen een lage overleving en bloei, vooral bij een hoge N:P verhouding. Deze resultaten benadrukken de sterk negatieve invloed van een lage relatieve P-beschikbaarheid op investeringen in reproductie. Dit was zeer duidelijk voor de algemene soort en, zij het minder duidelijk, ook voor de bedreigde soort die we hebben onderzocht.

In het laatste hoofdstuk (H5) werden de reproductie-eigenschappen van elf graslandsoorten langs een gradiënt van N:P stoichiometrie gedurende een groeiseizoen in het veld gemeten. Omdat er een aantal soorten op meerdere plekken langs de gradiënt voorkwamen stelde dit ons in staat om behalve naar inter-specifieke ook naar intra-specifieke verschillen te kijken. Een reeks reproductie-eigenschappen van de elf geselecteerde soorten werd gemeten als een maat voor investeringen in seksuele voortplanting. Onze resultaten tonen aan dat P-limitatie / N- en P-co-limitatie - in vergelijking met $\mathrm{N}$-limitatie - over het algemeen de seksuele reproductie van de geselecteerde graslandsoorten beperkte, zowel op intra-specifiek als op inter-specifiek niveau. Dit is waarschijnlijk van invloed op het verspreidingsvermogen van de graslandsoorten. Bovendien bleken de $\mathrm{pH}$ van de bodem en het bodemvochtgehalte een significante invloed te hebben op de reproductie van de geselecteerde graslandsoorten. We raden daarom aan om in toekomstige studies de relatie tussen de $\mathrm{pH}$ van de bodem en de N:P stoichiometrie en de invloed van de bodemzuurgraad evenals het bodemvochtgehalte op de reproductie van graslandsoorten betrekken, naast het analyseren van de N:P stoichiometrie.

De resultaten beschreven in dit proefschrift hebben diverse implicaties voor bescherming en behoud van kruidenrijke graslanden. Aangezien eutrofiëring en beheermaatregelen voor graslandecosystemen vaak asymmetrische effecten hebben op de biologische beschikbaarheid van $\mathrm{N}$ en $\mathrm{P}$, en aangezien mijn 
proefschrift heeft aangetoond dat planten verschillende reacties vertonen in de belangrijkste fasen in de levenscyclus tussen N-beperkte en P-beperkte plekken, beveel ik het volgende aan 1) N: P stoichiometrische effecten op planten moeten expliciet in overweging worden genomen bij het ontwikkelen van beheersmaatregelen; 2) Het is essentieel om P-beperkte ecosystemen te behouden en te herstellen. Aangezien N-beperkte graslanden echter ook soortenrijk zijn en veel bedreigde soorten bevatten en aangezien $\mathrm{N}$-eutrofiëring kan leiden tot een omslag naar P-limitatie, is het van het grootste belang dat $\mathrm{N}$ en $\mathrm{P}$ samen worden beschouwd. Bovendien, vanwege het feit dat $\mathrm{N}$-eutrofiering naar verwachting in de nabije toekomst groter zal zijn dan P-eutrofiering, kunnen kruidenrijke en sterk N-gelimiteerde graslanden verschuiven naar een minder sterke N-limitatie, waardoor mogelijk snelgroeiende soorten de bedreigde en langzamer groeiende soorten verdringen.

De resultaten in dit proefschrift laten een significante invloed van N: P-stoichiometrie op belangrijke planteneigenschappen zien, met name dat P-limitatie belangrijke processen in de verschillende levensfasen van graslandsoorten negatief beïnvloedt. Dit benadrukt het belang van het in samenhang beschouwen van de relatieve $\mathrm{N}$ - en P-beschikbaarheid naast pogingen om de absolute $\mathrm{N}$ - en P-beschikbaarheid te verlagen. 



\section{Chinese Summary}



人类的生产和生活已经严重干扰自然界中氮元素 $(\mathrm{N})$ 和磷元素 $(\mathrm{P})$ 的生物 地球化学循环, 并引发一系列环境问题。在欧洲, 大量实验表明, 大气氮沉降会 导致草原生态系统物种多样性不同程度的下降。而近期的研究结果显示, 磷污染 对草原濒危物种的生存具有直接的影响。

关于富营养化对草原生态系统生物多样性的研究, 最为著名的理论, 则是富 营养化提高了草原生态系统植物地上部分生物量, 从而加大了植物对光等有限生 存资源的竞争。这种紧张的竞争关系实际上更有利于生长速率较快、植株体型偏 大的植物。而生长速率较慢、体型较小的物种则会被不同程度地剥夺生存资源, 从而被削弱生存能力, 甚至被淘汰。

然而氮元素和磷元素在富营养化过程中的绝对影响力一直比较模糊。传统 观点认为氮元素是富营养化过程的关键元素。而一些最新的研究则认为, 磷元素 其实更应该作为研究富营养化对全球环境影响的重点元素。另外, 虽然总体而 言, 常见物种更喜爱氮限制的生长环境, 据大量野外调查数据显示, 濒危物种则 更多出现在磷限制的生长环境。这一发现强了控制磷污染的重要性。考虑到氮元 素富营养化具有改变环境营养状况的可能性, 即从氮限制转化为其他元素的限 制, 例如磷元素, 因此, 了解氮元素和磷元素的相对含量对植物生长影响的研究 就显得格外重要。

这篇论文的主要目的, 是研究在个体水平, $\mathrm{N}: \mathrm{P}$ 化学计量比, 也就是氮元素和 磷元素的相对含量 (以下统称 $\mathrm{N}$ : $\mathrm{P}$ 比), 对草原植物的性状特征以及功能特征的影 响。论文的研究主要集中在植物生命周期的主要阶段, 即种子萌发、营养生长、有 性繁殖, 以及存活率等。论文通过一系列温室实验和野外调查研究, 将具体探索 以下问题: 亲本的 $\mathrm{N}: \mathrm{P}$ 比如何影响其种子的性状和发芽率, 以及子代的存活率? 氮 元素和磷元素的相对及绝对量对植物营养生长的影响如何? 氮元素和磷元素的 相对及绝对量对植物的有性繁殖有何影响? 通过探索以上问题, 可以帮助我们更 好地了解矿物营养元素对植物功能性状的影响。在环境污染日益严峻的当下, 这 项研究能够帮助我们更为合理地制定环保方案, 从而为自然生态系统生物多样性 保护提供可靠的理论和政策支持。

首先, 论文的第二章主要介绍了亲本 $\mathrm{N}$ : $\mathrm{P}$ 比对其种子的性状及其子代存活率 的影响。一个常见物种Holcus lanatus和一个濒危物种Parnassia palustris被选定为研 究对象。这两种植物的种子分别采集自生长于两个不同 $\mathrm{N}: \mathrm{P}$ 比的自然环境下的亲 本植物。采集得到的种子被分别检测其各自的性状, 如大小、重量、氮元素和磷 元素含量、发芽率, 以及存活率等。其中存活率的研究是基于两种成年植物在不 同营养条件下的生长状况, 即三种不同 $\mathrm{N}$ : $\mathrm{P}$ 比和两种不同营养水平组合而成的六 种营养条件。研究结果显示, 总体而言, 高亲本 N:P比抑制了常见物种Holcus lanatus的种子性状, 却促进了濒危物种Parnassia palustris的种子性状。意外的是, 种子发芽率的结果与基于种子磷元素含量的预测相反: 对于Holcus lanatus而言, 来自于两个不同 $\mathrm{N}: \mathrm{P}$ 亲本背景的种子的发芽率没有明显区别; 对于Parnassia palustris而言, 来自高 $\mathrm{N}: \mathrm{P}$ 亲本的种子其发芽率则明显高于来自低 $\mathrm{N}: \mathrm{P}$ 亲本种子的发 芽率。另外, 整体而言, 濒危物种Parnassia palustris的子代存活率远低于常见物种 Holcus lanatus, 而此研究并未发现亲本 N:P对后代成体成活率的影响。这项研究的 
结果证实了之前大量的实验结论, 即濒危物种可以通过产生更大的种子, 更高的 氮元素和磷元素含量, 以及更高的发芽率, 来应对低磷环境的影响。

接着, 第三章介绍了在上述营养条件下, 即三种不同 $\mathrm{N}: \mathrm{P}$ 比和两种不同营养水 平组合而成的六种营养条件下, 常见物种Holcus lanatus的营养生长状况。这项研究 主要集中在植物生长的两个主要方面: 最大光饱和点下的净光合速率 $\left(\mathrm{A}_{\max }\right)$

(即为植物生长提供所需碳元素 (C) 的 “源活动” ) 和生物量 (即对C及其他矿物 元素 (如N和P) 进行合成从而构建植物体的 “汇活动” )。研究结果显示, 氮元素 的相对和决定量和 $\mathrm{A}_{\text {max }}$ 之间存在显著的正相关性, 而矿物元素, 尤其是磷元素, 则和生物量之间存在显著的正相关性。然而, 研究结果显示源活动 $\left(\mathrm{A}_{\text {max }}\right)$ 和汇 活动 (生物量) 之间并无任何相关性。这项研究的结果表明, 矿物元素 (尤其是磷 元素) 可能是决定植物营养生长的主要因素, 而非光合作用。

最后, 在论文的第四章和第五章, 研究的重点转移到植物生长的下一个阶 段, 即研究N:P 比梯度对植物有性繁殖的影响。这一阶段的研究会结合温室实验, 以及野外调查实验, 并在种内和种间共同开展。

在第四章, 同样于上述营养条件下, 即三种不同 $\mathrm{N}: \mathrm{P}$ 比和两种不同营养水平组 合而成的六种营养条件下, 培养与第二章相同的两个物种, 即常见种Holcus lanatus和濒危物种Parnassia palustris, 从而研究不同 N:P比在不同营养水平下对常见 物种和濒危物种有性繁殖的影响。结果发现, 在营养水平较低的条件下, N:P比对 植物有性繁殖无任何显著性影响。而当营养水平较高时, 高 $N$ : $P$ 比与低 $N: P$ 比相 比, 很大程度地抑制了植物体的有性繁殖。另外, 在高 N:P比条件下, 提高营养水 平并未对常见种Holcus lanatus的有性繁殖产生显著性影响。而当将两个物种相互 比较时, 发现濒危物种Parnassia palustris的总体存活率和开花率明显低于常见物种 Holcus lanatus, 这个情况在高 $\mathrm{N}$ : $\mathrm{P}$ 比条件下尤其明显。这个实验强调了磷限制对草 原植物有性繁殖的抑制作用。这种作用对于常见物种Holcus lanatus十分显著, 而对 于濒危物种Parnasisa palustris则较为显著。

关于N:P比对植物有性繁殖的影响, 论文在第五章进行了更为深入和全面的 探讨。这一章主要在自然条件而非人为控制条件下, 通过野外调查的方式, 从种 内和种间两个角度, 阐述了在一系列 $\mathrm{N}: \mathrm{P}$ 比梯度下, 草原生态系统植物有性繁殖的 变化。在此次调研中, 一系列常见的植物有性繁殖性状被选择作为衡量有植物性 繁殖的标准。研究结果显示, 总体而言, 磷限制和受氮磷共同限制的生长条件显 著抑制草原植物的有性繁殖。这种抑制不仅体现在物种内, 也体现在物种间。这 种对草原植物有性繁殖的抑制作用, 可能会不同程度地损害草原植物的传播和扩 散, 从而影响草原生态系统的生物多样性。另外, 土壤 $\mathrm{pH}$ 和土壤湿度也被发现和 草原植物有性繁殖间存在显著相关性。基于以上结果, 我们建议, 未来的研究中 需要关注土壤 $\mathrm{pH}$ 和土壤 $\mathrm{N}: \mathrm{P}$ 比之间的关系。同时, 在关注土壤 $\mathrm{N}: \mathrm{P}$ 比对植物有性繁 殖作用的情况下, 也需要注意土壤pH和土壤湿度对植物有性繁殖的影响。

这篇论文在对自然生态系统的保护上提供了几点启示。由于富营养化和对草 原生态系统的人为保护管理对氮元素和磷元素的生物地球化学循环往往产生不 对称的影响, 同时考虑到在草原植物在其不同生命阶段均对氮限制和磷限制的生 长条件产生不同的性状特征, N:P化学计量比对植物生长, 以及生物多样性的影 
响应当明确考虑在环境开发保护策略中。鉴于濒危物种在磷限制条件下比在氮限 制条件下有更高的出现率, 以及低生产力且低磷的生态系统正在逐渐消失, 保护 和恢复磷限制的环境条件对于生物多样性的保护显得尤为重要。然而, 由于大量 濒危物种也同样出现在氮限制的条件下, 同时由于氮富营养化最终可能导致生态 系统由氮限制转变为磷限制的可能性, 因此, 同时考虑限制氮污染和磷污染对生 物多样性和生态系统的保护也至关重要。此外, 在高度氮限制条件下, 相比磷污 染而言, 程度更高的氮污染可能会使得生态系统由高度氮限制, 转变为低度氮限 制。这一改变很可能会更有利于生长速度较快的物种, 进而威胁到生长速度较慢 的物种, 最终对生态系统生物多样性产生不利影响。

本文的研究结果表明了 $\mathrm{N}$ : $\mathrm{P}$ 化学剂量比, 尤其是磷限制, 对草原植物生命周期 中主要阶段的显著性影响。这些影响强调了 $\mathrm{N}: \mathrm{P}$ 化学计量比在研究植物生长和生 物多样性保护方面的重要性。 

Acknowledgements 

The journey towards this thesis has been both long and challenging, but also rewarding and memorable. At this final and special moment, I would like to look back the past few years, and thank all of those who joined me along the way and without whom this would could have never been possibly completed.

First, I would like to express my greatest gratitude to my two supervisors. I want to thank Prof. Martin Wassen for offering me the opportunity to explore the wonderful vegetation world, and his scientific advice and guidance throughout all these years. I benefited a lot from his insightful comments to my manuscripts. His passion in research also impressed me and influenced me deeply. My sincere appreciations also go to the other supervisor of mine, assistant Prof. Jerry van Dijk, for his constant and solid support. He has been intending to train me to be a real scientific researcher, and encouraging me when I felt frustrated. His brilliant ideas have remarkably improved all of my work and the manuscripts. He was also one of the most patient teachers I have ever met, answering all of my daily questions, no matter how basis they were. It was very lucky to have both of them as my supervisors.

I would like to extend my heartfelt thanks to people, who have directly or indirectly, made efforts and contributions to the thesis. I would like to appreciate Ineke Roeling for her countless help during my greenhouse experiments, lab work, and field survey. When I got trouble in my life in the Netherlands, she was also the one I often went for help and suggestions. Her kindness of thinking for others, for example, she even reminded me of which side of the road to walk on in the Netherlands, made I felt very touched. I felt also grateful to a postgraduate student Sietse-Jelle Bijkerk, for our helping each other learn how to make nutrient treatments and how to cultivate plants at the beginning of our greenhouse experiments. I am also indebted to assistant Prof. Hugo Boer, for his invaluable input and ideas with my second paper. His praises also encouraged me a lot at multiple moments. My sincere appreciation also goes to Prof. Hans Lambers, for his kindness and effort of discussing with me on my field work paper.

A large part of the thesis is the product of practical work in the greenhouse and in the lab, as well as in the field. I had so much fun when I was working the in botanical garden, surrounded by various plants and gorgeous flowers, as well as warmhearted and humor people there. Roel Vonk, you know that each time when I went to you, there must be something needed to be solved, but you always looked happy to help (at least in my eyes). And thank you for the beautiful orchid you once allowed me to take from the greenhouse. Fred and Bas, thank you for taking care of my daily work in the greenhouse, I really appreciate it. Gerard van Buiten, 
we did not meet a lot, but the times of chatting with you were pleasant, and thank you for offering to identify grassland species for me. All in all, I thank all of you in the greenhouse, and I will never forget the time working there. I would also like to thank the staffs from the Geolab, for their patience and guidance when I was preparing nutrient treatments, as well as measuring nutrient elements. My appreciations also go to the ecologists from Natuurmonumenten and State Forestry Service for protecting the study plots of my field work.

During my thesis writing, I got a lot of excellent help from some professionals. I want to thank Ton Markus, for his patient adjustment to my figures over and over again. My sincere appreciation also goes to Joy Burrough, for her professional and very efficient checking on the English writing of the main chapters of the thesis.

I am also indebted to my colleagues. Tanapipat Walalitte, as well as an Asian, gave me advices how to live happily and study efficiently in Europe. I also had a lot of fun when we once both worked in the lab. Elizabeth Haber for helping me determine botanical terms, and for her delicious home-made cookies she often brought to the office. My special gratitude goes to Yasmina Loozen, who offered great help to clean the plant material from my greenhouse experiment, and also helped during my field survey. It was unforgettable that you borrowed me your dress when we went to a party together, and you also drove me home far away from the city at that night. I must say that meeting you was one of the most wonderful things happening to me in the Netherlands. I'd also like to thank Koen Siteur and Jiefei Mao, as my original office mates, helped me to know better about the Netherlands and Utrecht University when I first arrived. Mara Baudena, Feroz Islam, Mojtaba Zaresefat, D.M. Narain-Ford, Arjan Wardekker, Paul Schot, Iris Pit, Brian Dermody, Max Rietkerk, and so many other colleagues, it was very nice to meet and work with all of you at the Copernicus Institute of Sustainable Development. My thanks also go to the four subsequent office mates of mine from the Environmental Governance group. Yu Yang, Sanchayan Nath, Y Yanuardi, and Richard Lane, staying with you was really happy, warm and fun, you guys have made my life at van Unnik colorful. I hope someday there would be a chance for me make real "bao zi" for you.

My roommates were the ones I spent most in my spare time. Lei Ge, Duo Duo, Chen Ge, thank you for giving me so much pleasance and happiness, the time living with you will be my very cherished memory. I also want to apologize for often singing loudly in my room, without considering your feelings. However, you never interrupted me or complained. I feel very grateful for your tolerance and kindness. My thanks extend to Yumao Zhang, for his countless help without 
expecting anything in return, when I first arrived the Netherlands. My sincere thanks also go to Ada and Kees, for their nice presents, their help with moving my heavy furniture, and their constant care of my Ph.D. process and my health, etc. I also thank Lin Zhang and Jianmin Chen, for the wonderful travels we went together in Europe.

When I was working in China at the final phrase of my Ph.D. project, Gan Zheng was the one who steadily offering IT supports for me. He was also a great listener when I needed someone to talk with. Having a friend like him is definitely my great luck. I also want to extent my thanks to a traditional Chinese medicine doctor Luo Jianmin, for her excellent medical skill, which helped me become healthier and stronger during the process of writing my thesis. Moreover, I sincerely appreciate Chinese government for financially supporting my life in the Netherlands.

最后, 其实我最最想要感谢的人, 还是我的父母。他们是我永远的倾听者和谋士, 也是我休鄎的港湾和能量的来源。在整个博士阶段, 是他们让我无数次地从挫败 和低谷中找回勇气和自我。在最后撰写论文期间, 他们给我提供了舒适的生活条 件和事无巨细的照料, 以便我能够全身心地专注于科研和论文。爸爸妈妈, 谢谢 你们! 很开心我的博士论文完成了, 这是我们一家人努力的成果! 未来希望我们会 更加感恩, 更加努力, 永远向阳而生! 

Curriculum Vitae 
Shuqiong Wang was born on 08 August 1992 in Anhui, P. R. China. Growing up in a beautiful countryside town meant that from an early age she developed a profound fascination for nature. In her high school, the famous pea plant crossbreeding experiment by Gregor Mendel in the biology course opened a new world of science for her. This fascination with experimental biology ultimately led Shuqiong to pursue a bachelor degree in Biology at Huainan Normal University, which was followed by a Master degree in Ecology at East China Normal University. There she started her original academic education on the effects of $\mathrm{N}$ and $\mathrm{P}$ eutrophication and increasing atmospheric $\mathrm{CO}_{2}$ concentration on wetland plant growth, which was published and became the first scientific paper in her career. After finishing her MSc education, it became clear that her main interest lay in plant ecology. She then came to the Copernicus Institute of Sustainable Development, Utrecht University, to pursue a Ph.D., under the supervision of Jerry van Dijk and Martin Wassen, with the financial support of China Scholarship Council (CSC). 

Publications 
Wang S., van Dijk J., Wassen M.J. (2019) Sexual reproduction traits of Holcus lanatus L. and Parnassia palustris L. in response to absolute and relative supply of nitrogen and phosphorus. Environmental and Experimental Botany, 103813.

Loozen Y., Karssenberg D., de Jong S.M., Wang S., van Dijk J., Wassen M.J., Rebel K.T. (2019) Exploring the use of vegetation indices to sense canopy nitrogen to phosphorus ratio in grasses. International Journal of Applied Earth Observation and Geoinformation, 75 (1-14).

Wang S., van Dijk J., de Boer H.J., Wassen M.J. (2021) Source and sink activity of Holcus lanatus in response to absolute and relative supply of nitrogen and phosphorus. Functional Plant Biology, 48 (493-502).

Wang S., van Dijk J., Wassen M.J. Sexual reproduction trait expressions of grassland species along a gradient of nitrogen : phosphorus stoichiometry.

Currently under Review.

Wang S., van Dijk J., Wassen M.J. Influence of parental nitrogen : phosphorus stoichiometry on seed performance of Holcus lanatus L. and Parnassia palustris L. Currently under Review.

\section{Other publications}

Wang S., Wang H., Fang Y., Li K. (2014) Ability of plant carbon fixation in the coastal wetland of Chongming Island. Chinese Journal of Ecology, 33 (915-921) (In Chinese).

Wang H., Wang S., Fang Y., Li K. (2014) Estimation on carbon sequestration of aboveground part of Phragmites australis around Chongming Island. Wetland Science, 12 (539-543) (In Chinese).

\section{Conference}

Wang S., van Dijk J., Wassen M.J. (2021) Influence of parental N:P stoichiometry on seed performance of Holcus lanatus L. and Parnassia palustris L. Poster Session 2: Conservation Science, NAEM. 


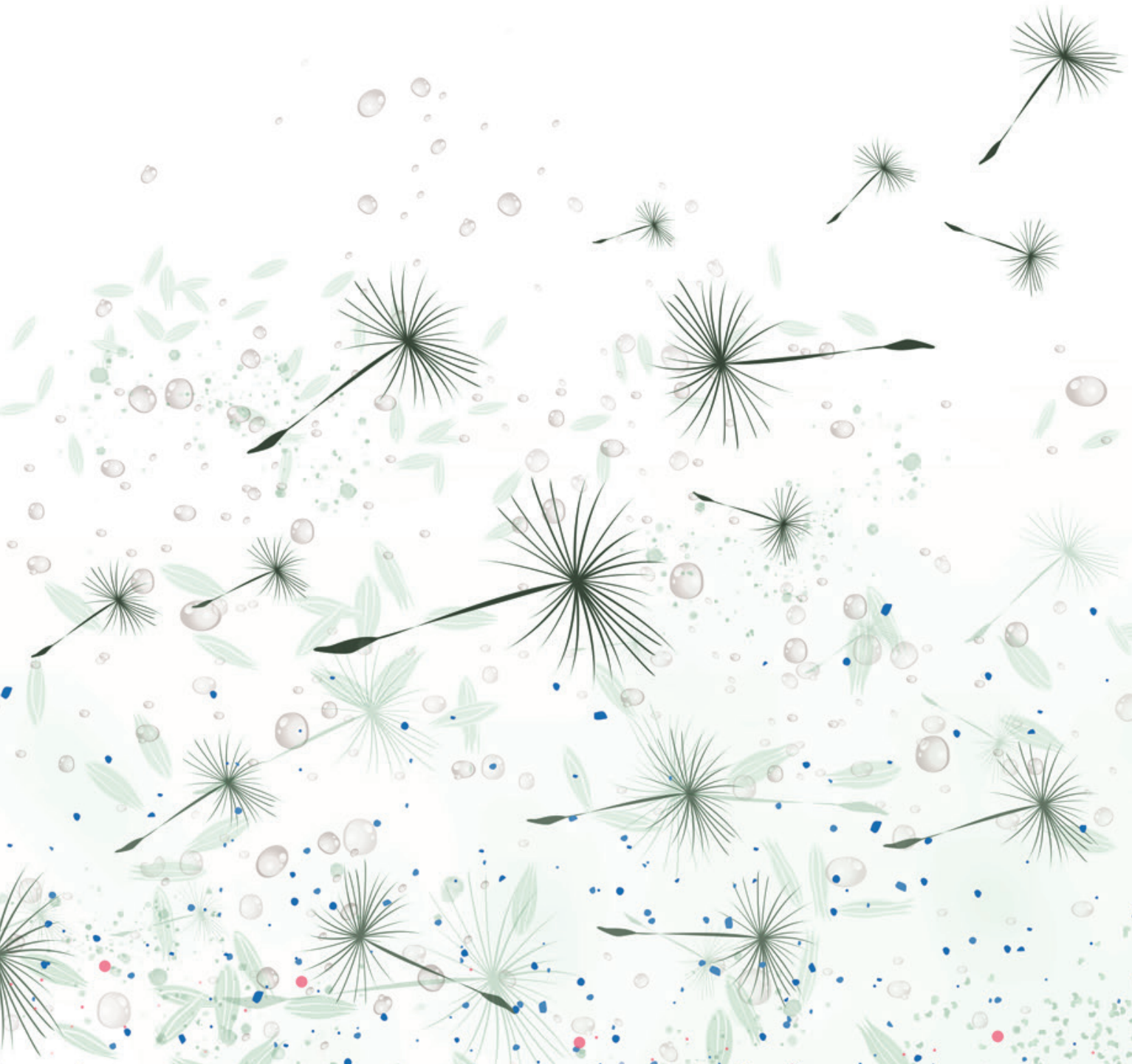

